\title{
Effects of Modified Solution Heat Treatment on the Mechanical Properties and Stress Corrosion Cracking Susceptibility of Aluminum Alloy 7075
}

by

\author{
Alessandro G. Pagliarello \\ B.Sc., Mechanical Engineering \\ Queen's University, 2009
}

\begin{abstract}
A thesis submitted to the Faculty of Graduate and Postdoctoral Affairs in partial fulfillment of the requirements for the degree

Master of Applied Science
\end{abstract}

Ottawa-Carleton Institute for Mechanical and Aerospace Engineering

\author{
Department of Mechanical and Aerospace Engineering \\ Carleton University \\ Ottawa, Ontario \\ Canada
}

(C) Copyright 2011

Alessandro G. Pagliarello 
Library and Archives

Canada

Published Heritage Branch

395 Wellington Street Ottawa ON K1A ON4

Canada
Bibliotheque et

Archives Canada

Direction du

Patrimoine de l'édition

395 , rue Wellington

Ottawa ON K1A ON4

Canada
Your file Votre référence

ISBN: 978-0-494-81669-1

Our file Notre référence

ISBN: 978-0-494-81669-1
NOTICE:

The author has granted a nonexclusive license allowing Library and Archives Canada to reproduce, publish, archive, preserve, conserve, communicate to the public by telecommunication or on the Internet, loan, distribute and sell theses worldwide, for commercial or noncommercial purposes, in microform, paper, electronic and/or any other formats.

The author retains copyright ownership and moral rights in this thesis. Neither the thesis nor substantial extracts from it may be printed or otherwise reproduced without the author's permission.
AVIS:

L'auteur a accordé une licence non exclusive permettant à la Bibliothèque et Archives Canada de reproduire, publier, archiver, sauvegarder, conserver, transmettre au public par télécommunication ou par l'Internet, prêter, distribuer et vendre des thèses partout dans le monde, à des fins commerciales ou autres, sur support microforme, papier, électronique et/ou autres formats.

L'auteur conserve la propriété du droit d'auteur et des droits moraux qui protège cette thèse. $\mathrm{Ni}$ la thèse ni des extraits substantiels de celle-ci ne doivent être imprimés ou autrement reproduits sans son autorisation.
In compliance with the Canadian Privacy Act some supporting forms may have been removed from this thesis.

While these forms may be included in the document page count, their removal does not represent any loss of content from the thesis.
Conformément à la loi canadienne sur la protection de la vie privée, quelques formulaires secondaires ont été enlevés de cette thèse.

Bien que ces formulaires aient inclus dans la pagination, il n'y aura aucun contenu manquant.

\section{Canadä}




\begin{abstract}
Stress corrosion cracking (SCC) is a concern in applications of many high strength structural alloys, including Al alloy 7075. A trade off typically exists between strength and SCC resistance for 7075 , and the precipitate morphology is thought to be one of the controlling microstructural features.

Sixteen experimental tempers are produced by varying the solution heat treatment parameters, including temperature of isothermal and stepped solution heat treatments, cooling rate during slow cooling (referred to as high temperature pre-precipitation, HTPP), and final temperature prior to quenching during HTPP. Hardness, electrical conductivity, tensile, and double beam SCC tests are conducted to assess the effects of the experimental solution heat treatments. Microstructural examination of selected tempers is conducted using SEM.

All experimental tempers exhibit inferior yield and tensile strengths compared to the T6 temper. One experimental temper shows improved SCC resistance compared to T6, but this temper is less resistant to SCC than T73. Coarse grain boundary precipitates observed in the T73 microstructure are not observed in any other tempers. The cooling rate during HTPP appears to have little effect on properties, but the final temperature prior to quenching has a significant effect: lower final temperature gives reduced mechanical properties and increased electrical conductivity.
\end{abstract}




\section{Acknowledgements}

First and foremost I would like to thank my parents for everything they have ever given me. They have supported me in every venture I have undertaken in my life, they have given me a great appreciation for knowledge and education, and they have provided me with the means to pursue my educational and personal goals. I am grateful for their love and support every day.

A great deal of credit is due to my thesis supervisor, Dr Jonathan Beddoes, for his guidance, enthusiasm, and mentorship. I would not have come to Carleton were it not for the opportunity to work with him, and his support in conducting this research and writing this thesis has been invaluable. I have also thoroughly enjoyed our many conversations on topics entirely unrelated to my project.

A number of people contributed to the execution of the experimental program described herein. For their expertise and assistance I would like to thank Jianqun (JJ) Wang, Alex Proctor, Kevin Sangster, and Steve Truttman at Carleton; David Chow at the NRC; and Tim Lang at the TSB.

The financial assistance provided by the Natural Sciences and Engineering Research Council of Canada and Carleton University has been greatly appreciated.

Last, I need to thank Carly for her love and seemingly infinite patience. Sharing this achievement with you means the world to me.

This thesis is dedicated to my grandparents: George and Barbara, Mario and Ida 


\section{Table of Contents}

Abstract

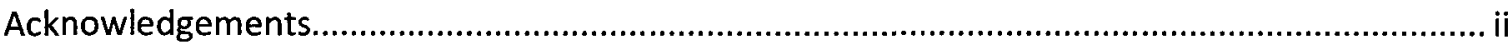

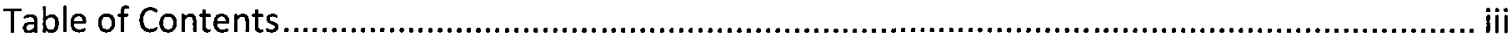

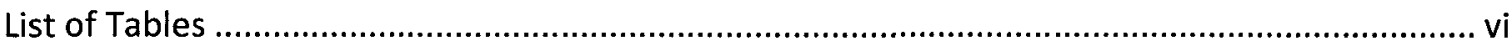

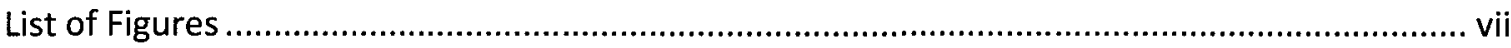

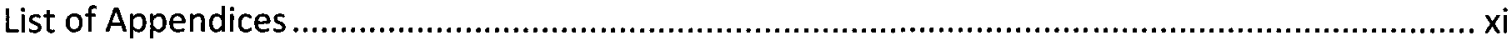

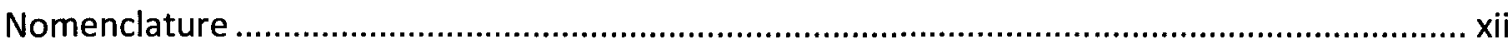

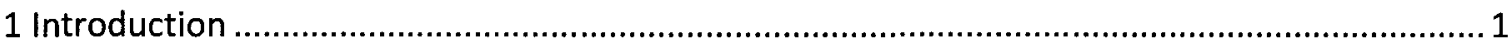

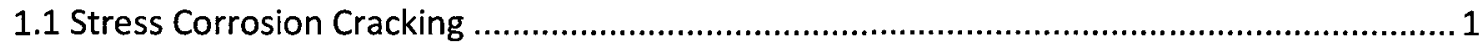

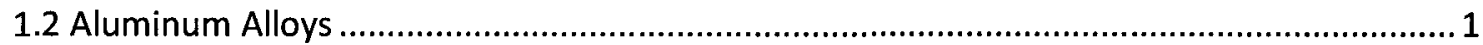

1.2.1 Aluminum Alloy and Temper Designation System.................................................. 1

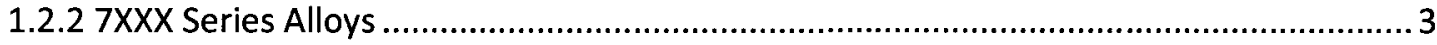

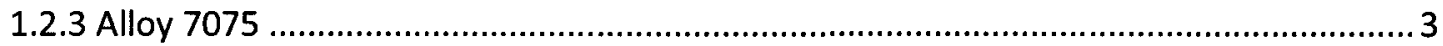

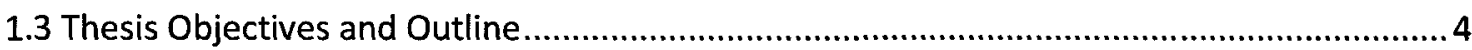

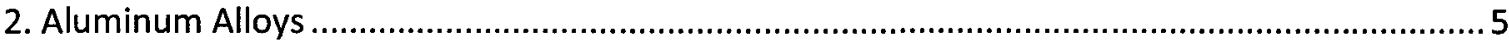

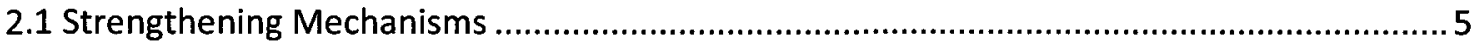

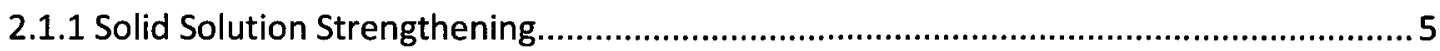

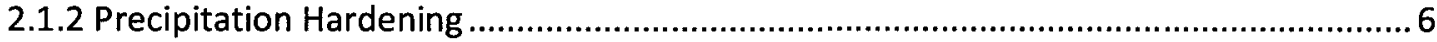

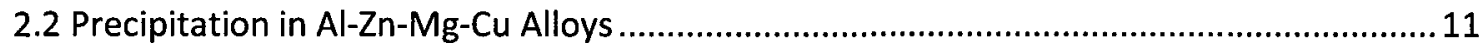

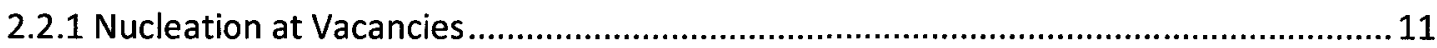

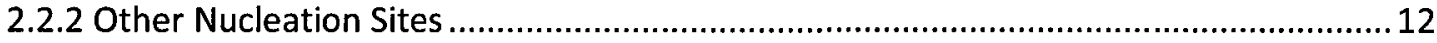

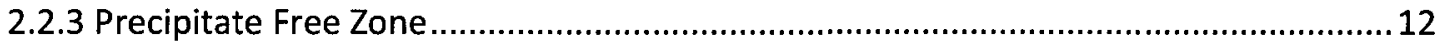

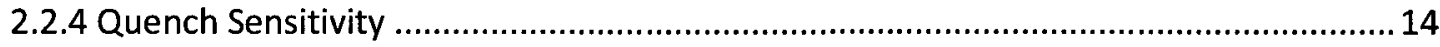

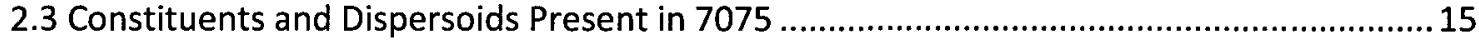

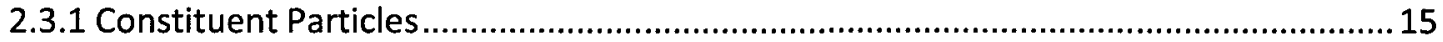

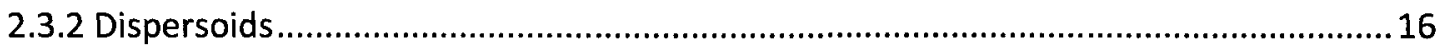

2.4 Alloying Additions and Impurities in 7075 and Their Effects ...........................................16

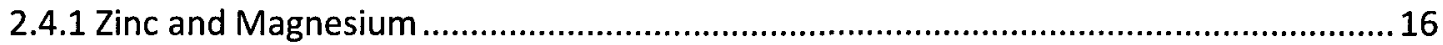

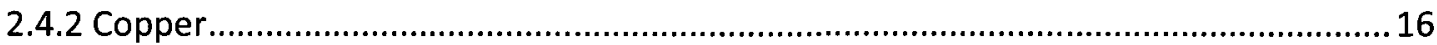

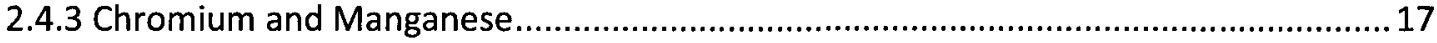

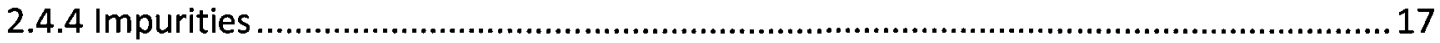


2.5 Standard Thermal Treatments Applied to 7075

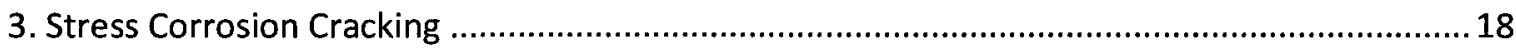

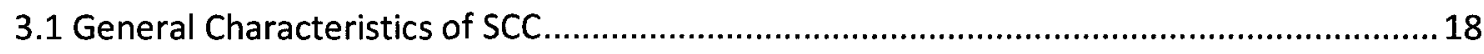

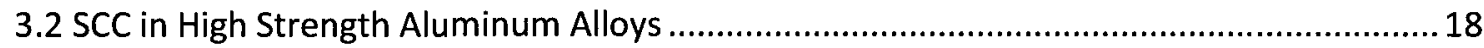

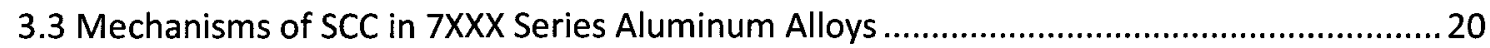

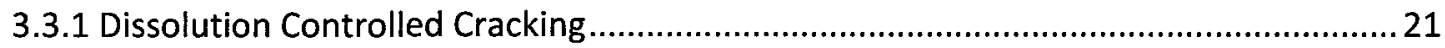

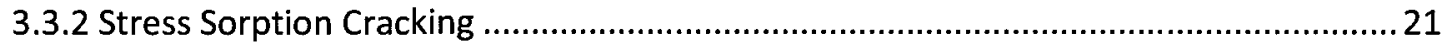

3.3.3 Combined Effects of Multiple Mechanisms .........................................................21

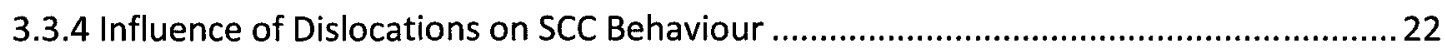

3.4 Relationship between Electrical Conductivity and SCC Resistance ..................................22

3.5 Testing Methods to Assess the SCC Susceptibility of Materials ......................................23

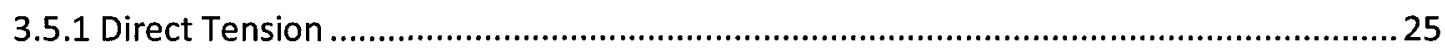

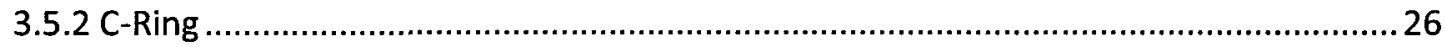

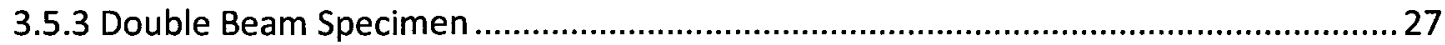

4. Effects of Thermal Processing on the Microstructure and SCC Behaviour of Al-Zn-Mg-Cu Alloys .30

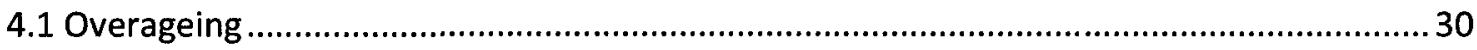

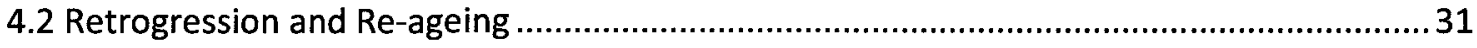

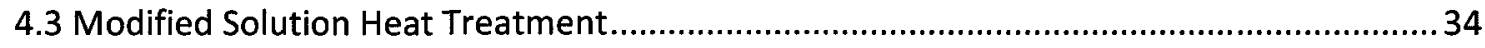

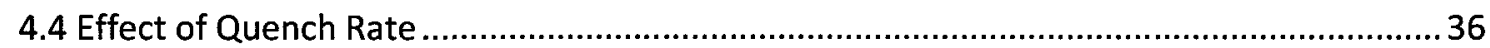

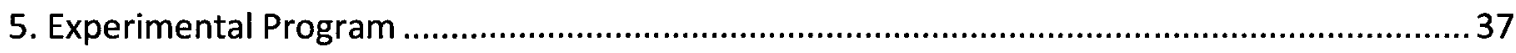

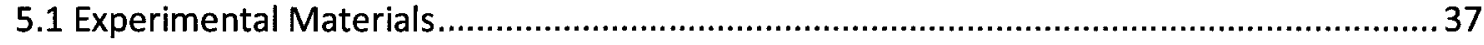

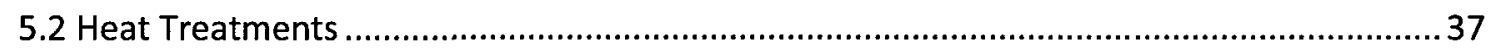

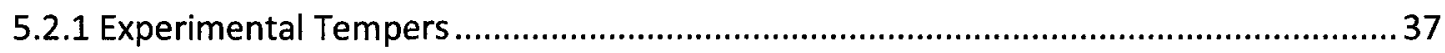

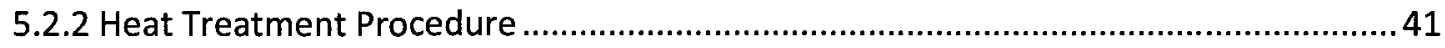

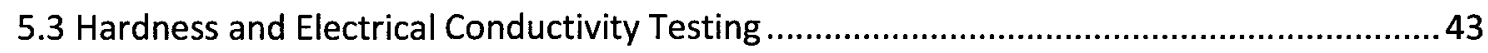

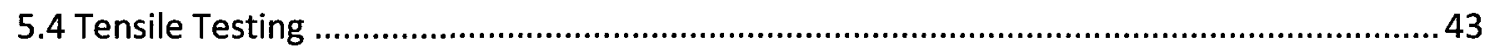

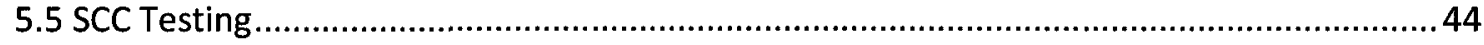

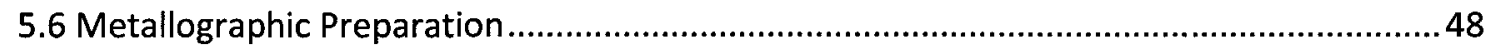

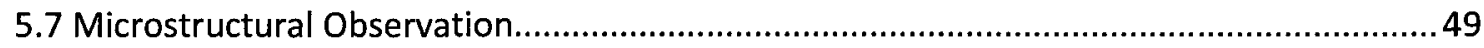

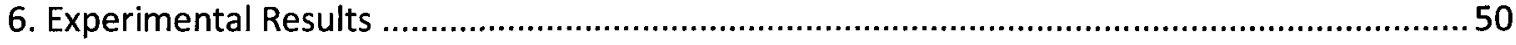

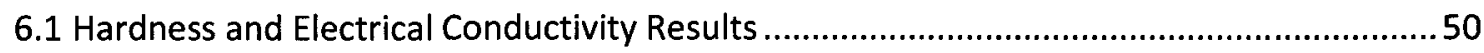


6.1.1 Hardness and Electrical Conductivity Test Coupons .................................................50

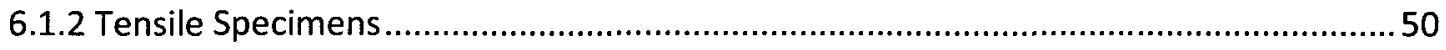

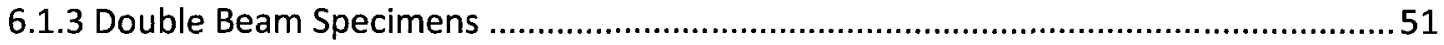

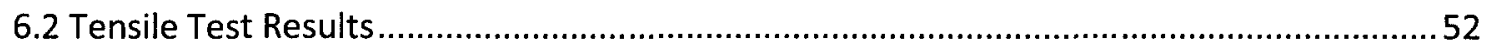

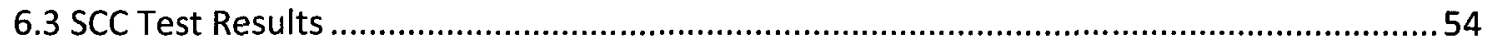

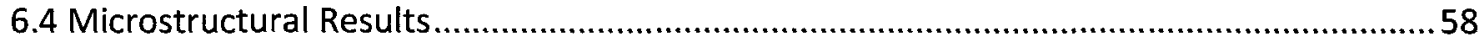

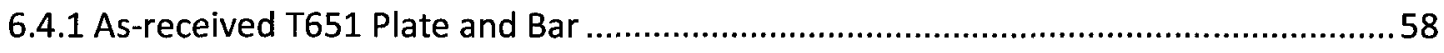

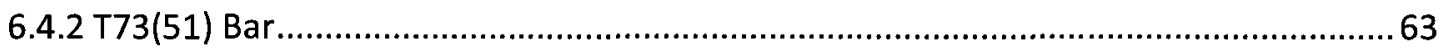

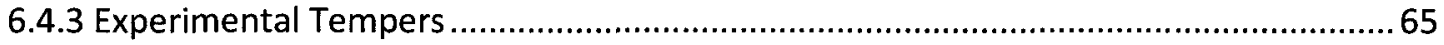

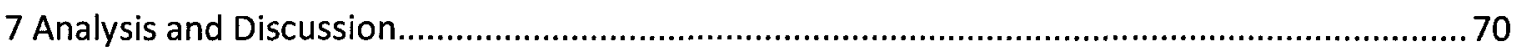

7.1 Effects of Variation in Solution Heat Treatment on Mechanical Properties and Electrical

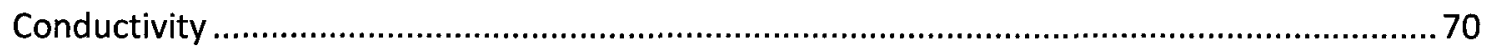

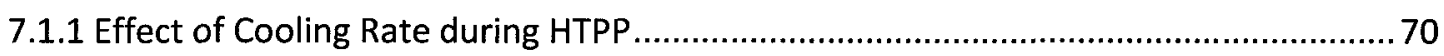

7.1.2 Effect Final Temperature during HTPP............................................................... 72

7.1.3 Effect of Increased Solution Heat Treatment Temperature .....................................76

7.1.4 Change in Hardness and Electrical Conductivity with Ageing...................................79

7.2 Correlation of Hardness and Tensile Test Data ............................................................. 81

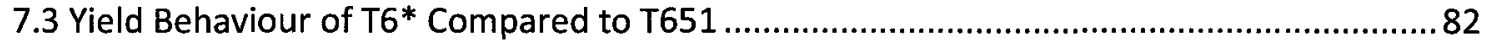

7.4 Effects of Variation in Solution Heat Treatment on SCC Behaviour .................................86

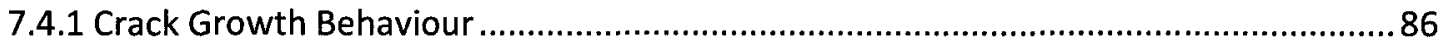

7.4.2 Correlation between SCC Behaviour and Electrical Conductivity ...............................91

8 Summary, Conclusions, and Recommendations for Future Work........................................ 93

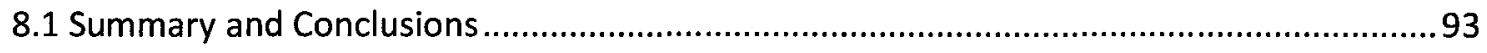

8.2 Recommendations for Future Work .......................................................................... 94

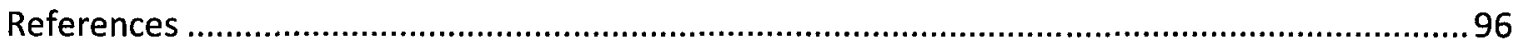




\section{List of Tables}

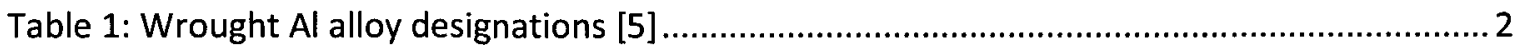

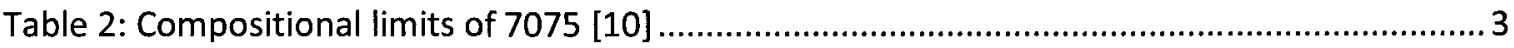

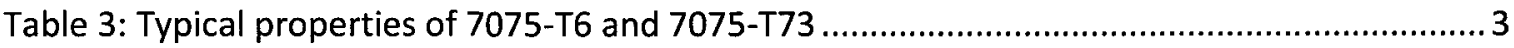

Table 4: Chemical composition of 7075-T651 round bar and flat plate ...................................37

Table 5: Summary of heat treatment parameters.................................................................... 38

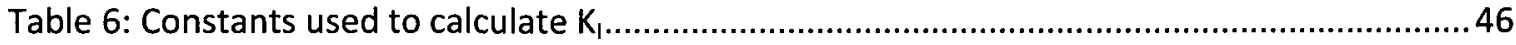

Table 7: Hardness and EC results for small test coupons ...................................................... 50

Table 8: Hardness and EC results from tensile specimen blanks......................................... 51

Table 9: Hardness and EC results for DB specimen blocks ..................................................52

Table 10: Summary of uniaxial tensile test results .................................................................. 53

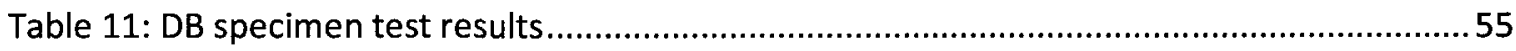

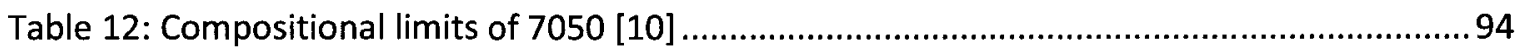




\section{List of Figures}

Figure 1: Solid solution strengthening effect of various elements on an at\% basis [4]................ 5

Figure 2: Solid solution strengthening effect of various elements on a wt\% basis [4]................. 6

Figure 3: Schematic illustration of the variation in critical resolved shear stress (CRSS) to cause dislocation motion as a function of precipitate size [4]

Figure 4: Yield strength as a function of total alloying content in an Al-Zn-Mg-Cu alloy in two tempers [4]

Figure 5: Schematic phase diagram for a precipitation heat treatable alloy system [2]...............8

Figure 6: Schematic illustration of thermal treatment to produce precipitation hardening [2] ..... 9

Figure 7: Al-MgZn 2 phase diagram [14]

Figure 8: PFZ in an Al-Zn-Mg alloy as well as $\eta^{\prime}$ precipitates in the matrix and $\eta$ precipitates on the grain boundary [4]

Figure 9: PFZ in an Al-Zn-Mg-Cu alloy shown at 59200X magnification [12] ............................ 13

Figure 10: Vacancy concentration profile near a grain boundary $(G B)$ following quenching. $X_{V}{ }^{e}$ indicates the equilibrium vacancy concentration at the ageing temperature [12]................... 13

Figure 11: Variation of PFZ width with quenching rate from solutionizing temperature. $X_{V}{ }^{c}$ indicates the critical excess vacancy concentration for precipitation [12] ................................ 14

Figure 12: Tensile strength of several commercial Al alloys as a function of average cooling rate from solution heat treatment temperature [13]. 14

Figure 13: Effect of different alloying additions on the strength of two Al-Zn-Mg-Cu alloys as a function of cooling rate [4]. .15

Figure 14: Dispersoid particles in 7075 [4] 16

Figure 15: Effect of stressing direction with respect to microstructural texture in extruded 7075 exposed to $3.5 \% \mathrm{NaCl}$ solution by alternate immersion [19]

Figure 16: Schematic representation of the relationship between stress intensity and crack growth rate [17] 20

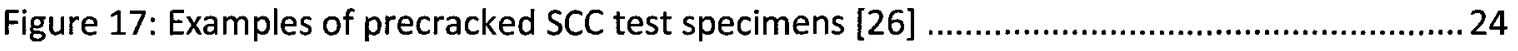

Figure 18: Schematic depiction of the critical strain rate range for SCC [29] ...........................25

Figure 19: Typical C-ring specimen geometry [30] .......................................................... 26

Figure 20: Possible loading configurations for C-ring specimens. A similar notch to that shown in

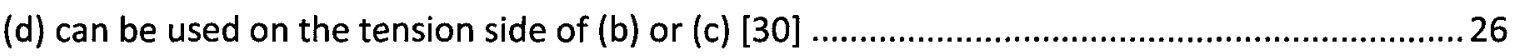

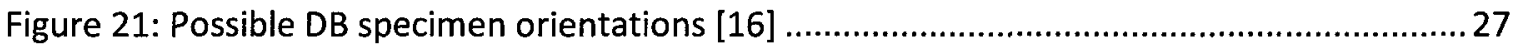

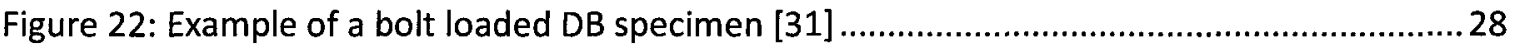

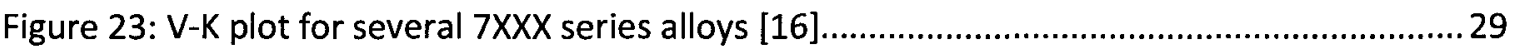


Figure 24: Variation of strength and SCC resistance with ageing in 7XXX series alloys [16]

Figure 25: Effect of retrogression temperature on yield strength as a function of time for 7075 [36]

Figure 26: Stress corrosion crack growth rates as a function of stress intensity for selected conditions of 7075 [36]

Figure 27: Grain boundary precipitate structures found in various heat treatment conditions of 7075 imaged by TEM [36]

Figure 28: Grain boundary precipitate structures produced by solutionizing at $450^{\circ} \mathrm{C}$ (a) and solutionizing at $450^{\circ} \mathrm{C}$ then heating to $480^{\circ} \mathrm{C}$ at $5^{\circ} \mathrm{C} / \mathrm{h}(\mathrm{b})[41]$ 34

Figure 29: Grain boundary precipitate structure produced by solution heat treatment that included slow heating and HTPP [41]

Figure 30: Stress corrosion crack velocities as a function of stress intensity for four tempers of an $\mathrm{Al}-\mathrm{Zn}-\mathrm{Mg}-\mathrm{Cu}$ alloy tested using DB specimens in $3.5 \% \mathrm{NaCl}$ aqueous solution [41] 35

Figure 31: Schematic illustration of heat treatment for \$495 temper.... 39

Figure 32: Schematic illustration of heat treatments for $\mathrm{H}$ series tempers 39

Figure 33: Schematic illustration of heat treatments for $F, M$, and $L$ series tempers .40

Figure 34: Schematic illustration of heat treatments for $\mathrm{H}-\mathrm{F}$ series tempers 41

Figure 35: Schematic illustration of heat treatments for S-F series tempers.

Figure 36: Heat bath for ageing treatments .42

Figure 37: Tensile specimen installed in the test frame with extensometer attached .44

Figure 38: Double beam specimen .45

Figure 39: Travelling microscope used for all crack length measurements on DB specimens......47

Figure 40: Two pieces of a DB specimen after mechanical separation 48

Figure 41: Tensile stress-strain plot for specimen M400 B. 52

Figure 42: Yield strength and UTS of all tempers based on tensile testing. Solid and dashed lines represent the typical T6 and T73 yield strengths [11], respectively.

Figure 43: Crack in specimen H495 $\mathrm{C}$ at $10 \mathrm{X}$ magnification, as viewed through the travelling microscope. .56

Figure 44: Crack length as a function of time in DB specimens. .57

Figure 45: As-received T651 plate microstructure: the rolling direction is horizontal and the short transverse direction is vertical in the image. .58

Figure 46: As-received T651 plate microstructure: the rolling direction is horizontal and the long transverse direction is vertical in the image. 
Figure 47: As-received T651 plate microstructure: the long transverse direction is horizontal and the short transverse direction is vertical in the image

Figure 48: As-received T651 bar microstructure: the extrusion direction is normal to the plane of the image 60

Figure 49: Grain boundary area in T651 bar at 20000X magnification. .61

Figure 50: Grain boundary area in T651 bar at 20000X magnification. 61

Figure 51: Grain boundary area in T651 bar at 40000X magnification. .62

Figure 52: Grain boundary area in T651 bar at $40000 \mathrm{X}$ magnification. .62

Figure 53: Grain boundary area in the T73(51) bar at 20000X magnification. 63

Figure 54: Grain boundary area in the T73(51) bar at 20000X magnification... .64

Figure 55: Grain boundary area in the T73(51) bar at 40000X magnification... .64

Figure 56: Grain boundary area in the T73(51) bar at 40000X magnification. 65

Figure 57: Grain boundary area in the $\mathrm{H} 495$ bar at $10000 \mathrm{X}$ magnification .66

Figure 58: Grain boundary area in the $\mathrm{H} 495$ bar at $40000 \mathrm{X}$ magnification 66

Figure 59: Grain boundary area in the H495-F400 bar at 20000X magnification. 67

Figure 60: Grain boundary area in the H495-F400 bar at 20000X magnification. 67

Figure 61: Grain boundary area in the S495-F400 bar at 10000X magnification 68

Figure 62: Grain boundary area in the $\$ 495-\mathrm{F} 400$ bar at 35000X magnification .68

Figure 63: Hardness as a function of cooling rate in the $F, M$, and $L$ series tempers... 70

Figure $64: 0.2 \%$ offset yield strength as a function of cooling rate for the $F, M$, and $L$ series tempers .71

Figure 65: Electrical conductivity as a function of cooling rate for the $F, M$, and $L$ series tempers

Figure 66: Hardness as a function of final temperature of solution heat treatment for $F, M$, and $L$ series tempers. 72

Figure 67: Yield strength as a function of final temperature of solution heat treatment for $F, M$, and $L$ series tempers .73

Figure 68: Electrical conductivity as a function of final temperature of solution heat treatment for $F, M$, and $L$ series tempers .73

Figure 69: Hardness as a function of final temperature of solution heat treatment for tempers cooled at $45^{\circ} \mathrm{C} / \mathrm{h}$

Figure $70: 0.2 \%$ offset yield strength as a function of final temperature of solution heat treatment for tempers cooled at $45^{\circ} \mathrm{C} / \mathrm{h}$ .75 
Figure 71: Electrical conductivity as a function of final temperature of solution heat treatment

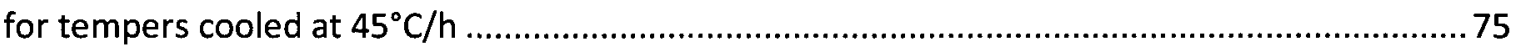

Figure 72: Comparison of yield strengths of T651, T6*, S495, H480, and H495 tempers .............77

Figure 73: Comparison of hardness of T651, T6*, S495, H480, and H495 tempers ..................... 77

Figure 74: Change in hardness from pre- to post-ageing for tensile and DB specimen blanks of all

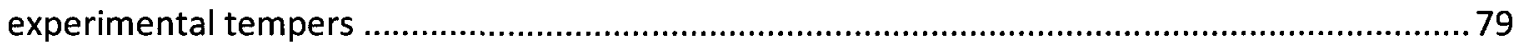

Figure 75: Change in hardness from pre- to post-ageing for tensile and DB specimen blanks of all experimental tempers

Figure 76: Yield strength as a function of Rockwell B hardness for all tempers ......................... 81

Figure 77: Tensile strength as a function of Rockwell B hardness for all tempers ..................... 82

Figure 78: Tensile stress-strain curves for T6* and T651 specimens...................................... 83

Figure 79: Portion of the tensile stress-strain curves near the yield point for T6* and T651 specimens 84

Figure 80: Variation in dislocation density with increasing deformation in an Al-Li-Cu alloy [4].. 85

Figure 81: Crack growth rate as a function of stress intensity for the T651 and T73(51) DB

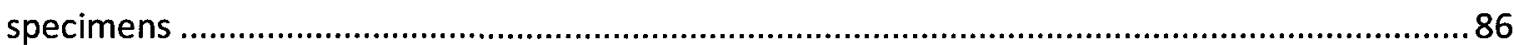

Figure 82: Crack growth rate as a function of stress intensity for the T651 and H495 DB

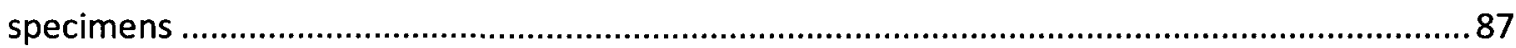

Figure 83: Crack growth rate as a function of stress intensity for the T651, F400, H495-F400, and S495-F400 DB specimens. .88

Figure 84: Crack growth rate as a function of stress intensity for the T651 and L370 DB

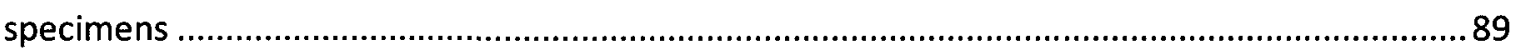

Figure 85: Crack growth rate as a function of stress intensity for the T73(51) and L370 DB

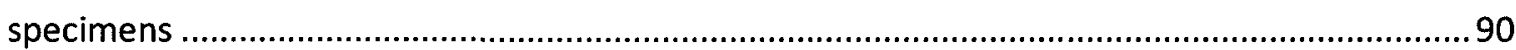

Figure 86: Threshold stress intensity for SCC as a function of electrical conductivity ...............91 


\section{List of Appendices}

Appendix A: Tensile and DB Specimen Geometries ....................................................... 100

Appendix B: DB Specimen Test Environmental Measurements .............................................. 102

Appendix C: Complete Results of Uniaxial Tensile Tests ................................................... 109

Appendix D: Interim DB Specimen Measurements ............................................................ 110 


\title{
Nomenclature
}

\author{
SCC Stress corrosion cracking \\ HRB Rockwell B hardness unit \\ \%EL Percent elongation \\ \%IACS Percentage of international annealed copper standard \\ SEM Scanning electron microscope \\ at\% Atomic percent \\ $w t \% \quad$ Weight percent \\ GP zone Guinier-Preston zone \\ $\eta^{\prime} \quad$ Precursor to $\eta$ phase \\ $\eta \quad$ Equilibrium precipitate phase in $7075, \mathrm{MgZn}_{2}$ or $\mathrm{Mg}(\mathrm{Al}, \mathrm{Cu}, \mathrm{Zn})_{2}$ \\ PFZ Precipitate free zone \\ $\mathrm{K}_{\mathrm{I}} \quad$ Crack tip stress intensity factor \\ $\mathrm{K}_{\text {Iscc }} \quad$ Threshold stress intensity factor for stress corrosion cracking \\ $\mathrm{K}_{\mathrm{Ic}} \quad$ Plane-strain fracture toughness \\ HIC Hydrogen induced cracking \\ EC Electrical conductivity \\ ASTM American Society for Testing and Materials \\ DB Specimen Double beam specimen \\ RRA Retrogression and re-ageing \\ HTPP High temperature pre-precipitation \\ CNC Computer numerical control \\ E Young's (elastic) modulus \\ $\sigma_{y} \quad$ Yield strength \\ UTS Ultimate tensile strength \\ TEM Transmission electron microscope
}




\section{Introduction}

\subsection{Stress Corrosion Cracking}

Stress corrosion cracking (SCC) is a process that results from the cooperative action of tensile stress and a corrosive environment $[1,2]$. SCC was first discovered to be a problem in the late $19^{\text {th }}$ century in cartridge brass and boiler steels. Early in the $20^{\text {th }}$ century the phenomenon was also found to exist in high strength and austenitic steels, magnesium alloys, and aluminum alloys, and during the 1960's SCC of high strength structural alloys was a major concern for the US Department of Defence [1].

While a material may be nearly inert to a specific environment in the absence of loading, it can be susceptible to SCC once tensile stress is applied. The source of this stress need not be external, such as service loading, as in many cases residual stresses within the part or the wedging action of built up corrosion products can supply enough stress to cause SCC [1,2]. High concentrations of corrodent in the surrounding environment are also not required for SCC to occur. Even very dilute solutions can cause SCC as the local concentration of the corrosive species near the crack tip can be radically different from that in the bulk environment [1].

SCC occurs in many alloys that are quite resistant to general corrosion under normal atmospheric conditions, such as Al alloys and stainless steels. These materials are protected from more uniform corrosive attack by a protective oxide film, $\mathrm{Al}_{2} \mathrm{O}_{3}$ in the case of $\mathrm{Al}$ alloys, but they are susceptible to more localized forms of corrosion, such as SCC. The localization of corrosive attack can make detection of SCC damage difficult: the material may appear corrosion free, or nearly so, on its surface while fine stress corrosion cracks are growing within. This can lead to structures being near failure with little or no evidence of their condition [3]. SCC failure is typically by brittle fracture even though the material may normally fail in a ductile manner $[1,2]$.

\subsection{Aluminum Alloys}

Pure Al is highly corrosion resistant, but it is not of much use structurally due to its low strength. By alloying $\mathrm{Al}$ with $\mathrm{Mn}, \mathrm{Zn}, \mathrm{Mg}, \mathrm{Cu}, \mathrm{Si}$, or $\mathrm{Li}$, strength can be significantly improved; however, these alloying additions can lead to SCC susceptibility [3] with corrosion resistance typically declining with increasing alloying content [4]. Due to their relatively light weight and high strength, Al alloys are attractive for many applications that require high specific strength [4].

\subsubsection{Aluminum Alloy and Temper Designation System}

A four digit system is used to identify wrought Al alloys with the first digit signifying the primary alloying element in the series. Table 1 gives the various series of wrought Al alloys. 
Table 1: Wrought Al alloy designations [5]

\begin{tabular}{|l|l|}
\hline Primary alloying element & Alloy series \\
\hline$>99.00 \%$ Aluminum & $1 \mathrm{XXX}$ \\
\hline Copper & $2 \mathrm{XXX}$ \\
\hline Manganese & $3 \mathrm{XXX}$ \\
\hline Silicon & $4 \mathrm{XXX}$ \\
\hline Magnesium & $5 \mathrm{XXX}$ \\
\hline Magnesium and silicon & $6 \mathrm{XXX}$ \\
\hline Zinc & $7 \mathrm{XXX}$ \\
\hline Other elements & $8 \mathrm{XXX}$ \\
\hline Unused series & $9 \mathrm{XXX}$ \\
\hline
\end{tabular}

For further details on the designation of alloys, refer to [5]. Within the 7XXX series there are three distinct types of alloys, each with unique properties and applications: Al-Zn alloys, $\mathrm{Al}-\mathrm{Zn}$ $\mathrm{Mg}$ alloys, and $\mathrm{Al}-\mathrm{Zn}-\mathrm{Mg}-\mathrm{Cu}$ alloys. The latter of these three alloy groups, and more specifically alloy 7075 which contains both $\mathrm{Mg}$ and $\mathrm{Cu}$, will be the focus of this thesis.

Standard heat treatment conditions, or tempers, for Al alloys are also designated by a specific system [6]. This system applies to both wrought and cast Al alloy products except for ingots. The basic temper designation is made by a single capital letter separated from the alloy designation by a hyphen. Subdivisions of the basic tempers are denoted by one or more digits following the letter. The letter $\mathrm{H}$ is used to designate tempers in alloys whose properties are modified through strain hardening and in some cases subsequent thermal treatments, such as annealing. Similarly, the letter $T$ is used for designation of tempers in alloys whose properties can be affected by precipitation heat treatment, and it is always followed by one or more digits which describe a specific sequence of thermal treatments.

Two of the temper designations are of importance in this research, $T 6$ and $T 73$, and they are detailed as follows:

- T6: products have been solution heat treated, quenched, and artificially aged to provide substantial improvements in either mechanical properties or dimensional stability through precipitation hardening. The products are not cold worked following solution heat treatment.

- T7: products have been solution heat treated, quenched, and artificially aged beyond the point of maximum strength to provide some specific benefit, such as enhanced corrosion or SCC resistance. T73 is a specific overaged temper which involves a two step artificial ageing treatment.

Artificial ageing refers to an ageing process carried out at an elevated temperature, but still well below the solution heat treatment temperature. This differs from so-called natural ageing which occurs at ambient temperature in some alloys. 
Additional variations on these tempers are possible, and these are denoted by additional digits in the temper designation. Specifically, the designation Tx51 denotes that the products have been stretched following solution heat treatment to straighten them. Tx51 denotes that 1-3\% plastic strain has been applied for rod or bar products, and $1.5-3 \%$ plastic strain for plate products.

For complete details of the temper designation system, see [6].

\subsubsection{XXX Series Alloys}

The 7XXX series alloys can have some of the highest strengths among all Al alloys. Due to this high strength, and their relatively low weight, they are commonly found in applications such as airframe structures and other highly stressed components [7]. With the primary alloying addition of $\mathrm{Zn}$ in amounts from 1-8 wt\% and a smaller amount of $\mathrm{Mg}$, the result is a series of heat treatable alloys which can achieve very high strengths [7]. Al-Zn-Mg alloys show the greatest response to age hardening of all Al alloys [4], and the 7XXX series alloys exhibit lower densities than Al-Cu based alloys.

\subsubsection{Alloy 7075}

Al alloy 7075 was introduced in 1943 by Alcoa [8] and is primarily an aircraft and aerospace alloy [4]. 7075 is typically used in applications requiring a combination of high strength and moderate toughness and corrosion resistance [8], including aircraft structures, gears and shafts, missile parts, and various defence equipment $[8,9]$. The chemical composition of 7075 is given in Table 2.

Table 2: Compositional limits of 7075 [10]

\begin{tabular}{|c|c|c|c|c|c|c|c|c|c|}
\hline \multicolumn{10}{|c|}{ Concentration [wt\%] } \\
\hline $\mathrm{Cr}$ & $\mathrm{Cu}$ & $\mathrm{Fe}$ & $\mathrm{Mg}$ & $\mathrm{Mn}$ & $\mathrm{Si}$ & $\mathrm{Ti}$ & $\mathrm{Zn}$ & $\begin{array}{c}\text { Other } \\
(\text { each/total) }\end{array}$ & $\mathrm{Al}$ \\
\hline $0.18-0.28$ & $1.2-2.0$ & $<0.50$ & $2.1-2.9$ & $<0.30$ & $<0.40$ & $<0.20$ & $5.1-6.1$ & $0.05 / 0.15$ & Balance \\
\hline
\end{tabular}

7075 has a density of $2.80 \mathrm{~g} / \mathrm{cm}^{3}$ and an elastic modulus of $71.0 \mathrm{GPa}$ [11]. 7075 suffers from poor SCC resistance in the T6 temper; however, this can be alleviated by employing overaged tempers, such as T73, but this comes at the cost of strength $[7,8]$. Table 3 gives some typical properties of 7075 in the T6 and T73 tempers.

Table 3: Typical properties of 7075-T6 and 7075-T73

\begin{tabular}{|l|c|c|}
\hline \multicolumn{1}{|c|}{ Property } & T6 value & T73 value \\
\hline Rockwell B hardness [HRB] & 84 & 78 \\
\hline Yield strength [MPa] & 503 & 434 \\
\hline Tensile Strength [MPa] & 572 & 503 \\
\hline Ductility [\%EL] & 11 & 13 \\
\hline Fracture toughness [MPaVm] & 17.6 & 22.0 \\
\hline Electrical conductivity [\%IACS] & 33 & 40 \\
\hline
\end{tabular}


In Table 3, hardness values are from [4] and all other values are from [11]. Toughness values are for T651 and T7351 and are for the S-L orientation (stress applied in the short transverse direction with crack propagation in the longitudinal direction).

\subsection{Thesis Objectives and Outline}

The goal of this research was to examine the effects of modified solution heat treatment on the microstructure, mechanical properties, and SCC resistance of 7075. This was done through an experimental program which included heat treating specimens of the alloy to various metallurgical conditions, a two part testing program with one phase designed to evaluate the resulting mechanical and physical properties and the other phase to assess the SCC susceptibility of the various conditions, and microstructural examination using a scanning electron microscope (SEM). The objective of this study was not to generate design data or to assess the suitability of the various experimental tempers for any specific purpose, but to compare the various experimental tempers against each other and against standard tempers, namely the T6 and T73 conditions, and relate the differences in their properties and microstructures to the applied solution heat treatments.

This thesis will present the research described above, along with a review of literature pertaining to some of the major topics related to this work. Al alloys, specifically the 7XXX series and $\mathbf{7 0 7 5}$, are discussed in greater detail in chapter two, and stress corrosion cracking, including the proposed mechanisms responsible for the phenomenon and typical testing methods, are presented in chapter three. Chapter four reviews some thermal processing approaches applied to Al-Zn-Mg-Cu alloys and the effects of these thermal treatments on microstructure and SCC resistance. Following the literature review, chapter five gives an outline of the experimental program, chapter six the experimental results, and chapter seven discussion of the results. Finally, conclusions and recommendations for further work are given in chapter eight. 


\section{Aluminum Alloys}

\subsection{Strengthening Mechanisms}

The strength of Al alloys can be derived from a number of different mechanisms; however, all of these methods rely on impeding the motion of dislocations through the material. Specifically, the mechanisms of solid solution strengthening and precipitation hardening will be discussed here.

\subsubsection{Solid Solution Strengthening}

The strengthening effect of solute atoms in solution is the result of misfit between the solute atoms and the $\mathrm{Al}$ atoms in the matrix. Due to the difference in atomic size between different species, solute atoms will exert either a tensile or compressive stress on the surrounding matrix depending on whether the solute atoms are smaller or larger than an Al atom, respectively. The strain fields generated by the solute atoms will interact with the strain fields of dislocations, and this tends to impede the motion of the dislocations. This mechanism is discussed briefly and illustrated in [2].

The effect on yield strength of various alloying elements as a function of their concentration in at\% and wt\% is given in Figure 1 and Figure 2, respectively. These plots show the increment in yield strength for material in the annealed condition containing each alloying addition compared to the yield strength of unalloyed Al.

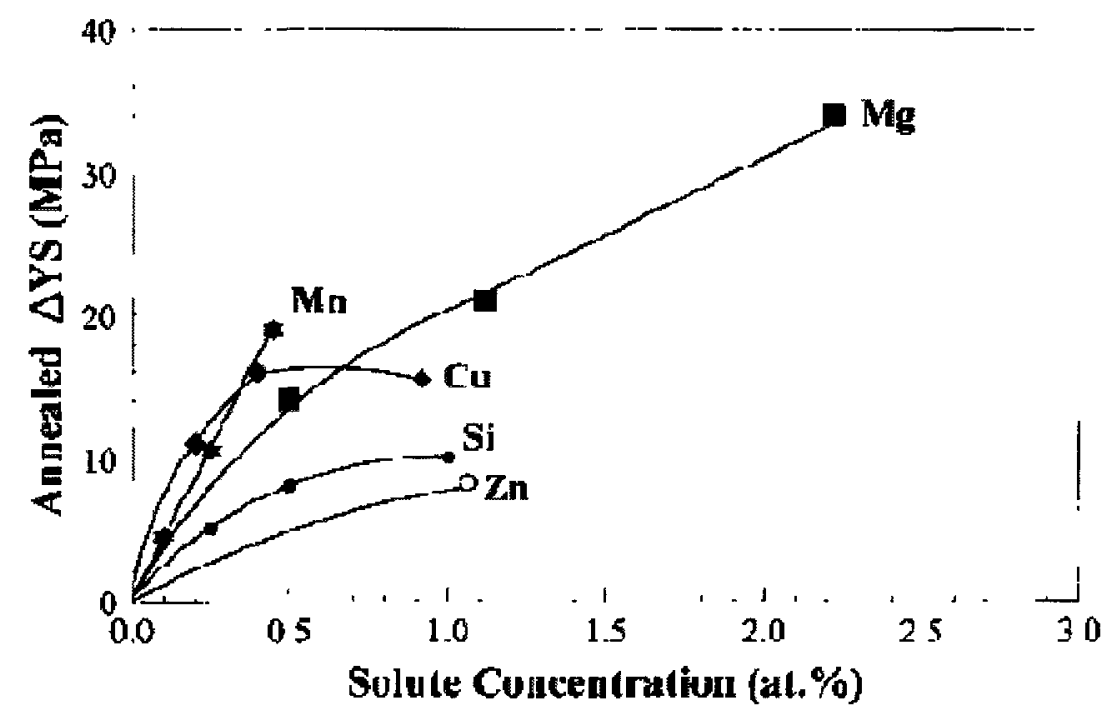

Figure 1: Solid solution strengthening effect of various elements on an at\% basis [4] 


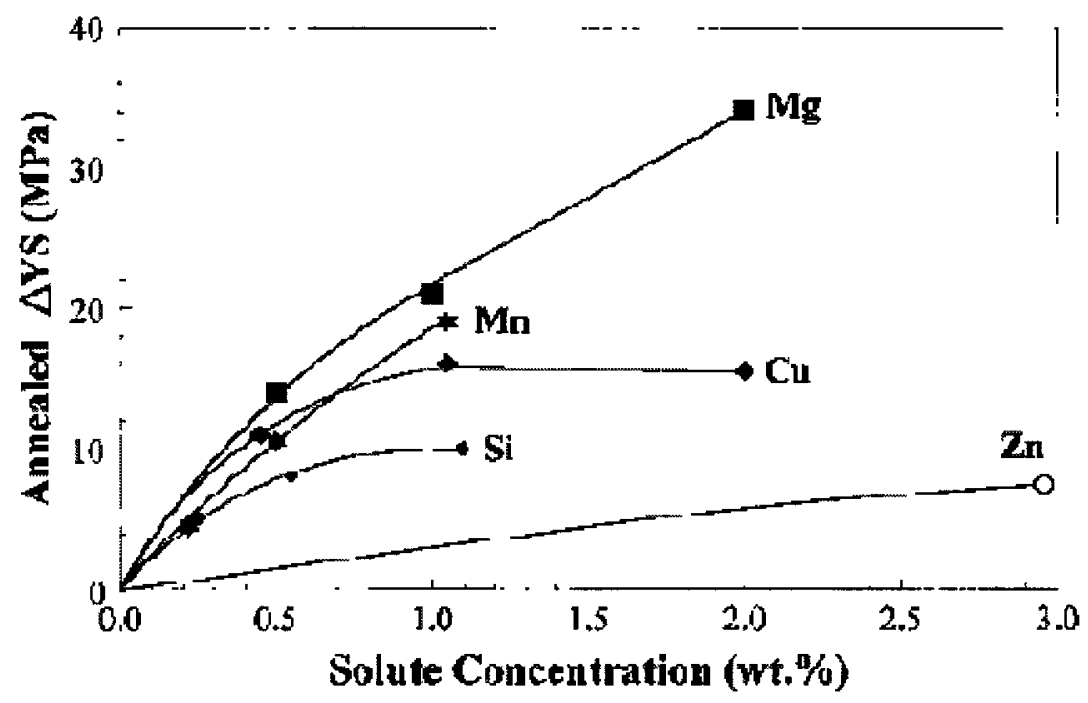

Figure 2: Solid solution strengthening effect of various elements on a wt\% basis [4]

Some Al alloys, such as the $5 \mathrm{XXX}$ series (Al-Mg), rely mainly on solid solution strengthening [4]; however, it is apparent from the above figures that the high strength of the 7XXX series alloys must originate from some other source as $\mathrm{Zn}$ is a relatively ineffective strengthening element in solution.

\subsubsection{Precipitation Hardening}

The 7XXX series alloys, along with the $2 X X X$ series (Al-Cu) and the $6 X X X$ series (Al-Mg-Si), derive most of their strength from the interactions between dislocations and second phase particles, known as precipitates. The process of developing these second phase particles is referred to as precipitation hardening or age hardening.

There are several mechanisms by which dislocations can interact with precipitates, and two of these mechanisms are of importance in this work. Precipitates can be sheared by dislocations or they can be bypassed and which of these two mechanisms is operative depends on the size and spacing of the precipitates. In early stages of ageing, precipitates are relatively small and have a coherent or semi-coherent interface with the matrix, so they can be sheared relatively easily by passing dislocations. As ageing progresses, precipitates grow, as does the average distance between them, and the interface between the matrix and precipitates becomes incoherent due to the increasing strains imposed on the matrix by maintaining a coherent interface. Due to this loss of coherency and increased inter-particle spacing, there exists a critical precipitate size where shearing of the precipitates becomes too difficult and it is easier for dislocations to bypass the precipitates by bowing around them. Figure 3 illustrates the effect of precipitate size on the critical resolved shear stress to cause dislocation motion and the transition between dislocation-precipitate interaction mechanisms. 


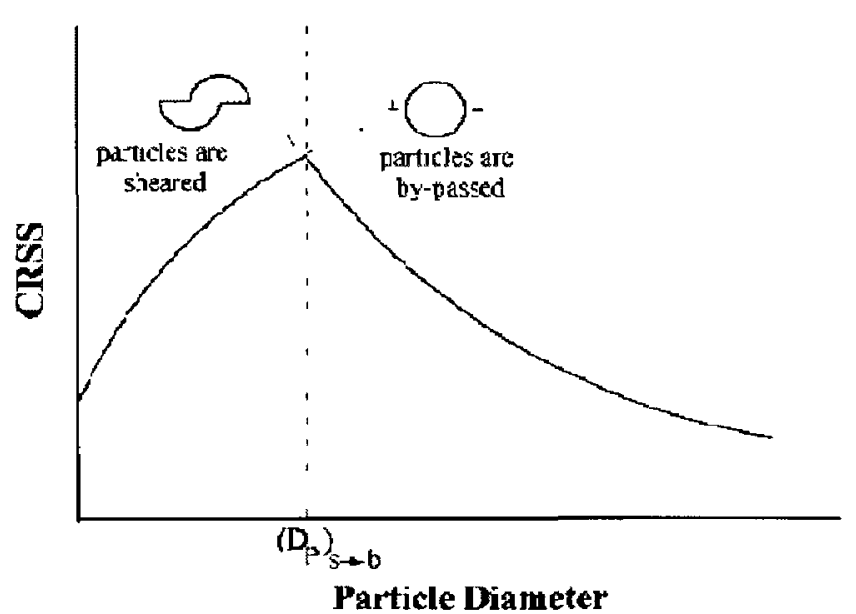

Figure 3: Schematic illustration of the variation in critical resolved shear stress (CRSS) to cause dislocation motion as a function of precipitate size [4]

The maximum strength typically results when the average particle diameter is near the critical size for the change in mechanism, as indicated by $\left(D_{p}\right)_{s \rightarrow b}$, the particle diameter for the shearingto-bowing transition, in Figure 3.

In precipitation hardenable alloys, there is a much greater strengthening contribution provided by the precipitates as compared to the solid solution strengthening effects. Figure 4 shows the effect of total alloying content on yield strength in the T6 and $W$ (as quenched) tempers of an Al-Zn-Mg-Cu alloy.

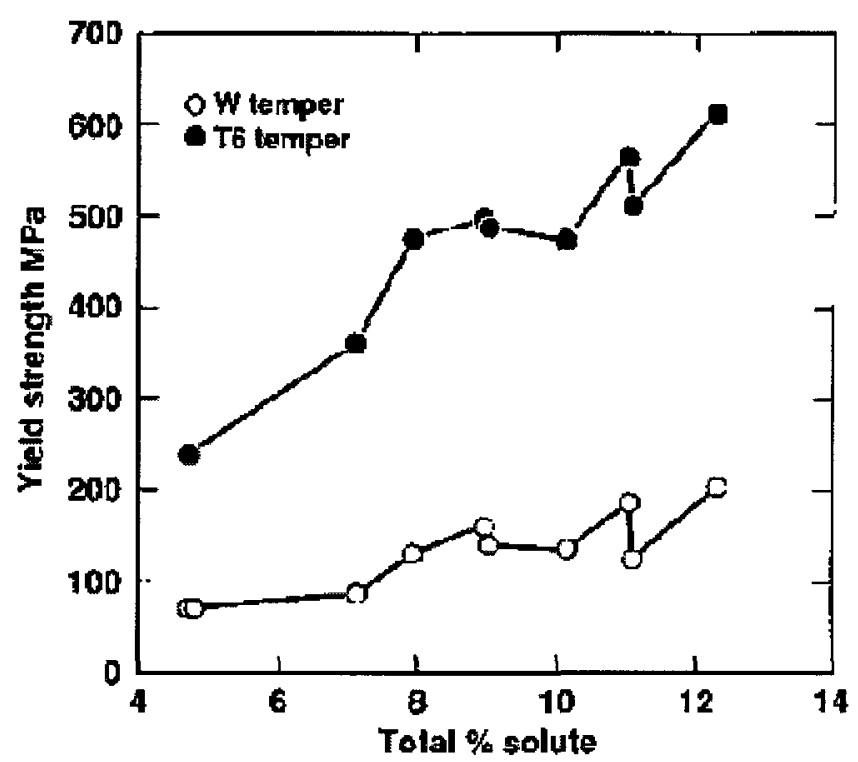

Figure 4: Yield strength as a function of total alloying content in an $\mathrm{Al}-\mathrm{Zn}-\mathrm{Mg}-\mathrm{Cu}$ alloy in two tempers [4]

Based on an approximate alloy content of $5.5 \mathrm{wt} \% \mathrm{Zn}, 2.5 \mathrm{wt} \% \mathrm{Mg}$, and $1.5 \mathrm{wt} \% \mathrm{Cu}$ the total solute content of 7075 is about 9.5 wt\%. From Figure 4 , the corresponding yield strength in the 
T6 temper is about $500 \mathrm{MPa}$, and this agrees very closely with the typical value of $503 \mathrm{MPa}$ given in Table 3.

For precipitation hardening to be possible, the alloy system must have a phase diagram similar to that shown in Figure 5.

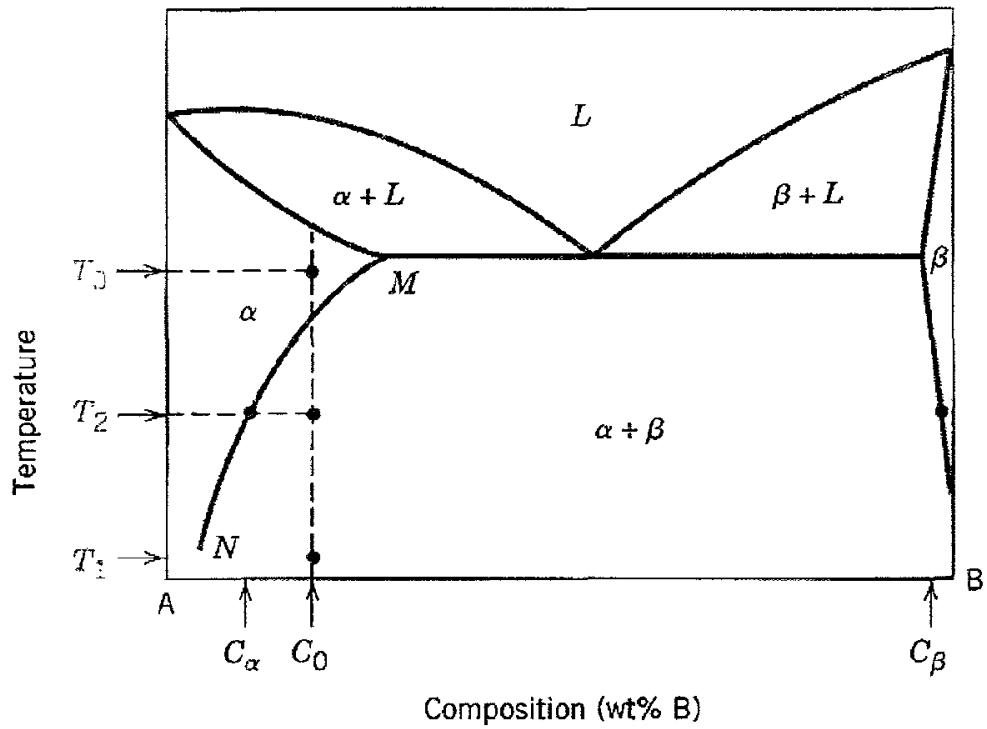

Figure 5: Schematic phase diagram for a precipitation heat treatable alloy system [2]

Two features of this phase diagram are important as they represent the prerequisites for precipitation hardening: the significant solid solubility of one element in the other, and the rapid decrease in the solubility limit with decreasing temperature.

To produce a precipitate-laden microstructure in a precipitation hardenable alloy, a two step thermal treatment must be applied. First, the alloy must be heated to some temperature within the single phase solid region, such as $\mathrm{T}_{0}$ in Figure 5 , and held there for some time to allow all of the solute elements to be dissolved into solution. This is termed the solution heat treatment or solutionizing heat treatment. Following solutionizing, the alloy is rapidly cooled, or quenched, to some temperature within the two-phase region, shown as $T_{1}$ in Figure 5 . By rapidly cooling, the solute atoms do not have enough time to form precipitates and are trapped in a supersaturated solid solution. This supersaturated solution is thermodynamically unstable, so there is a driving force for the solute atoms to congregate and form precipitates. By heating the alloy to some intermediate temperature, $T_{2}$ in Figure 5 , and holding for some time, the system is given sufficient thermal energy to allow solute atom diffusion and the formation of precipitates. This thermal treatment process is shown schematically in Figure 6. 


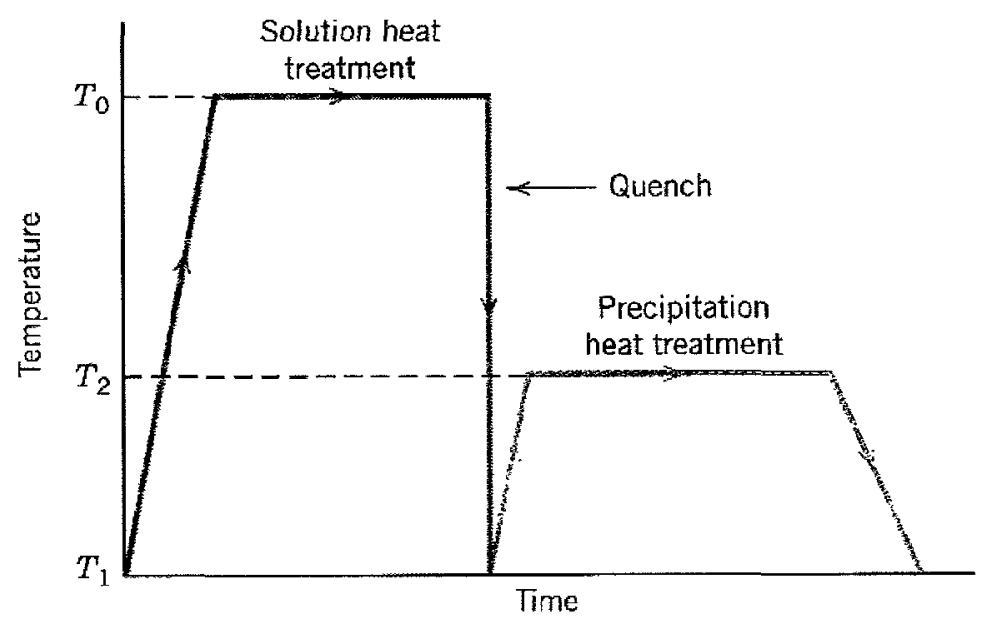

Figure 6: Schematic illustration of thermal treatment to produce precipitation hardening [2]

One of the most important steps in the thermal treatment process is quenching as the final properties of some Al alloys depend heavily upon the quench rate. This phenomenon, termed quench sensitivity, is discussed in detail in section 2.2.4.

This is a very brief overview of precipitation hardening, which is in fact quite a complex process. For a more detailed discussion of precipitation hardening see references [4], [12], and [13].

It is also important to note that while the schematic phase diagram employed in this explanation depicts a binary alloy system, most commercial precipitation hardenable alloys contain more than one primary alloying element; however, in many cases higher order alloy systems can be represented by a binary phase diagram. A vertical section taken from a ternary phase diagram will give a binary phase diagram which can be used to represent the key elements of the system. The Al-MgZn $\mathrm{n}_{2}$ binary phase diagram illustrates this point, and it is shown in Figure 7. 


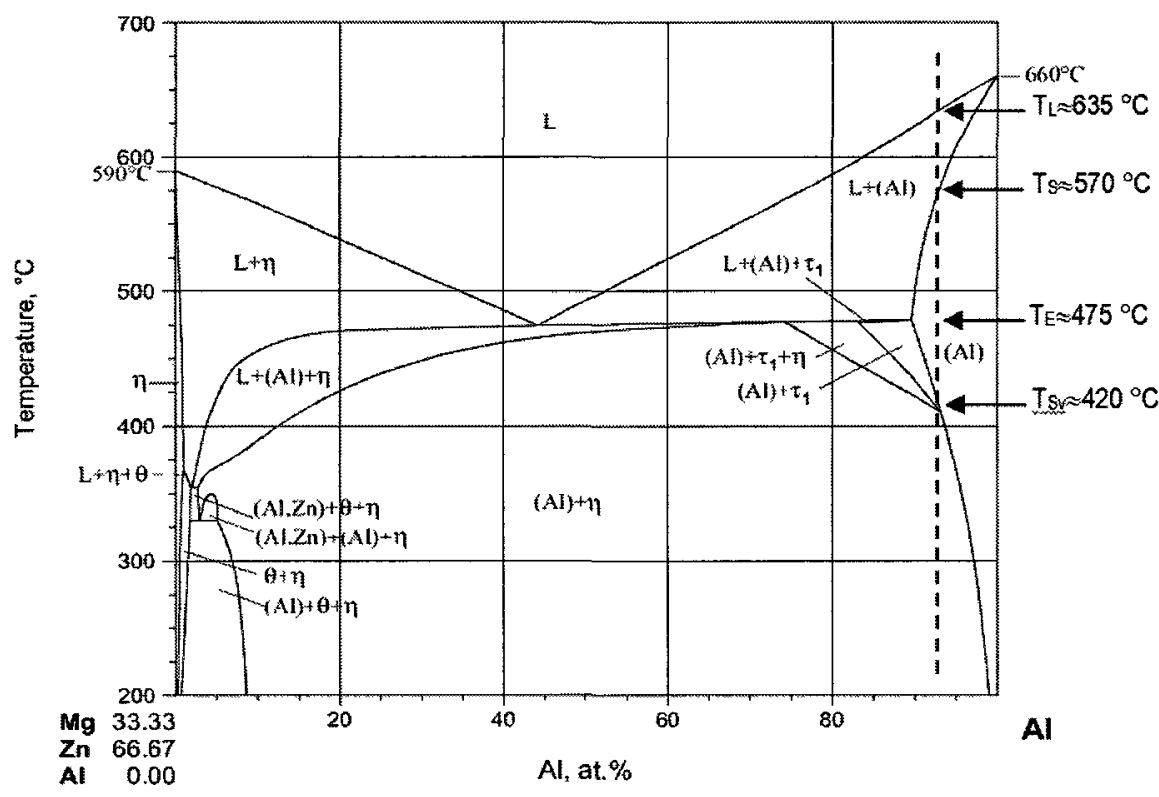

Figure 7: Al-MgZn phase diagram [14]

In Figure 7, the vertical dashed line represents the approximate composition of 7075, and the solvus, eutectic, solidus, and liquidus temperatures are represented by $T_{S V}, T_{E}, T_{S}$, and $T_{L}$, respectively. Since the temperatures given in Figure 7 are based on a simplified ternary system of $\mathrm{Al}, \mathrm{Zn}$, and $\mathrm{Mg}$, the effects of the other alloying elements and impurities on the solidus, liquidus, and solvus temperatures are not taken into account; therefore, these temperatures can only be considered as approximations for 7075 .

The solvus temperature given in Figure 7 represents the solvus for the $\mathrm{MgZn}_{2}$ precipitate, referred to as the $n$ phase, specifically; however, the presence of other alloying elements in 7075 may alter the composition of the $\eta$ phase, and this can affect the solvus temperature. The $\eta$ phase solvus may be as high as 430 to $445^{\circ} \mathrm{C}$ in real $7 X X X$ series alloys [15], so it can only be said with reasonable certainty that the true solvus temperature for 7075 is somewhere in the range of 420 to $445^{\circ} \mathrm{C}$.

The actual values of the liquidus and solidus temperatures for 7075 are dependent on the exact composition and the homogeneity of the material. The liquidus temperature of 7075 is $635^{\circ} \mathrm{C}$ $[9,11]$, but some small variation can exist due to slight compositional differences. Conversely, the solidus temperature of 7075 varies widely, and this variation depends heavily on the level of homogeneity of the material. For well homogenized 7075 , the solidus temperature is $532^{\circ} \mathrm{C}$ [11]; however, for as-cast material that has not been heat treated the solidus temperature can be as low as $477^{\circ} \mathrm{C}[9,11]$, or even $466^{\circ} \mathrm{C}$ [15], which corresponds to the eutectic temperature.

In as-cast ingots, some segregation of alloying elements can exist within the material, and these localized differences in composition give rise to differences in the local solidus temperature. This segregation is due to compositional partitioning during cooling through the temperature range between the liquidus and solidus, often referred to as the "mushy zone." To reduce this 
segregation, ingots are typically subjected to a homogenization heat treatment for several hours, or even days, prior to hot working such as rolling or extrusion. Even though commercially available material is typically homogenized, the lower solidus temperature of $477^{\circ} \mathrm{C}$ is quoted on an Alcoa data sheet for 7075 [9] as this represents the lowest temperature at which some incipient melting may occur for the worst case composition and if homogenization was not complete during processing.

\subsection{Precipitation in Al-Zn-Mg-Cu Alloys}

Homogeneous nucleation of precipitates is very difficult to achieve due to the relatively high energy barrier. This is typically overcome by the nucleation of some precursor phase which then acts as a nucleation site for metastable or equilibrium precipitates, or by direct heterogeneous nucleation of these precipitates at defects in the crystal [4]. Nucleation sites include vacancies, dislocations, stacking faults, grain boundaries, and particles such as dispersoids (discussed in section 2.3.2).

\subsubsection{Nucleation at Vacancies}

The equilibrium concentration of vacancies in a material increases exponentially with temperature; hence, when the alloy is heated to the solutionizing temperature it will have a relatively high concentration of vacancies. If the alloy is then quenched, many of these vacancies will be trapped, just as with solute atoms, to create a supersaturation of vacancies, and these are termed quenched-in vacancies. The supersaturation of quenched-in vacancies results in a high rate of nucleation and growth of precipitates in precipitation heat treatable Al alloys [4]. The excess vacancies have two major effects: first, vacancies will tend to attract one another to form clusters, and these clusters are the nucleation sites for Guinier-Preston (GP) zones, the precursor to many metastable and equilibrium precipitates in many precipitation hardenable Al alloys. Second, this excess of vacancies leads to increased diffusion rates of solute atoms in the Al matrix, even at relatively low temperatures. It has been found that, given the same ageing treatment, samples solutionized at a higher temperature will have higher rates of GP zone formation compared to those solutionized at a lower temperature, due to the higher vacancy concentration [12]

GP zones typically originate as small clusters of vacancies at which $\mathrm{Zn}$ atoms collect forming a spherical precipitate which is coherent with the Al matrix. In some alloys this process can occur at ambient temperatures. As ageing progresses, $\mathrm{Mg}$ atoms will migrate to these $\mathrm{Zn}$ clusters with a typical $\mathrm{Zn}$ to $\mathrm{Mg}$ ratio of about 4:1 [4]. With further ageing, the zones will grow and start to lose coherency with the matrix resulting in the metastable $\eta^{\prime}$ precipitate with a plate-like morphology. Extended ageing will allow the equilibrium $\eta$ phase $\left(\mathrm{MgZn}_{2}\right.$ or $\left.\mathrm{Mg}(\mathrm{Al}, \mathrm{Cu}, \mathrm{Zn})_{2}\right)$ to form. The overall precipitation sequence in this case is as follows:

$$
\text { Supersaturated solid solution (SSSS) } \rightarrow \text { GP zones } \rightarrow \eta^{\prime} \rightarrow \eta
$$




\subsubsection{Other Nucleation Sites}

The metastable and equilibrium precipitates can form without the aid of GP zones by heterogeneous nucleation at defects. In one mechanism, solute can segregate to stacking faults and form precipitates, provided that the precipitate and the stacking fault have the same crystal structure. Alternatively, precipitates can nucleate at dislocations, and this is apparent when the dislocation density is relatively high [4].

Since the spacing of these type of defects is relatively large compared to that of GP zones, the resulting precipitate distribution tends to be more coarse when the $\eta^{\prime}$ and $\eta$ phases nucleate directly, which can result in reduced strength. The introduction of more heterogeneous nucleation sites, such as dislocations through cold work prior to ageing, can even reduce strength by promoting precipitate nucleation at these sites rather than through GP zone formation. In the case of 7075-T6, strength is typically unaffected by small amounts of cold work after quenching [4], such as the stretching applied to produce the T651 temper.

\subsubsection{Precipitate Free Zone}

During ageing, and possibly quenching, precipitation will occur in the matrix and in some cases along the grain boundaries as outlined above; however, in the region directly adjacent to the grain boundaries a precipitate free zone (PFZ) tends to form. Two examples of PFZs in an Al-Zn$\mathrm{Mg}$ and an $\mathrm{Al}-\mathrm{Zn}-\mathrm{Mg}-\mathrm{Cu}$ alloy are shown in Figure 8 and Figure 9, respectively.

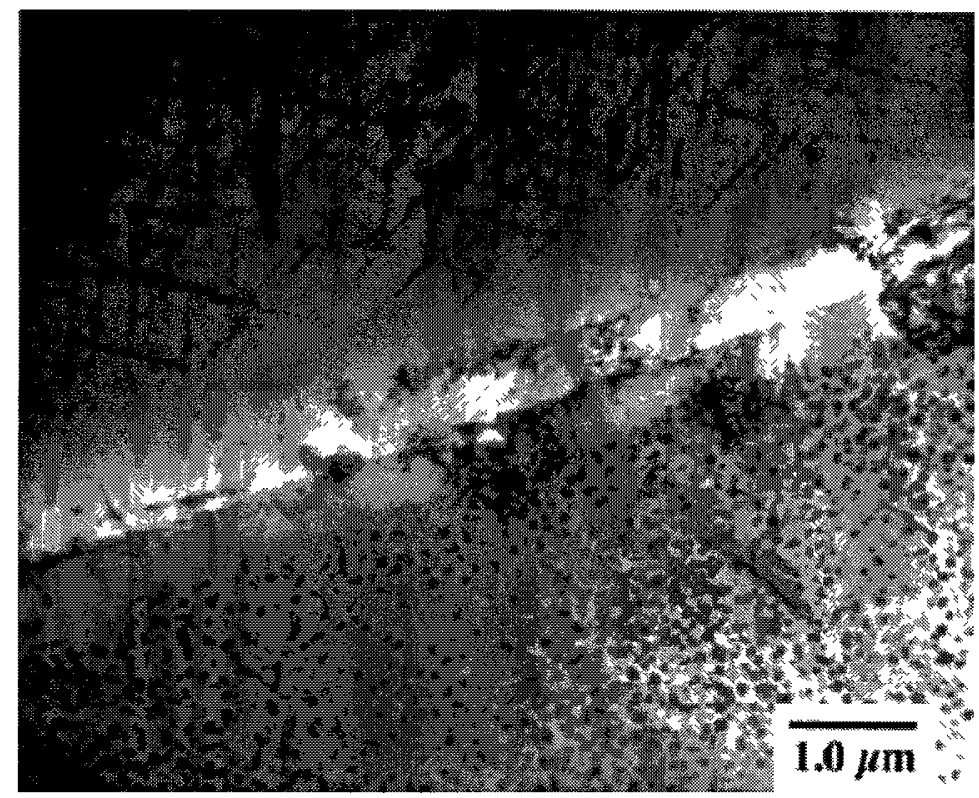

Figure 8: $\mathrm{PFZ}$ in an $\mathrm{Al}-\mathrm{Zn}-\mathrm{Mg}$ alloy as well as $\eta^{\prime}$ precipitates in the matrix and $\eta$ precipitates on the grain boundary [4] 


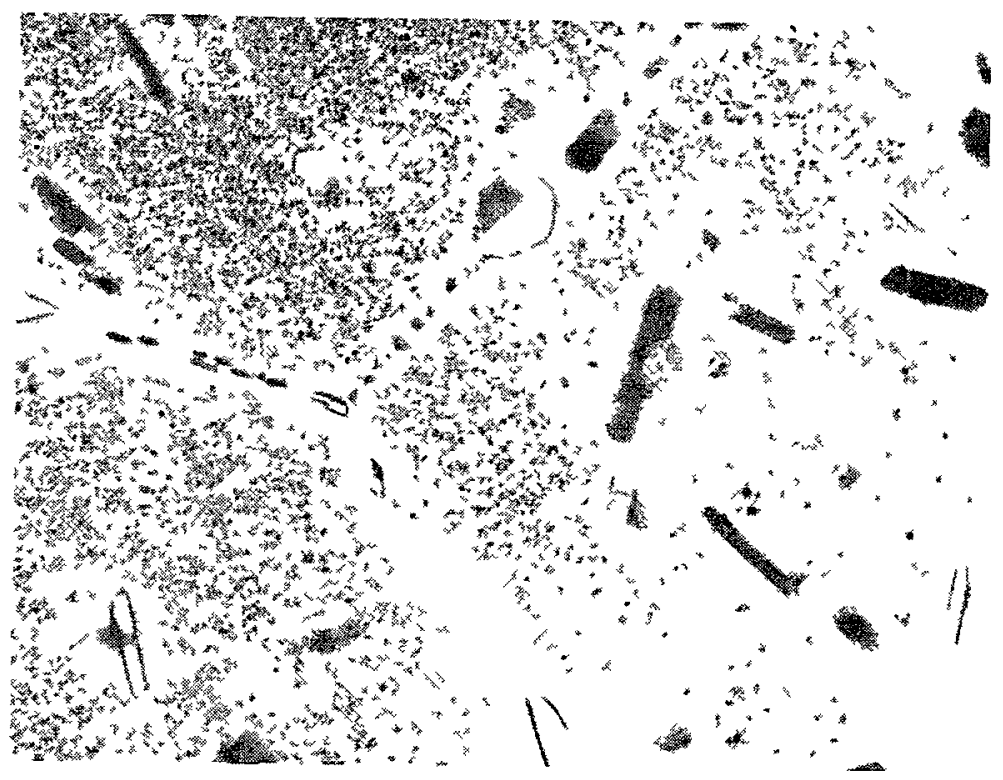

Figure 9: PFZ in an Al-Zn-Mg-Cu alloy shown at 59200X magnification [12]

The formation of the PFZ is due to the depletion of excess vacancies and solute at the grain boundaries caused by grain boundary precipitation. Grain boundaries and other interfaces within the material are the primary sinks for vacancies other than dislocations, meaning that vacancies will tend to diffuse to and collect at these locations during quenching. This leads to a vacancy concentration profile near the grain boundaries sımilar to that shown in Figure 10.

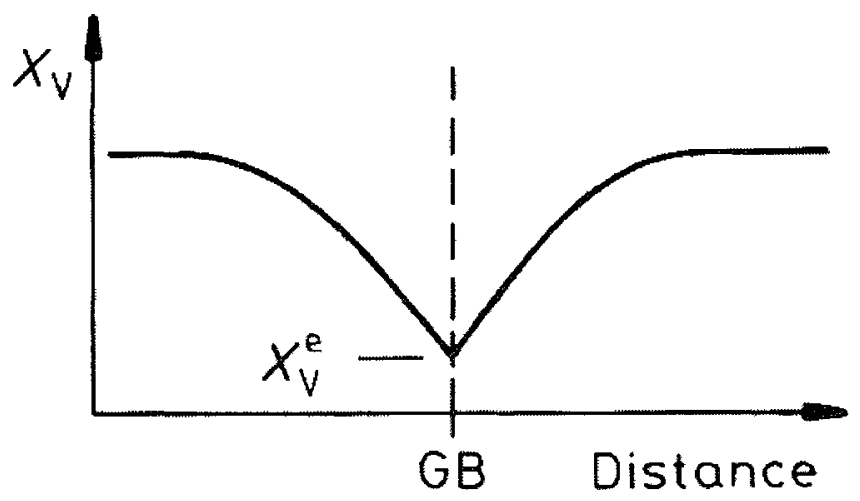

Figure 10: Vacancy concentration profile near a grain boundary $(G B)$ following quenching. $X_{V}{ }^{e}$ indicates the equilıbrium vacancy concentration at the ageing temperature [12]

Following quenching, the vacancy concentration at and near the grain boundaries is much closer to the equilibrium value for the ageing temperature or the temperature to which the material was quenched, whereas the matrıx has retained a much higher vacancy concentration.

For precipitation to occur there is a critical excess vacancy concentration required; therefore, in the regions adjacent to grain boundaries this criterion may not be met. The width of this vacancy depleted zone, and hence the PFZ, can be affected by the rate of quenchıng from the solution heat treatment temperature. Figure 11 illustrates this point. 


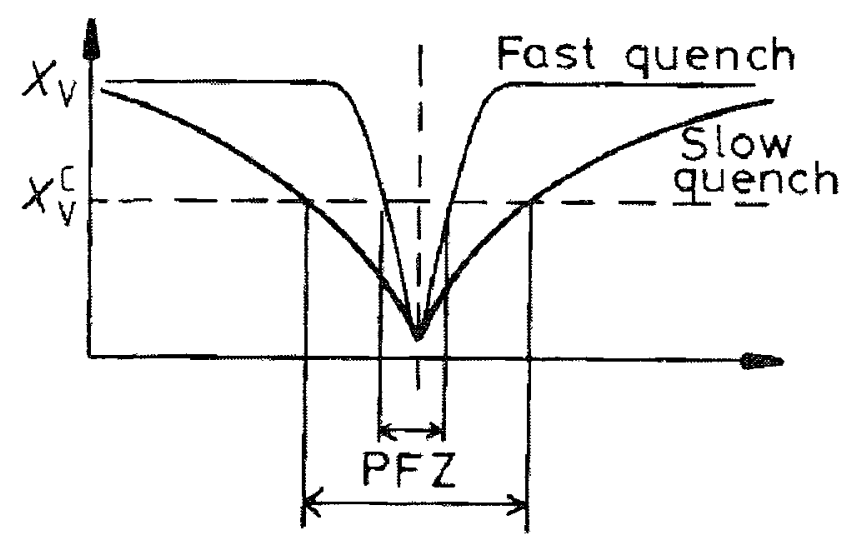

Figure 11: Variation of PFZ width with quenching rate from solutionizing temperature. $X_{v}{ }^{c}$ indicates the critical excess vacancy concentration for precipitation [12]

In addition to the quench rate, the solution heat treatment temperature can affect the size of the PFZ. Increasing the solutionizing temperature or the quench rate will generally reduce the width of the PFZ. Low temperature ageing can also reduce the PFZ by stimulating nucleation [4].

\subsubsection{Quench Sensitivity}

Quench sensitivity refers to the dependence of the properties of an alloy upon the rate of quenching from the solution heat treatment temperature. In high strength, precipitation heat treatable Al alloy products, the maximum possible strength that can be developed by ageing decreases with decreasing rate of cooling from the solutionizing temperature [4]. This is due to the loss of vacancies to sinks and the loss of solute to coarse, heterogeneously nucleated particles, such as those formed at grain boundaries, during quenching. When solute is extracted from solid solution by the formation of these particles, it reduces the amount of solute available to form the fine, densely distributed precipitates which contribute to strengthening. The tensile strength of several commercial Al alloys as a function of quenching rate is shown in Figure 12, and this figure demonstrates the strong quench sensitivity of 7075 .

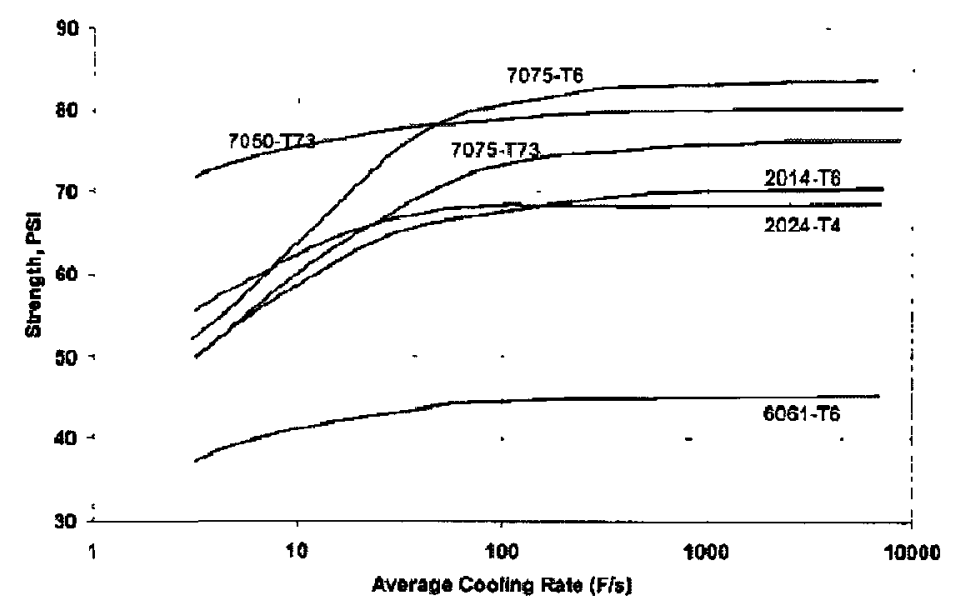

Figure 12: Tensile strength of several commercial Al alloys as a function of average cooling rate from solution heat treatment temperature [13] 
Quench sensitivity can be affected by alloying content: in general, alloys with higher solute content will be more quench sensitive, and the specific alloying additions can also have an effect. Alloys in which $\mathrm{Cr}$ and $\mathrm{Mn}$ are added to form dispersoid particles (discussed in section 2.3.2) tend to be more quench sensitive than those containing $\mathrm{Zr}$. Dispersoids containing $\mathrm{Zr}$ have a coherent interface with the matrix while $\mathrm{Cr}$ and $\mathrm{Mn}$ dispersoids are incoherent. These incoherent interfaces are much more active nucleation sites for precipitation; hence, solute loss from the solid solution will be greater when $\mathrm{Cr}$ or $\mathrm{Mn}$ dispersoids are present. Figure 13 illustrates the relationship between different alloying additions and strength as a function of the quenching rate in two $\mathrm{Al}-\mathrm{Zn}-\mathrm{Mg}-\mathrm{Cu}$ alloys.

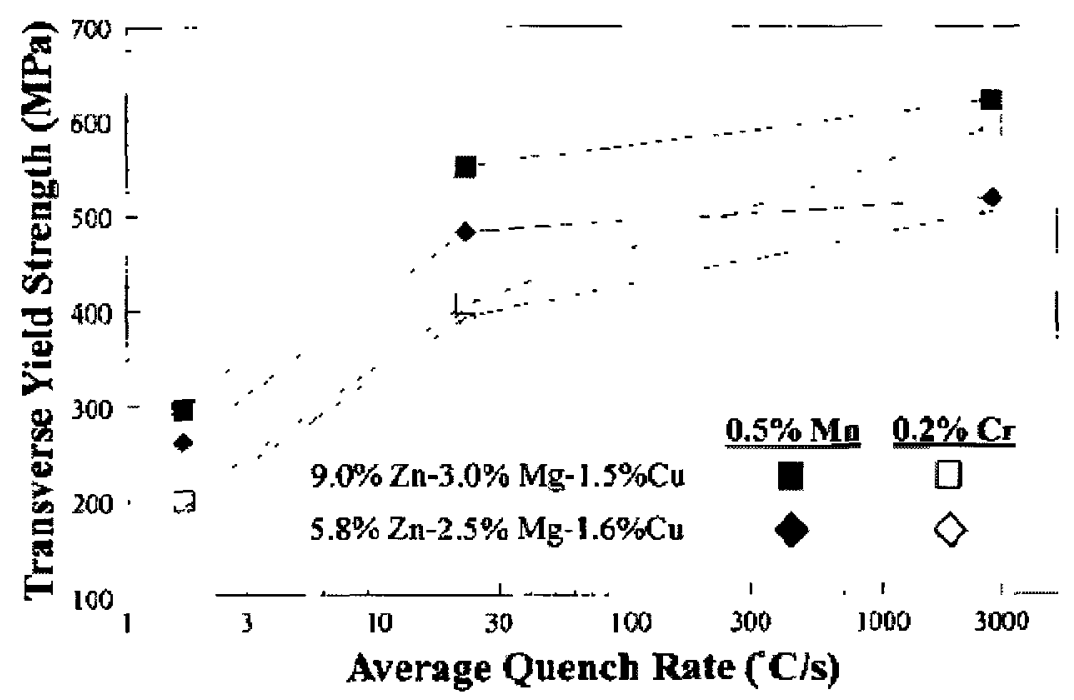

Figure 13: Effect of different alloying additions on the strength of two Al-Zn-Mg-Cu alloys as a function of cooling rate [4].

Note that in Figure 13 the alloy containing $5.8 \% \mathrm{Zn}$ and $0.2 \% \mathrm{Cr}$ corresponds to 7075 .

\subsection{Constituents and Dispersoids Present in $\mathbf{7 0 7 5}$}

\subsubsection{Constituent Particles}

Constituent particles are coarse intermetallic phases that form by a eutectic reaction during the solidification of Al alloys from the melt. These particles are too large to act as a significant barrier to dislocation movement, so they provide no strengthening effect. Constituents do, however, have a negative effect on both fatigue resistance and fracture toughness in high strength Al alloy products.

Constituent phases present in $7 \times 75$ alloys include $\mathrm{Al}_{7} \mathrm{Cu}_{2} \mathrm{Fe}, \mathrm{Al}_{12}(\mathrm{Fe}, \mathrm{Mn})_{3} \mathrm{Si}, \mathrm{Al}_{6}(\mathrm{Fe}, \mathrm{Mn})$, and $\mathrm{Mg}_{2} \mathrm{Si}$ [4]. The presence of these constituent particles is the reason for the limitations placed on the Fe and Si content in 7X75 alloys as higher Fe and Si contents lead to an increased quantity of constituent particles. 


\subsubsection{Dispersoids}

Dispersoids are very fine intermetallic particles which are typically formed during alloy solidification and modified during ingot homogenization and hot rolling operations. These fine particles have the beneficial effect that they tend to inhibit recrystallization by pinning subgrain boundaries during thermal processing, and this helps to control grain growth. The negative consequence is that dispersoids can act as nucleation sites for microvoids which help to initiate cracks [4].

$\mathrm{Al}_{12} \mathrm{Mg}_{2} \mathrm{Cr}$, known as the $\mathrm{E}$ phase, is the dispersoid phase found in $7 \times 75$ alloys [4]. These particles are shown in 7075 in Figure 14.

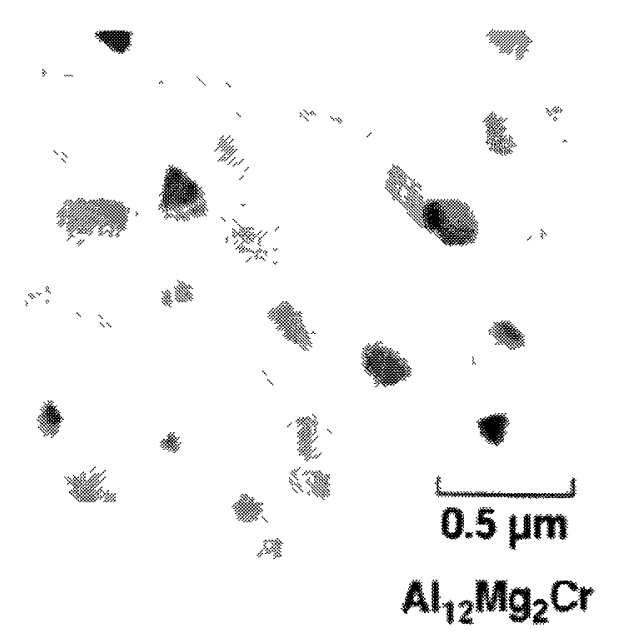

Figure 14: Dispersoid particles in 7075 [4]

\subsection{Alloying Additions and Impurities in 7075 and Their Effects 2.4.1 Zinc and Magnesium}

The addition of $\mathrm{Zn}$ and $\mathrm{Mg}$ to $\mathrm{Al}$ results in the formation of the intermetallic phase $\mathrm{MgZn}_{2}$, referred to as the $n$ phase, which is primarily responsible for the strength of Al-Zn-Mg alloys. $\mathrm{Mg}$ reduces the low temperature solubility of $\mathrm{Zn}$ in $\mathrm{Al}$ [4], so the precipitation hardening response of $\mathrm{Al}-\mathrm{Zn}-\mathrm{Mg}$ alloys is greatly improved compared to Al-Zn alloys. The disadvantage of alloying with $\mathrm{Zn}$ and $\mathrm{Mg}$ is that increasing additions of both elements tends to reduce the corrosion resistance of $\mathrm{Al}$; however, this can be controlled to some degree through the use of other alloying additions [7].

\subsubsection{Copper}

When $\mathrm{Cu}$ is added to Al-Zn-Mg alloys in amounts greater than about $0.25 \mathrm{wt} \%$ it contributes to increased strength in these alloys; however, the more important effect of $\mathrm{Cu}$ addition in $\mathrm{Al}-\mathrm{Zn}$ $\mathrm{Mg}$ alloys is that it reduces the susceptibility to SCC, especially when the Cu content is greater than $1.5 \mathrm{wt} \%$ [4]. The addition of $\mathrm{Cu}$ up to $1 \mathrm{wt} \%$ provides only enhanced solid solution strengthening, but greater additions of $\mathrm{Cu}$ stimulate precipitation in the matrix which helps to reduce the size of the PFZ [4,7]. $\mathrm{Cu}$, as well as $\mathrm{Al}$, can substitute for $\mathrm{Zn}$ in $\mathrm{MgZn}_{2}$, so this phase is sometimes referred to as $\mathrm{Mg}(\mathrm{Al}, \mathrm{Cu}, \mathrm{Zn})_{2}$ [4]. This substitution of $\mathrm{Cu}$ and $\mathrm{Al}$ in the $\eta$ phase during 
high temperature ageing (above $150^{\circ} \mathrm{C}$ ) results in a significant improvement in the SCC resistance of Al-Zn-Mg-Cu alloys. This will be discussed further in chapter four. Lower $\mathrm{Cu}$ content alloys, such as 7079 , show significantly reduced SCC resistance compared to alloys with greater additions of $\mathrm{Cu}$ [16]. The major disadvantages of the addition of $\mathrm{Cu}$ in $\mathrm{Al}-\mathrm{Zn}-\mathrm{Mg}$ alloys is that weldability typically decreases with increasing $\mathrm{Cu}$ content [4], and $\mathrm{Cu}$ tends to increase quench sensitivity in these alloys as well. This increase in quench sensitivity is due to the tendency for the $\mathrm{Cu}$-containing $\eta$ phase to precipitate at grain boundaries and at the interface between the matrix and dispersoid particles during quenching [4].

\subsubsection{Chromium and Manganese}

$\mathrm{Cr}$ and $\mathrm{Mn}$ are added to Al-Zn-Mg alloys mainly to help control the grain structure, more specifically the recrystallization behaviour during processing, and they also introduce a small solid solution strengthening effect. Due to the low diffusion rates of $\mathrm{Cr}$ and $\mathrm{Mn}$ in $\mathrm{Al}$, these elements, as well as $\mathrm{Zr}$, combine with $\mathrm{Al}$ to form finely dispersed intermetallic phases which help to inhibit recrystallization. This allows for some control over grain growth and morphology, especially in wrought products $[4,7]$. $\mathrm{Cr}$ can help to improve the SCC resistance of Al- $\mathrm{Zn}-\mathrm{Mg}$ alloys [4], but $\mathrm{Cr}$ and $\mathrm{Mn}$ both typically increase quench sensitivity [4,7] due to the formation of incoherent dispersoids which act as nucleation sites for precipitates during quenching.

\subsubsection{Impurities}

The primary impurities in 7075 are $\mathrm{Fe}$ and $\mathrm{Si}$. Si forms the constituent phase $\mathrm{Mg}_{2} \mathrm{Si}$ which is responsible for the precipitation strengthening effect in the 6XXX series (Al-Mg-Si) alloys; however, the formation of $\mathrm{Mg}_{2} \mathrm{Si}$ in $7 \mathrm{XXX}$ series alloys means that less $\mathrm{Mg}$ is available for precipitation in the strengthening $\eta$ phase. In $7 X X X$ series alloys containing $\mathrm{Cu}$, such as $7075, \mathrm{Fe}$ forms an intermetallic phase with $\mathrm{Al}$ and $\mathrm{Cu}$. While this has little effect on strength, since $\mathrm{Cu}$ is not the primary strengthening addition, it results in decreased fracture toughness, and both Fe and Si can contribute to quench sensitivity [4]. More modern alloys, such as 7175 and 7475, have much lower limits on the Fe and Si content than 7075 [10].

\subsection{Standard Thermal Treatments Applied to 7075}

The typical solution heat treatment temperature for 7075 products is between 460 and $499^{\circ} \mathrm{C}$, and solutionizing times depend on the dimensions of the product being processed. Ageing treatments to produce the T6 temper are carried out at $121^{\circ} \mathrm{C}$ for $23-25$ hours, and the T73 temper is produced by a two step ageing process with the T6 ageing treatment applied first followed by $26-28$ hours at $163^{\circ} \mathrm{C}$ or $8-9$ hours at $177^{\circ} \mathrm{C}$ [13]. Some typical properties of these two tempers are given in Table 3. 


\section{Stress Corrosion Cracking}

\subsection{General Characteristics of SCC}

In general, the requirements for SCC to occur are tensile stress, an aggressive environment, and a susceptible material; however, this statement is too general as only certain alloy-environment systems show susceptibility to SCC $[1,18]$. In many cases a material may be resistant to general corrosion or other specific forms of corrosion in a given environment, but upon the introduction of tensile stress the same material will suffer from SCC [1,2].

SCC does not require a high concentration of the corrodent in the environment or particularly high stresses [1]. The stresses needed to cause SCC are typically well below the materials yield stress $[1,4]$ and they can result from applied tensile stress, residual or thermal stress in a part, or even the force of built up corrosion products within a crack $[1,16,17]$. SCC results in reduced ductility and typically causes brittle failure $[1,2,18]$.

There are two stages to SCC: crack initiation and crack propagation. While the initiation stage is important, stress is not necessarily required to nucleate cracks. This can be the result of other processes, such as mechanical damage or a corrosion process like pitting, so the propagation of stress corrosion cracks will be the focus of the subsequent sections.

\subsection{SCC in High Strength Aluminum Alloys}

SCC can result when $\mathrm{Al}$ alloys are exposed to water or aqueous solutions of $\mathrm{Cl}^{-}[17,18], \mathrm{Br}$, or $\mathrm{I}^{-}$ ions [18], and these anions result in accelerated growth of stress corrosion cracks compared to water [16]. SCC in Al alloys occurs intergranularly $[16,17,19]$, so microstructural texture and the orientation of tensile stress with respect to the texture are important [16]. For example, rolled and extruded 7075 products show the greatest susceptibility to SCC when stressed in the short transverse direction (normal to the rolling direction) [16,19]. Figure 15 illustrates this relationship between stressing direction with respect to grain structure and SCC resistance. 


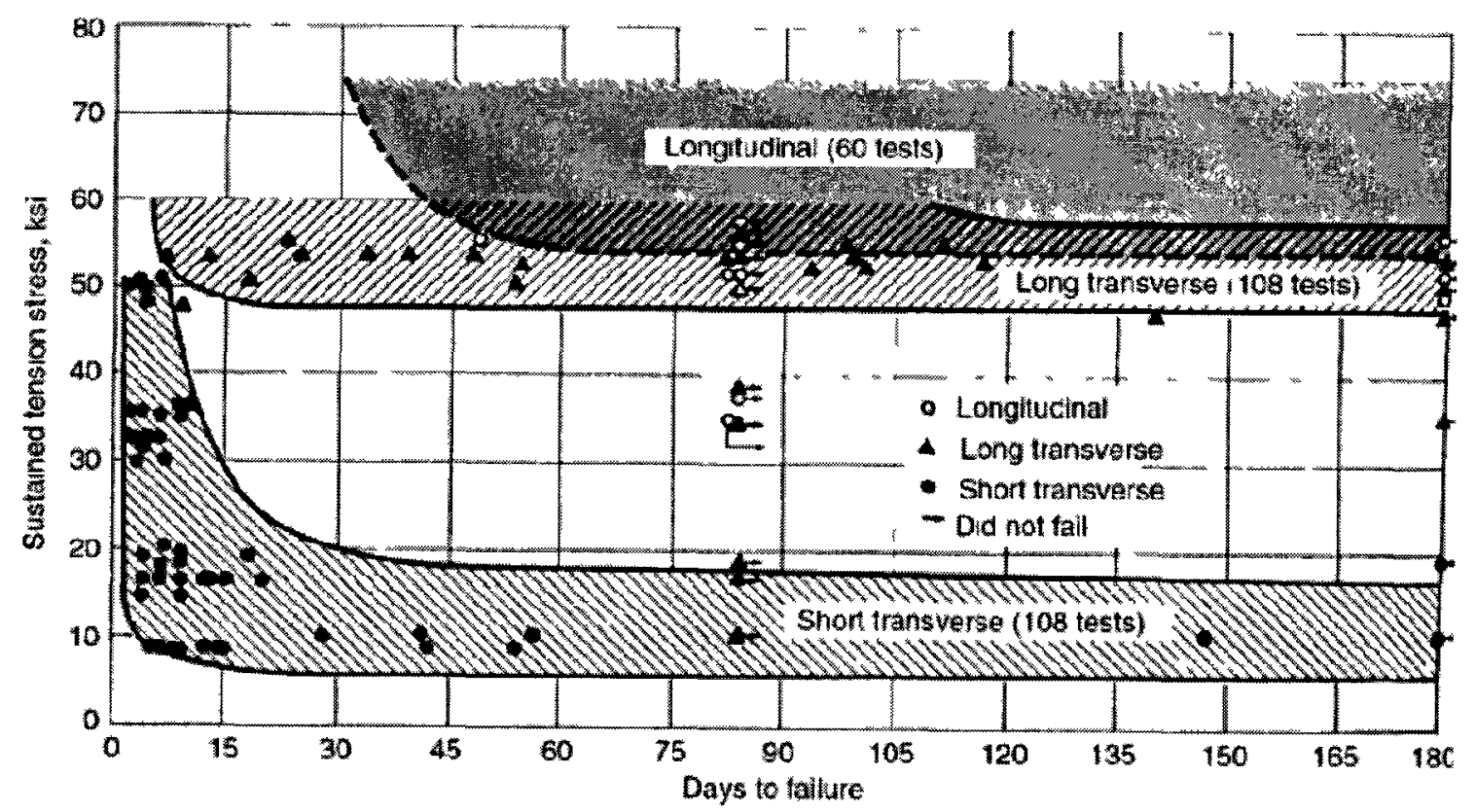

Figure 15: Effect of stressing direction with respect to microstructural texture in extruded 7075 exposed to $3.5 \% \mathrm{NaCl}$ solution by alternate immersion [19]

Figure 15 is based on data collected from smooth specimen tests, so it considers both the initiation and propagation stages of SCC; however, the crack propagation behaviour in precracked specimen tests shows the same strong dependence on microstructural texture as illustrated above.

The causes of SCC in Al alloys, and more specifically the mechanisms by which stress corrosion cracks propagate, are not particularly well understood. As a result, some disagreement exists about which mechanism, or combination of mechanisms, is responsible for SCC even within a single series of alloys $[3,16]$. Due to the differences in composition and structure of the various series of Al alloys, it seems obvious that different mechanisms may operate in different alloys. This review will focus on those mechanisms of crack propagation proposed for Al-Zn-Mg-Cu alloys.

If the stress corrosion crack growth rate, or crack velocity, is plotted as a function of crack tip stress intensity factor, $K_{1}$, the result is what is sometimes referred to as a V-K plot. A schematic representation of this type of plot is given in Figure 16. 


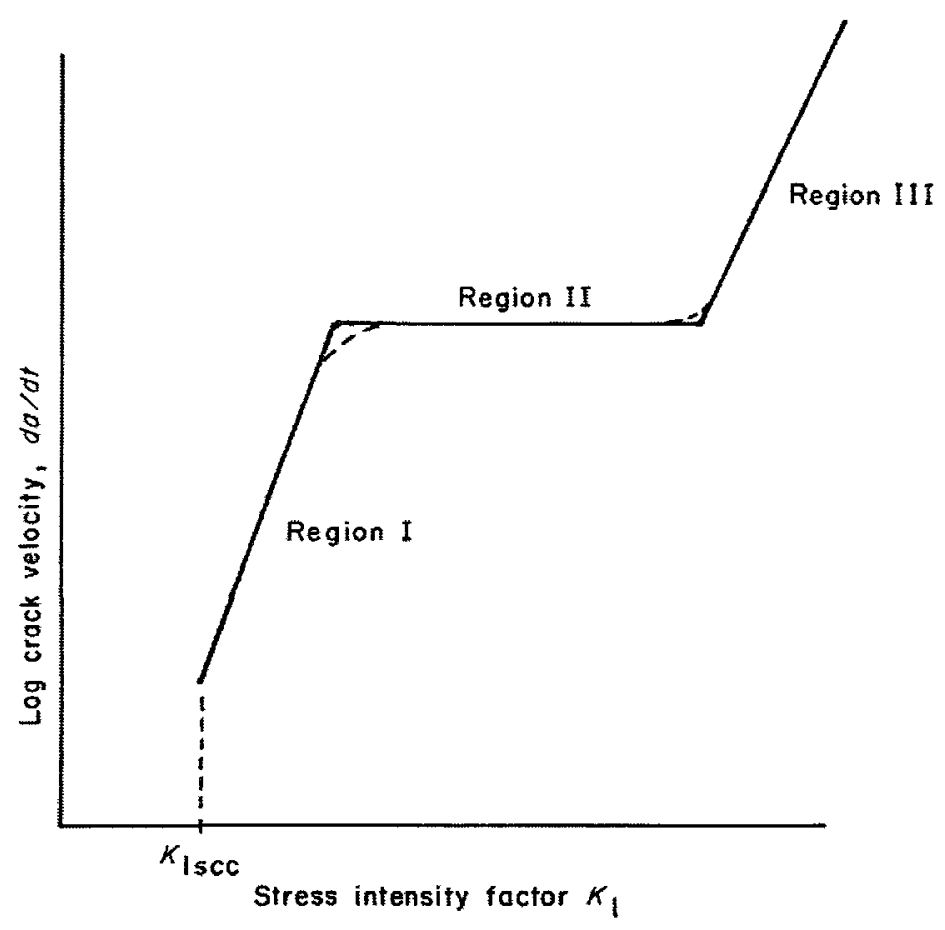

Figure 16: Schematic representation of the relationship between stress intensity and crack growth rate [17]

There are a few important features in Figure 16. First, there is a value of stress intensity denoted as $\mathrm{K}_{\mathrm{Iscc}}$. This corresponds to a threshold stress intensity below which the crack velocity is so low that it is essentially considered to be zero in short time tests [17]. This should not imply that SCC does not occur below this value of $K_{1}$; however, appreciable crack growth may require years to measure at the resultant crack velocities. Second, the curve is divided into three regions. In region I, the crack growth rate is highly dependent upon the stress intensity, whereas the region II crack velocity is mostly independent of stress intensity. Within region II the crack velocity is more strongly related to environmental factors such as $\mathrm{pH}$, temperature, and ionic species of the corrodent [17]. Region I crack velocities show some temperature dependence, but they are typically insensitive to $\mathrm{pH}$ except in highly acidic solutions. Region I tends to shift to lower stress intensities when the solution $\mathrm{pH}$ is less than 3 [16]. The crack velocity in Region III is strongly dependent on stress intensity as the crack growth in this region is primarily mechanically controlled. The upper limit on stress intensity in region III is $K_{I c}$, the plane-strain fracture toughness of the material.

\subsection{Mechanisms of SCC in 7XXX Series Aluminum Alloys}

While there is disagreement about the mechanisms that cause SCC in 7XXX series Al alloys, it is generally accepted that electrochemical factors are dominant [19]. This is supported by the fact that cathodic protection can help to reduce or prevent SCC susceptibility in these alloys $[16,18,19]$. 
There are two widely supported theories of SCC in high strength Al alloys, specifically the 7XXX series: dissolution controlled cracking and hydrogen induced cracking (HIC). HIC is a subset of a more general form of attack, referred to as stress sorption cracking, which may or may not involve $\mathrm{H}$ specifically.

\subsubsection{Dissolution Controlled Cracking}

Dissolution controlled cracking may also be referred to as electrochemical dissolution, anodic dissolution, or preferential corrosion. In this mechanism, it is considered that there are certain paths within the material which are inherently susceptible to anodic dissolution by a galvanic reaction. This galvanic reaction occurs between heterogeneous microstructural features such as the grain boundary precipitates, the PFZ, and the matrix material. This electrochemical dissolution initiates a crack, and the tensile stress acts to open this crack $[1,17]$.

In addition, the crack opening stress will rupture the brittle protective oxide film which forms at the crack tip and expose fresh, unprotected anodic material to corrosive attack $[16,17]$. In some literature [1,3], this film rupture process is considered to be a separate mechanism; however, in more recent literature [17] this is considered to be a part of the anodic dissolution process.

The theory of dissolution controlled cracking is supported by observations that the electrochemical potential of grain boundary regions is anodic with respect to the matrix material [17], and the fact that cathodic protection can be effective in reducing or preventing SCC attack $[16,17,19]$.

\subsubsection{Stress Sorption Cracking}

Stress sorption cracking is a mechanism which proposes that SCC occurs due to the weakening of bonds between metal atoms or the reduction of surface energy of the metal by the adsorption of some damaging species [17]. The atomic bonds are weakened by the interstitial presence of some other species as this causes a deviation from the equilibrium interatomic spacing, and this leads to reduced ductility. If the damaging species reduces the surface energy of the metal, then less energy is required to form new surface area; hence, the propensity to cracking under tensile stress is increased [17].

HIC is a specific form of stress sorption cracking which is thought to affect high strength Al alloys. In this case, atomic $\mathrm{H}$ is the damaging species which is thought to enter the metal at the grain boundaries [20]. This $H$ can exist interstitially in the metal [17], leading to reduced ductility, or it can lead to the formation of hydride phases such as $\mathrm{MgH}_{2}$ [20]. It can also be released as $\mathrm{H}_{2}$ gas bubbles at preferred sites, such as voids, dislocations, or grain boundary precipitates $[17,20]$.

\subsubsection{Combined Effects of Multiple Mechanisms}

A number of the articles reviewed in [3] indicated that the atomic $\mathrm{H}$ involved in cracking was likely the product of anodic dissolution or some other corrosion reaction near the grain 
boundaries. This suggests that perhaps more than one process is responsible for SCC in 7XXX series alloys.

One proposed sequence of events occurring during SCC of 7XXX series alloys is as follows [20]:

- Atomic $\mathrm{H}$ enters the metal along the grain boundaries

- Due to the low diffusivity and extremely low solubility of $H$ in the matrix, $H$ is trapped at the grain boundaries

- $H$ interacts with the grain boundary precipitates. The result of this interaction may be the formation of $\mathrm{H}_{2}$ gas bubbles or brittle $\mathrm{MgH}_{2}$, both of which can nucleate cracks

- A small amount of crack growth occurs and is then arrested by ductile crack tip blunting or remaining uncracked ligaments

- Local chemical activity occurs, such as anodic dissolution and $\mathrm{H}$ evolution, leading to a repetition of the process

\subsubsection{Influence of Dislocations on SCC Behaviour}

It has been proposed that the microstructural feature that has the greatest effect on SCC resistance in 7XXX series $\mathrm{Al}$ alloys is the dislocation structure, specifically in the vicinity of the grain boundaries [21]. These dislocations are predominantly quenched-in, but in the case of material in the Tx51 temper some additional dislocations are introduced by the stretching applied after solutionizing.

Different theories on the specific role of dislocations in the SCC of 7XXX series alloys have been proposed. One hypothesis is that dislocations provide an additional stress necessary to initiate cracking at sites of localized corrosion [21]. Another theory suggests that the interaction of dislocations with atomic $\mathrm{H}$ plays a key role. In this case, dislocations may act as paths for transport of $\mathrm{H}$ into the matrix [22] or as sites for the concentration of $\mathrm{H}$ at or near the grain boundaries [21]. It has also been suggested that the interaction between dislocations and matrix precipitates is related to SCC behaviour. This theory proposes that dislocations of irregular curvature or dislocation loops generated by bypassing matrix precipitates, as opposed to shearing them, lead to improved SCC resistance [16].

\subsection{Relationship between Electrical Conductivity and SCC Resistance}

The electrical resistivity, inverse of conductivity, in Al alloys is affected by the interaction of electrons with local strain fields generated by features such as solute atoms in solution, dislocations, and precipitates. As a result, an increased degree of ageing leads to an increase in electrical conductivity $(\mathrm{EC})$ due to loss of solute in the matrix to precipitates and relief of local strain due to the change from coherent to incoherent precipitate-matrix interfaces [23]. On this basis, EC testing, in conjunction with hardness measurements, can be used to verify the temper of heat treated Al alloys [24]. 
SCC resistance has been found to increase with increasing EC [25], but this relationship exists only in the range from near the peak aged condition to the overaged condition [23]. In a study on Al alloys 7475 and 7075, it was found that the as-quenched condition exhibited lower EC when compared to the T4 (slightly underaged) and T6 conditions, but it displayed better SCC resistance than both tempers. Both 7475 and 7075 showed a positive relationship between SCC resistance and EC when aged to at least the T4 condition. This same study found that the EC cannot be used to compare the SCC resistance of different alloys as 7475 displayed higher EC in both the T6 and T73 conditions, but SCC resistance was higher in the T73 condition and lower in the T6 condition [23].

One of the reasons that EC cannot be used to compare SCC resistance across alloys is that EC is affected primarily by changes in the matrix and features of the grain boundary microstructure have little effect. While EC is an effective indicator of changes occurring in the matrix and the effect of these changes on SCC behaviour, the effect of features such as grain size and grain boundary precipitates on SCC cannot be detected by this method [23].

\subsection{Testing Methods to Assess the SCC Susceptibility of Materials}

A number of standard methods are available to assess the SCC susceptibility of various materials, and the choice of testing method is usually governed by the form of material to be tested and the desired results of the test. There are essentially two extremes in SCC testing specimens: smooth and precracked. A smooth specimen models a perfect structure while a precracked specimen simulates the worst case that could be found in service. If the goal is to determine a parameter such as time to failure then a smooth specimen is suitable; however, if fracture mechanics data, such as crack velocity as a function of stress intensity, are desired then a precracked specimen must be employed. In either case, laboratory tests are only an effective indicator of the SCC resistance of a material if the tests recreate the service environment with reasonable accuracy [1].

One of the major drawbacks of smooth specimens for SCC testing is the crack initiation period, which for some materials may be months. In some cases, such as certain $\mathrm{Ti}$ alloys, pitting corrosion does not occur, so cracks are not initiated in a smooth specimen. This might lead some to the belief that these materials are immune to SCC attack when in fact a precracked specimen of the same material fails readily [1].

Precracked specimens are often employed in to determine the SCC behaviour of various alloys, and a wide array of possible precracked specimen configurations are given in Figure 17. 


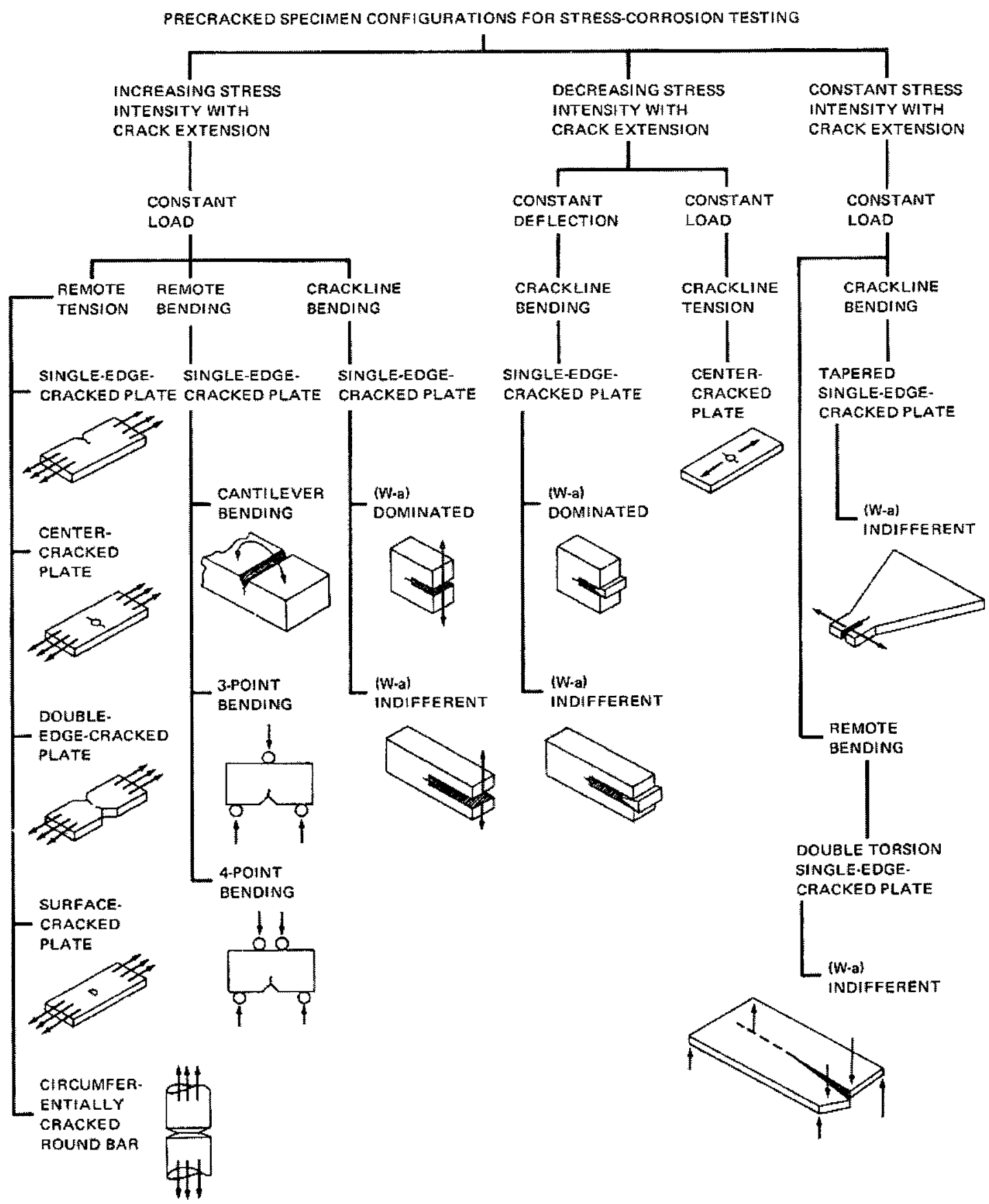

Figure 17: Examples of precracked SCC test specimens [26]

A variety of specimen geometries, loading configurations, and environmental exposure conditions are possible for both smooth and precracked SCC specimens. The choice of these parameters depends on the service environment to be simulated by the test. A selection of common testing methods is detailed in the following sections. 


\subsubsection{Direct Tension}

Direct tension SCC testing is very similar to general tension testing of materials with the addition of environmental exposure during the test. The standard practice for direct tension SCC testing is outlined in ASTM standard G49-85 [27].

Direct tension SCC testing can be applied to a range of specimen sizes and geometries depending on the product to be tested, and these specimens can be either smooth or precracked. When possible the specimen geometry should be similar to that of standard tensile test specimens given in [28]. Specimens can be tested under constant load, constant strain, or continuously increasing strain [27], and the latter of these is sometimes referred to as slow strain rate testing. This is due to the very low strain rates required to allow SCC to occur.

For SCC to occur during increasing strain direct tension testing there exists a critical range of strain rates within which the test must be performed. If the strain rate is too high then failure will be predominantly, or in some cases purely, mechanical with the corrosive environment playing little or no role. Conversely, if the strain rate is too low then sufficient time will be allowed for the formation of the protective oxide film on the material and SCC will not occur. Figure 18 illustrates this phenomenon schematically.

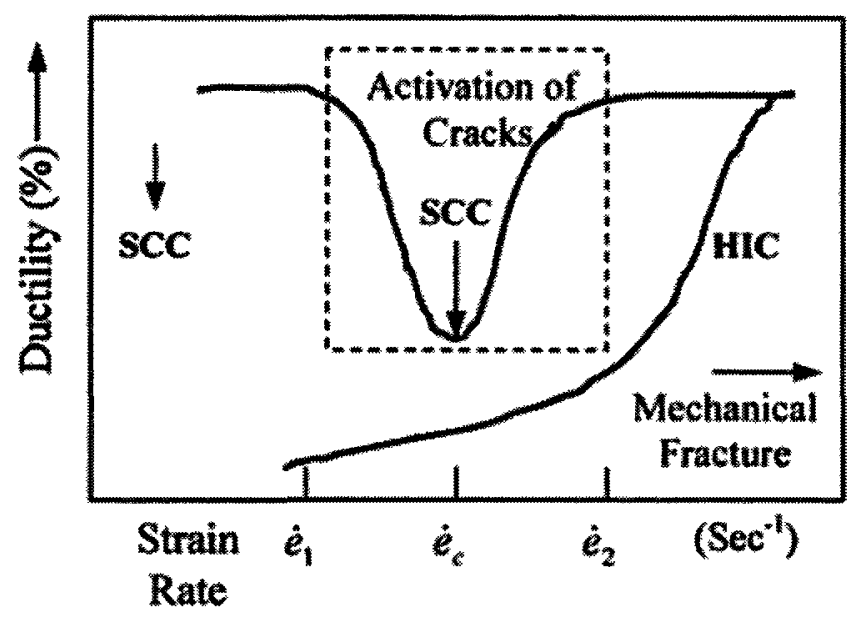

Figure 18: Schematic depiction of the critical strain rate range for SCC [29]

The range of critical strain rates may be different for different materials, and achieving these usually very low rates can be the determining factor in the ability for a facility to perform slow strain rate $\mathrm{SCC}$ tensile tests.

Environmental exposure can be by constant immersion, alternate immersion, or atmospheric exposure [27]. This is again determined by the environment which the test is intended to replicate. 


\subsubsection{C-Ring}

C-ring type SCC testing specimens are typically fabricated from tube, rod, or plate materials, and they can be made either smooth or notched. The typical C-ring specimen geometry is shown in Figure 19.

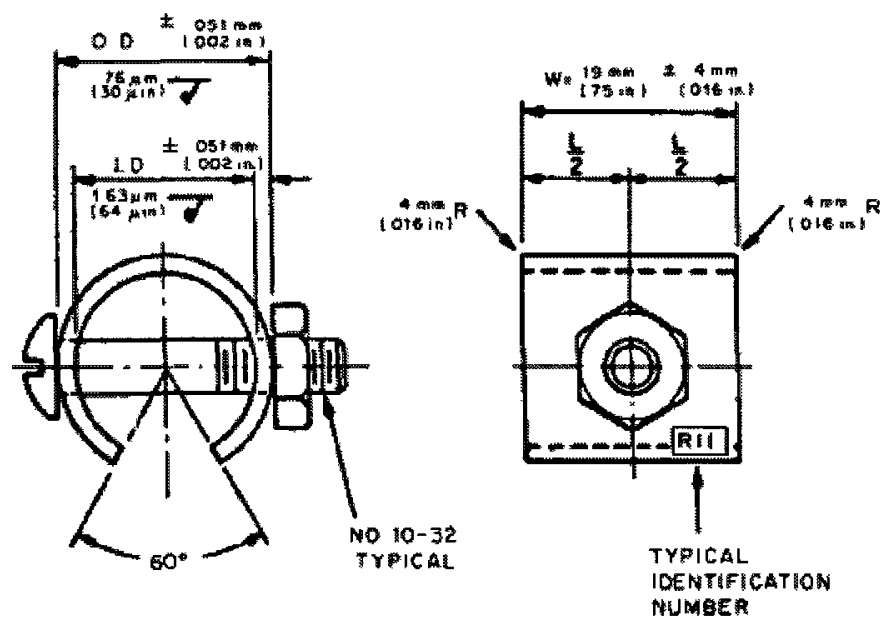

Figure 19: Typical C-ring specimen geometry [30]

The standard practice for C-ring SCC testing is outlined in [30]. C-ring specimens can be tested in constant displacement or approximately constant load with the former being the most common choice. Some possible loading configurations are illustrated in Figure 20.

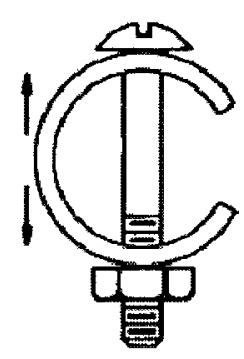

(o)

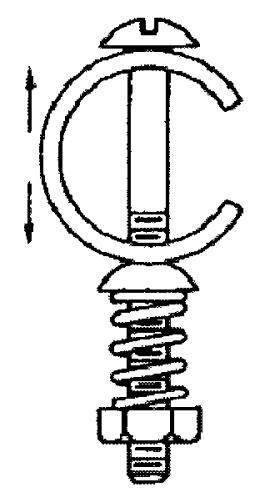

(b)

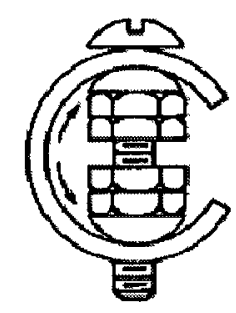

(c)

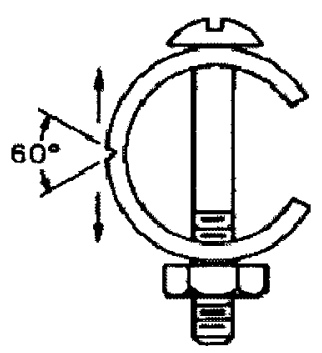

(d)

CONSTANT STRAIN

CONSTANT LOAD

CONSTANT STRAFN

NOTCHEO C-RING

Figure 20: Possible loading configurations for C-ring specimens. A similar notch to that shown in (d) can be used on the tension side of (b) or (c) [30]

C-ring specimens can be subjected to constant or alternate immersion, and the stressing hardware can be coated or insulated from the test material using bushings to prevent parasitic galvanic interaction. One of the disadvantages of the $\mathrm{C}$-ring specimen is that crack examination can be somewhat difficult. This leads to some influence of inspector skill and experience on the results. The results of $\mathrm{C}$-ring $\mathrm{SCC}$ tests are usually reported in terms of time to failure. 


\subsubsection{Double Beam Specimen}

Double beam (DB) SCC specimens, formerly referred to as double cantilever beam or DCB specimens [26,31], are a type of single-edge-cracked plate specimens, as shown in Figure 17 . DB specimens are particularly well suited to materials that have a highly directional grain structure [31], such as rolled sheet and plate and forgings. The standard practice for DB specimen testing is given in [31].

There are six possible DB specimen orientations from flat plate material, and these are illustrated in Figure 21.

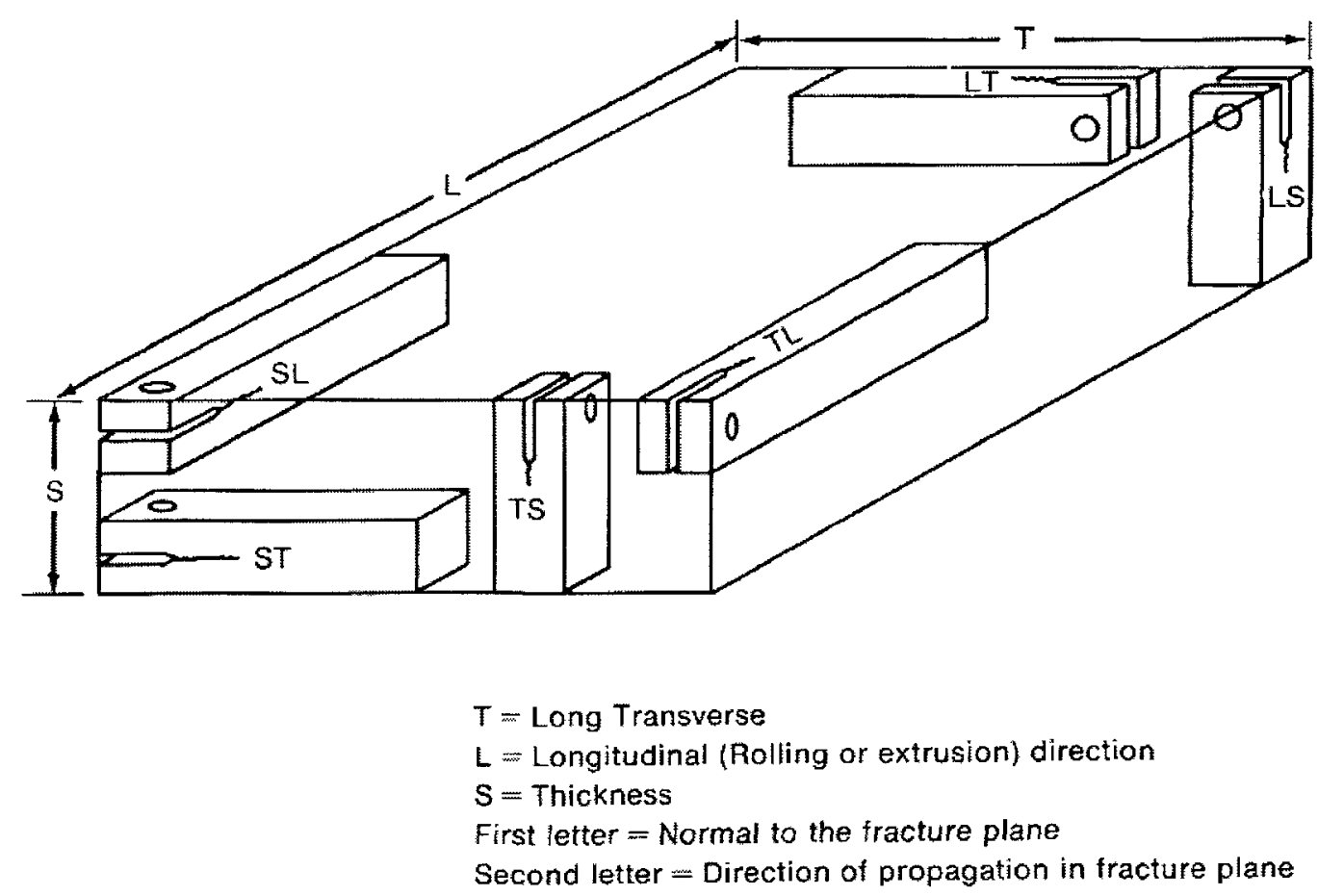

Figure 21: Possible DB specimen orientations [16]

DB specimens can be loaded in one of two ways: constant load, resulting in increasing stress intensity with crack extension, or constant displacement, which yields decreasing stress intensity with crack extension [26,31]. The latter loading scheme is attractive due to its simplicity as a fixed crack opening displacement can be easily achieved [26]. Constant displacement loading is often achieved using loading bolts as shown in Figure 22. 


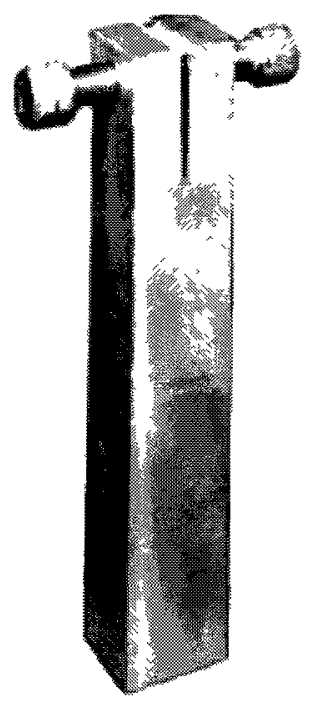

Figure 22: Example of a bolt loaded DB specimen [31]

The precrack can be extended from the machined starter notch either by mechanical overload or by fatigue precracking. In either case, the starting stress intensity is determined by a calibration equation given in [31], which is also used to determine the stress intensity based on crack length measurements made during the test. The starting stress intensity from a mechanical, or pop-in, precrack gives an estimate of the fracture toughness of the material.

DB specimens can be exposed to constant immersion, alternate immersion, or periodic application of corrodent, and the choice of environmental exposure conditions should be made based on the expected service environment [31].

The results of DB specimen tests are typically presented in terms of the threshold stress intensity for $\mathrm{SCC}, \mathrm{K}_{\mathrm{Iscc}}$, and the crack growth rate as a function of stress intensity. An example is given in Figure 23. 


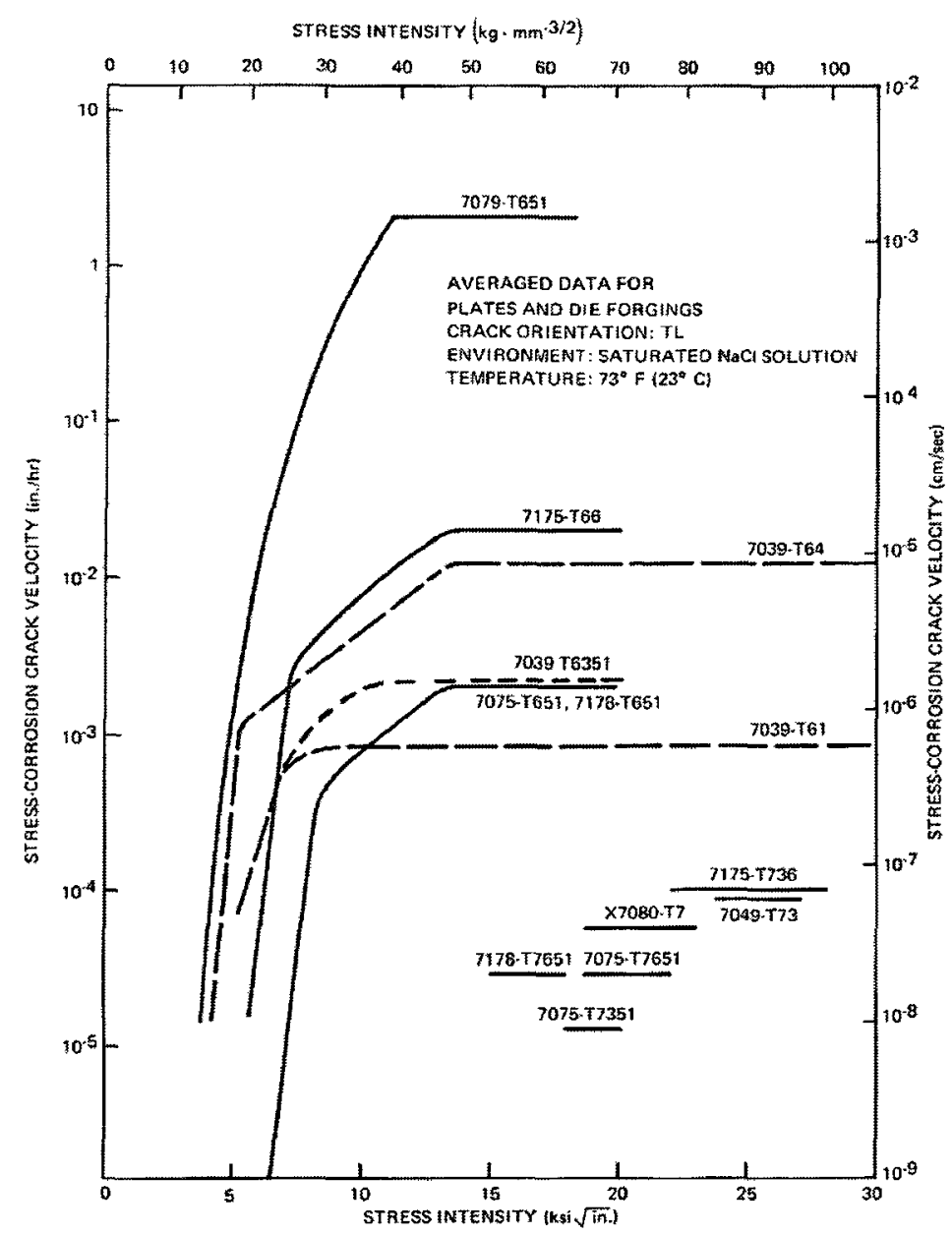

Figure 23: V-K plot for several 7XXX series alloys [16]

The width of a DB specimen plays an important role in determining whether the fracture surface is subjected to predominantly plane stress or plane strain. If the specimen is too narrow, then the fracture surface will experience predominantly plane stress which may lead to anomalous results. To ensure plane strain conditions, the minimum specimen width should meet the criteria outlined in the standard for plane strain fracture toughness testing, ASTM E399-09 [32]. 


\section{Effects of Thermal Processing on the Microstructure and SCC Behaviour of Al-Zn-Mg-Cu Alloys}

\subsection{Overageing}

Overageing refers to precipitation heat treatment in which the alloy is artificially aged to beyond the point of maximum strength following solution heat treatment. The T73 overaged temper, which was developed around 1960, was the first processing approach designed to increase the SCC resistance of alloys like 7075 [7]. Millions of pounds of 7XXX-T73 alloys have been used in service with no reported SCC failures [33], but this added SCC resistance comes at the cost of strength: the yield strength of $7075-\mathrm{T} 73$ is $10-15 \%$ lower than that of $7075-\mathrm{T} 6[7,16,25]$. The two-step artificial ageing process to produce $7075-T 73$ is described in section 2.5 .

The strength and SCC resistance of 7XXX series alloys are related to the degree of ageing applied, and this relationship is demonstrated schematically in Figure 24.

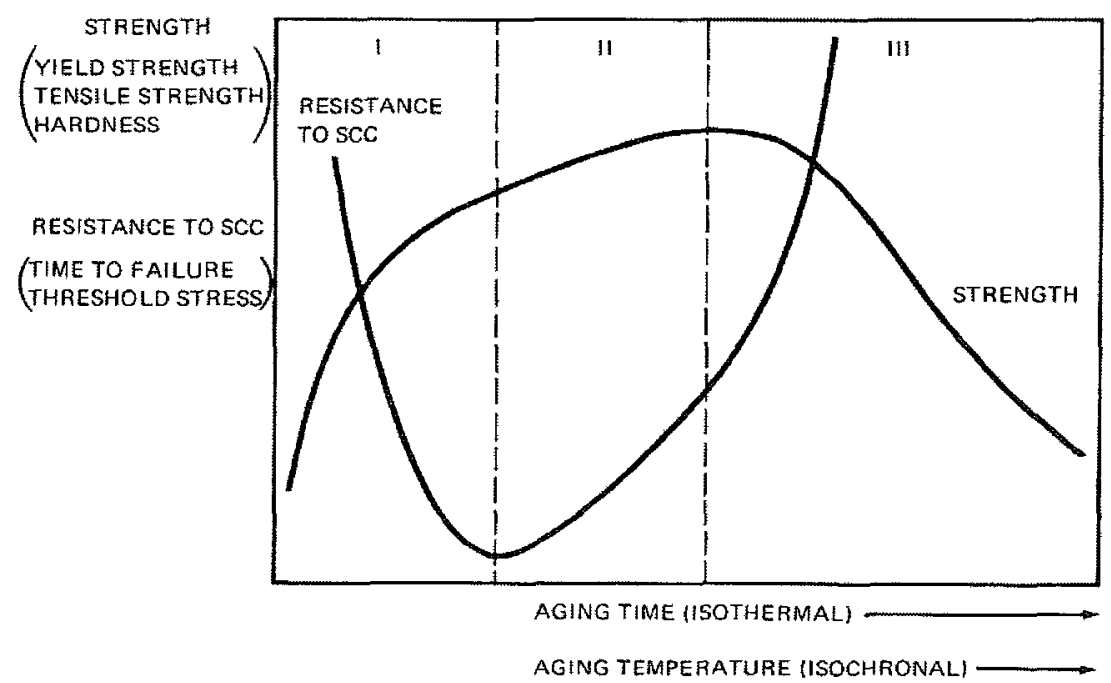

Figure 24: Variation of strength and SCC resistance with ageing in 7XXX series alloys [16]

As Figure 24 shows, underaged conditions result in the minimum SCC resistance for these alloys $[16,23]$, and the peak aged condition is also highly susceptible to SCC, especially when stressed in the short transverse direction [16].

During the first stage of ageing, a fine, dense dispersion of matrix precipitates is developed, just as in the T6 temper, and during the second phase the size, structure, and composition of the precipitates are modified [7]. The size and total volume fraction of precipitates are increased during the second stage of ageing, and the coherency of the interface between the precipitates and the matrix is reduced [34]. This change in interface is due to the evolution of precipitates 
from predominantly GP zones and some $\eta^{\prime}$ precipitates in the T6 condition to mostly $\eta^{\prime}$ and $\eta$ precipitates in the T73 condition [7]. In addition, the higher temperature of the second stage of ageing promotes the substitution of $\mathrm{Cu}$ and $\mathrm{Al}$ for $\mathrm{Zn}$ in the $\eta$ and $\eta^{\prime}$ phases [4].

The improved SCC resistance of the T73 temper may be related to a number of factors. First, the dislocation density and the mechanism of dislocation-precipitate interaction are altered by the overageing treatment. Since the precipitates in the T73 condition are mostly semicoherent or incoherent with the matrix, dislocations will tend to bow around precipitates rather than shear them leading to dislocation loops and dislocations of irregular curvature. The combination of fewer dislocations and irregular dislocations results in less stress exerted on the grain boundaries; hence, less driving force exists for the propagation of stress corrosion cracks $[16,33]$. Second, the change in the composition of the precipitates, specifically along the grain boundaries, results in a decrease in the relative electrochemical potential of the grain boundaries with respect to the matrix material $[33,35]$. The substitution of $\mathrm{Cu}$ and $\mathrm{Al}$ for $\mathrm{Zn}$ makes the grain boundary $\eta$ precipitates less anodic compared to the matrix and the PFZ resulting in improved SCC resistance [4]. Finally, the increased size and discontinuity of the grain boundary precipitates is thought to play a role [33]. The larger, incoherent precipitates evolved due to overageing can act as a trapping site for atomic $\mathrm{H}$ along the grain boundaries and lead to the formation of $\mathrm{H}_{2}$ bubbles. The precipitates and the $\mathrm{H}_{2}$ bubbles will tend to blunt the tip of the advancing crack and retard its progress [36].

\subsection{Retrogression and Re-ageing}

Retrogression and re-ageing (RR or RRA) is a specific overageing heat treatment designed to give a combination of high strength and good SCC resistance. The RRA process was originally conceived based on the idea that quenched in dislocations, generated during quenching from the solutionizing temperature and especially near the grain boundaries, were the cause of SCC susceptibility. The goal was to heat the material for a short time at a high enough temperature to remove the dislocations but not cause overageing [21].

The original process for RRA of 7XXX series alloys is described in some detail in a 1974 patent [37], and it can be summarized as follows: first, the material should be solution heat treated and aged to the T6 temper. Next, a short retrogression heat treatment is applied at some temperature between the ageing temperature and the solutionizing temperature. Finally, the material is re-aged for a substantially longer period of time, preferably at the original ageing temperature. For 7075 , the suggested RRA parameters are a retrogression time of a few seconds to a few minutes at a temperature of $200-260^{\circ} \mathrm{C}$, followed by re-ageing for $16-48$ hours at $115-125^{\circ} \mathrm{C}$.

The benefit of RRA is that the process is capable of producing the desirable combination of T6 strength with SCC resistance that is near that of the T73 condition $[21,25,36]$. Figure 25 shows the effect of retrogression temperature on strength as a function of time, and Figure 26 shows the results of SCC tests on various conditions in the form of a V-K plot. 


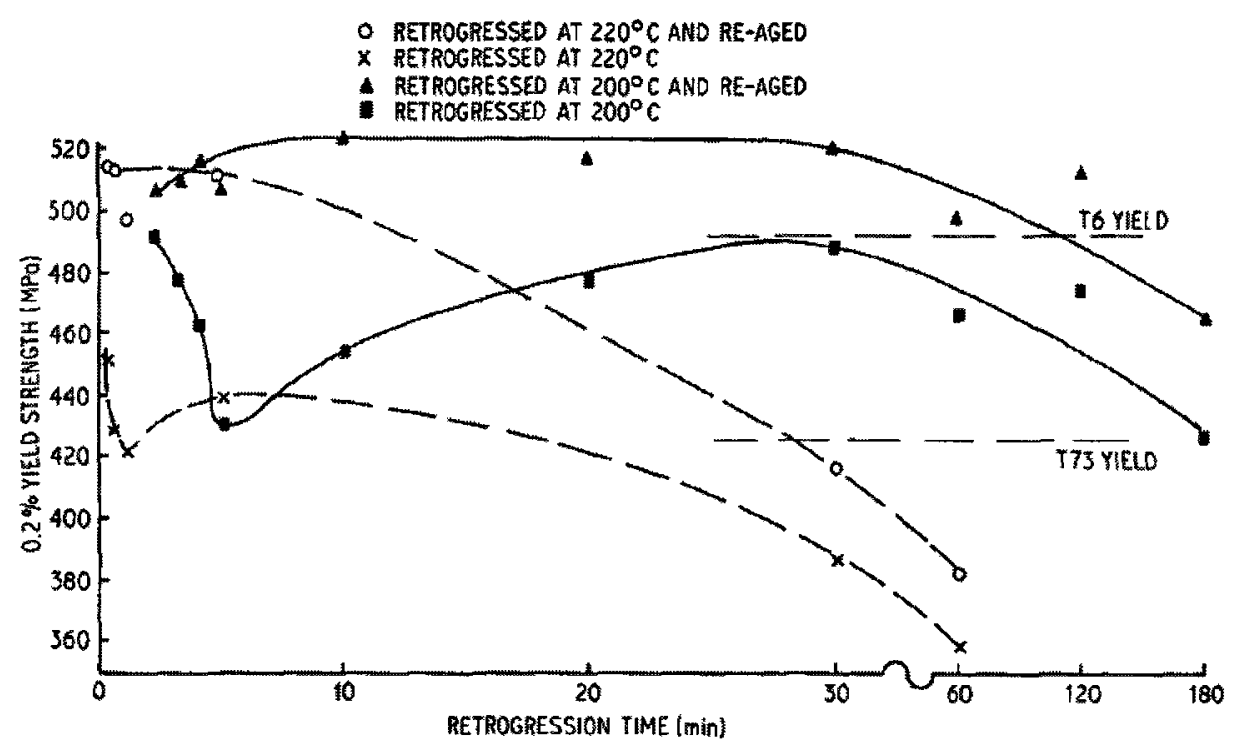

Figure 25: Effect of retrogression temperature on yield strength as a function of time for 7075

[36]

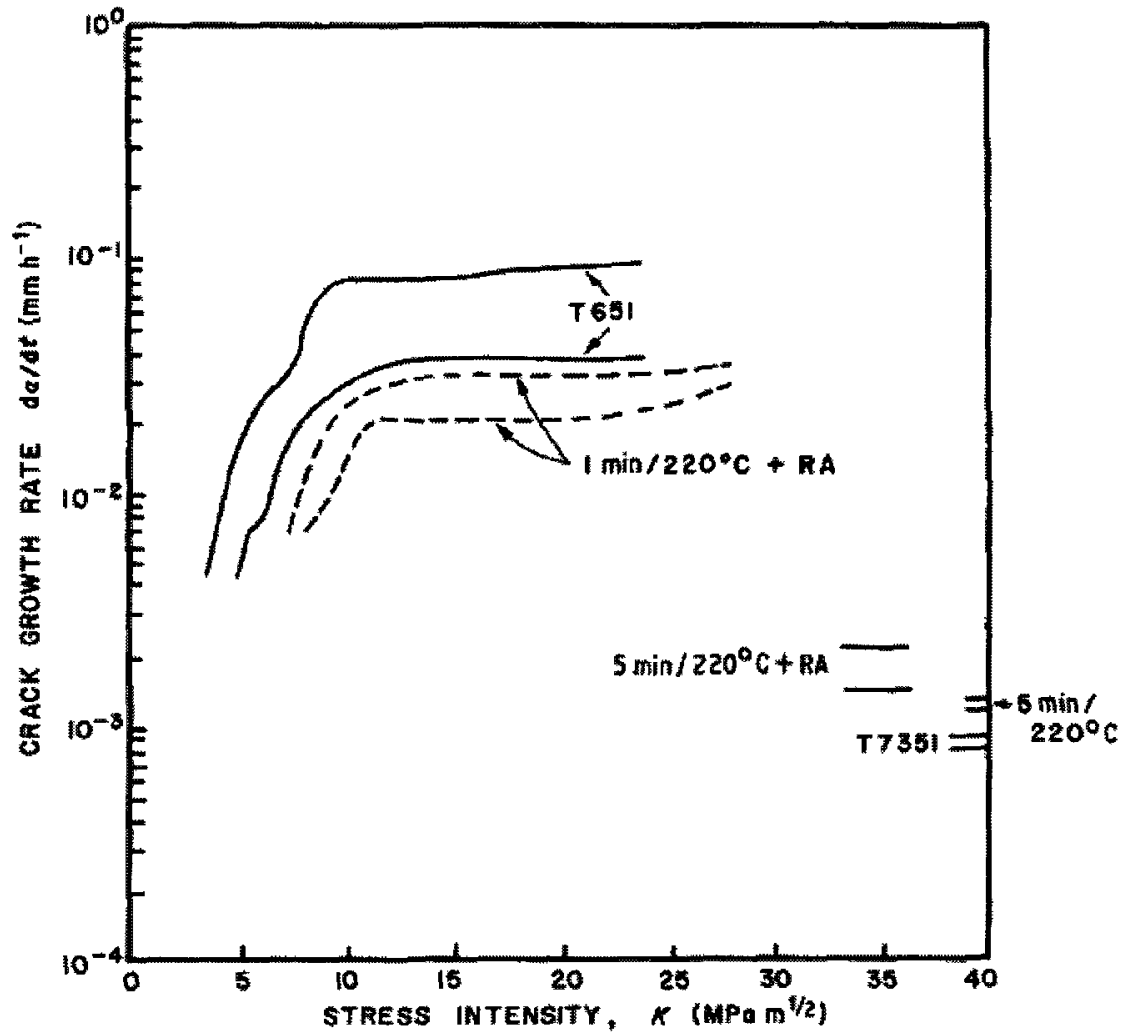

Figure 26: Stress corrosion crack growth rates as a function of stress intensity for selected conditions of 7075 [36]

The desirable combination of properties displayed by the RRA temper results from the combination of precipitates developed during the process: matrix precipitates have a coherent interface similar to the T6 condition, which enhances strength, while the grain boundary 
precipitates are coarse and incoherent like those in $T 73[36,38]$. The decreased dislocation density of the RRA condition compared to the T6 or T651 temper was originally cited as the reason for the enhanced SCC resistance [21], but more recently the coarse grain boundary precipitate structure has been suggested as the most important feature $[36,38]$. Just as in the T73 condition, the coarse, incoherent $\eta$ precipitates along the grain boundary, and the accumulation of dislocations at these particles, act as $\mathrm{H}$ trapping sites. These particles and $\mathrm{H}_{2}$ bubbles that they may nucleate result in the retardation of advancing cracks [36]. Figure 27 shows the different grain boundary precipitate structures developed in 7075 subjected T6, T73, and RRA treatments.
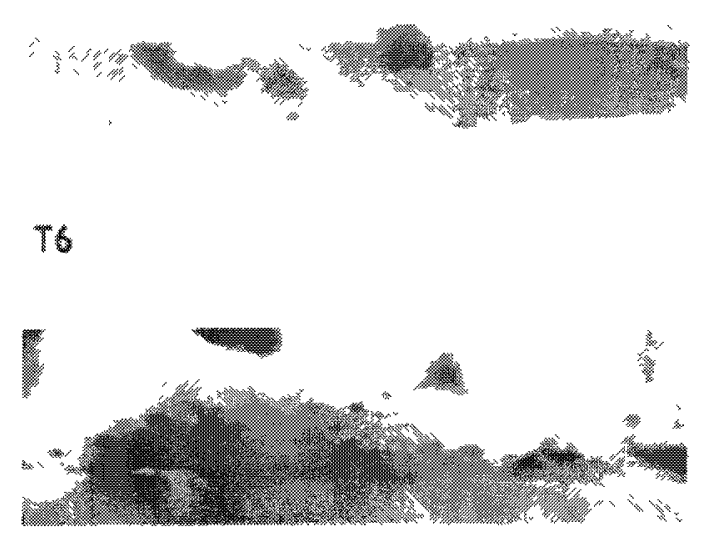

RETROGRESSED

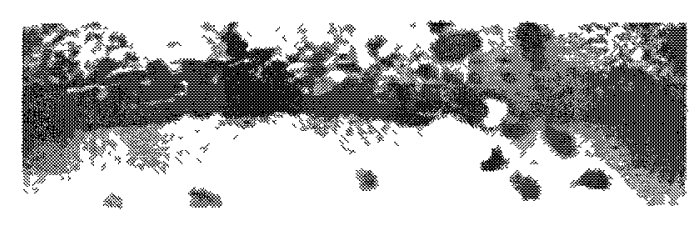

RETROGRESSED AND REMAGED

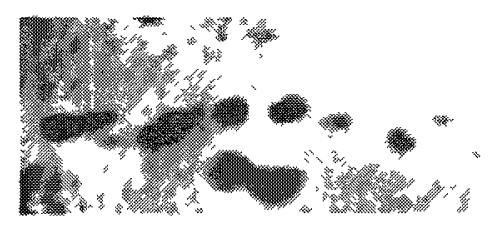

773

$0.1 \mu \mathrm{m}$

Figure 27: Grain boundary precipitate structures found in various heat treatment conditions of 7075 imaged by TEM [36]

RRA has one major disadvantage: the short times and relatively high temperatures of the retrogression treatment restrict its use to mostly thin section components, like sheet material $[36,39]$. This can be alleviated to some degree through the use of longer retrogression times at lower temperatures. Lower temperature RRA treatments, typically less than $200^{\circ} \mathrm{C}$ and as low as $160^{\circ} \mathrm{C}$, have been found to produce a combination of strength and SCC resistance similar to that generated by higher temperature RRA treatments, and these processes could be applied to 
thicker sections. Two different studies found that low temperature RRA treatments on 7075 gave SCC resistance near that of the T73 condition while sacrificing only between $1 \%$ [39] and $6 \%[40]$ of T6 yield strength.

\subsection{Modified Solution Heat Treatment}

Modified solution heat treatment has been proposed as another means of improving the SCC resistance of $\mathrm{Al}-\mathrm{Zn}-\mathrm{Mg}-\mathrm{Cu}$ alloys. Alterations to the solution heat treatment may include the addition of slow heating from the original solutionizing temperature to a higher temperature, cooling from the solutionizing temperature to a lower temperature prior to quenching, or stepped temperature treatments $[41,42]$.

Increasing temperature solution heat treatment has been found to improve the mechanical properties, including yield strength, ductility, and fracture toughness, but decrease the SCC resistance [41]. Solutionizing for two hours at $450^{\circ} \mathrm{C}$ and then heating to 465 or $480^{\circ} \mathrm{C}$ at a rate of $5^{\circ} \mathrm{C} / \mathrm{h}$ prior to quenching and ageing for 24 hours at $120^{\circ} \mathrm{C}$ improved all three mechanical properties compared to samples given only the two hour solution heat treatment and 24 hour ageing, and the improvement in properties increased with higher final temperature. The reduced SCC resistance is attributed to the continuous distribution of grain boundary $\eta$ precipitates produced by this process, illustrated in Figure 28.
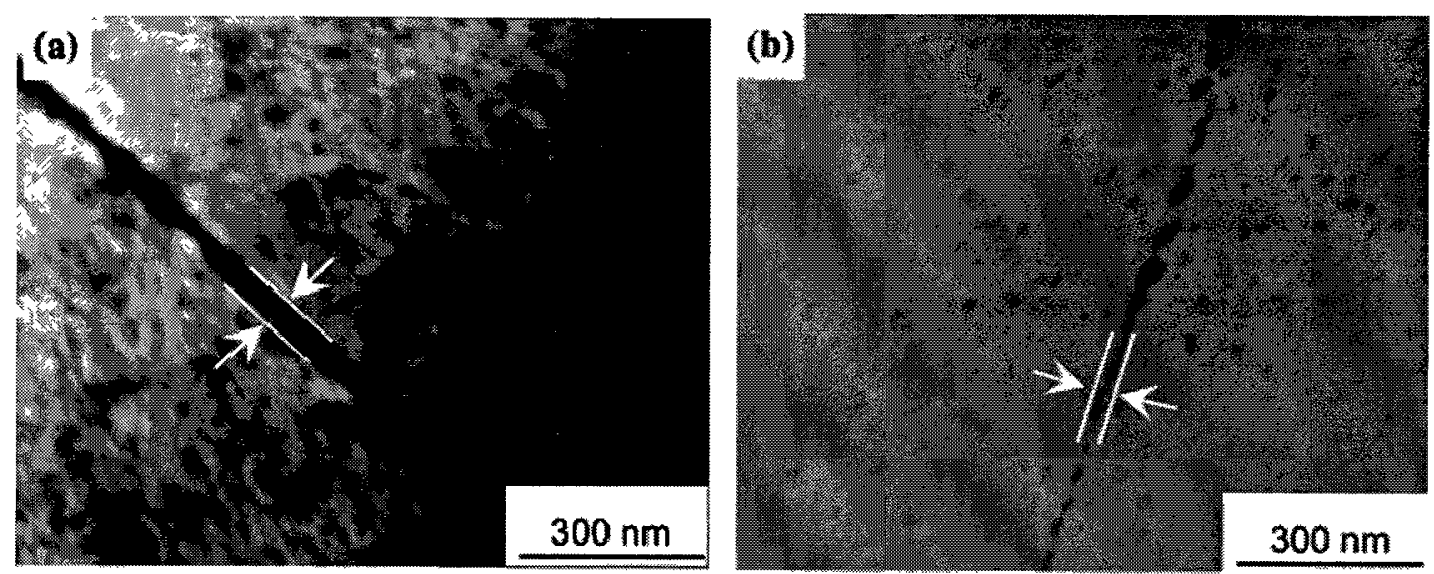

Figure 28: Grain boundary precipitate structures produced by solutionizing at $450^{\circ} \mathrm{C}(\mathrm{a})$ and solutionizing at $450^{\circ} \mathrm{C}$ then heating to $480^{\circ} \mathrm{C}$ at $5^{\circ} \mathrm{C} / \mathrm{h}$ (b) [41]

The width of the grain boundary precipitation zone is reduced by the higher temperature heat treatment, but the distribution of precipitates is still almost continuous. It has been suggested that this provides a continuous path for corrosive attack along the grain boundaries [41].

A combination of increasing temperature solutionizing followed by slow cooling from the solutionizing temperature prior to quenching, referred to as high temperature pre-precipitation (HTPP), has been found to produce a more discontinuous distribution of coarse grain boundary precipitates, and the degree of discontinuity increases with lower final temperatures $[41,42]$. Figure 29 shows the grain boundary precipitate structure that results from solutionizing for two 
hours at $450^{\circ} \mathrm{C}$, heating to $480^{\circ} \mathrm{C}$ at $5^{\circ} \mathrm{C} / \mathrm{h}$, cooling to $400^{\circ} \mathrm{C}$ at a rate of $30^{\circ} \mathrm{C} / \mathrm{h}$ before quenching to room temperature, and then ageing for 24 hours at $120^{\circ} \mathrm{C}$.

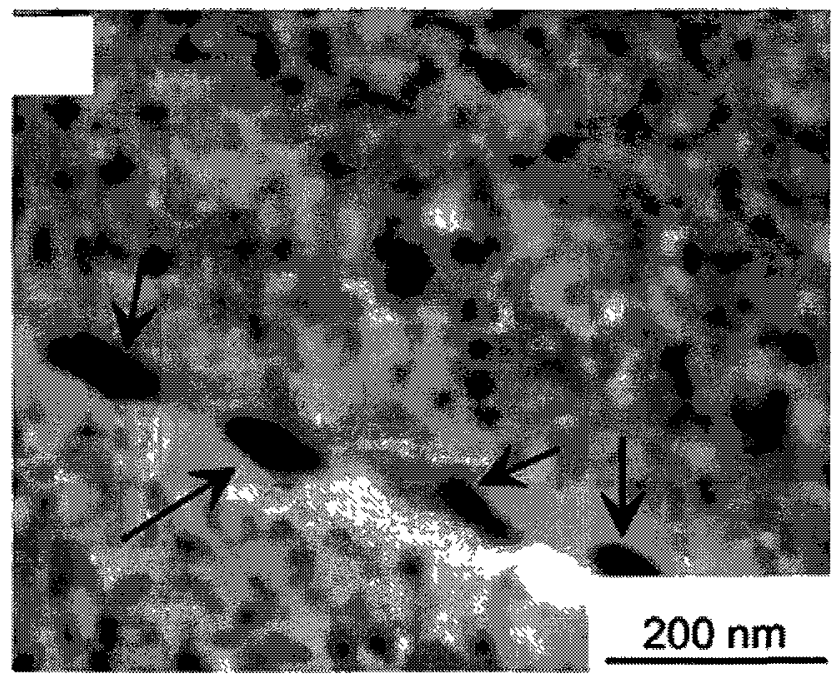

Figure 29: Grain boundary precipitate structure produced by solution heat treatment that included slow heating and HTPP [41]

Figure 30 shows a $\mathrm{V}-\mathrm{K}$ plot for the three tempers described in this section, denoted in the figure as $\mathrm{S} 3\left(2 \mathrm{~h} / 450^{\circ} \mathrm{C}\right.$ then heat to $480^{\circ} \mathrm{C}$ at $\left.5^{\circ} \mathrm{C} / \mathrm{h}\right), \mathrm{S} 1\left(2 \mathrm{~h} / 450^{\circ} \mathrm{C}\right)$, and $\mathrm{S} 5\left(2 \mathrm{~h} / 450^{\circ} \mathrm{C}\right.$, heat to $480^{\circ} \mathrm{C}$ at $5^{\circ} \mathrm{C} / \mathrm{h}$, then cool to $400 \mathrm{C}$ at $30^{\circ} \mathrm{C} / \mathrm{h}$ ), respectively, and a fourth temper, s6, which was given the same solutionizing treatment as S5 except that the final temperature before quenching was $370^{\circ} \mathrm{C}$.

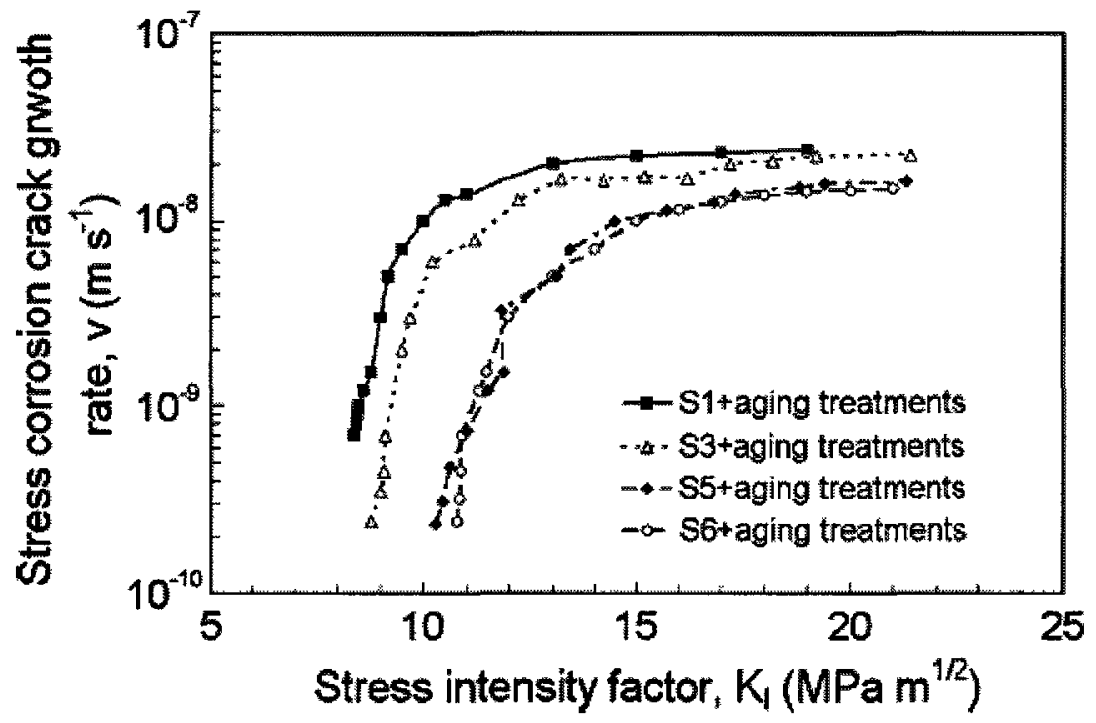

Figure 30: Stress corrosion crack velocities as a function of stress intensity for four tempers of an Al-Zn-Mg-Cu alloy tested using DB specimens in 3.5\% $\mathrm{NaCl}$ aqueous solution [41]

The improved SCC behaviour of the slow cooled tempers is attributed to two factors: the increased size and discontinuity of the grain boundary precipitates and the substitution of $\mathrm{Cu}$ for 
$\mathrm{Mg}$ in the grain boundary precipitates [41,42]. The effect of these two factors on SCC behaviour has previously been detailed in section 4.1 .

The disadvantage of HTPP treatments is that they negatively affect mechanical properties [41]. Due to the loss of solute from solution to coarse precipitates during the HTPP treatment, there is less solute available to form the fine strengthening precipitates during the ageing treatment. The coarse grain boundary precipitates can also act as crack initiation sites during mechanical fracture, and this leads to reduced tensile ductility and fracture toughness [41].

\subsection{Effect of Quench Rate}

The cooling rate through the temperature range from $400-290^{\circ} \mathrm{C}$ can have a significant effect on the susceptibility to corrosive attack and the type of corrosive attack experienced by Al-Zn-Mg$\mathrm{Cu}$ alloys [16]. In thin section components of 7075, rapid cooling through this range, in excess of $200^{\circ} \mathrm{F} / \mathrm{s}\left(93^{\circ} \mathrm{C} / \mathrm{s}\right)$, results in immunity to intergranular corrosion and SCC and gives optimum tensile properties. Reduction of the cooling rate through this range to $40^{\circ} \mathrm{F} / \mathrm{s}$ (less than $5^{\circ} \mathrm{C} / \mathrm{s}$ ) results poor mechanical properties and very low SCC resistance [16]. However, thicker section components of 7075 do not see the same effect of quench rate on SCC behaviour. Even extreme quench rates, greater than $1000^{\circ} \mathrm{F} / \mathrm{s}\left(538^{\circ} \mathrm{C} / \mathrm{s}\right)$, result in no appreciable improvement in the SCC resistance when stress is applied in the short transverse direction [16]. 


\section{Experimental Program}

An experimental program was undertaken to determine the effects of modifying the solution heat treatment on the microstructure, mechanical properties, and SCC susceptibility of 7075 . A range of solution heat treatments were applied to material in the as received T651 temper, followed by a standard ageing treatment. These experimental conditions were compared with each other and against the standard T6 and T73 tempers.

To evaluate the experimental tempers against one another and the standard tempers, a two part testing program was conducted. The first phase of testing consisted of hardness, electrical conductivity $(E C)$, and uniaxial tensile tests on round bar specimens of all tempers to determine their mechanical properties and EC. In the second phase of tests, the SCC susceptibility of a selection of tempers was evaluated using precracked double beam (DB) specimens cut from flat plate. Plate material was used for the second phase since DB specimens cannot be fabricated from round stock. Hardness and EC data were also collected from all DB specimens prior to SCC testing.

\subsection{Experimental Materials}

Two different parent materials were used in this study: for the first phase of the test program 7075-T651 extruded round bar stock, 5/8 inch $(15.875 \mathrm{~mm}$ ) diameter (manufactured by Kaiser Tennalum, Jackson, TN), and for the second phase of the test program 7075-T651 rolled flat plate, 1 inch $(25.4 \mathrm{~mm}$ ) thickness (manufactured by Kaiser Aluminum, Spokane, WA). The chemical composition of the two materials is given in Table 4 along with the compositional limits for 7075 .

Table 4: Chemical composition of 7075-T651 round bar and flat plate

\begin{tabular}{|c|c|c|c|c|c|c|c|c|c|c|c|}
\hline \multicolumn{12}{|c|}{ Composition [wt\%] } \\
\hline & Al & $\mathrm{Cr}$ & $\mathrm{Cu}$ & $\mathrm{Fe}$ & $\mathrm{Mg}$ & $\mathrm{Mn}$ & $\mathrm{Si}$ & $\mathrm{Ti}$ & $\mathrm{Zn}$ & $\mathrm{Zr}$ & $\begin{array}{c}\text { Other } \\
\text { (each/total) }\end{array}$ \\
\hline $\begin{array}{l}\text { Nominal } \\
{[10]}\end{array}$ & Balance & $\begin{array}{c}0.18- \\
0.28 \\
\end{array}$ & $\begin{array}{l}1.2- \\
2.0 \\
\end{array}$ & $<0.50$ & $\begin{array}{l}2.1- \\
2.9 \\
\end{array}$ & $<0.30$ & $<0.40$ & $<0.20$ & $\begin{array}{l}5.1- \\
6.1 \\
\end{array}$ & - & $0.05 / 0.15$ \\
\hline Bar & 90.4 & 0.20 & 1.26 & 0.26 & 2.40 & 0.034 & 0.13 & 0.032 & 5.27 & $<0.011$ & - \\
\hline Plate & 89.84 & 0.20 & 1.5 & 0.17 & 2.5 & 0.03 & 0.09 & 0.03 & 5.6 & 0.01 & 0.03 \\
\hline
\end{tabular}

The analysis of the bar stock was conducted by NSL Analytical Services (Cleveland, $\mathrm{OH}$ ) and the plate analysis was supplied with the material by the manufacturer.

\subsection{Heat Treatments}

\subsubsection{Experimental Tempers}

Sixteen experimental heat treatments were developed in this research based on some of the modified solution heat treatments discussed in section 4.3. Table 5 summarizes the heat treatment parameters for each condition. 
Table 5: Summary of heat treatment parameters

\begin{tabular}{|c|c|}
\hline Designation & $\begin{array}{l}\text { Heat treatment schedule } \\
\left(\mathrm{WQ}=\text { water quench at room temp, age }=24 \mathrm{~h} / 120^{\circ} \mathrm{C}\right)\end{array}$ \\
\hline T651 & as received \\
\hline T6* & $2 \mathrm{~h} / 465^{\circ} \mathrm{CWQ}+$ age \\
\hline $\mathrm{T73}(51)$ & as received $+24 \mathrm{~h} / 160^{\circ} \mathrm{C}$ \\
\hline T73* & $2 \mathrm{~h} / 465^{\circ} \mathrm{CWQ}+$ age $+24 \mathrm{~h} / 160^{\circ} \mathrm{C}$ \\
\hline S495 & $2 \mathrm{~h} / 495^{\circ} \mathrm{CWQ}+\mathrm{age}$ \\
\hline $\mathrm{H} 480$ & $2 \mathrm{~h} / 465^{\circ} \mathrm{C}$ heat to $480^{\circ} \mathrm{C}$ at $5^{\circ} \mathrm{C} / \mathrm{h} \mathrm{WQ}+$ age \\
\hline $\mathrm{H} 495$ & $2 \mathrm{~h} / 465^{\circ} \mathrm{C}$ heat to $495^{\circ} \mathrm{C}$ at $5^{\circ} \mathrm{C} / \mathrm{h} \mathrm{WQ}+$ age \\
\hline 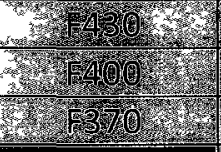 & 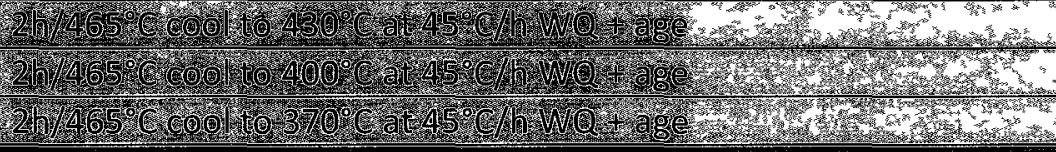 \\
\hline M430 & 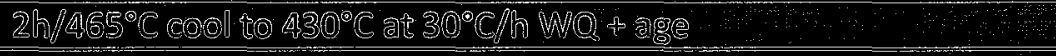 \\
\hline Mag0 & 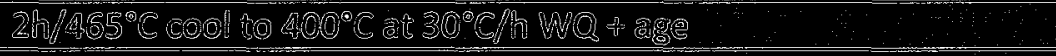 \\
\hline M370 & 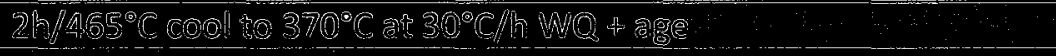 \\
\hline 1430 & 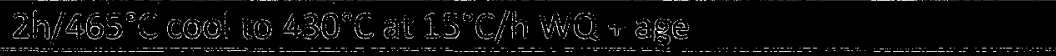 \\
\hline 140 & 2) \\
\hline $\mathrm{H} 495-\mathrm{F} 430$ & $2 \mathrm{~h} / 465^{\circ} \mathrm{C}$ heat to $495^{\circ} \mathrm{C}$ at $5^{\circ} \mathrm{C} / \mathrm{h}$ cool to $430^{\circ} \mathrm{C}$ at $45^{\circ} \mathrm{C} / \mathrm{h} \mathrm{WQ}+$ age \\
\hline $\mathrm{H} 495-\mathrm{F} 400$ & $2 \mathrm{~h} / 465^{\circ} \mathrm{C}$ heat to $495^{\circ} \mathrm{C}$ at $5^{\circ} \mathrm{C} / \mathrm{h}$ cool to $400^{\circ} \mathrm{C}$ at $45^{\circ} \mathrm{C} / \mathrm{h} \mathrm{WQ}+$ age \\
\hline (5.95 & 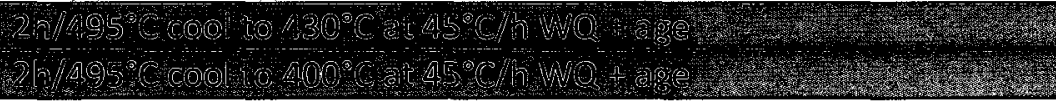 \\
\hline
\end{tabular}

The experimental heat treatments were designated as follows: $S$ followed by three digits indicates a solutionizing temperature different from $465^{\circ} \mathrm{C} ; \mathrm{H}$ followed by three digits indicates that slow heating was applied following the standard solutionizing treatment, up to the indicated temperature; and $F, M$, or L followed by three digits indicates that slow cooling to the indicated temperature was applied following the standard solutionizing treatment, with $F$ indicating relatively fast cooling, $M$ for a medium cooling rate, and $L$ for a relatively low cooling rate. From this point forward, all of metallurgical conditions will be referred to by the designations given in Table 5 .

In Table 5, some of the standard tempers are denoted with special characters. The temper designated T73(51) was produced by applying the second stage of the standard T73 ageing procedure, 24 hours at $160^{\circ} \mathrm{C}$ [13], to the as received T651 material. Since this material received some stretching prior to the first ageing step, it is technically in the T7351 temper, not T73; however, the proprietary sequence of thermomechanical treatments applied to produce the commercial 77351 temper may differ slightly from the standard practices. For this reason, the condition generated by applying only the second stage ageing to the T651 material is denoted as $\mathrm{T73}(51)$. The $\mathrm{T}^{*}$ and $\mathrm{T73}$ * tempers are designated with an asterisk to denote that these conditions were produced by applying the standard solution heat treatment and ageing procedures [13] for 7075-T6 and 7075-T73, respectively. Again these practices may differ slightly from proprietary commercial heat treatments used to generate T6 and T73 tempers. 
The experimental solution heat treatments were designed to examine the effects of a number of heat treatment parameters independently and in different combinations. These parameters included isothermal solutionizing temperature, final temperature during slow heating or slow cooling, and cooling rate during slow cooling. The $S, H, F, M$, and $L$ series heat treatments independently varied each of these parameters, and the $\mathrm{H}-\mathrm{F}$ and S-F series combined the variation of multiple parameters in each solution heat treatment. Many of the experimental tempers were designed with reference to the modified solution heat treatments presented in [41] and [42].

The $\mathrm{S}$ and $\mathrm{H}$ series solution heat treatments were devised to examine the effects of solutionizing at higher than normal temperatures. The $\mathbf{S} 495$ temper employed an elevated temperature isothermal solution heat treatment, and the $\mathrm{H} 480$ and $\mathrm{H} 495$ solution heat treatments included two isothermal steps with a slow rate of heating, $5^{\circ} \mathrm{C} / \mathrm{h}$, between steps. These two series of heat treatments are depicted schematically in Figure 31 and Figure 32.

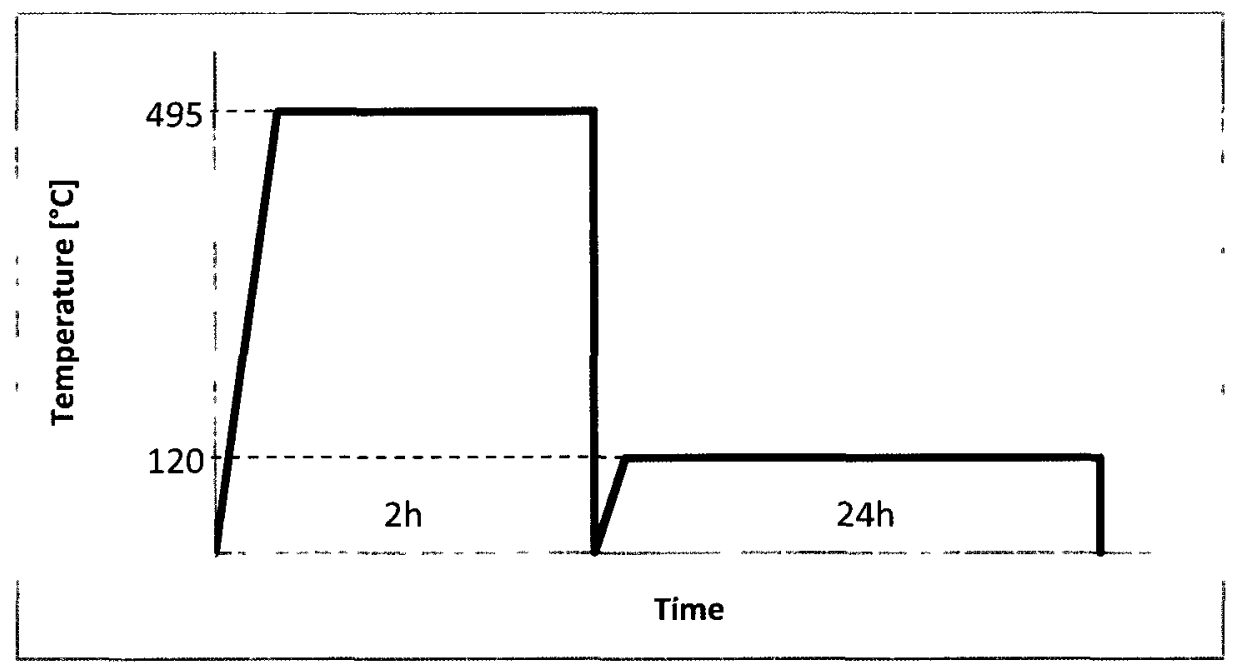

Figure 31: Schematic illustration of heat treatment for \$495 temper

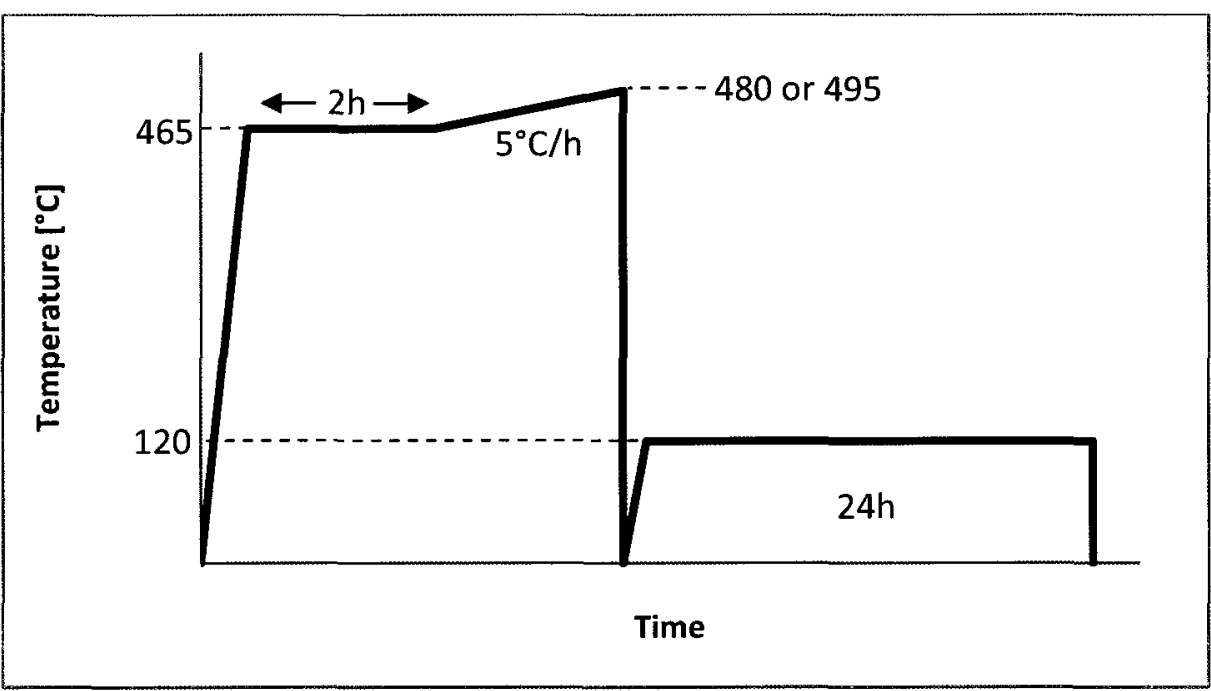

Figure 32: Schematic illustration of heat treatments for $\mathrm{H}$ series tempers 
The $F, M, L, H-F$, and $S-F$ series solution heat treatments were designed to give final temperatures prior to quenching that fall on either side of the solvus temperature for 7075 . $430^{\circ} \mathrm{C}$ is above the minimum solvus temperature, and $400^{\circ} \mathrm{C}$ and $370^{\circ} \mathrm{C}$ are slightly below and well below the solvus temperature of 420 to $445^{\circ} \mathrm{C}$, respectively. It was expected that cooling to these temperatures prior to quenching would result in no pre-precipitation, some preprecipitation, and an increased level of pre-precipitation during cooling in the tempers cooled to $430^{\circ} \mathrm{C}, 400^{\circ} \mathrm{C}$, and $370^{\circ} \mathrm{C}$, respectively. The cooling rates for these experimental tempers were selected based on the literature $[41,42]$ in which a consistent cooling rate of $30^{\circ} \mathrm{C} / \mathrm{h}$ was applied. This same rate of cooling was applied to one series of experimental tempers, the $M$ series, and the other two cooling rates were at an equal increment above and below this rate: $45^{\circ} \mathrm{C} / \mathrm{h}$ in the $F, H-F$, and $S-F$ series and $15^{\circ} \mathrm{C} / \mathrm{h}$ in the $\mathrm{L}$ series. The $\mathrm{F}, \mathrm{M}$, and $\mathrm{L}$ series tempers are illustrated schematically in Figure 33, and the H-F and S-F series tempers are illustrated in Figure 34 and Figure 35 , respectively.

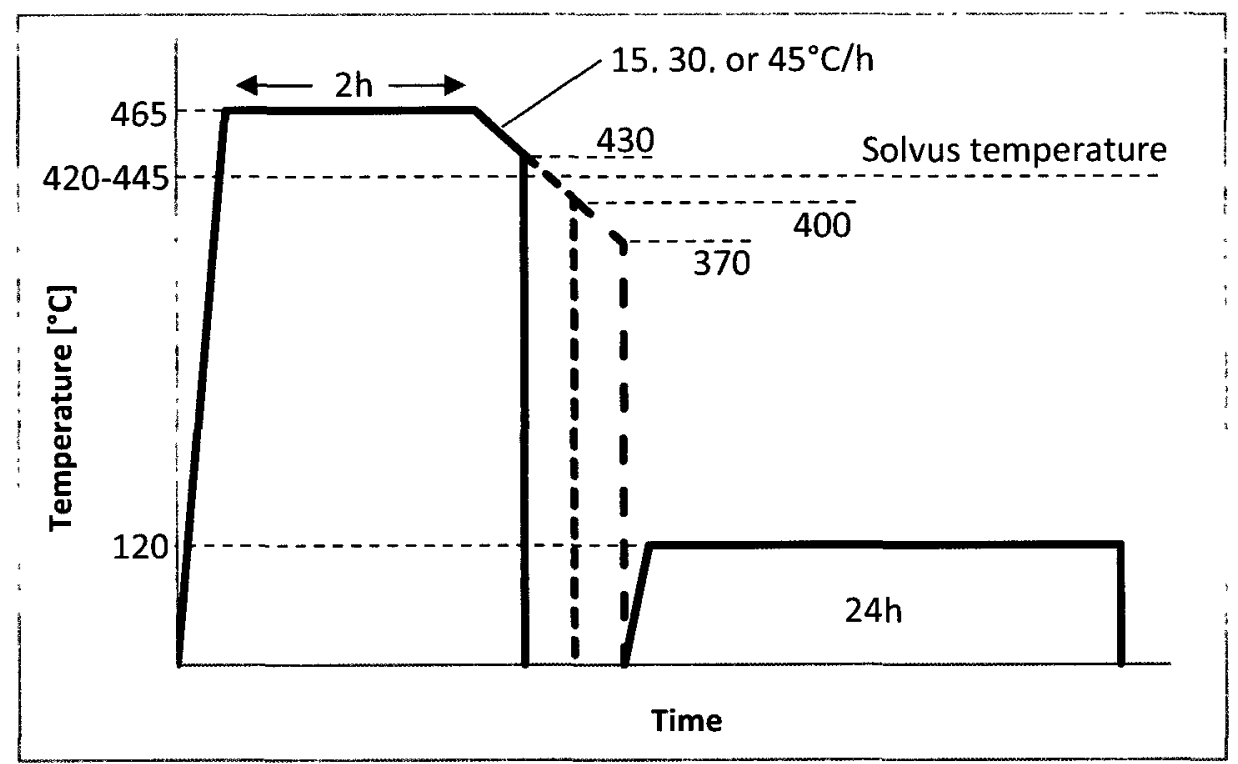

Figure 33: Schematic illustration of heat treatments for $F, M$, and $L$ series tempers 


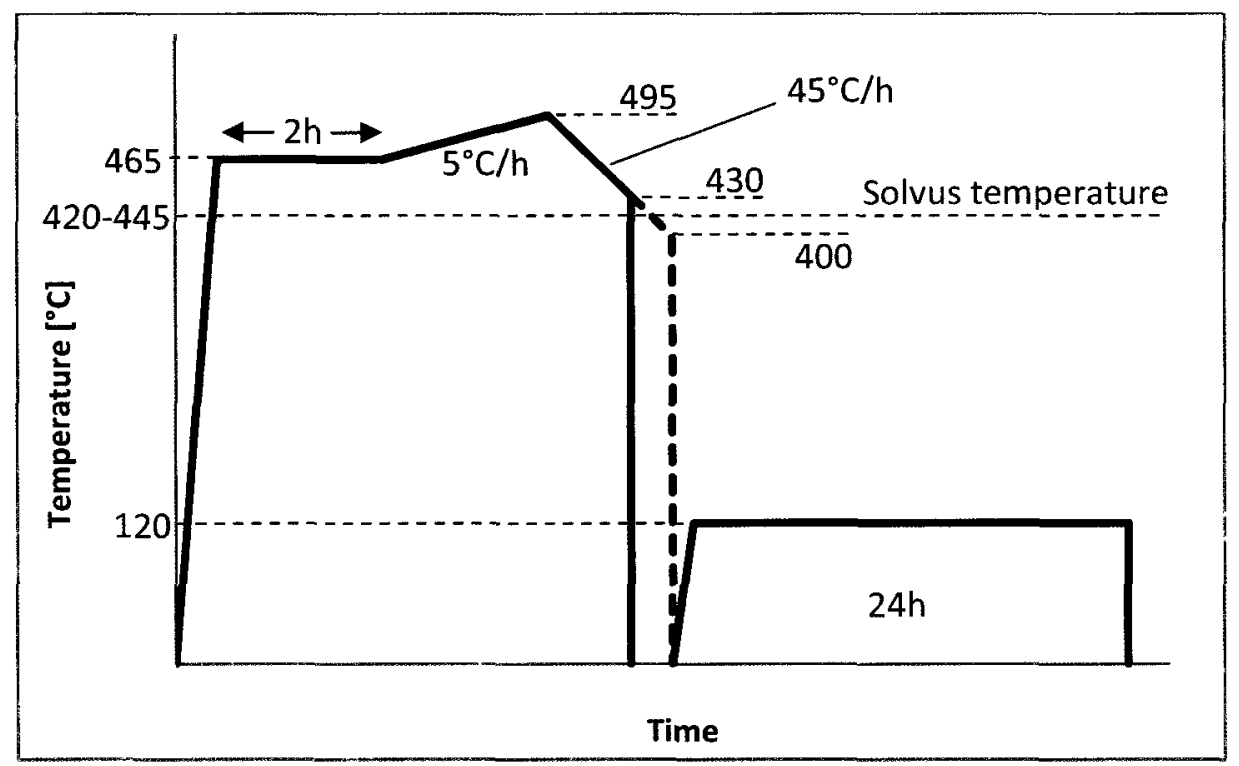

Figure 34: Schematic illustration of heat treatments for $\mathrm{H}-\mathrm{F}$ series tempers

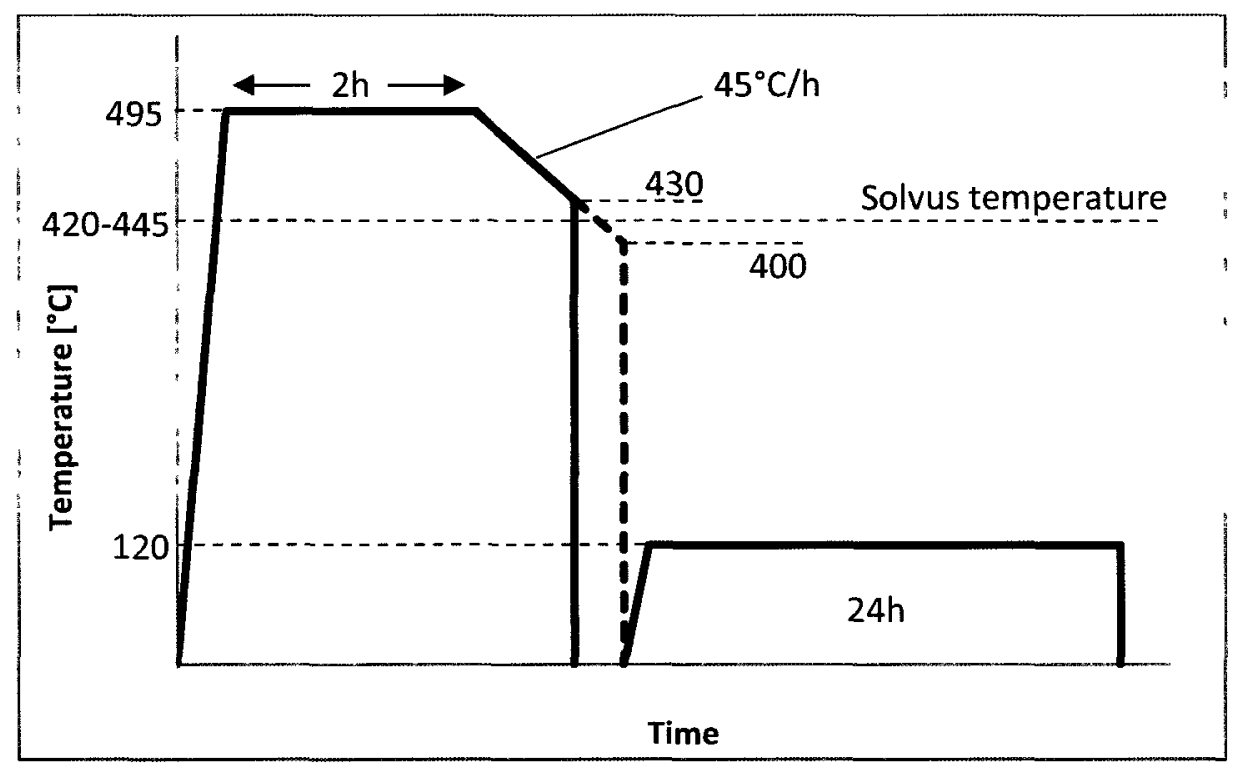

Figure 35: Schematic illustration of heat treatments for S-F series tempers

\subsubsection{Heat Treatment Procedure}

All of the experimental solution heat treatments were conducted in air in a furnace (Lindberg type 51442) with a programmable temperature controller (Lindberg/Blue M, model UP150). The controller was connected to a K-type thermocouple which was inserted through a small hole in the door of the furnace. While the furnace had a built in control thermocouple, it was located in the top back corner of the furnace cavity. Since all of the specimens were on the floor of the furnace cavity near the front during heat treatments, the thermocouple inserted through the door gave a much more accurate measurement of the air temperature in the vicinity of the samples. 
To place the specimens in the furnace, the door had to be opened, and this caused a sudden drop in temperature inside the furnace. As a result, the heaters were activated which lead to some slight overshoot past the set point of the furnace. To alleviate this problem, the programmable temperature controller included an alarm feature which would turn off the heaters when a specified temperature above the set point was reached. This feature was set to $10^{\circ} \mathrm{C}$ above the solutionizing temperature in all cases to prevent overheating the samples. Since the temperature of the air inside the furnace was measured by the control thermocouple and not the specimen temperature, a ten minute heating period was added to the beginning of all solution heat treatments to allow the specimens to reach the same temperature as the air before the specified solutionizing time.

Specimens were quenched by immersion in water at room temperature. The parts were removed from the furnace and placed in the quenchant as quickly as possible, and the maximum delay between opening the furnace door and completely immersing each specimen did not exceed the typical maximum quench delay time of 15 seconds specified in [13].

Due to the relatively low temperature required for the ageing treatments, the furnace was not suitable because of the large temperature fluctuations generated by opening the furnace door to insert the samples. Instead, the ageing treatments were all carried out using a heat bath which consisted of a large beaker of glycerine seated on an electrical hot plate (Fisher Scientific Isotemp model). This apparatus is shown in Figure 36.

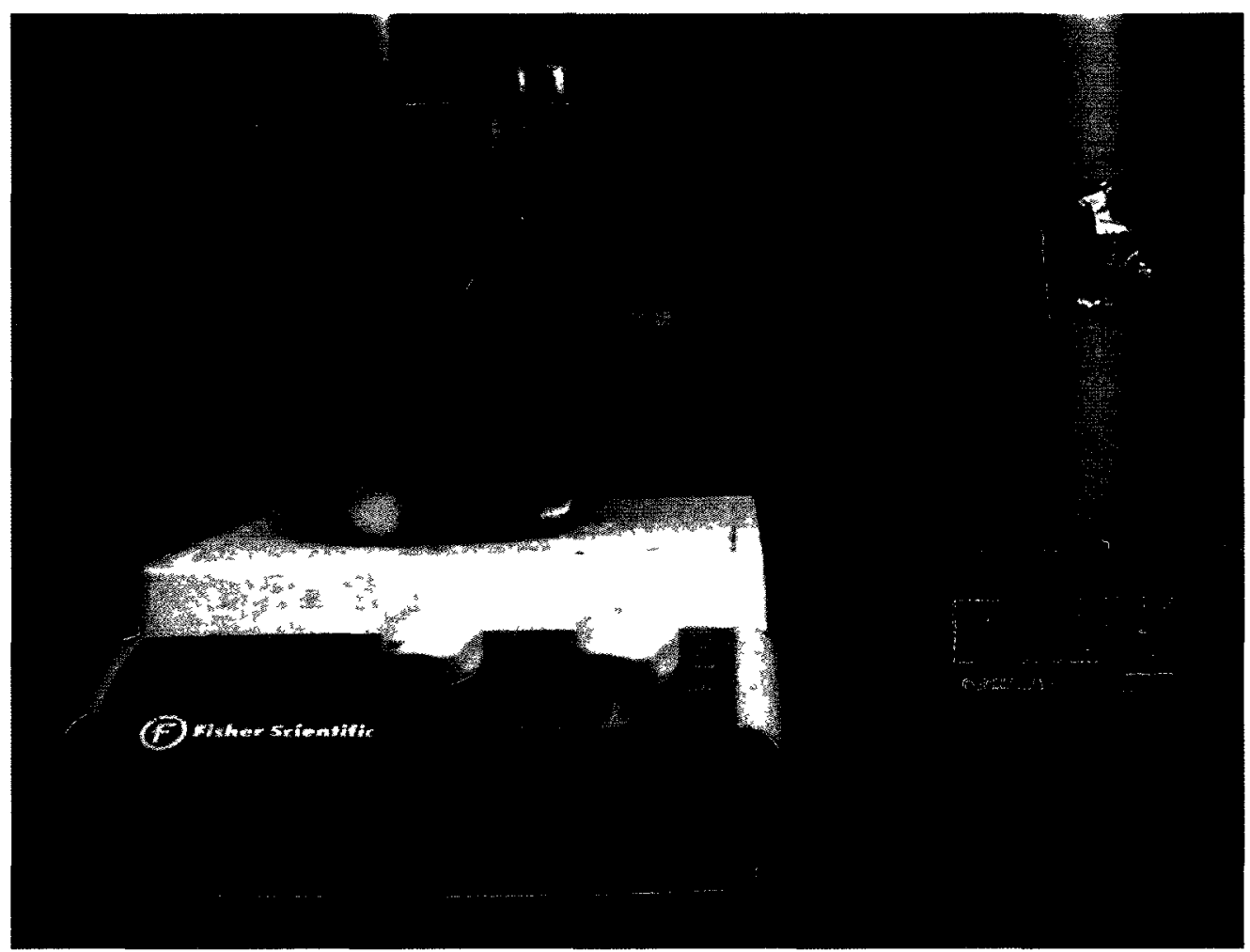

Figure 36: Heat bath for ageing treatments 
The temperature of the heat bath was monitored using a K-type thermocouple connected to a digital temperature display (Omega, model DP462), also pictured in Figure 36.

\subsection{Hardness and Electrical Conductivity Testing}

The hardness and electrical conductivity measurements were made on specimens approximately one inch long cut from the round bar stock, and these coupons were then heat treated according to the various schedules outlined in Table 5.

The Rockwell B hardness test was selected since it is the most commonly used for aluminum alloys and other relatively soft alloys. Measurements were made using an automated hardness testing machine (Instron Wilson Rockwell Series 2000). At least six hardness measurements were made on each specimen, and all indentations were made on the flat ends of the test coupons. Prior to testing the specimens, the hardness tester was calibrated using a standard calibration block of known hardness.

$E C$ tests were performed using an eddy current probe tester (Foerster Sigmatest D 2.068). One measurement was taken from each sample, and these readings were made with the probe applied to the flat surface on the end of the specimen. The conductivity meter was calibrated using several test blocks of known electrical conductivity.

EC and hardness data were also collected from the blanks used to produce all of the tensile and DB specimens. These measurements were taken twice: once after the specimens had undergone the various solutionizing treatments and again after the pieces had received the ageing treatment. All hardness and conductivity data were collected prior to any machining operations being performed on the blanks. The hardness measurements were taken using the same machine as the other hardness tests, but the EC measurements were made using a different eddy current probe tester (Zetec DC-1 Conductivity Instrument). Two EC measurements were made from each tensile specimen blank and three measurements were taken from each DB specimen block. Ten hardness indentations were made on each sample.

\subsection{Tensile Testing}

Uniaxial tensile tests were conducted to assess the mechanical properties of the various tempers. These tests employed cylindrical specimens based on the geometry given in [28]. A dimensioned drawing of the tensile specimen geometry is given in Appendix A. The blanks for the tensile specimens were cut from the round bar stock and fully heat treated prior to machining. These blanks were turned down to the final dimensions using a CNC lathe, and they were flooded with coolant during machining to keep them cool. Following machining, all of the tensile specimens were cleaned briefly using water and a mild soap in an ultrasonic bath to remove any grease and dirt.

The tensile tests were performed using a hydraulic testing frame (MTS 810 Material Test System). The specimen was gripped using wedge-type grips (MTS model 647 Hydraulic Wedge Grips) and the load was measured using the test frame's built in load cell (MTS model 661.20E- 
01 Force Transducer). The strain in the gauge section was measured using a clip-on extensometer (MTS model 634.12E-24 Extensometer) with a 1 inch $(25.4 \mathrm{~mm}$ ) gauge length. The tensile test set up is shown in Figure 37.

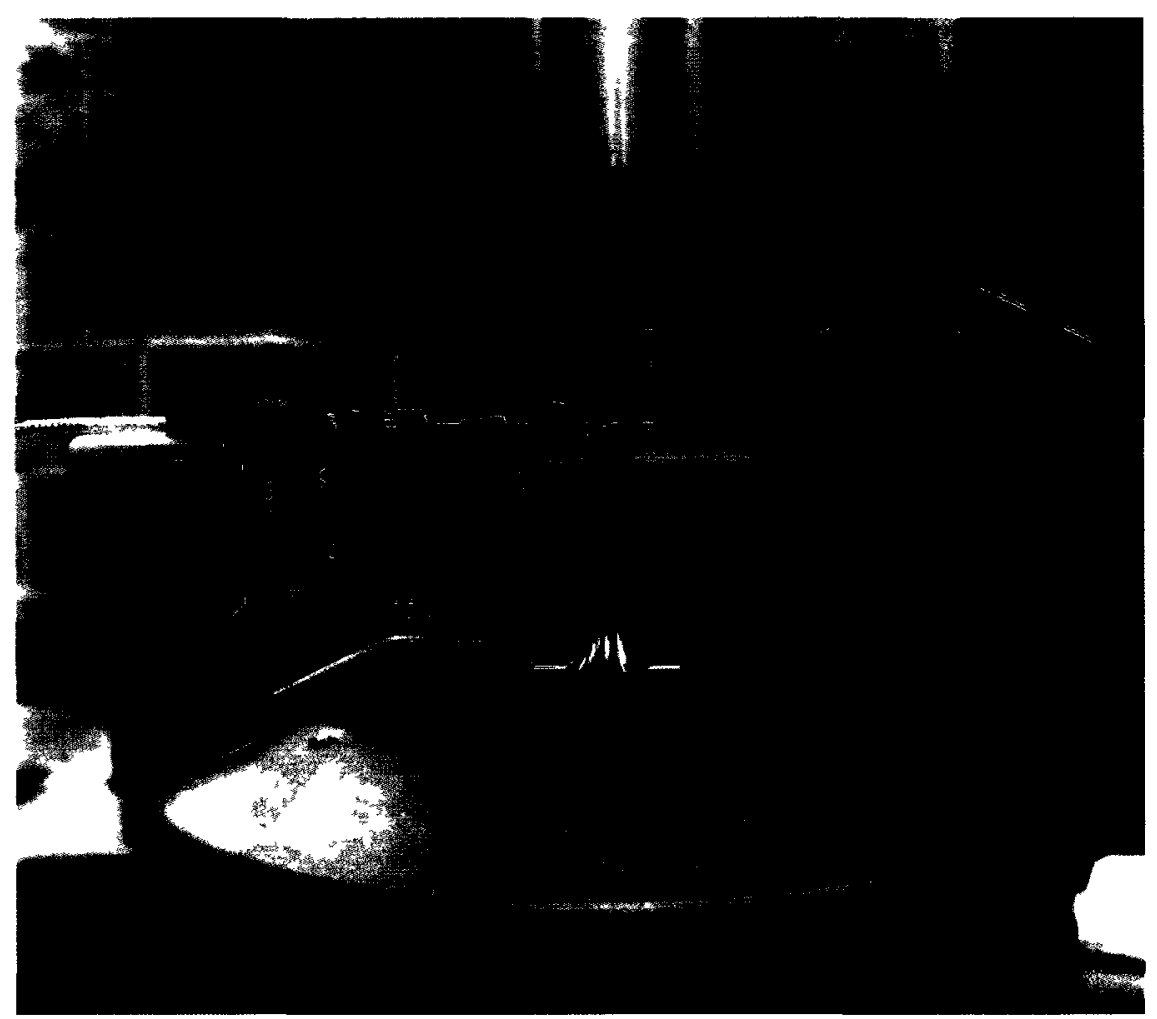

Figure 37: Tensile specimen installed in the test frame with extensometer attached

Prior to testing, the diameter of the gauge section was measured on each specimen at three points: near the top of the gauge section, in the middle of the gauge section, and near the bottom of the gauge section. The specimen was then gripped in the test frame, and the extensometer was clipped onto its surface. All specimens were tested using the testing machine in displacement control mode at an extension rate of $0.0423 \mathrm{~mm} / \mathrm{s}$, which corresponds to a strain rate of approximately $10^{-3} \mathrm{~s}^{-1}$. Two specimens of each metallurgical condition were tested, and the load, extension, and strain data were collected during each test at a rate of 10 $\mathrm{Hz}$ using the testing frame's data acquisition software.

\subsection{SCC Testing}

To assess the SCC susceptibility of the various metallurgical conditions, pre-cracked DB specimens were employed. One of the DB specimens used in this study is pictured in Figure 38. 


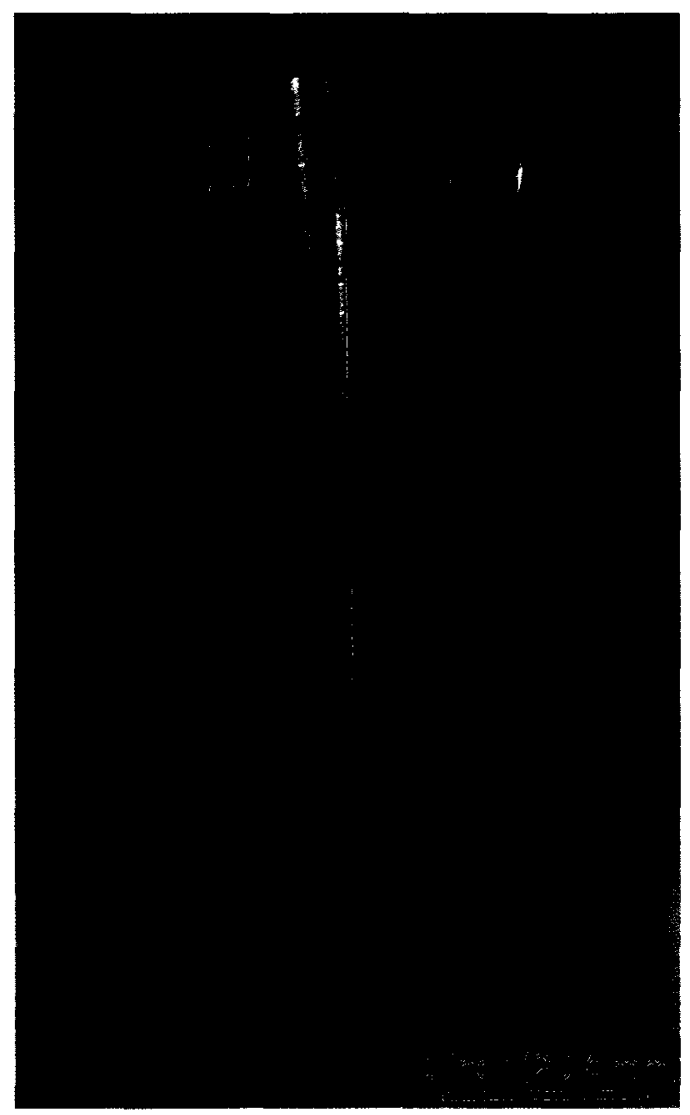

Figure 38: Double beam specimen

The DB specimen tests were based on ASTM standard G 168-00 [31] with two slight deviations which will be discussed later. The DB specimens were produced from 1 inch $X 1$ inch $X 5$ inch $(25.4 \mathrm{~mm} \times 25.4 \mathrm{~mm} \times 127 \mathrm{~mm}$ ) blanks which were cut from the rolled plate and then fully heat treated prior to machining. The blanks were machined to the proper dimensions using a CNC milling machine, and they were flooded with coolant during the machining operations to ensure that they were kept cool. A dimensioned drawing of the DB specimen geometry is shown in Appendix A.

Four DB specimens were produced in each of the T651 and T73(51) tempers, and two specimens were fabricated in each of experimental conditions H495, F400, L370, H495-F400, and S495F400. All of the DB specimens were produced in the ST orientation with respect to the parent material as shown in Figure 21.

Following machining, all of the DB specimens were cleaned briefly in an ultrasonic bath with water and a mild soap to remove any dirt and grease.

In this study, the DB specimens were tested in constant displacement, and this was achieved using loading bolts. The precrack was started from the tip of the machined V-notch by mechanical overload. The length of the precrack and the crack opening displacement were recorded, and the corrodent was then applied to the crack. The time at which the corrodent was initially applied was taken as the starting time for the test. 
The crack tip stress intensity factor at initial crack arrest, $K_{l a}$, was calculated according to the following equation [31]:

$$
K_{I a}=\frac{V_{0} E}{2.309 \sqrt{H}\left(\frac{a_{0}}{H}+0.673\right)^{2}\left[1+1.5\left(\frac{C_{0}}{a_{0}}\right)-1.15\left(\frac{C_{0}}{a_{0}}\right)^{2}\right]}
$$

where

$K_{l a}$ is the crack tip stress intensity, in MPaVm,

$\mathrm{V}_{0}$ is the crack mouth opening displacement, in $\mathrm{m}$,

$E$ is the Young's modulus, in MPa,

$a_{0}$ is the starting crack length at start of exposure, in $\mathrm{m}$,

$\mathrm{C}_{0}$ is the distance from the load line to the crack opening displacement measurement location, in $\mathrm{m}$, and

$H$ is the specimen half height, in $\mathrm{m}$.

The starting crack lengths were found by taking a measurement on both side surfaces of each specimen and computing the average of these two values. In calculating the value of $K_{\mathrm{la}}$, the values of $\mathrm{C}_{0}$ and $\mathrm{H}$ were taken to be constants since the specimen geometry was consistent, and E was considered constant as well. These values are summarized in Table 6.

Table 6: Constants used to calculate $K_{1}$

\begin{tabular}{|l|l|}
\hline Parameter & Value \\
\hline$E$ & $71.0 \times 10^{3} \mathrm{MPa}[11]$ \\
\hline $\mathrm{C}_{0}$ & $6.35 \times 10^{-3} \mathrm{~m}$ \\
\hline $\mathrm{H}$ & $12.7 \times 10^{-3} \mathrm{~m}$ \\
\hline
\end{tabular}

The corrodent used in these tests was $3.5 \% \mathrm{NaCl}$ aqueous solution. This solution was prepared using reagent grade $\mathrm{NaCl}$ and distilled water, and its $\mathrm{pH}$ was found to be between 6.8 and 7.2 using a home water testing kit. The corrodent was applied to the crack twice daily for the duration of the test using a small pipette. Three drops of the solution were applied to each specimen each time for a total of six drops daily.

During the testing period, crack length measurements were taken periodically using a travelling microscope (Scientific Equipment and Services, model TVM-02). Figure 39 shows this apparatus. 


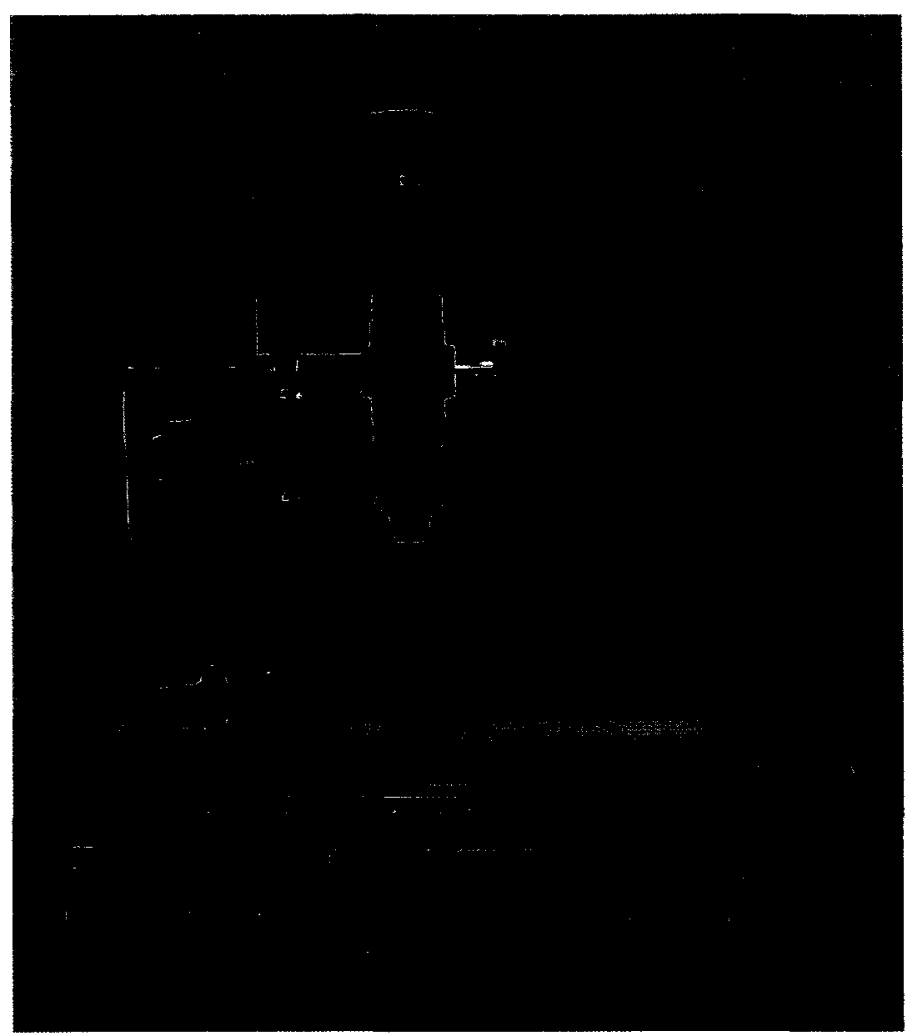

Figure 39: Travelling microscope used for all crack length measurements on DB specimens

For these interim measurements, one reading was taken from each of the side surfaces of each specimen, and the average of these two values was taken to be the crack length at that point in time. Build up of dried salt and corrosion products often made inspection of the crack tip difficult, so a small plastic brush was used to clean the side surface of the specimens in the area of the crack tip prior to measurement.

Throughout the testing period, the temperature and humidity of the test environment were monitored using a digital thermometer/hygrometer. These readings were recorded each time that the corrodent was applied and each time that crack length measurements were made, and they are included in Appendix B.

As stated previously, there were two deviations from the standard test procedure for the DB specimens. First, the loading bolts used in these specimens were 5/16-18UNC and the bolt hole was centred 0.25 inches $(6.35 \mathrm{~mm})$ from the end of the specimen while in [31] this distance is specified as 0.35 inches $(9.52 \mathrm{~mm})$. This was due to tooling constraints which restricted the depth of the $V$-notch to 0.6 inches $(15.24 \mathrm{~mm})$, so the bolt hole position and size had to be adjusted accordingly. Second, the test was stopped before the crack growth rates for all specimens had decreased to the suggested minimum rate of $10^{-9} \mathrm{~cm} / \mathrm{s}$ (approximately $2.78 \times 10^{-12}$ $\mathrm{mm} / \mathrm{h}$ ) since even for incremental test times of several days the change in crack length at this low growth rate was within the measurement error of the travelling microscope. 
At the conclusion of the test, the DB specimens were mechanically cracked until separation. This was achieved by tightening the loading bolts until a mechanical crack extended from the tip of the stress corrosion crack through one of the specimen surfaces. Figure 40 shows one of the separated DB specimens.

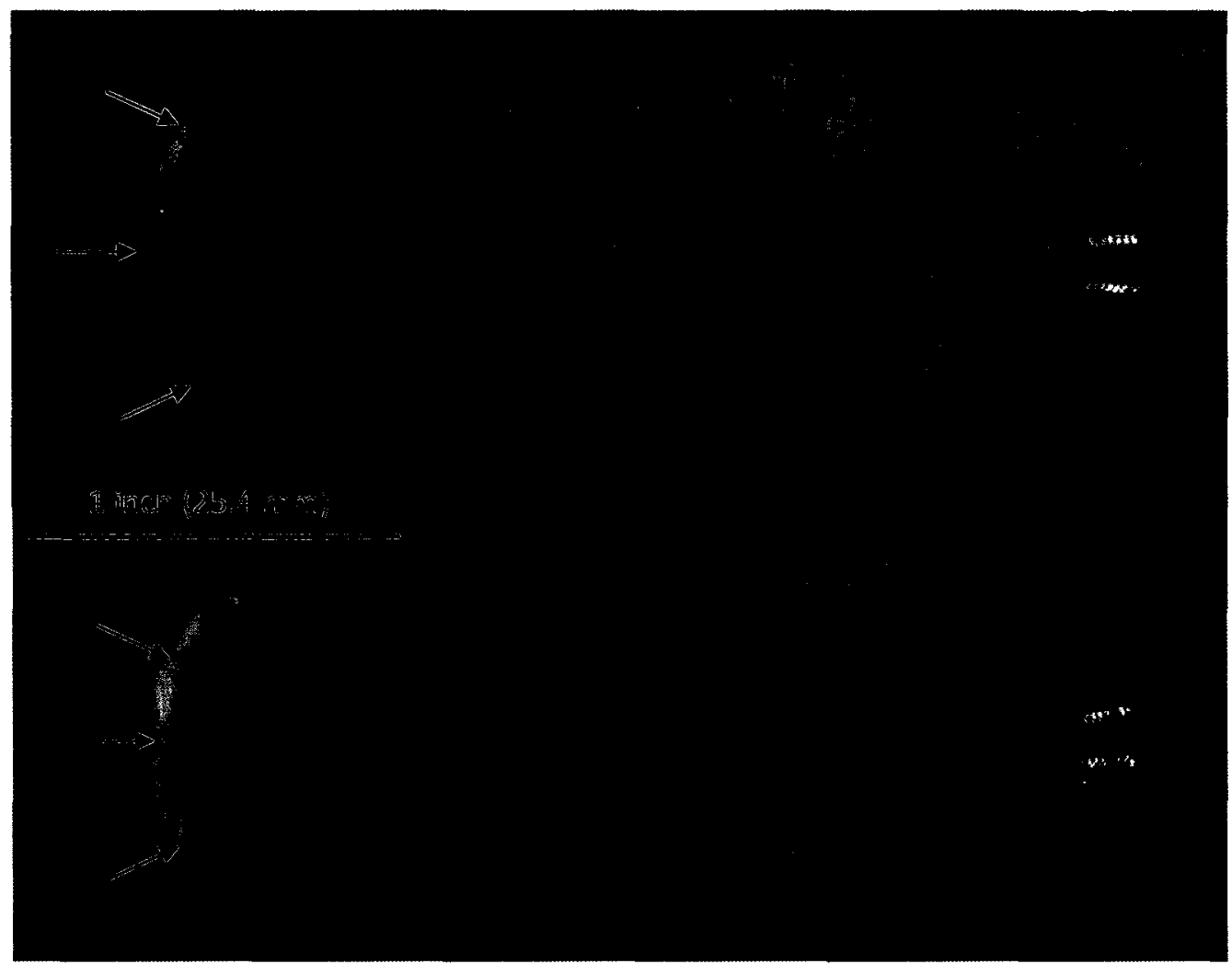

Figure 40: Two pieces of a DB specimen after mechanical separation

The extent of the stress corrosion crack is marked with arrows in the photos. The final crack length measurements were taken from these fracture surfaces using the same travelling microscope as the interim crack length measurements. As specified in [31], these final measurements were taken at five points across the width of the specimen: on the centreline, mid way between the centreline and each side surface, and at each side surface. The average of these five measurements was taken to be the final crack length.

\subsection{Metallographic Preparation}

To facilitate the examination of the various microstructures, metallographic specimens were prepared from a selection of the experimental conditions, as well as from the T651 and T73(51) tempers. All of the metallographic specimens were cut from the round bar stock, except for three specimens which were produced from the as received plate material.

To prepare the metallographic samples, sections approximately $4 \mathrm{~mm}$ thick were cut from fully heat treated pieces of the round bar stock using a diamond abrasive saw (Buehler Isomet 1000). These sections were then mounted in phenolic resin (Buehler PhenoCure Black) using a 
hydraulic mounting press. All of the metallographic specimens were polished according to the following procedure:

- Grind on 240, 320, 400, and 600 grit papers (Buehler CarbiMet) until the surface is planar and all scratches are aligned in one direction

- Rinse well with water after each level of abrasive

- Grind on 800 grit disc (Buehler Microcut) until all scratches are aligned in one direction

- Clean with mild soap and water solution using a cotton ball, then rinse with water and blow dry with warm air

- Polish with $6 \mu \mathrm{m}$ diamond suspension (Buehler MetaDi) on polishing disc (Buehler TexMet) for about 5 minutes using light to medium pressure

- Clean with mild soap and water solution using a cotton ball, then rinse with water and blow dry with warm air

- Polish with $0.05 \mu \mathrm{m}$ alumina solution (Buehler MicroPolish powder in distilled water) on polishing cloth (Buehler MicroCloth) for about 5 minutes using light pressure

- Clean with mild soap and water solution using a cotton ball, then rinse with water, rinse with alcohol, and blow dry with warm air

This polishing procedure was developed based on the four step process outlined for Al alloys in [43].

Following polishing, each metallographic sample was etched to reveal the microstructure. The etching times varied slightly for each metallurgical condition, but all specimens were etched by immersion in Keller's reagent. The composition of Keller's reagent is as follows [44]:

- $2.5 \mathrm{~mL} \mathrm{HNO}_{3}$

- $1.5 \mathrm{~mL} \mathrm{HCl}$

- $1.0 \mathrm{~mL} \mathrm{HF}$

- $\quad 95 \mathrm{~mL} \mathrm{H}_{2} \mathrm{O}$ (distilled)

\subsection{Microstructural Observation}

All microstructural observations were made on a Tescan Vega XMU scanning electron microscope (SEM). SEM images were generated using an excitation voltage of either $15 \mathrm{kV}$ or $20 \mathrm{kV}$ and the back scattered electron detector. 


\section{Experimental Results}

\subsection{Hardness and Electrical Conductivity Results}

\subsubsection{Hardness and Electrical Conductivity Test Coupons}

The results of the hardness and electrical conductivity (EC) tests performed on the small, round bar specimens are given in Table 7. For comparison, typical values for the T6 and T73 tempers are presented in Table 7 as well.

Table 7: Hardness and EC results for small test coupons

\begin{tabular}{|c|c|c|}
\hline Condition & Hardness [HRB] & Electrical Conductivity [\%IACS] \\
\hline T6 typical & $84[13]$ & $33[11]$ \\
\hline T73 typical & 78 [13] & $40[11]$ \\
\hline T651 & 90.8 & 31.45 \\
\hline $\mathrm{T73}(51)$ & 85.7 & 37.60 \\
\hline S495 & 91.1 & 30.59 \\
\hline $\mathrm{H} 480$ & 91.0 & 30.84 \\
\hline $\mathrm{H} 495$ & 91.3 & 30.95 \\
\hline (1) & 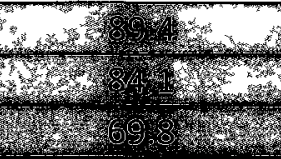 & (2) \\
\hline 到名, & $(8), 3$ & Sinitis \\
\hline $2 / 3$ & 8 & $3 / 4$ \\
\hline 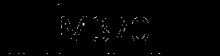 & s. & 35 \\
\hline $4+\infty$ & s. & $\therefore s$ \\
\hline 3 & 3 & 36.6 \\
\hline $\mathrm{H} 495-\mathrm{F} 430$ & 87.8 & 32.19 \\
\hline $\mathrm{H} 495-\mathrm{F} 400$ & 81.2 & 34.64 \\
\hline S4:95=E.430. & 89.78 & $3121,-20$ \\
\hline
\end{tabular}

The values presented in Table 7 are the average of the various measurements taken from each specimen. For the hardness measurements on specimens of H495-F430, H495-F400, S495-F430, and $\mathrm{H} 495-\mathrm{F} 400$, the maximum and minimum values were discarded, and the average of the remaining ten values was computed. For all other specimens, the hardness given in Table 7 is the average of six measurements as indicated in section $\mathbf{5 . 3 .}$

\subsubsection{Tensile Specimens}

The hardness and EC were measured for the blanks used to produce the tensile specimens both before and after the ageing treatment was applied. The results of these tests are shown in Table 8 along with typical values for the T6 and T73 tempers. 
Table 8: Hardness and EC results from tensile specimen blanks

\begin{tabular}{|c|c|c|c|c|}
\hline Condition & $\begin{array}{c}\text { Pre-ageing } \\
\text { hardness [HRB] }\end{array}$ & $\begin{array}{c}\text { Post-ageing } \\
\text { hardness [HRB] }\end{array}$ & $\begin{array}{c}\text { Pre-ageing EC } \\
\text { [\%|ACS] }\end{array}$ & $\begin{array}{c}\text { Post-ageing EC } \\
\text { [\%IACS] }\end{array}$ \\
\hline T6 typical & N/A & 84 [13] & N/A & $33[11]$ \\
\hline T73 typical & $\mathrm{N} / \mathrm{A}$ & 78 [13] & N/A & $40[11]$ \\
\hline T651 & $\mathrm{N} / \mathrm{A}$ & 90.5 & N/A & 33.87 \\
\hline T6* & $\mathrm{N} / \mathrm{A}$ & 90.5 & $\mathrm{~N} / \mathrm{A}$ & 33.70 \\
\hline T73(51) & $\mathrm{N} / \mathrm{A}$ & 85.8 & $\mathrm{~N} / \mathrm{A}$ & 40.59 \\
\hline T73* & $N / A$ & 87.9 & $N / A$ & 37.85 \\
\hline$\$ 495$ & 78.4 & 88.6 & 29.68 & 32.93 \\
\hline $\mathrm{H} 480$ & 79.2 & 90.7 & 29.13 & 32.36 \\
\hline $\mathrm{H} 495$ & 80.9 & 91.1 & 28.88 & 32.25 \\
\hline 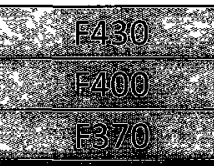 & 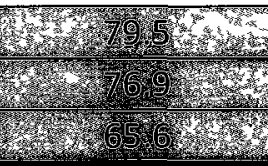 & 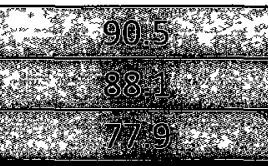 & 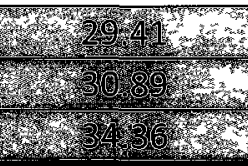 & (1) \\
\hline MA30 & 80.2 & 898,5 & 29.5 & 32.99 \\
\hline Mi400 & 71.3 & 83,7 & 32.35 & 35.92 \\
\hline \multirow[t]{2}{*}{ W 78} & 583 & 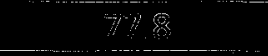 & 36.66 & $57(9) ?$ \\
\hline & 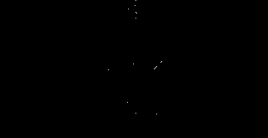 & $\therefore$ & $\ldots \ldots v$ & $\because$ \\
\hline H495-F430 & 78.6 & 89.8 & 29.61 & 33.08 \\
\hline H495-F400 & 73.6 & 86.1 & 31.76 & 35.20 \\
\hline 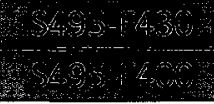 & 800 & 3 & 2.38 & 3. \\
\hline
\end{tabular}

The results presented in Table 8 are the average values of the various measurements taken. For the hardness measurements, the maximum and minimum measured values for each specimen were discarded, and the average of the remaining eight measurements was computed.

\subsubsection{Double Beam Specimens}

Hardness and EC data were collected from the blocks used to fabricate the DB specimens before and after ageing. Table 9 shows the results of these tests and the typical values for the T6 and T73 tempers. 
Table 9: Hardness and EC results for DB specimen blocks

\begin{tabular}{|c|c|c|c|c|}
\hline Condition & $\begin{array}{c}\text { Pre-ageing } \\
\text { hardness [HRB] }\end{array}$ & $\begin{array}{c}\text { Post-ageing } \\
\text { hardness [HRB] }\end{array}$ & $\begin{array}{c}\text { Pre-ageing EC } \\
{[\% \mid A C S]}\end{array}$ & $\begin{array}{c}\text { Post-ageing EC } \\
\text { [\%IACS] }\end{array}$ \\
\hline T6 typical & N/A & $84[13]$ & $\mathrm{N} / \mathrm{A}$ & 33 [11] \\
\hline T73 typical & N/A & 78 [13] & N/A & 40 [11] \\
\hline T651 & N/A & 87.6 & $\mathrm{~N} / \mathrm{A}$ & 33.58 \\
\hline $\mathrm{T73}(51)$ & N/A & 80.8 & $\mathrm{~N} / \mathrm{A}$ & 40.63 \\
\hline $\mathrm{H} 495$ & 80.8 & 90.8 & 28.60 & 31.65 \\
\hline 45 & 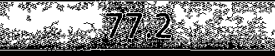 & $48060 \%$ & 55 & 3.729 \\
\hline $37 \%$ & 8 & 16,8 & 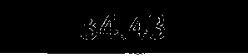 & 84 \\
\hline $\mathrm{H} 495-\mathrm{F} 400$ & 74.4 & 86.9 & 31.25 & 34.65 \\
\hline
\end{tabular}

\subsection{Tensile Test Results}

The data obtained from the uniaxial tensile tests were used to generate an engineering stressstrain plot for each specimen. The load data were normalized by the cross sectional area of the gauge section as determined based on the average of three measurements of the gauge section diameter taken prior to testing. The strain data were read directly from the extensometer output. A typical tensile stress-strain plot is shown in Figure 41.

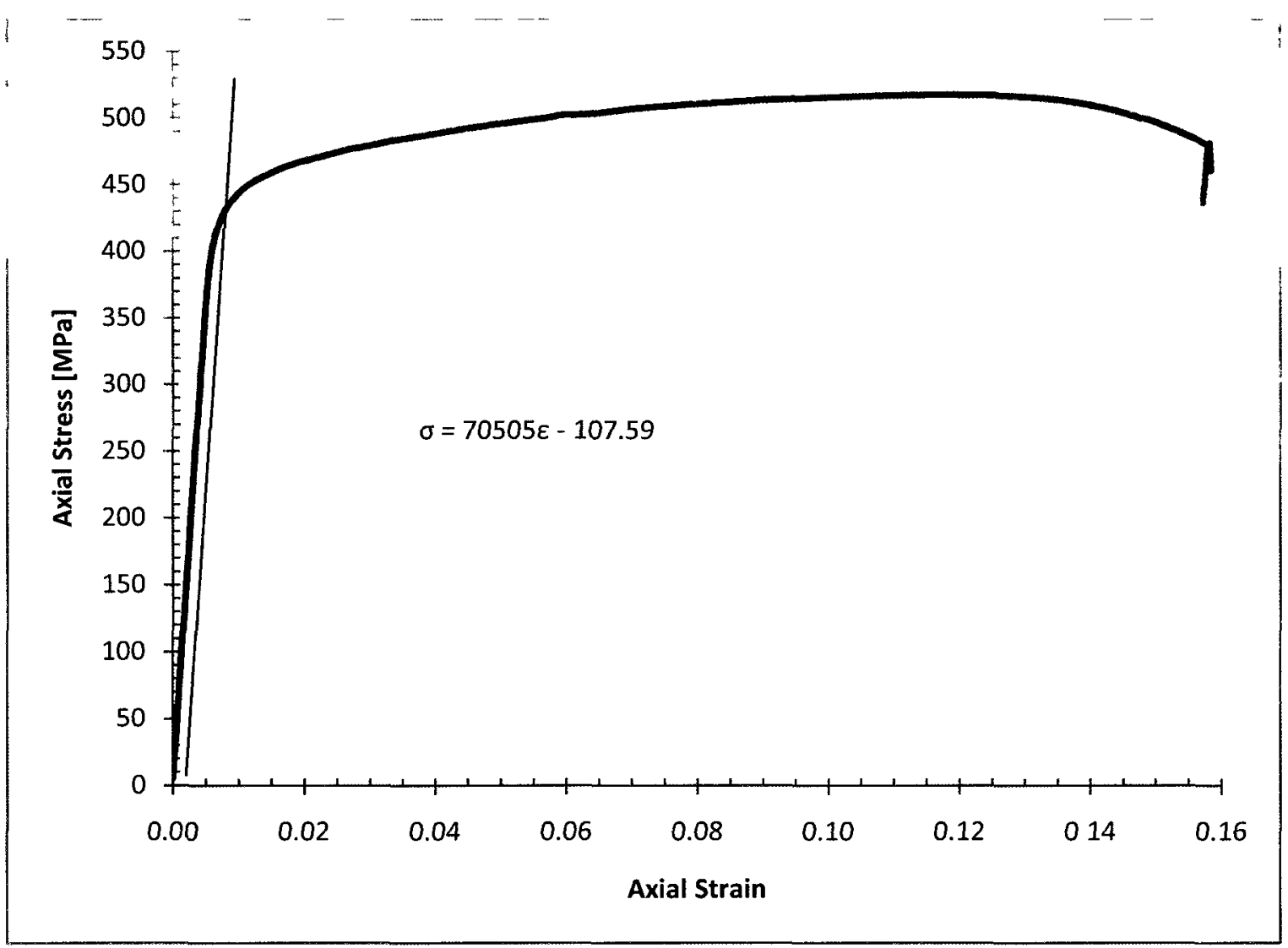

Figure 41: Tensile stress-strain plot for specimen M400 B 
Determination of the elastic modulus and $0.2 \%$ strain offset yield strength for each specimen were done using the stress-strain curve. The ultimate tensile strength (UTS) of each specimen was found directly from the data as the maximum engineering stress applied during the test, and the ductility, in terms of percent elongation, was determined based on the final strain prior to failure. Table 10 summarizes the results of the tensile tests conducted. Typical values for the T6 and T73 tempers are also given in Table 10.

Table 10: Summary of uniaxial tensile test results

\begin{tabular}{|c|c|c|c|c|}
\hline Condition & $\begin{array}{c}E \\
{[\mathrm{GPa} \text { ] }}\end{array}$ & $\begin{array}{c}\sigma_{\mathrm{y}} \\
{[\mathrm{MPa}]}\end{array}$ & $\begin{array}{c}\text { UTS } \\
\text { [MPa] }\end{array}$ & $\begin{array}{c}\text { Ductility } \\
\text { [\%EL] }\end{array}$ \\
\hline T6/T651 typical [11] & 71.0 & 503 & 572 & 11 \\
\hline T73/T7351 typical[11] & 71.0 & 434 & 503 & 13 \\
\hline T651 & $69.65 \pm 0.90$ & $529.0 \pm 1.0$ & $592.4 \pm 4.8$ & $11.4 \pm 1.2$ \\
\hline T6* & $70.76 \pm 0.26$ & $501.0 \pm 1.0$ & $589.0 \pm 1.1$ & $9.6 \pm 0.4$ \\
\hline $\mathrm{T73}(51)$ & $70.57 \pm 0.14$ & $453.5 \pm 3.5$ & $532.7 \pm 1.2$ & $12.2 \pm 3.7$ \\
\hline $\mathrm{T} 73^{*}$ & $70.32 \pm 0.29$ & $482.0 \pm 3.0$ & $567.7 \pm 0.4$ & $9.9 \pm 3.5$ \\
\hline S495 & 69.92 & 470.0 & $577.4 \pm 4.6$ & 13.9 \\
\hline $\mathrm{H} 480$ & $70.20 \pm 0.13$ & $492.5 \pm 2.5$ & $584.9 \pm 0.7$ & $11.6 \pm 1.1$ \\
\hline H495 & $69.67 \pm 0.42$ & $498.5 \pm 1.5$ & $591.0 \pm 2.1$ & $13.9 \pm 4.1$ \\
\hline \multicolumn{5}{|c|}{ 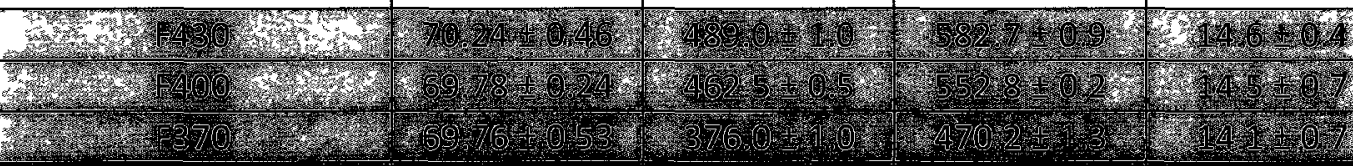 } \\
\hline Nasto & 7004,050 & $4820=0.0$ & b) & $16 .(6-0) 9$ \\
\hline Who & Wo 48,000 & 420030 & $330=2$ & 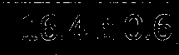 \\
\hline 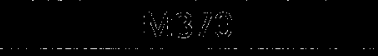 & 290.8. & $830=0$ & $4886 \cdots 2$ & $=34 c^{2}$ \\
\hline$\cdots$ & $x+\cdots$ & $\therefore \ldots$ & $\therefore$ & $i^{\prime}$ \\
\hline (a) & 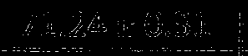 & 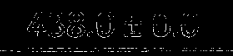 & $28,2=2$ & 42,26 \\
\hline i. 270 & $5,960.04$ & 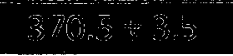 & $46,6-6$ & $130+1,0$ \\
\hline $\mathrm{H} 495-\mathrm{F} 430$ & $69.90 \pm 0.03$ & $486.5 \pm 0.5$ & $577.9 \pm 0.7$ & $15.6 \pm 1.0$ \\
\hline $\mathrm{H} 495-\mathrm{F} 400$ & $69.82 \pm 0.45$ & $440.0 \pm 2.0$ & $532.9 \pm 1.4$ & $13.6 \pm 0.0$ \\
\hline 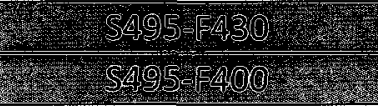 & 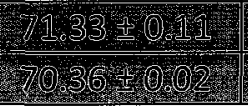 & 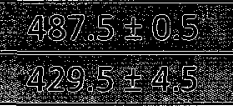 & 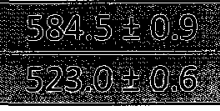 & 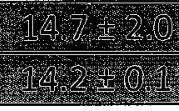 \\
\hline
\end{tabular}

All of the values given in Table 10 represent the average of the two specimens tested in each condition with the exception of those for experimental temper \$495. For this temper, all of the values except UTS are from just one specimen (S495 B) as the strain data for the other specimen were invalid due to an extensometer attachment error. The complete results from all of the tensile tests are given in Appendix $\mathrm{C}$.

To facilitate the comparison of the various tempers, the yield strength and UTS data given in Table 10 are presented graphically in Figure 42. The solid and dashed horizontal lines on the plot represent the typical T6 and T73 yield strengths, respectively, according to [11]. 


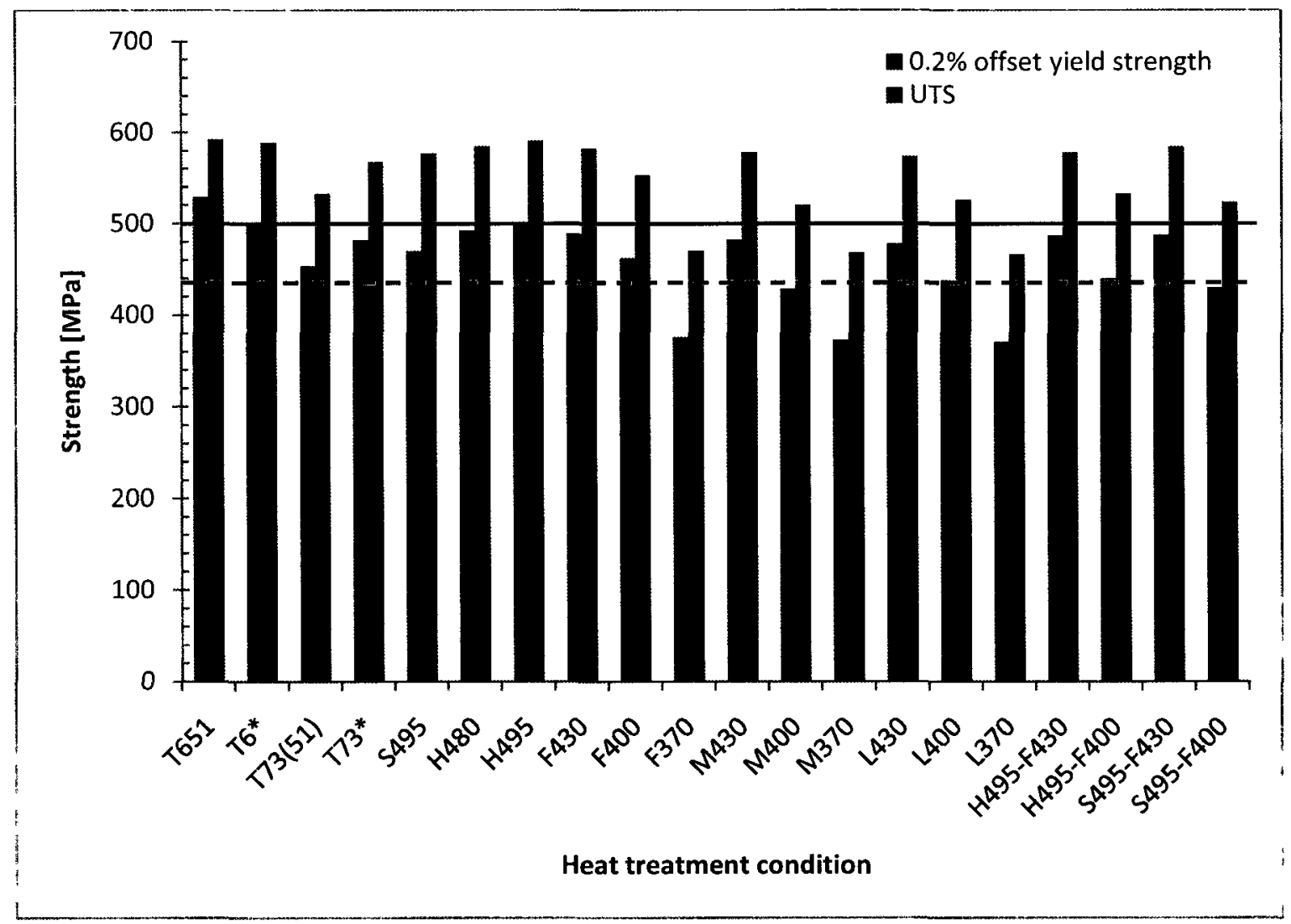

Figure 42: Yield strength and UTS of all tempers based on tensile testing. Solid and dashed lines represent the typical T6 and T73 yield strengths [11], respectively.

\subsection{SCC Test Results}

The final stress intensity at the conclusion of the test was computed for each specimen using the following equation [31]:

$$
K_{I \text { final }}=\frac{V_{0} E}{2.309 \sqrt{H}\left(\frac{a_{0}}{H}+0.673\right)^{2}\left[1+1.5\left(\frac{C_{0}}{a_{0}}\right)-1.15\left(\frac{C_{0}}{a_{0}}\right)^{2}\right]}
$$

where

$K_{\text {final }}$ is the crack tip stress intensity, in MPaVm,

$V_{0}$ is the crack mouth opening displacement, in $\mathrm{m}$,

$E$ is the Young's modulus, in MPa,

$a_{f}$ is the final crack length at end of exposure, in $m$,

$\mathrm{C}_{0}$ is the distance from the load line to the crack opening displacement measurement

location, in $\mathrm{m}$, and

$H$ is the specimen half height, in $\mathrm{m}$.

This equation is the same as that used to find the initial stress intensity, except that the final crack length is substituted for the initial crack length. The values of the constants used in the calculating the final stress intensity are the same as those used in finding the initial stress 
intensity; hence, they are not repeated here and can be found in Table 6 . Table 11 summarizes the results of the DB specimen tests.

Table 11: DB specimen test results

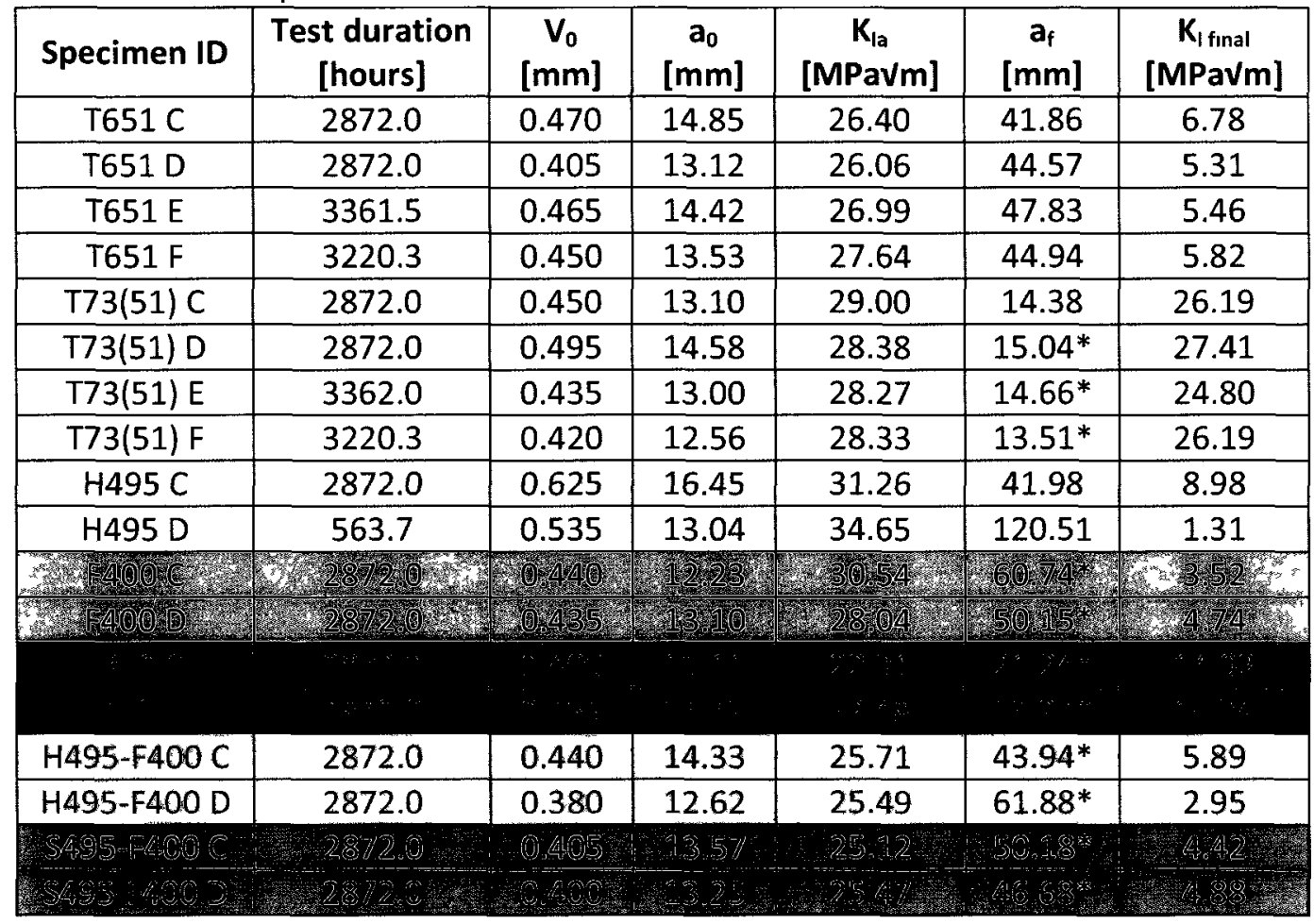

Final crack length measurements in Table 11 denoted with an asterisk indicate that the crack was not considered symmetric based on the criteria outlined in [31]. The results for specimen $\mathrm{H} 495 \mathrm{C}$ are presented in Table 11; however, these results are considered invalid according to [31]. This is due the fact that the crack deviated significantly from the specimen centreline, as illustrated in Figure 43. 


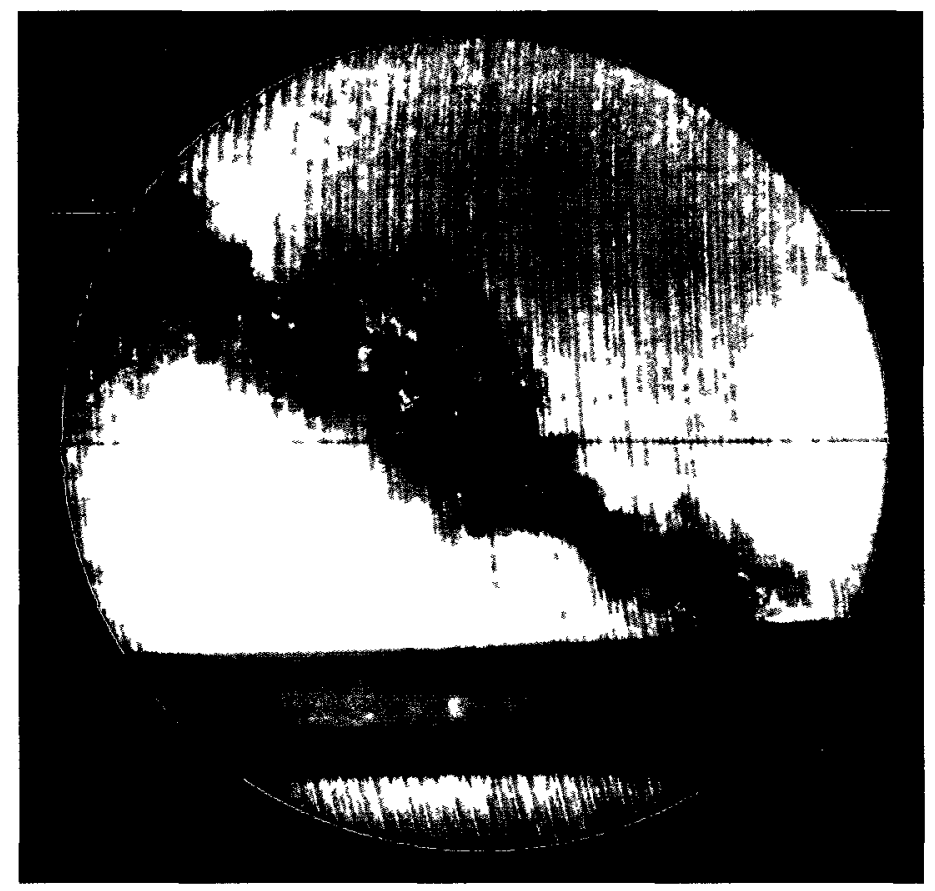

Figure 43: Crack in specimen $\mathrm{H} 495 \mathrm{C}$ at $10 \mathrm{X}$ magnification, as viewed through the travelling microscope

In Figure 43, the machined V-groove, which corresponds to the specimen centreline and within which the crack started growing, can be seen in the bottom of the field, and the crack has departed considerably from this path. The direction of crack propagation in the figure is from right to left.

The complete record of the SCC tests, including interim crack length measurements and crack growth rates, is presented in Appendix D. Figure $\mathbf{4 4}$ shows the crack lengths of the various DB specimens as a function of time. 


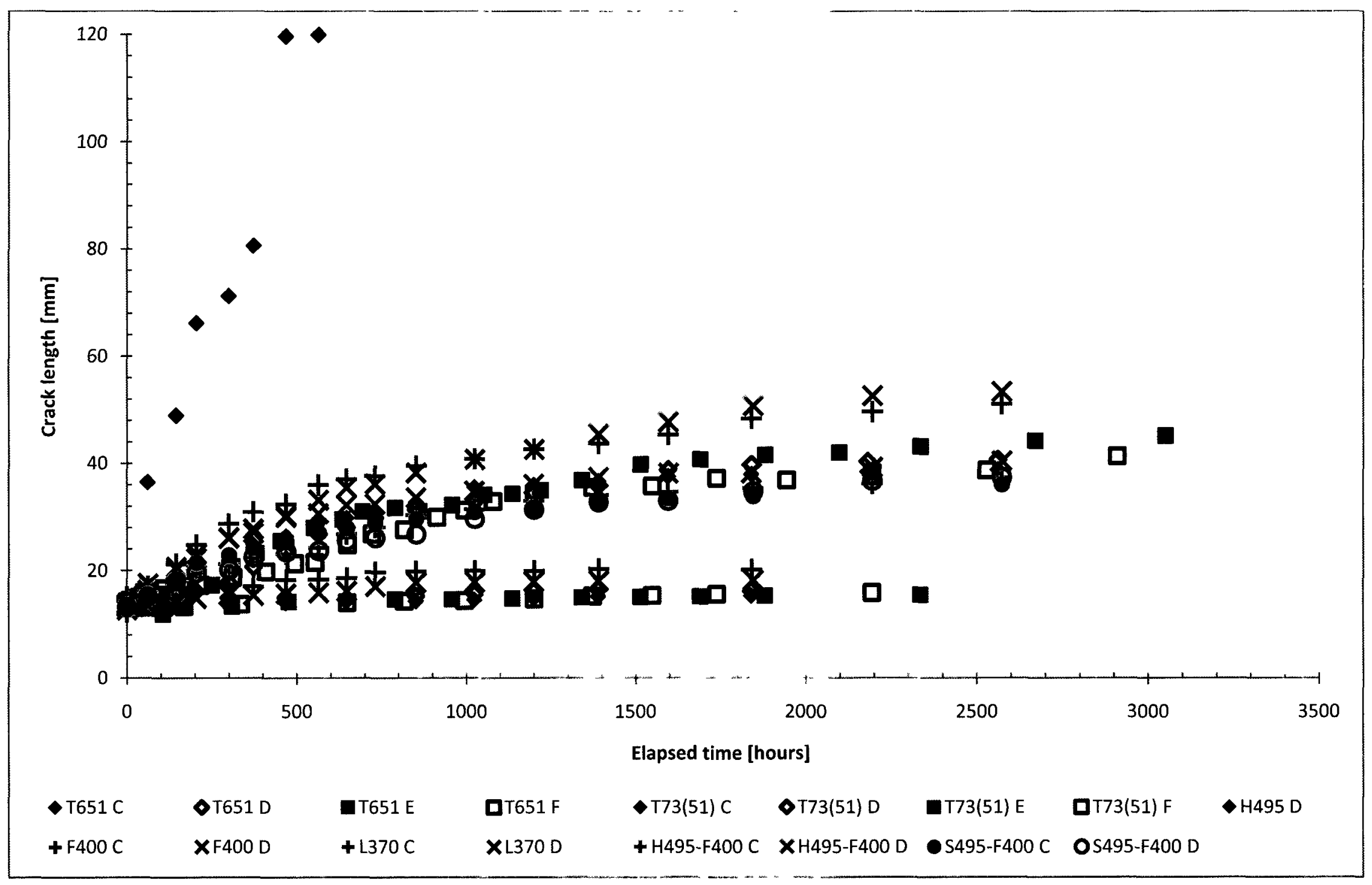

Figure 44: Crack length as a function of time in DB specimens 


\subsection{Microstructural Results}

\subsubsection{As-received T651 Plate and Bar}

The microstructures of the as-received material were observed at relatively low magnification to examine their general microstructural characteristics. Sections were taken from the T651 plate in each of the three grain orientations and one transverse section was taken from the T651 bar. Figure 45, Figure 46, and Figure 47 show the plate microstructure with the various material directions indicated in the caption to each image, and Figure 48 shows the bar microstructure.

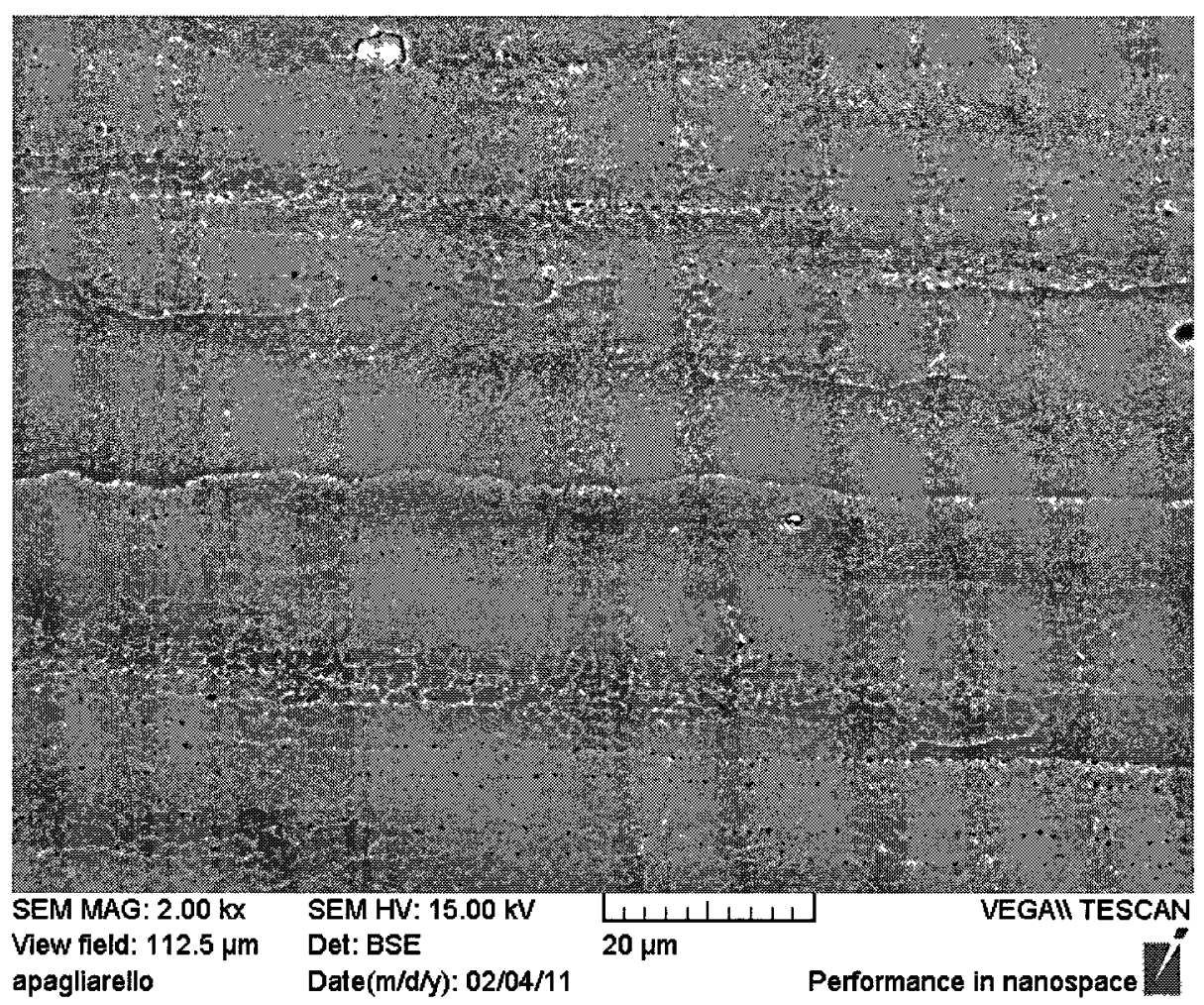

Figure 45: As-received T651 plate microstructure: the rolling direction is horizontal and the short transverse direction is vertical in the image 


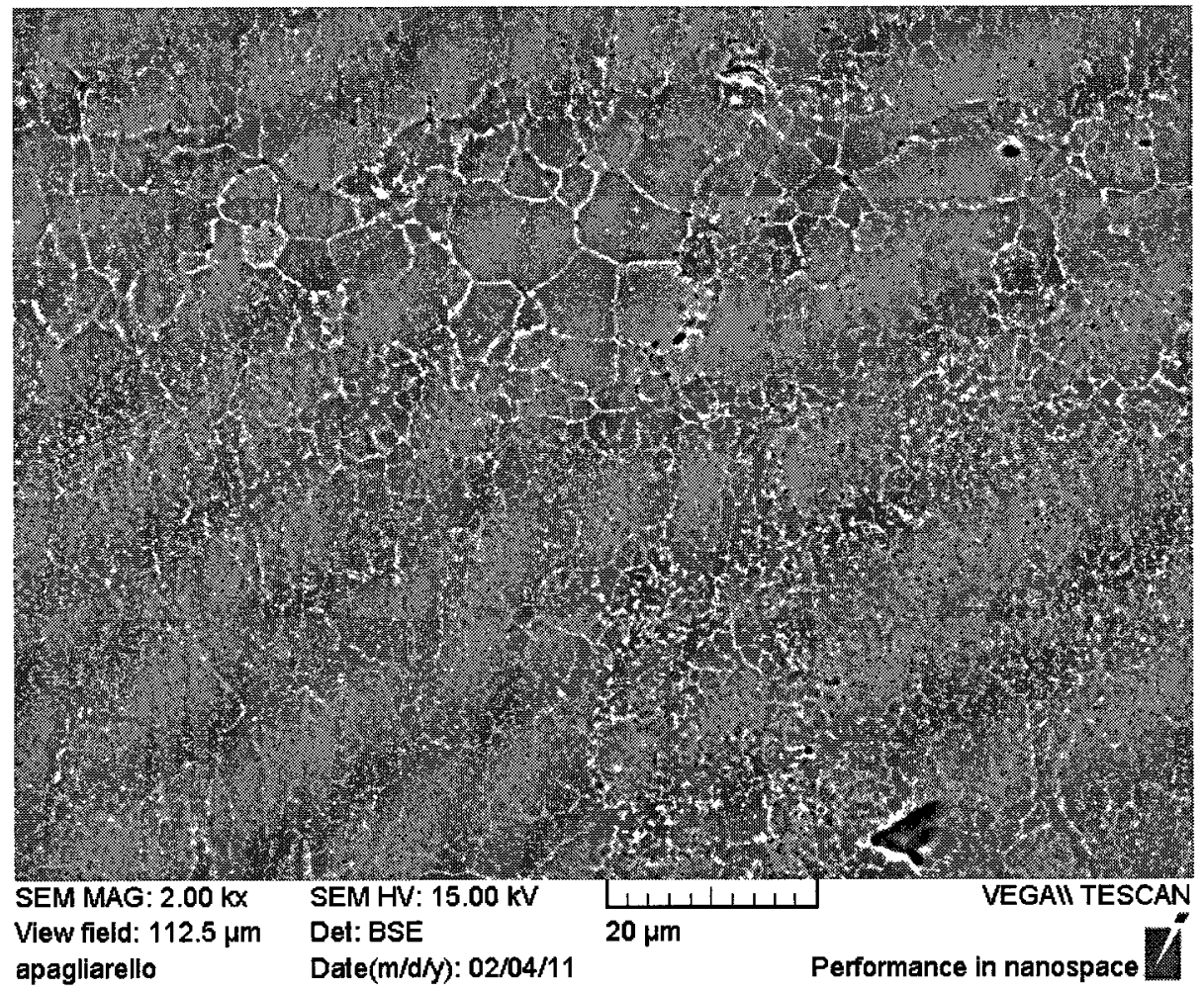

Figure 46: As-received T651 plate microstructure: the rolling direction is horizontal and the long transverse direction is vertical in the image

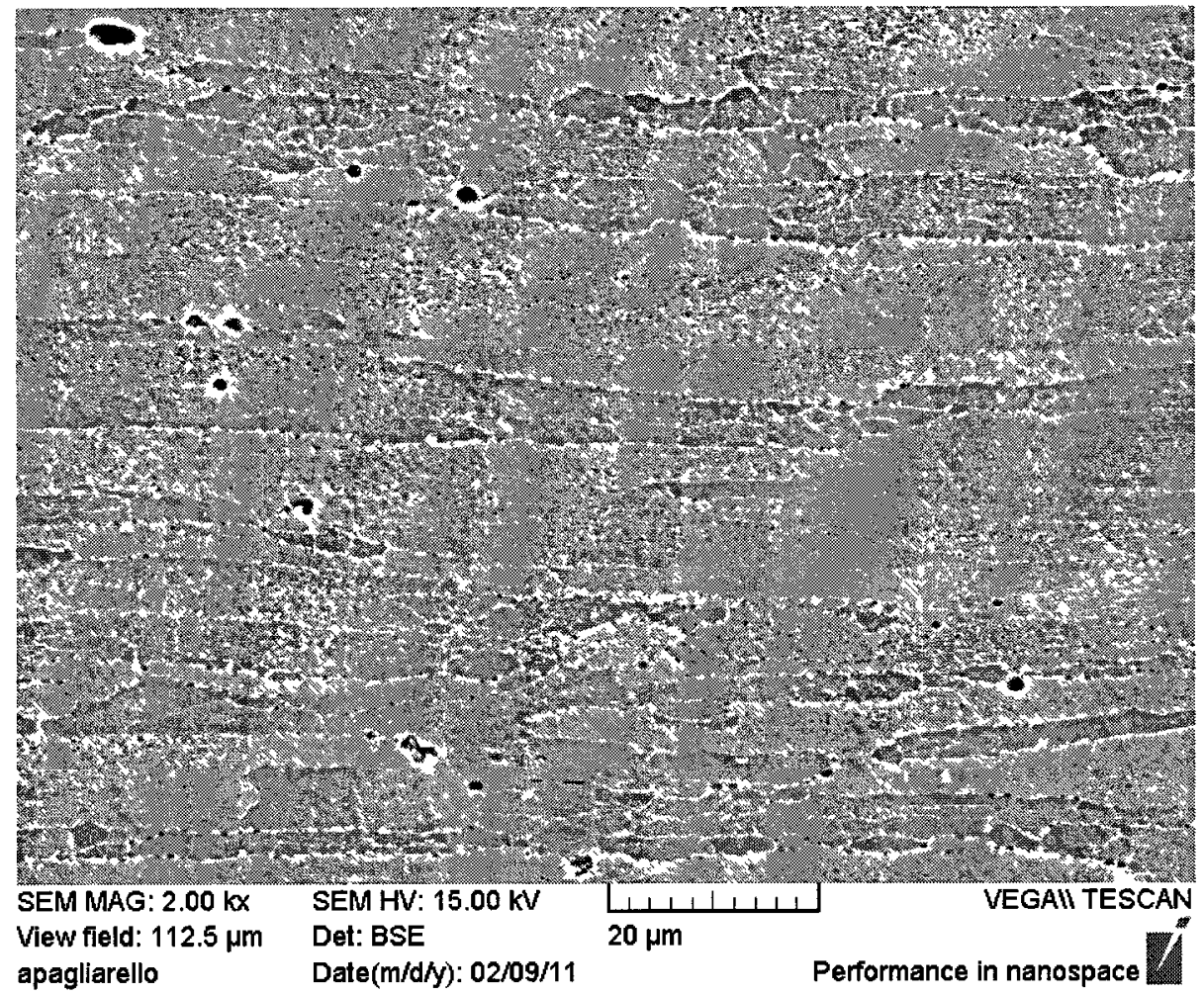

Figure 47: As-received T651 plate microstructure: the long transverse direction is horizontal and the short transverse direction is vertical in the image 


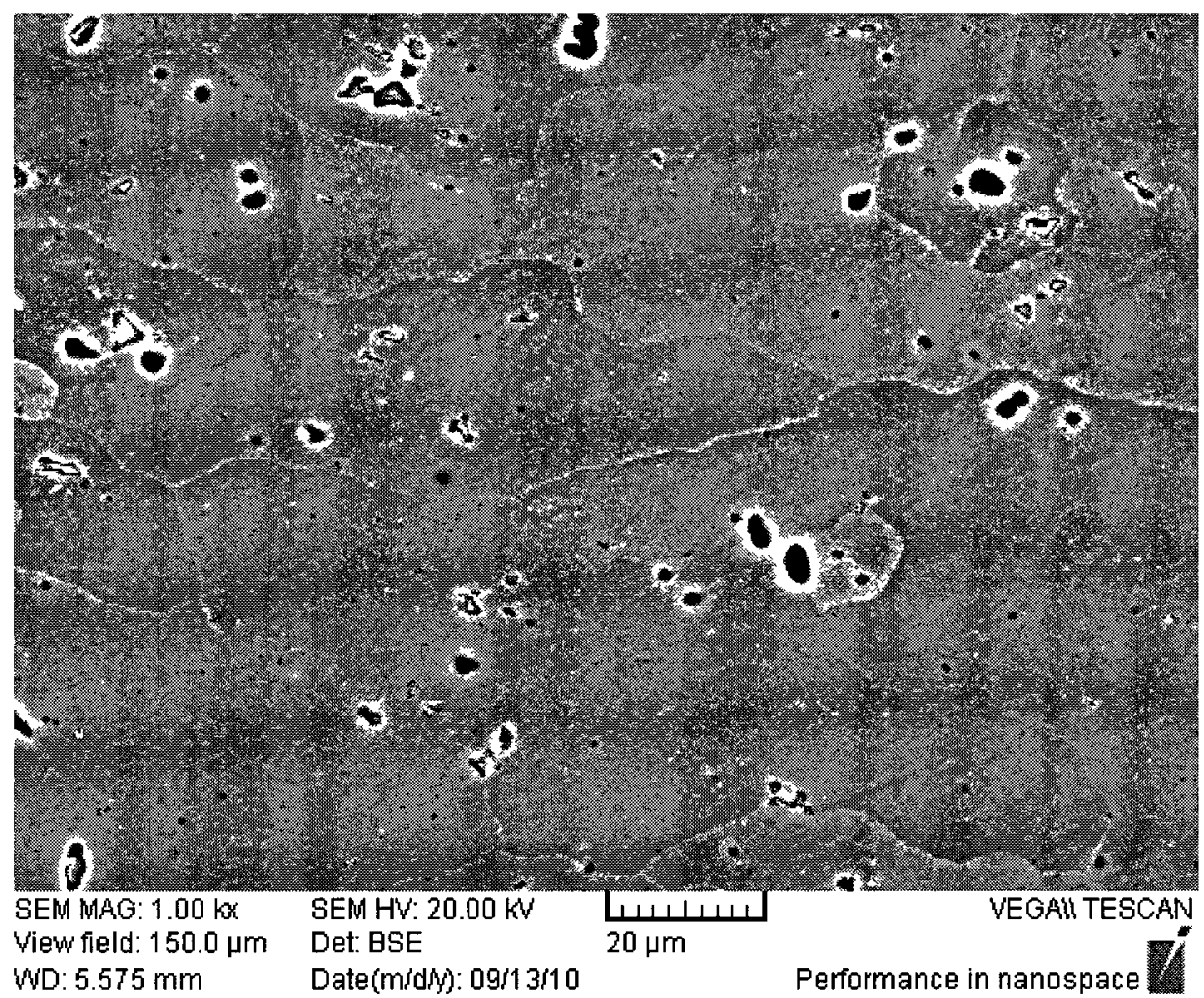

Figure 48: As-received T651 bar microstructure: the extrusion direction is normal to the plane of the image

Higher magnification images of the T651 bar microstructure were also taken to examine the grain boundaries and specifically the grain boundary precipitates. Figure 49, Figure 50, Figure 51, and Figure 52 show typical grain boundary areas in the T651 bar at higher magnifications. All images are transverse sections, meaning that the extrusion direction is normal to the plane of the image. The grain boundaries have been marked with black arrows in the images. 


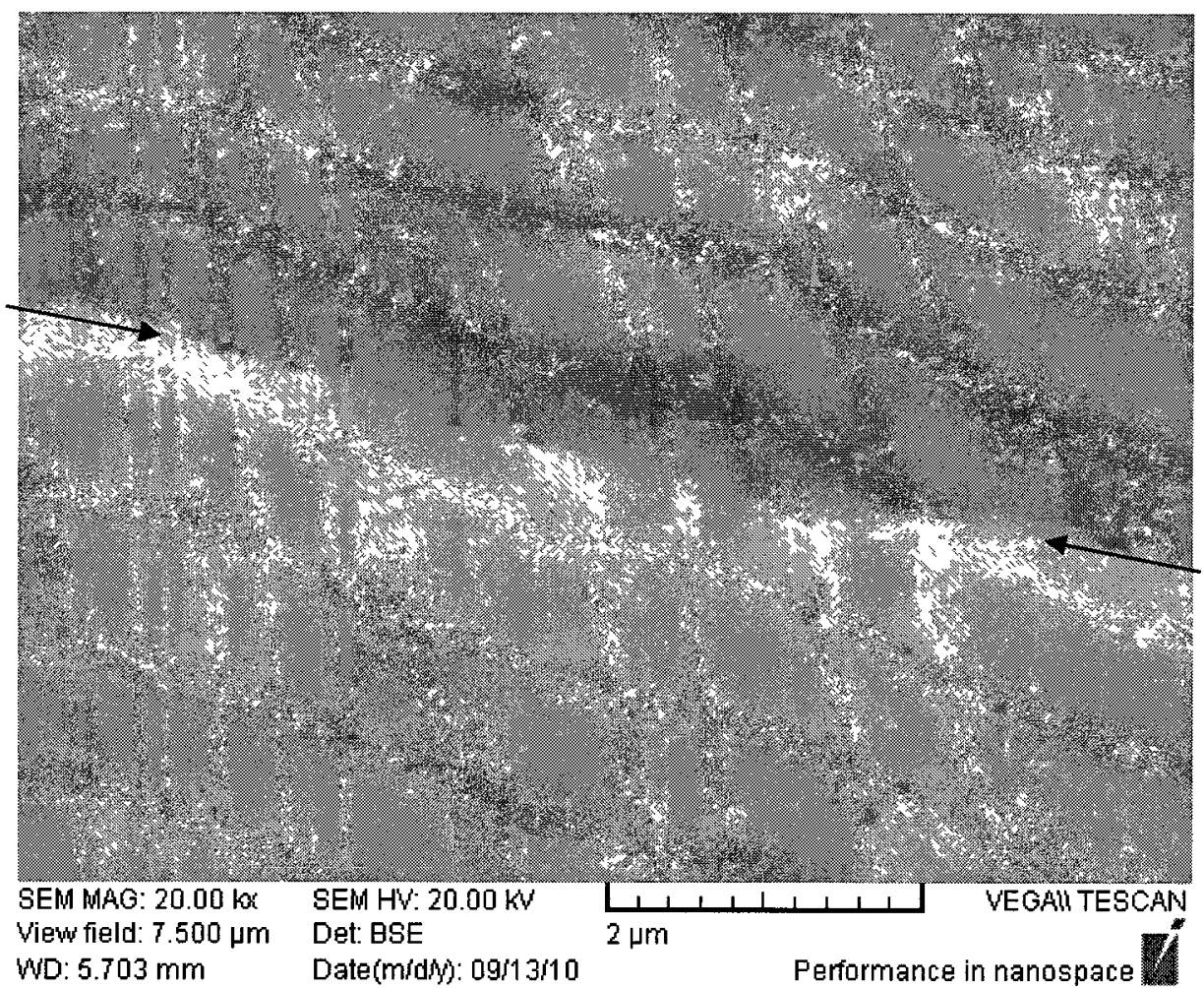

Figure 49: Grain boundary area in T651 bar at 20000X magnification

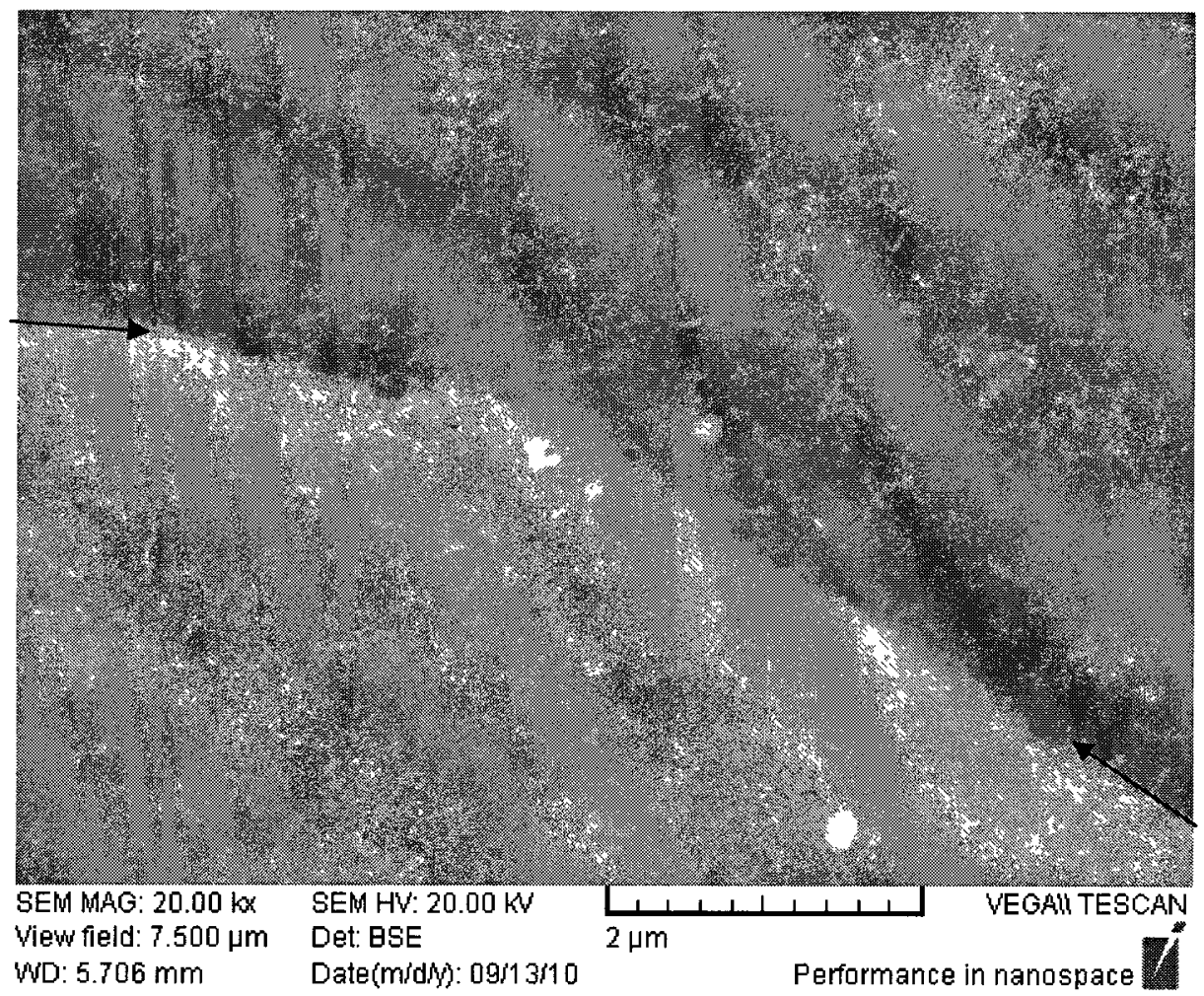

Figure 50: Grain boundary area in T651 bar at 20000X magnification 


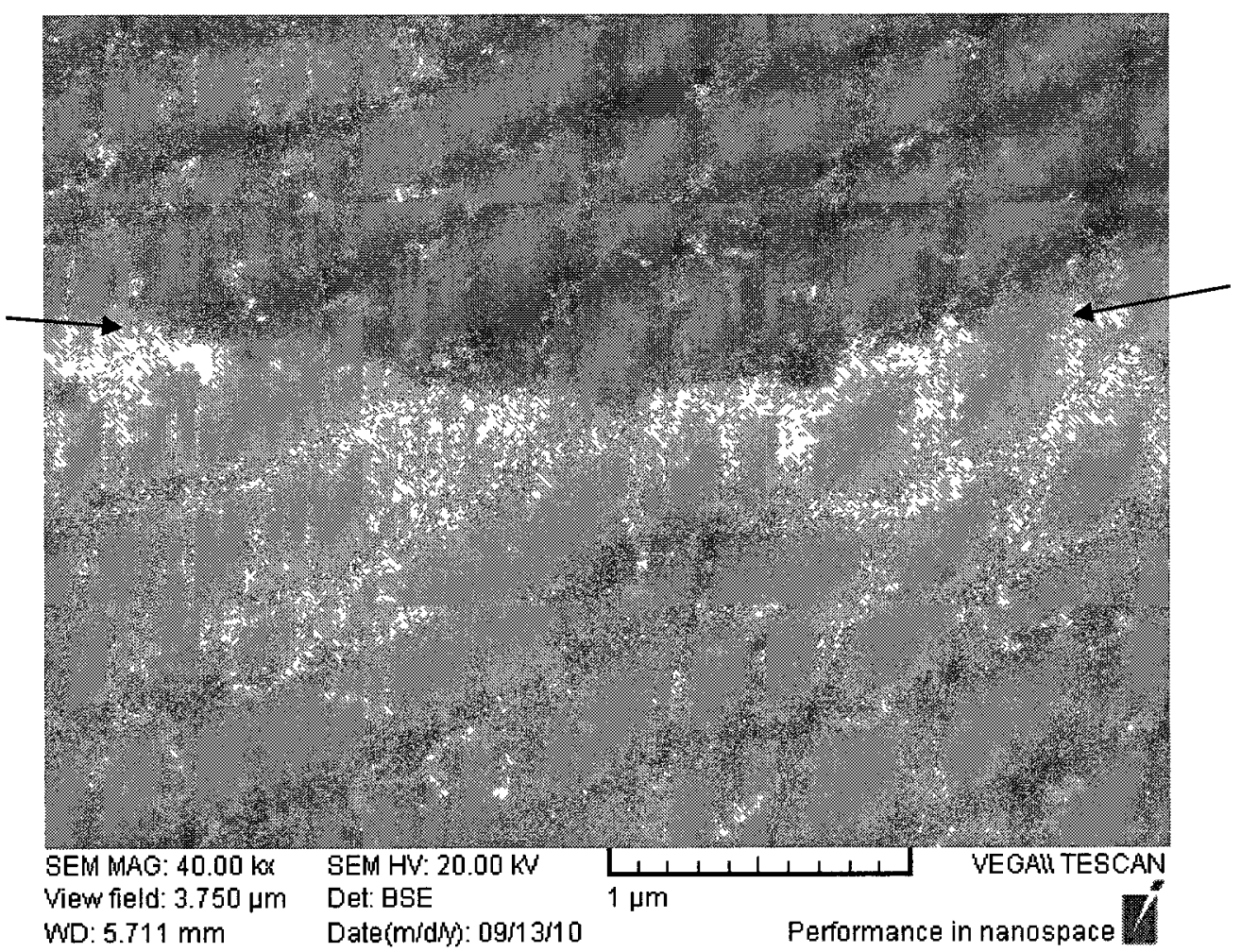

Figure 51: Grain boundary area in T651 bar at 40000X magnification

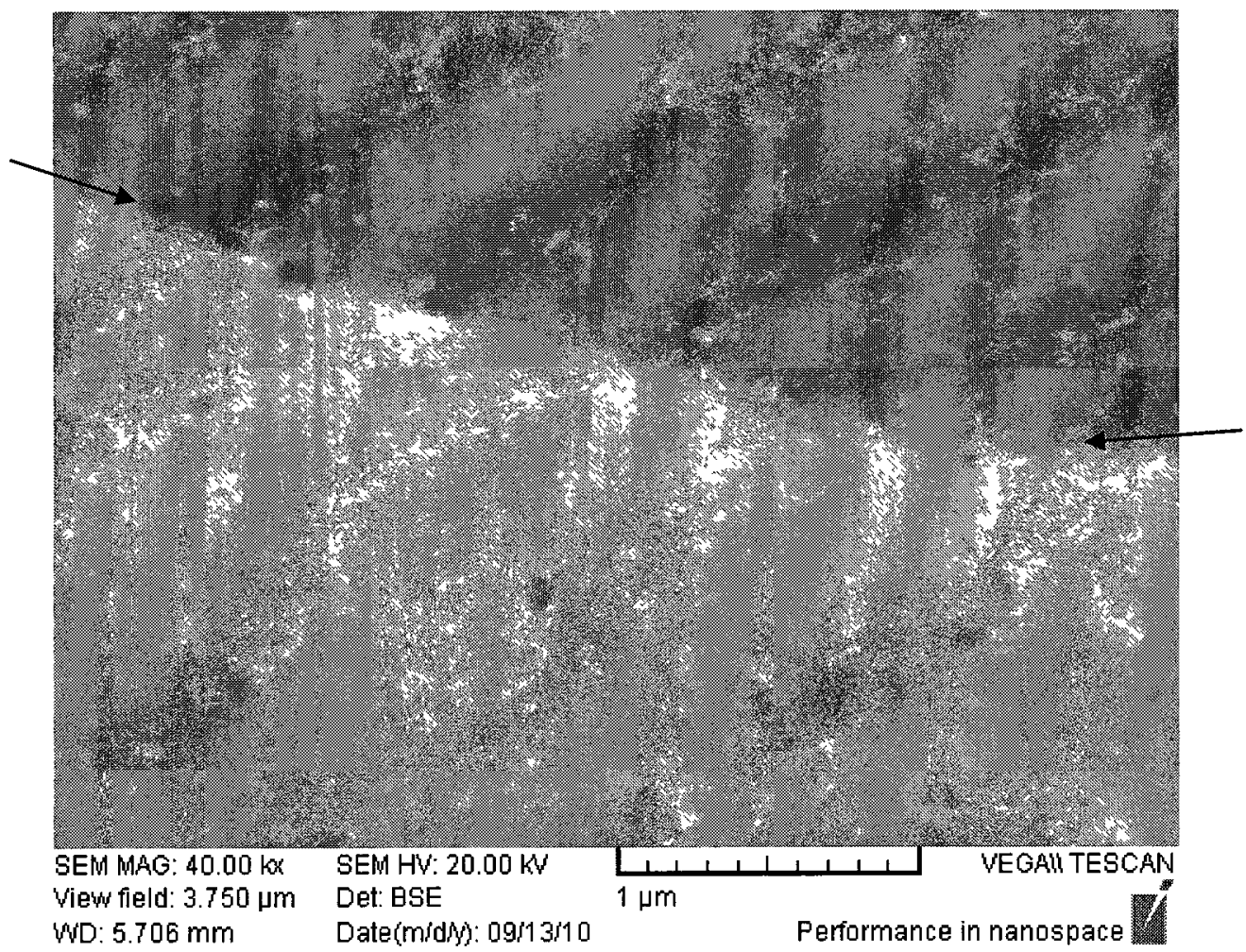

Figure 52: Grain boundary area in T651 bar at $40000 \mathrm{X}$ magnification 


\subsubsection{T73(51) Bar}

The microstructure of the T73(51) bar was also examıned at high magnificatıons to reveal the grain boundary structure Figure 53, Figure 54, Figure 55, and Figure 56 show typical grain boundary areas in the $T 73(51)$ bar at higher magnifications The graın boundaries are marked with black arrows and along the graın boundaries coarse, discontınuously distributed precıpitates can be seen Some of these grain boundary precıpıtates are indicated by red arrows in the figures All images are transverse sections

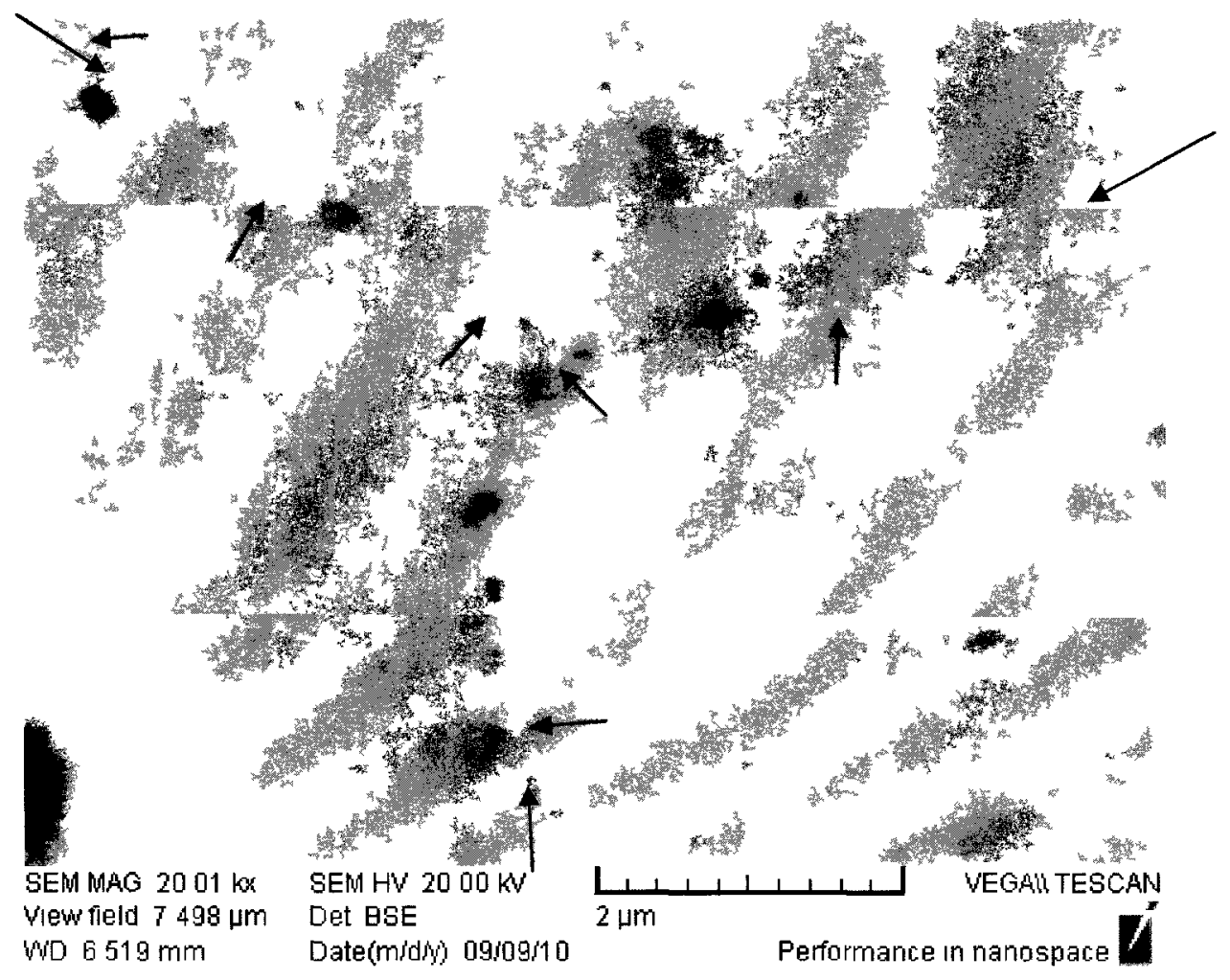

Figure 53 Graın boundary area in the T73(51) bar at 20000X magnification 


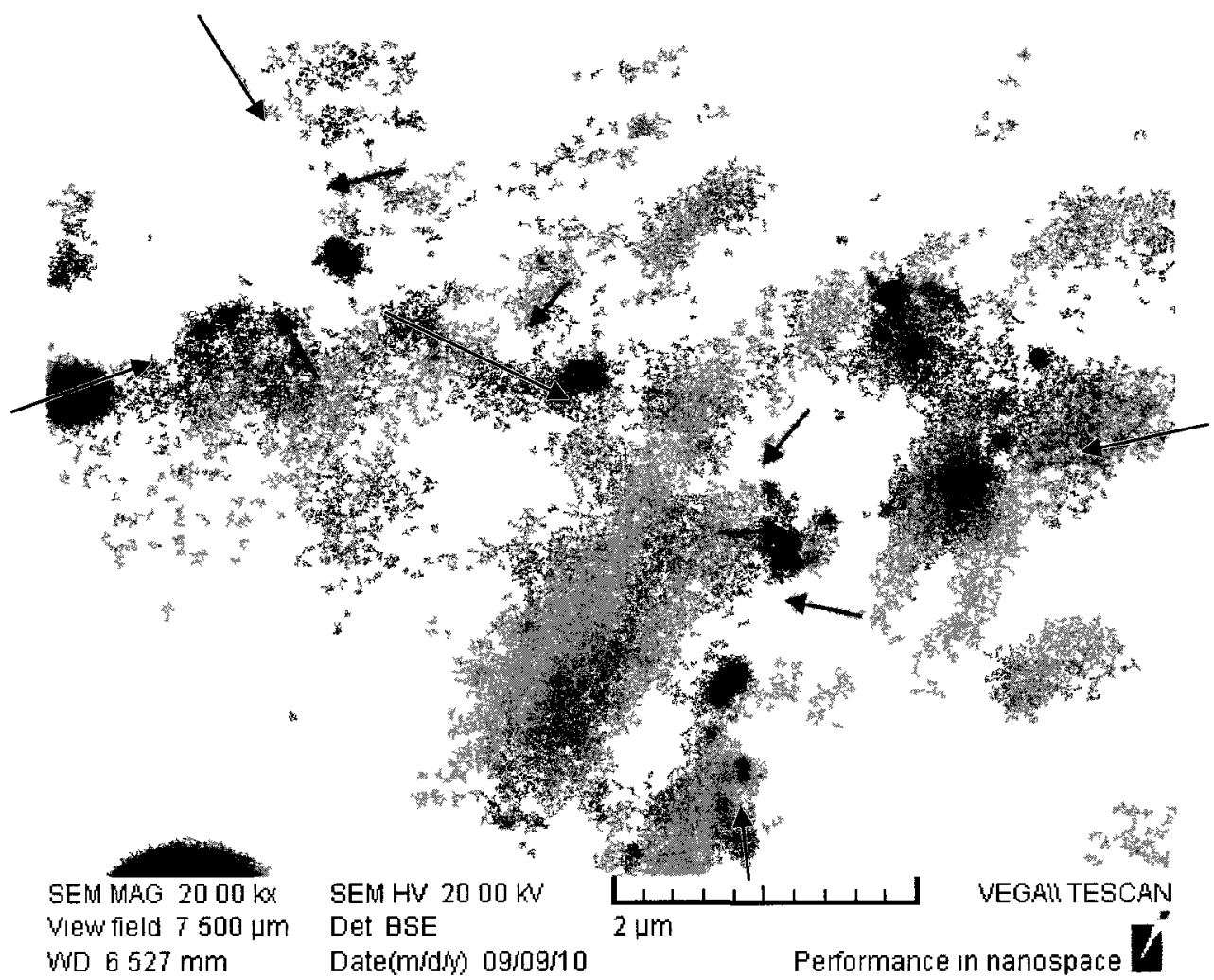

Figure 54 Graın boundary area in the T73(51) bar at 20000X magnification

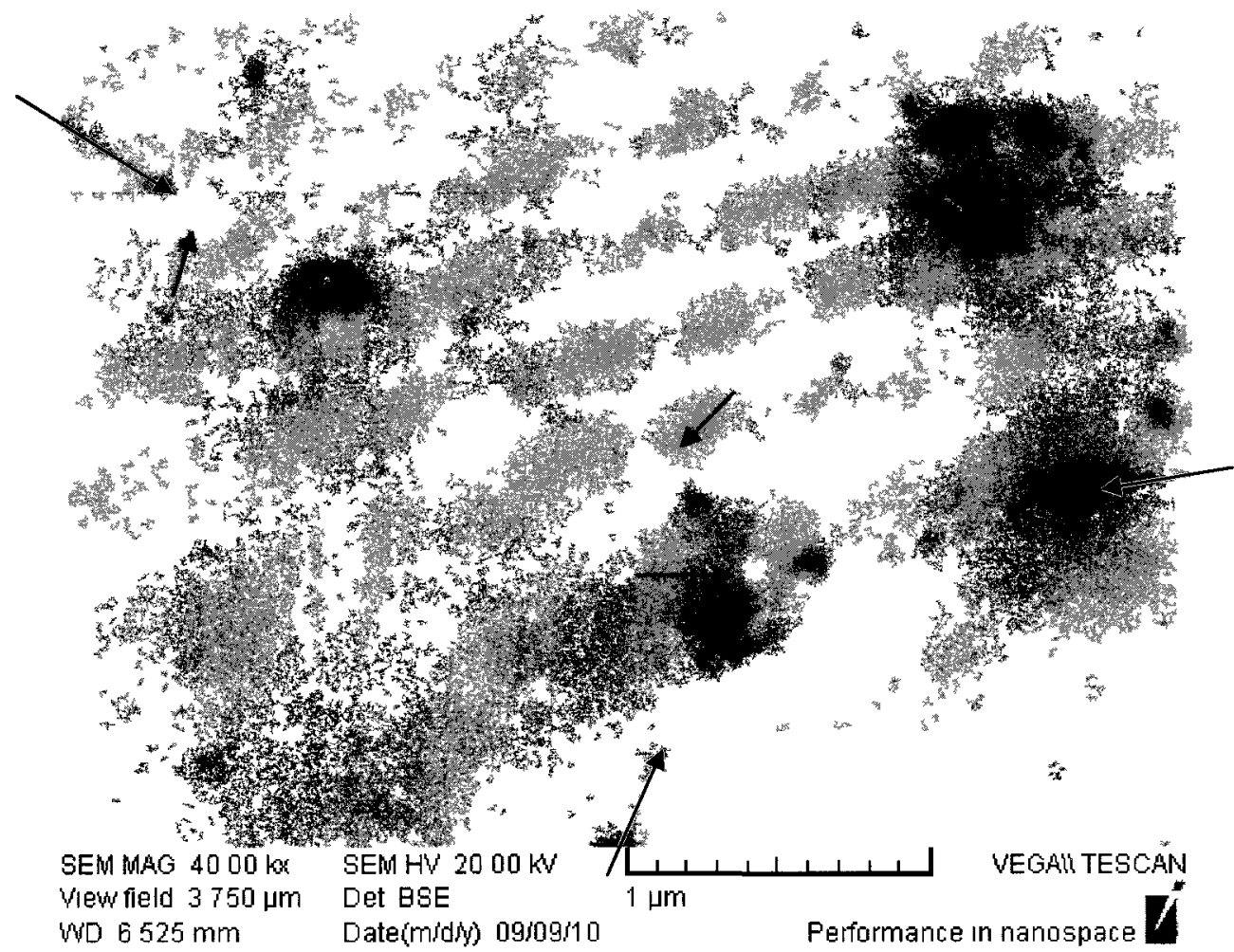

Figure 55 Graın boundary area in the T73(51) bar at 40000X magnification 


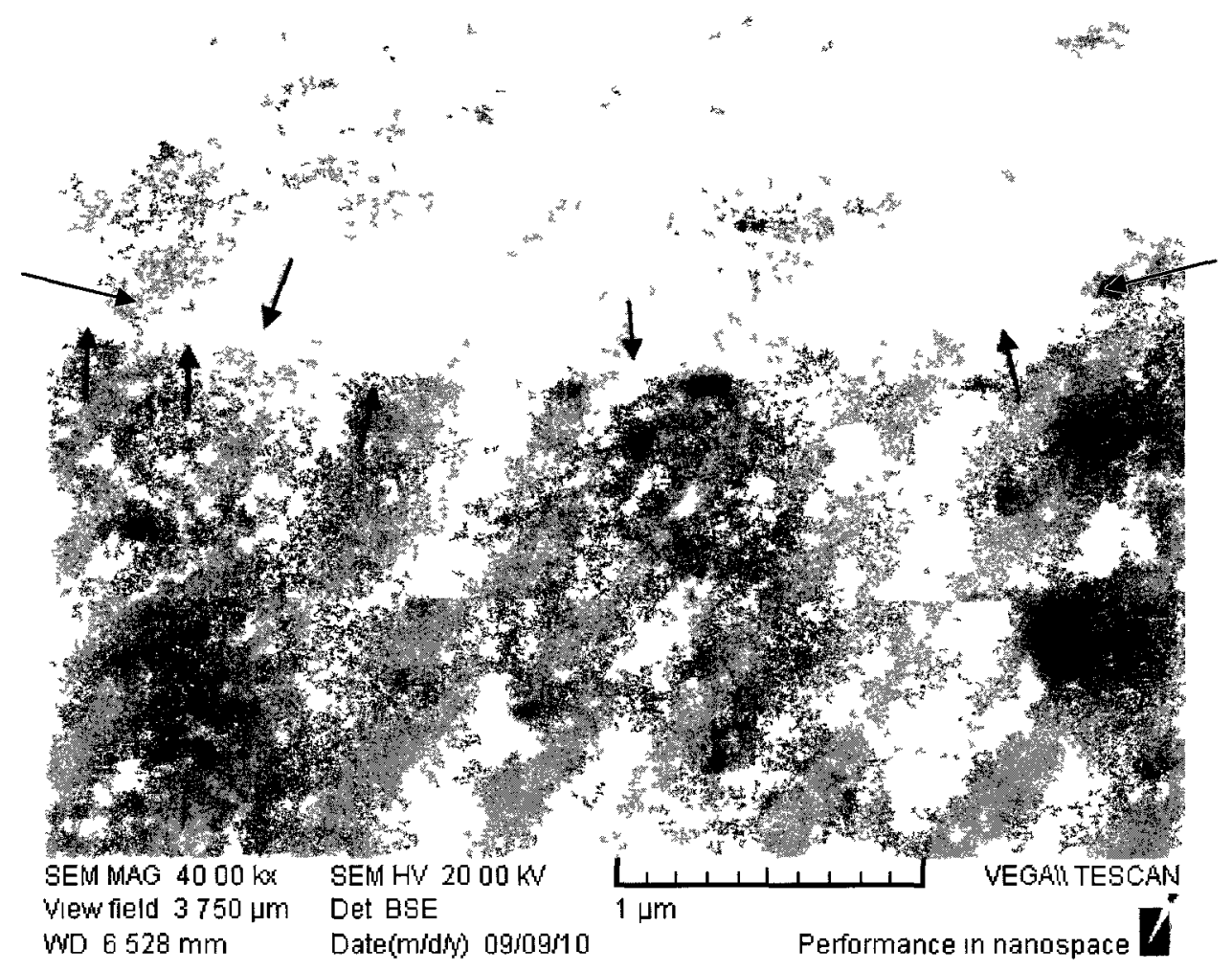

Figure 56: Grain boundary area in the T73(51) bar at 40000X magnification

\subsubsection{Experimental Tempers}

Some of the experimental tempers were examined to observe the microstructures resulting from these heat treatments. Again the grain boundary areas have been studied, and several images of transverse sections from the fully heat treated bar of tempers H495, H495-F400, and S495-F400 are shown in Figure 57 through Figure 62. The grain boundaries are indicated with black arrows in the figures. Note that similar coarse precipitates observed on the grain boundaries in Figure 53 through Figure 56 are not present in the following figures. This suggests that grain boundary precipitates are either not present in these experimental tempers, or they are too small to be visible at the magnifications employed. 


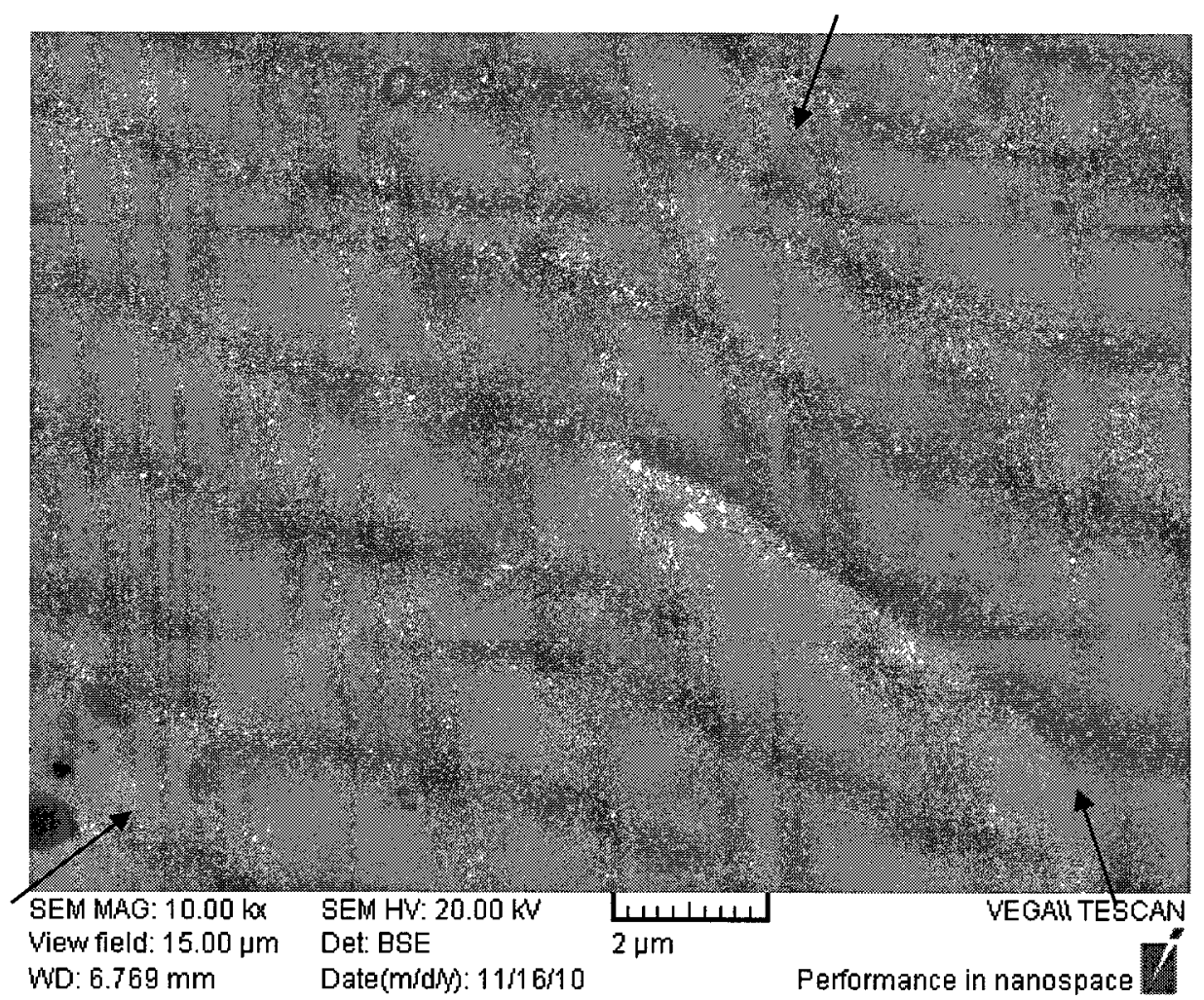

Figure 57: Grain boundary area in the $\mathrm{H} 495$ bar at $10000 \mathrm{X}$ magnification

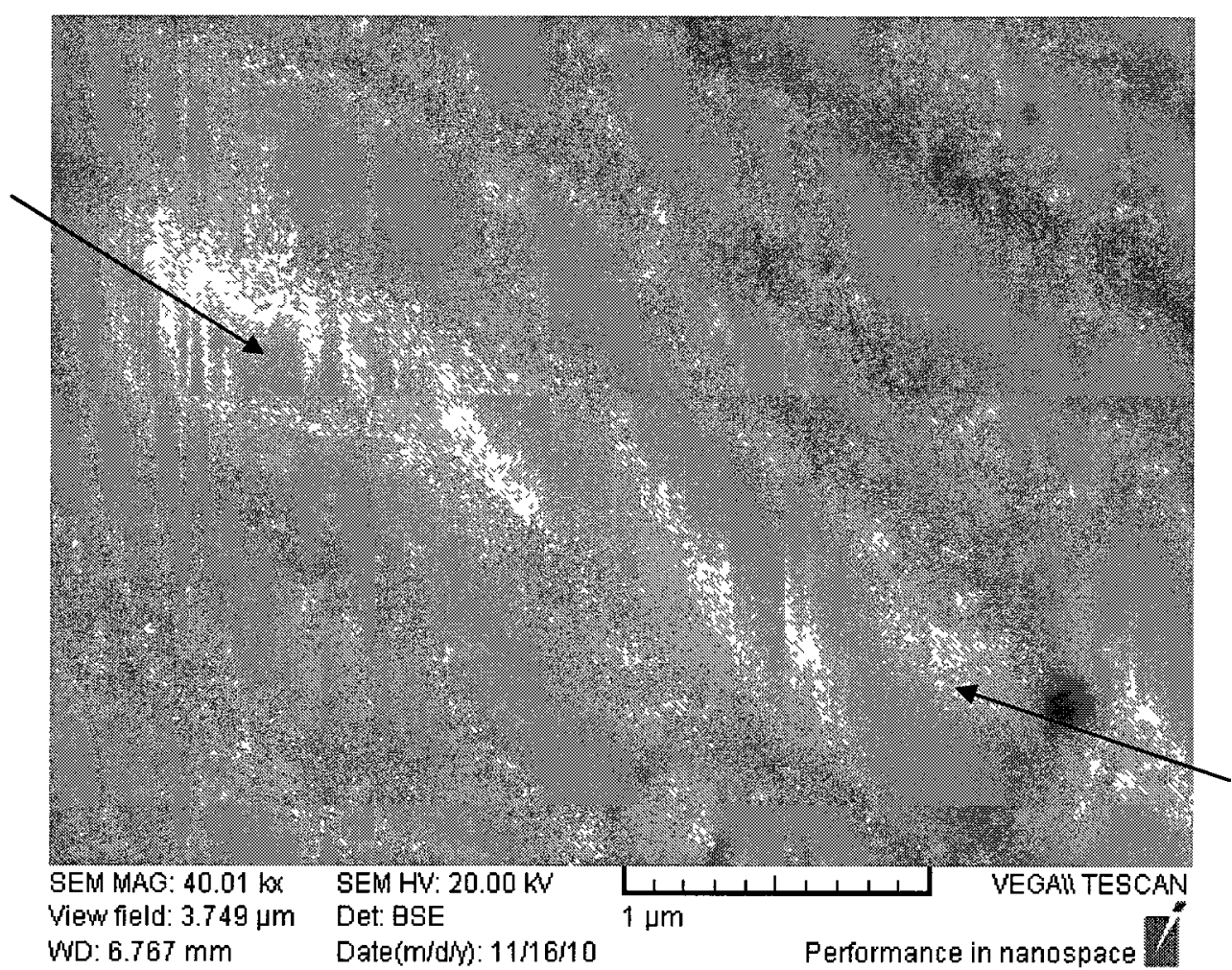

Figure 58: Grain boundary area in the $\mathrm{H} 495$ bar at $40000 \mathrm{X}$ magnification 


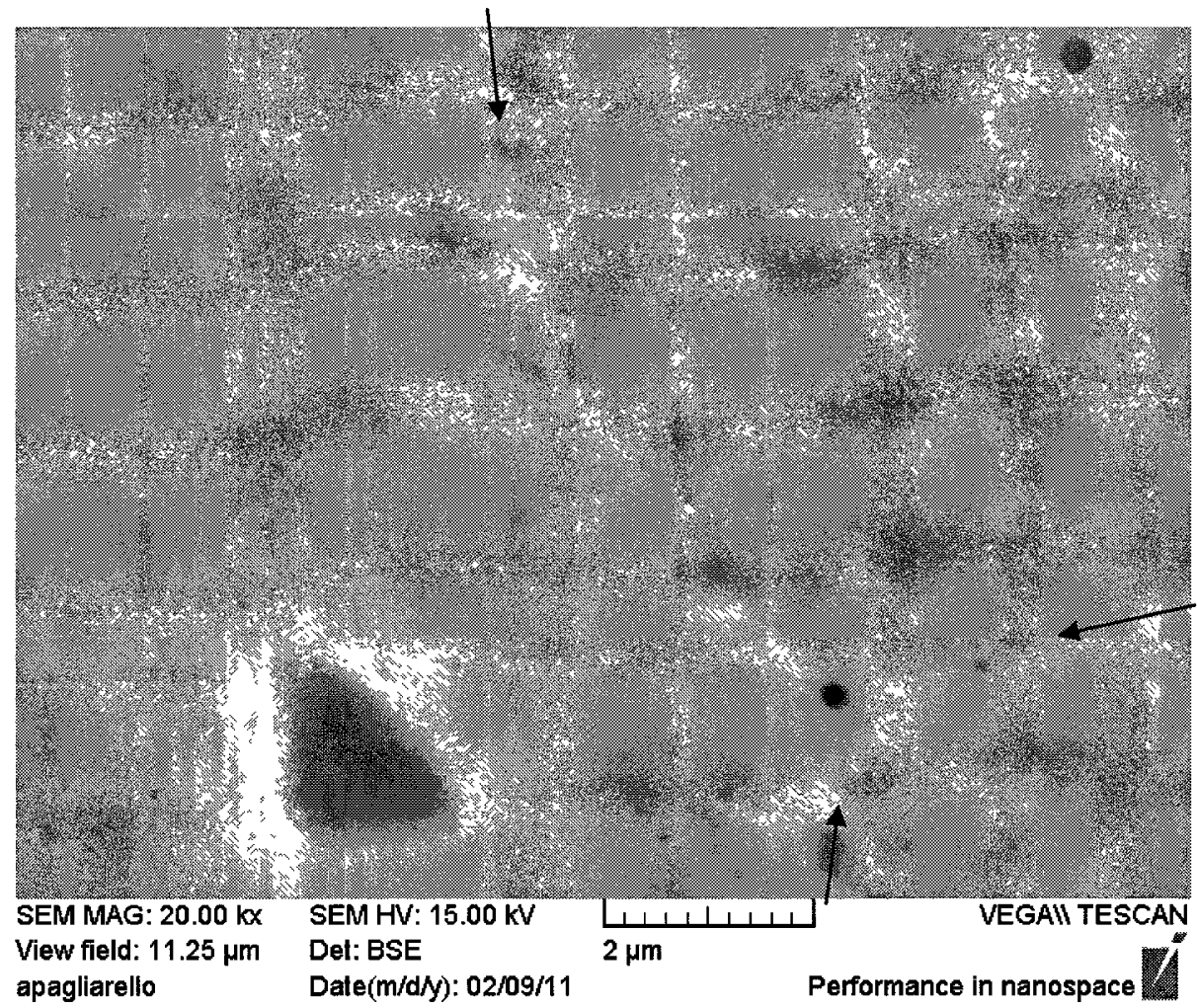

Figure 59: Grain boundary area in the H495-F400 bar at 20000X magnification

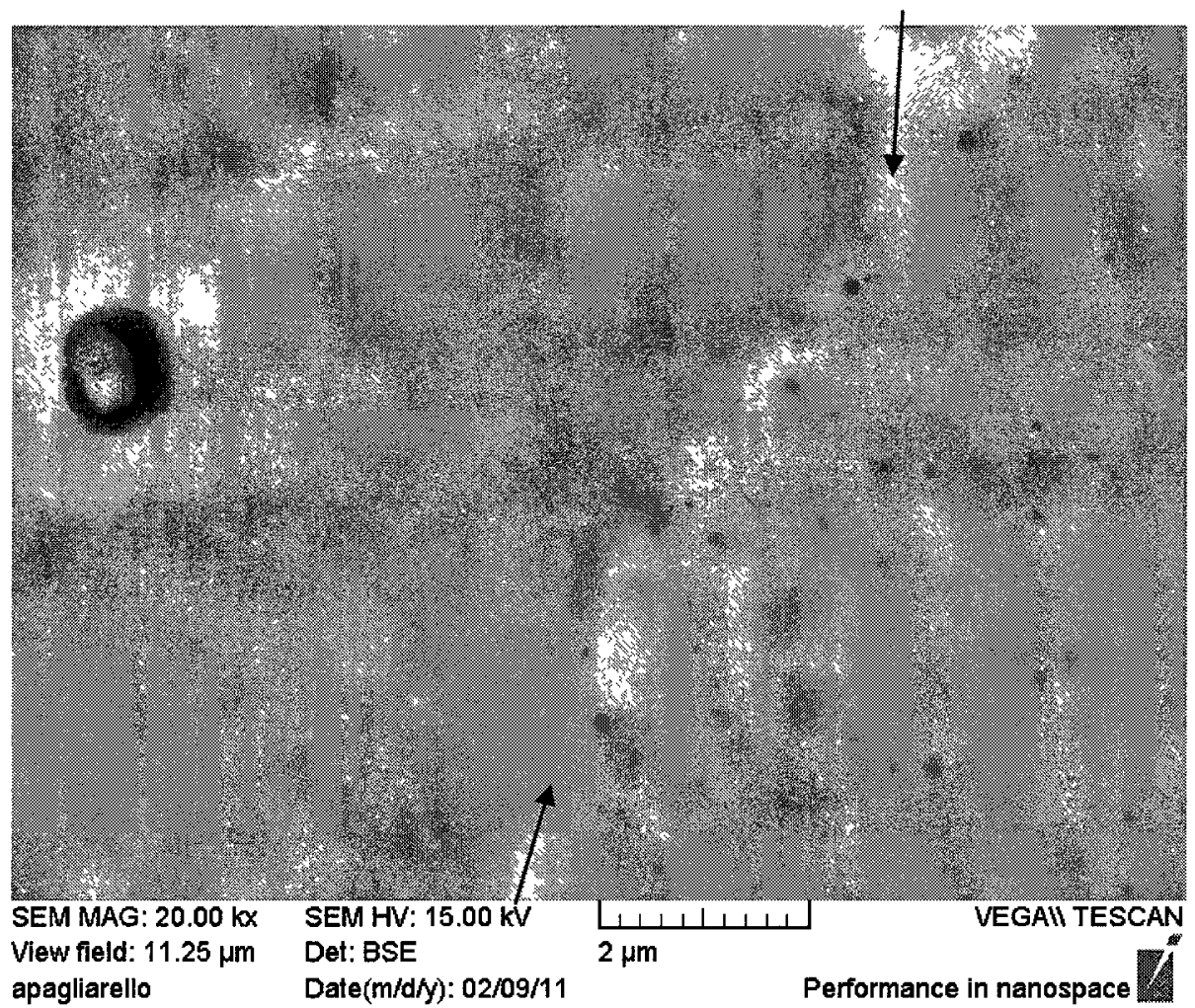

Figure 60: Grain boundary area in the $\mathrm{H} 495-\mathrm{F} 400$ bar at 20000X magnification 


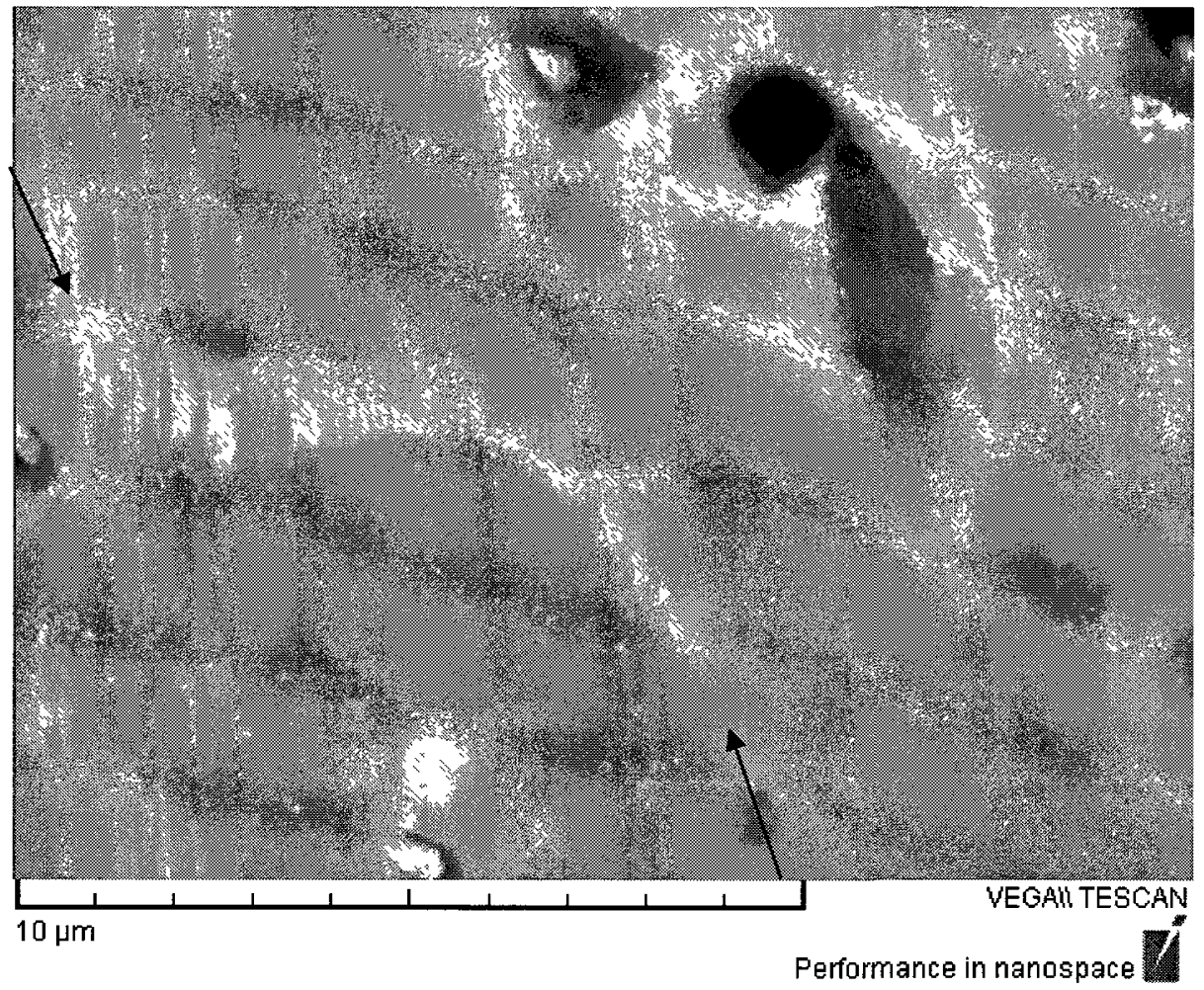

Figure 61: Grain boundary area in the $\$ 495-\mathrm{F} 400$ bar at $10000 \mathrm{X}$ magnification

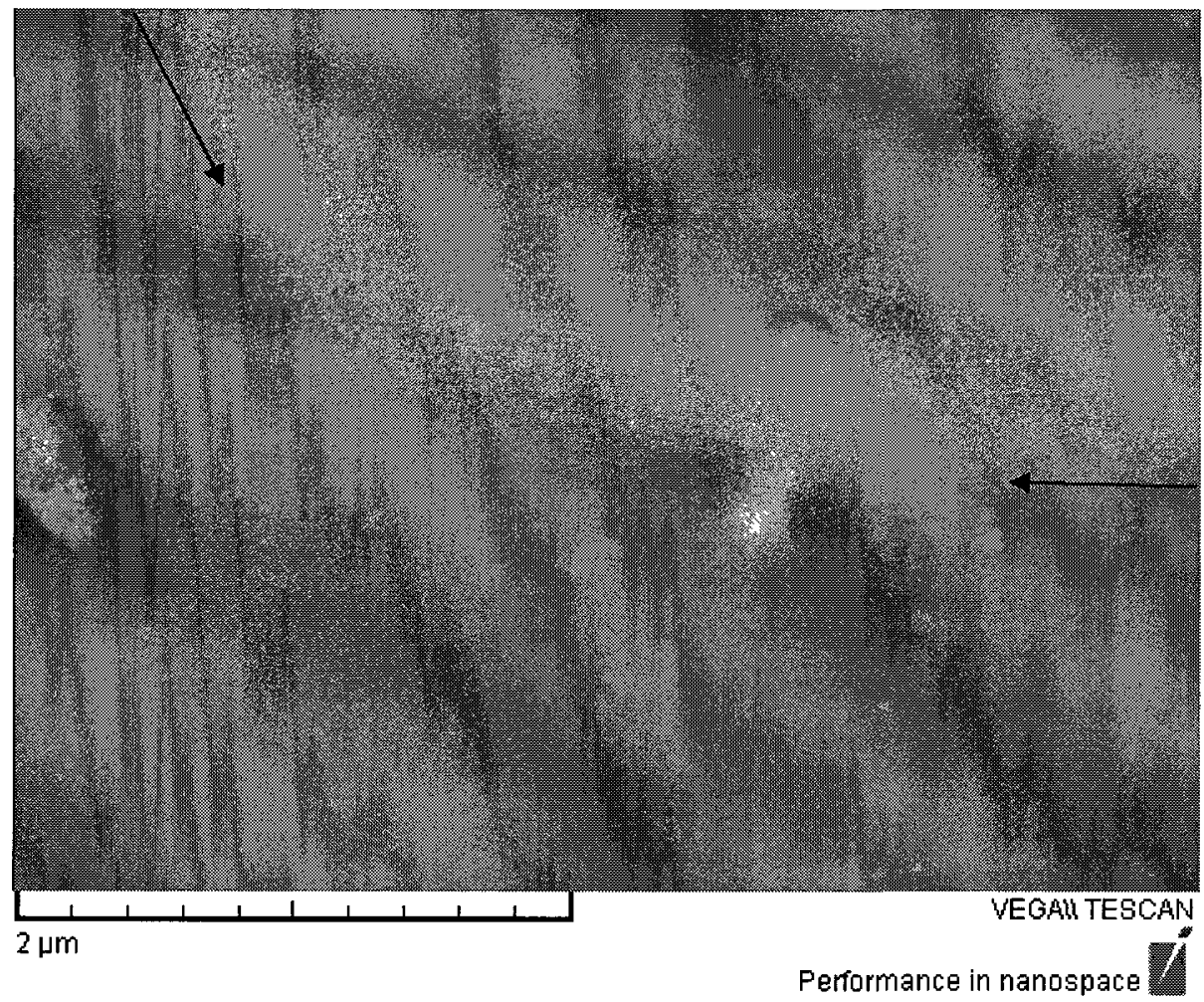

Figure 62: Grain boundary area in the $5495-\mathrm{F} 400$ bar at 35000X magnification 
Attempts were made to obtain high magnification images of the grain boundary areas in the L370 temper, but no grain boundaries could be found at lower magnifications. Several different levels of etching were used but all ultimately gave this same result. 


\section{Analysis and Discussion}

In all figures presented in this chapter where a solid or dashed line is present these lines represent the typical T6 and T73 values, respectively, for a given property. These typical values have been presented previously in Table 3.

\subsection{Effects of Variation in Solution Heat Treatment on Mechanical Properties and Electrical Conductivity}

\subsubsection{Effect of Cooling Rate during HTPP}

Figure 63, Figure 64, and Figure 65 show the variation in the hardness, yield strength, and EC, respectively, of the $F, M$, and $L$ series tempers as a function of the cooling rate applied durıng the HTPP portion of the solution heat treatment.

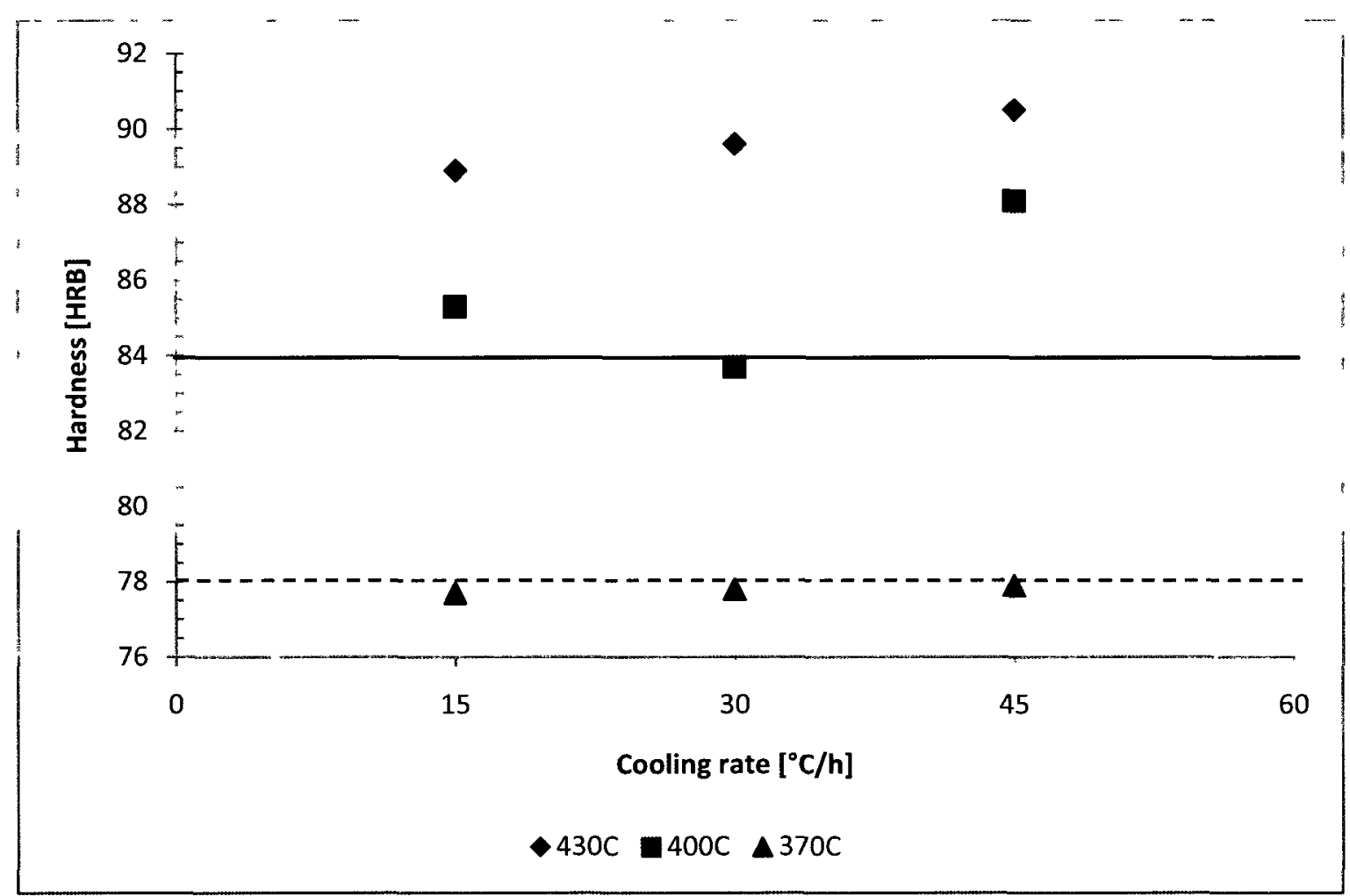

Figure 63: Hardness as a function of cooling rate in the $F, M$, and $L$ series tempers 


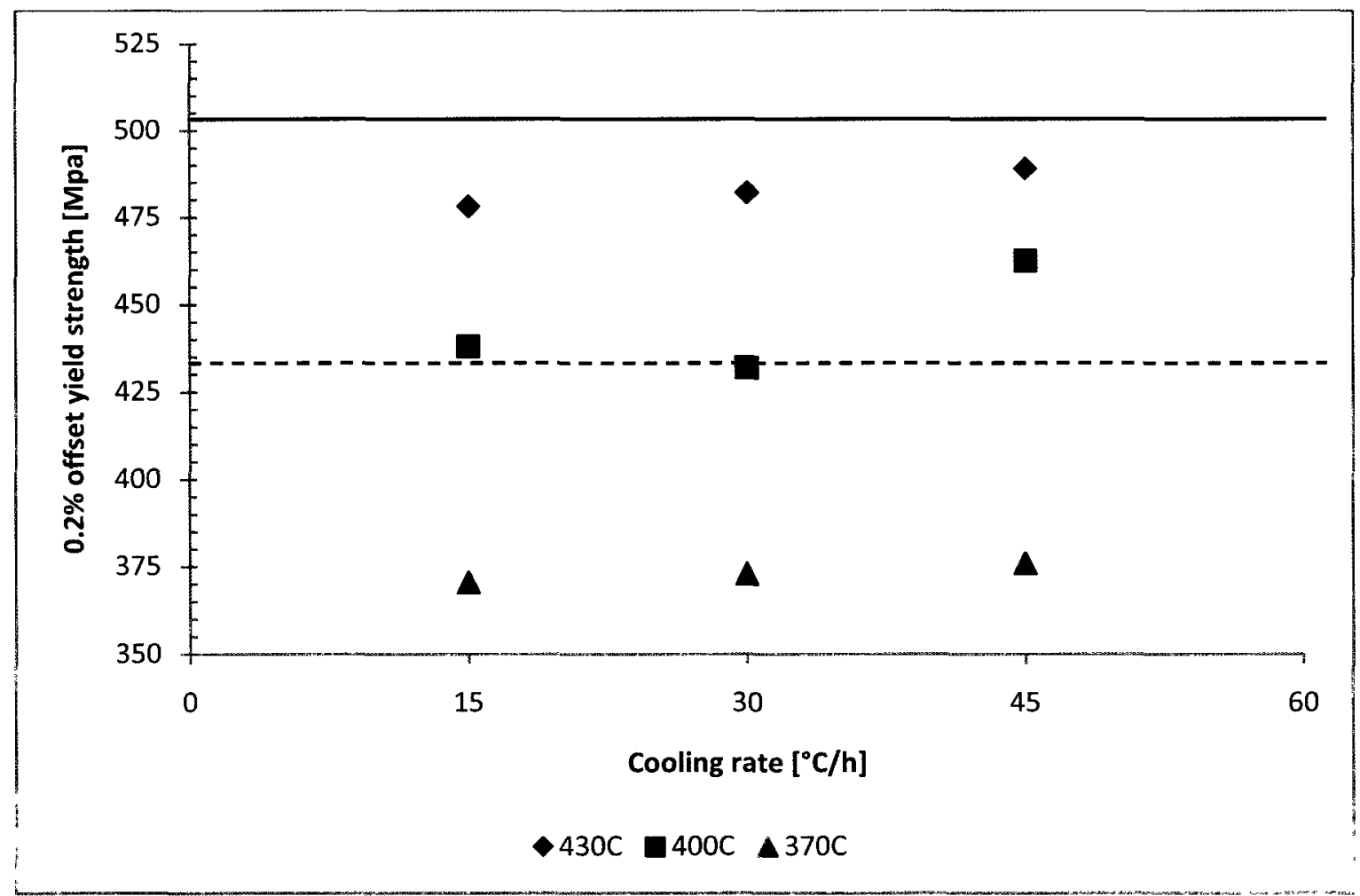

Figure $64: 0.2 \%$ offset yield strength as a function of cooling rate for the $F, M$, and $L$ series tempers

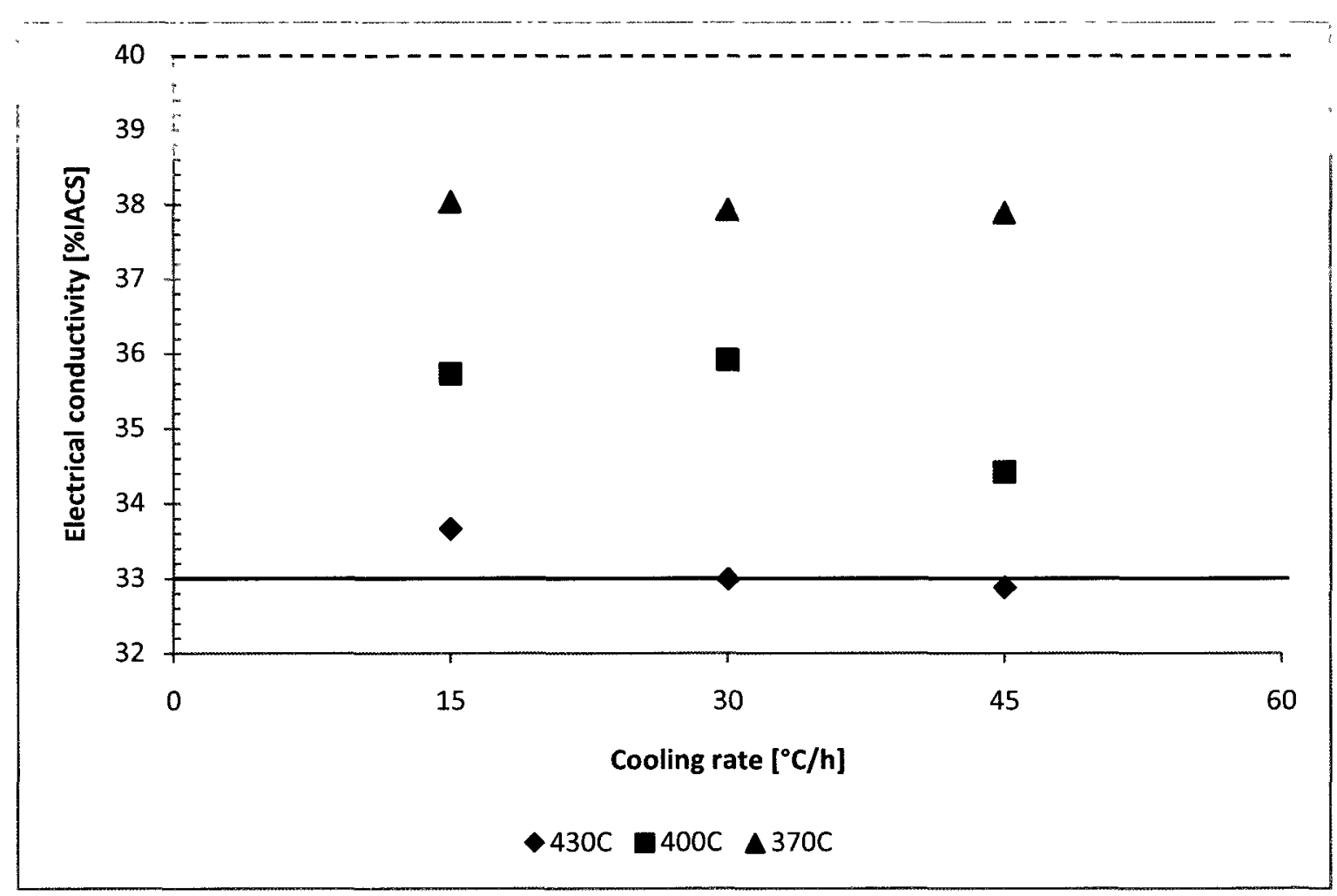

Figure 65: Electrical conductivity as a function of cooling rate for the $F, M$, and $L$ series tempers 
From these figures it is apparent that variation of the cooling rate in the range from $15^{\circ} \mathrm{C} / \mathrm{h}$ to $45^{\circ} \mathrm{C} / \mathrm{h}$ results in little change in any of these properties; however, these figures also demonstrate that the final temperature of the solution heat treatment has a significant effect on the mechanical properties and EC in these tempers.

\subsubsection{Effect Final Temperature during HTPP}

Figure 66, Figure 67, and Figure 68 show the variation in hardness, yield strength, and EC, respectively, for the $F, M$, and $L$ series tempers as a function of the final temperature of the solution heat treatment.

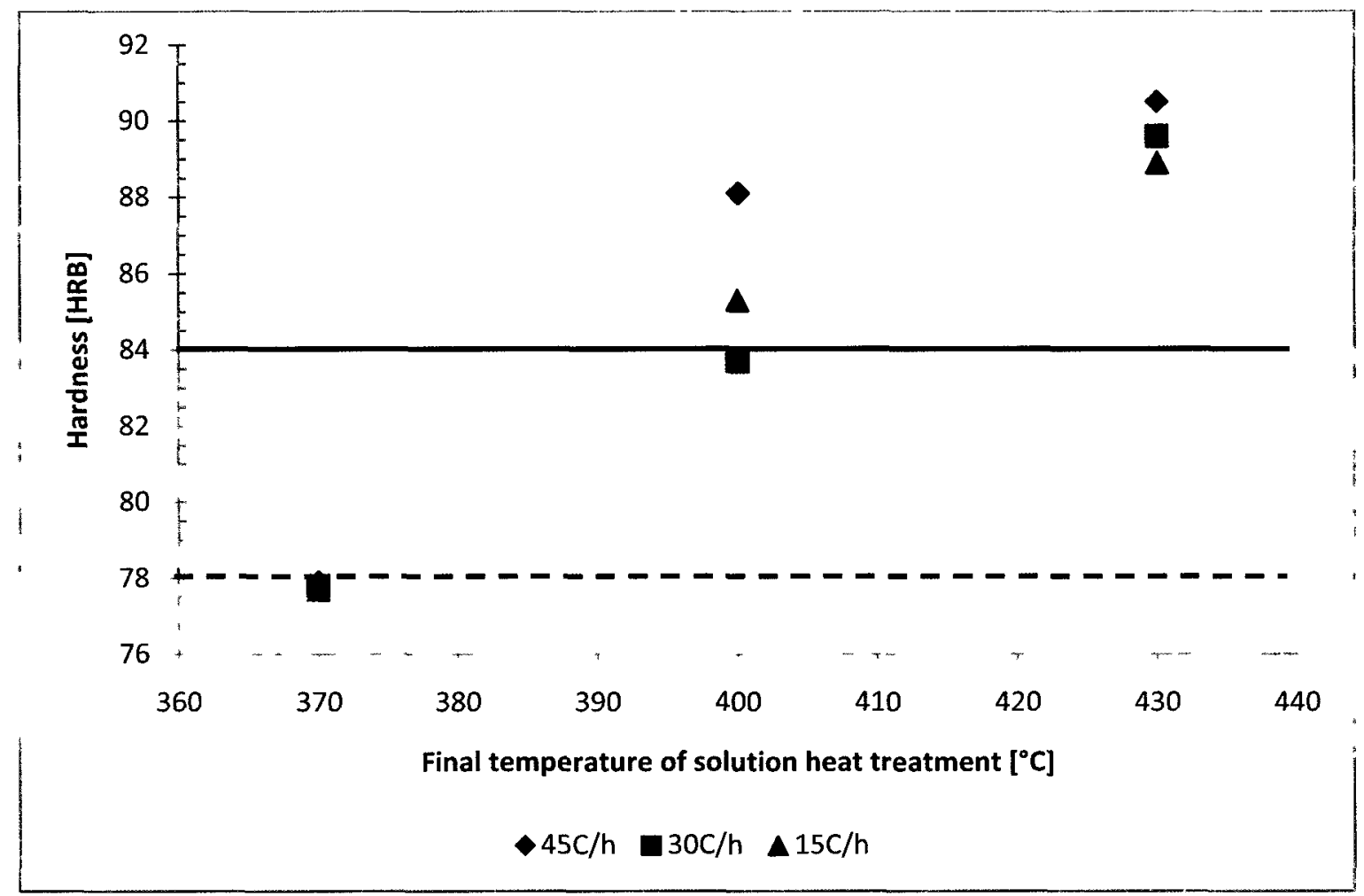

Figure 66: Hardness as a function of final temperature of solution heat treatment for $F, M$, and $L$ series tempers 


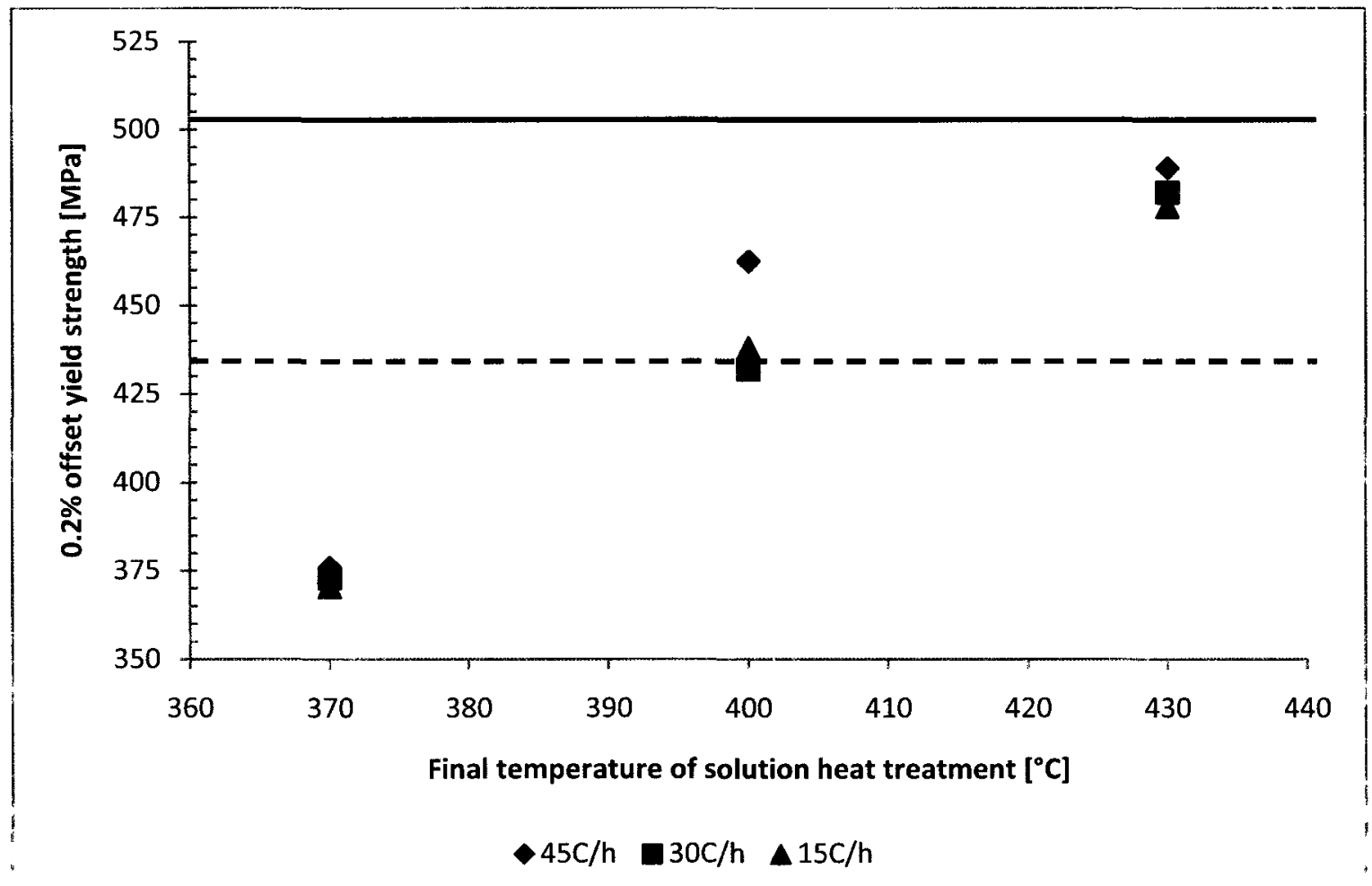

Figure 67: Yield strength as a function of final temperature of solution heat treatment for $F, M$, and $L$ series tempers

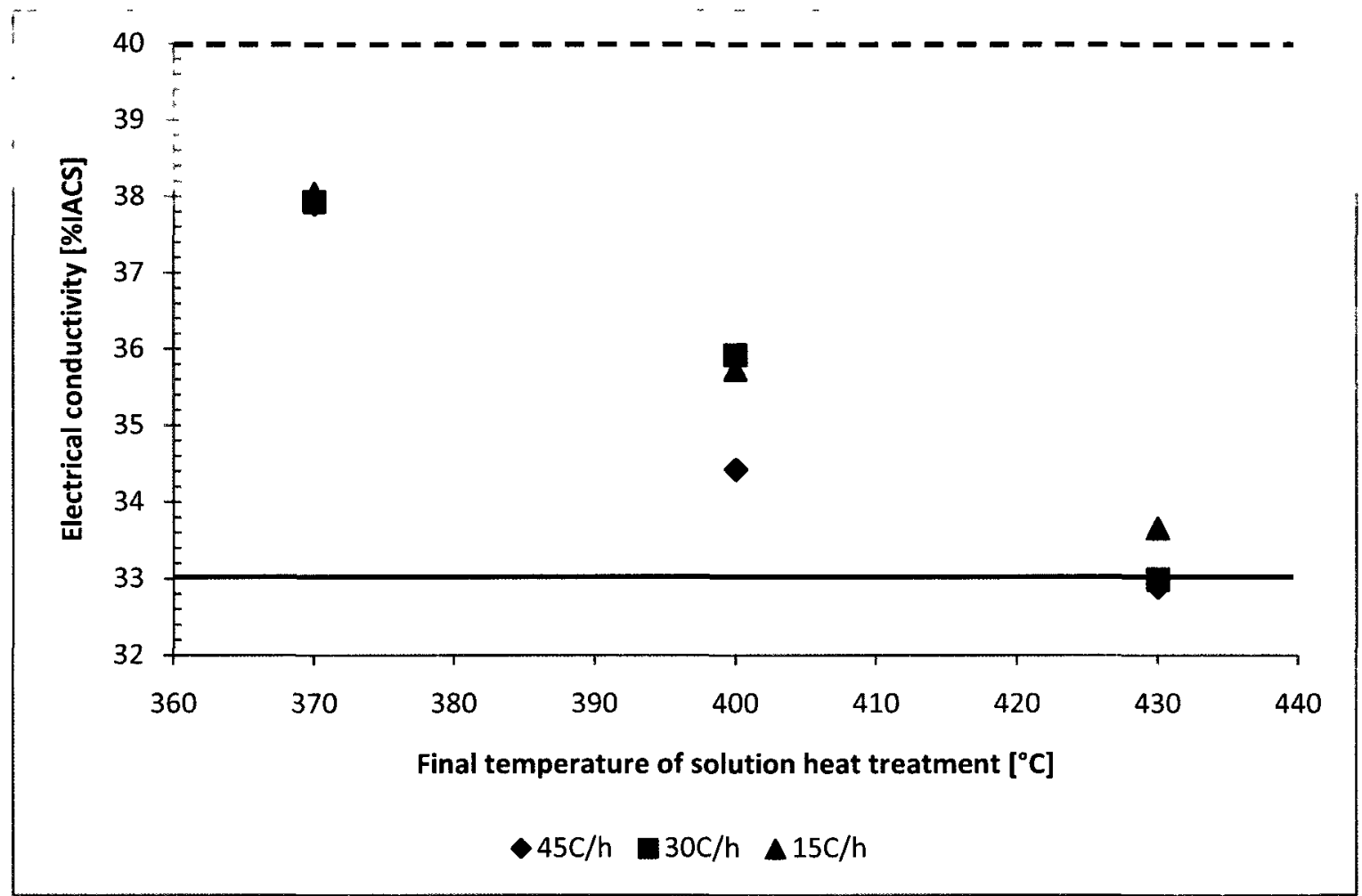

Figure 68: Electrical conductivity as a function of final temperature of solution heat treatment for $F, M$, and $L$ series tempers 
It is evident from these figures that the mechanical properties of all tempers cooled to $370^{\circ} \mathrm{C}$ prior to quenching are drastically reduced and the EC of these tempers is significantly increased. The mechanical properties of the tempers cooled to $400^{\circ} \mathrm{C}$ are also degraded and the EC of these tempers is higher than that of the tempers cooled to $430^{\circ} \mathrm{C}$. This degradation of mechanical properties, and higher EC, is interpreted to be due to the depletion of solute from the matrix during the HTPP portion of the solution heat treatment by the precipitation of the $\eta$ phase since the final temperatures of $400^{\circ} \mathrm{C}$ and $370^{\circ} \mathrm{C}$ are below the solvus temperature of 420 to $445^{\circ} \mathrm{C}$. The matrix solute content has been reduced, considerably in the case of the tempers cooled to $370^{\circ} \mathrm{C}$, by this precipitation, so less solute is available for the formation of the strengthening phases, GP zones and $\eta^{\prime}$, during subsequent ageing.

Figure 69, Figure 70, and Figure 71 show the variation in hardness, yield strength, and EC, respectively, for the various tempers cooled at $45^{\circ} \mathrm{C} / \mathrm{h}$ as a function of the final temperature of the solution heat treatment.

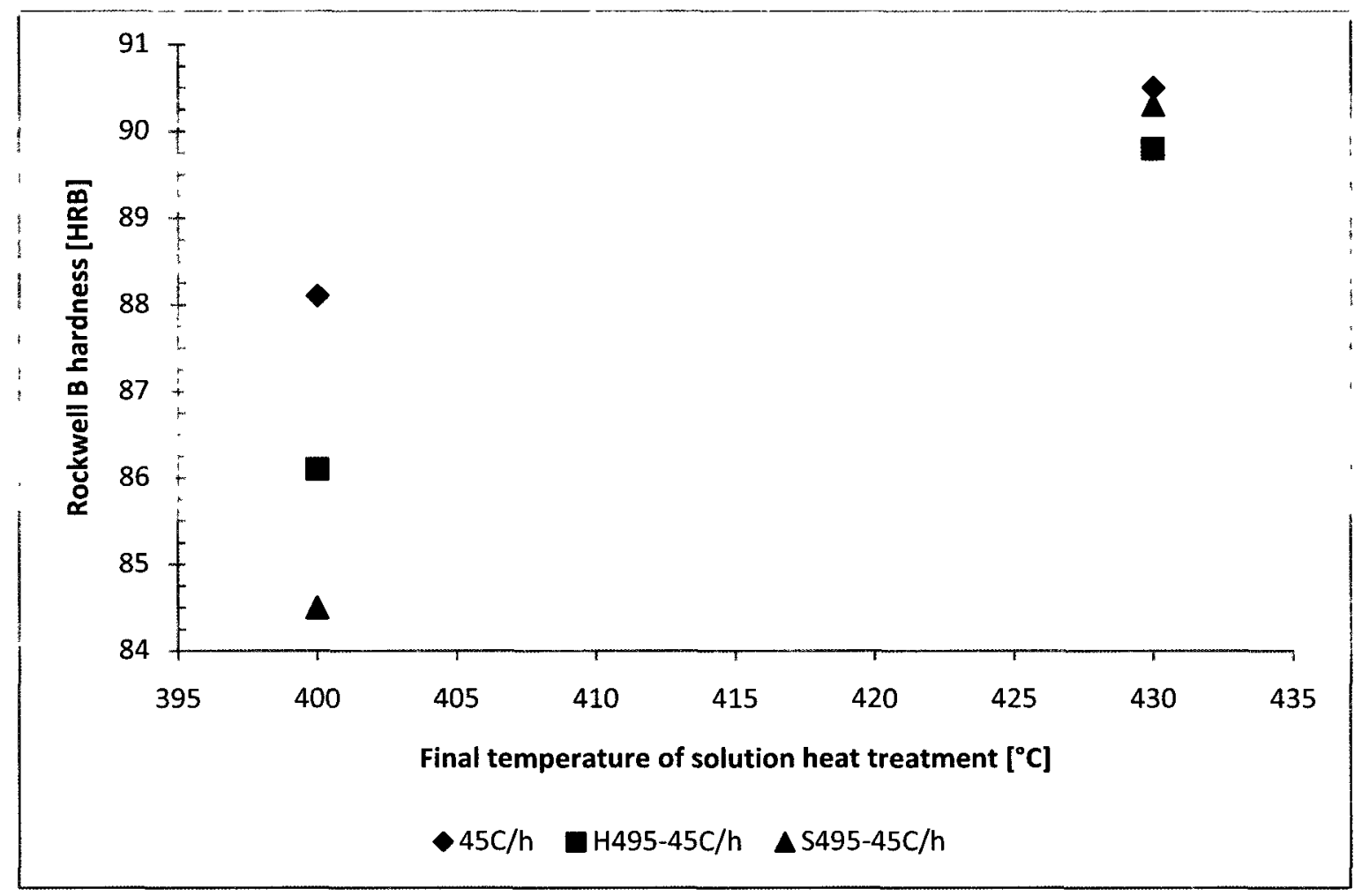

Figure 69: Hardness as a function of final temperature of solution heat treatment for tempers cooled at $45^{\circ} \mathrm{C} / \mathrm{h}$ 


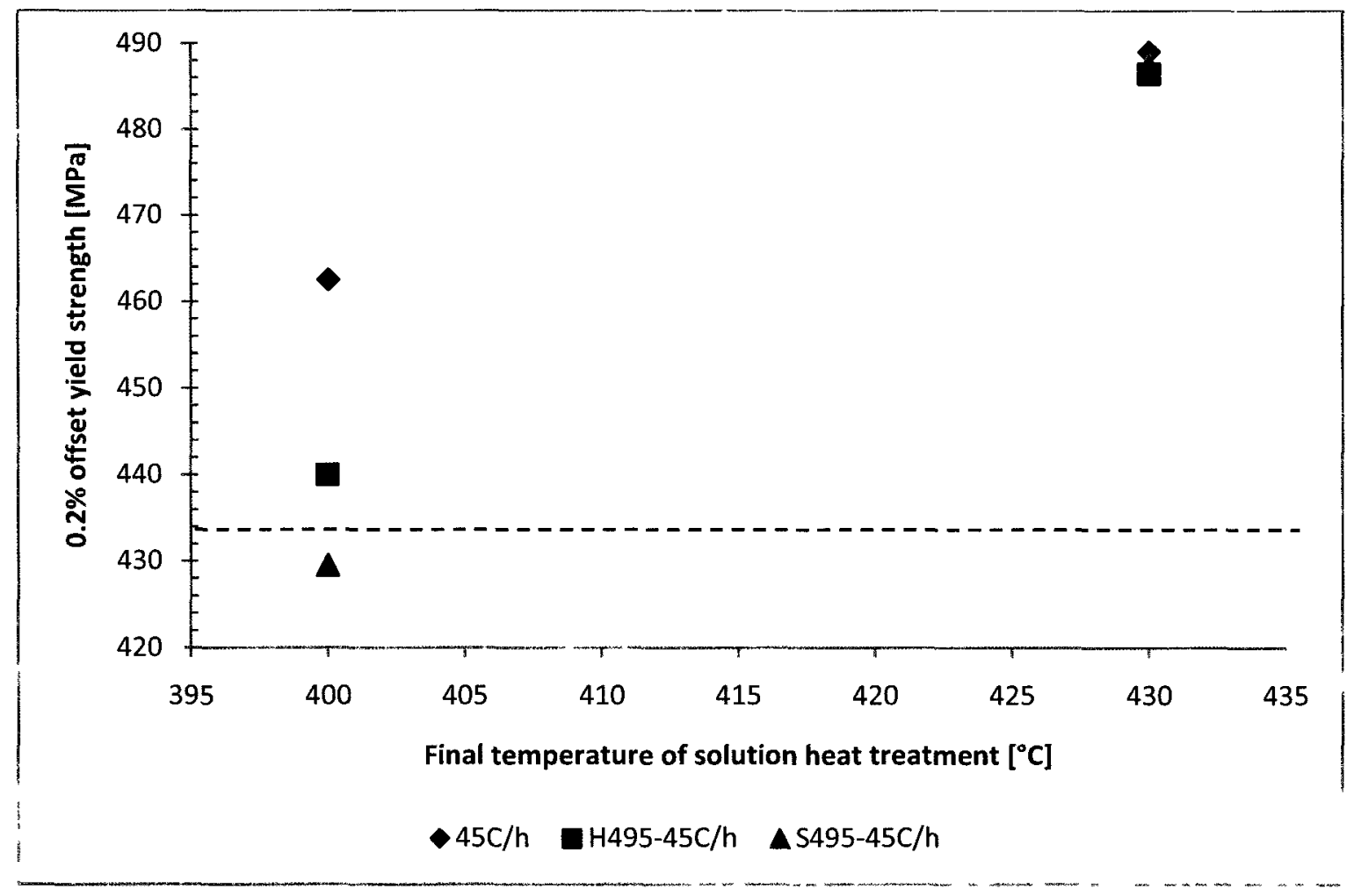

Figure 70: $0.2 \%$ offset yield strength as a function of final temperature of solution heat treatment for tempers cooled at $45^{\circ} \mathrm{C} / \mathrm{h}$

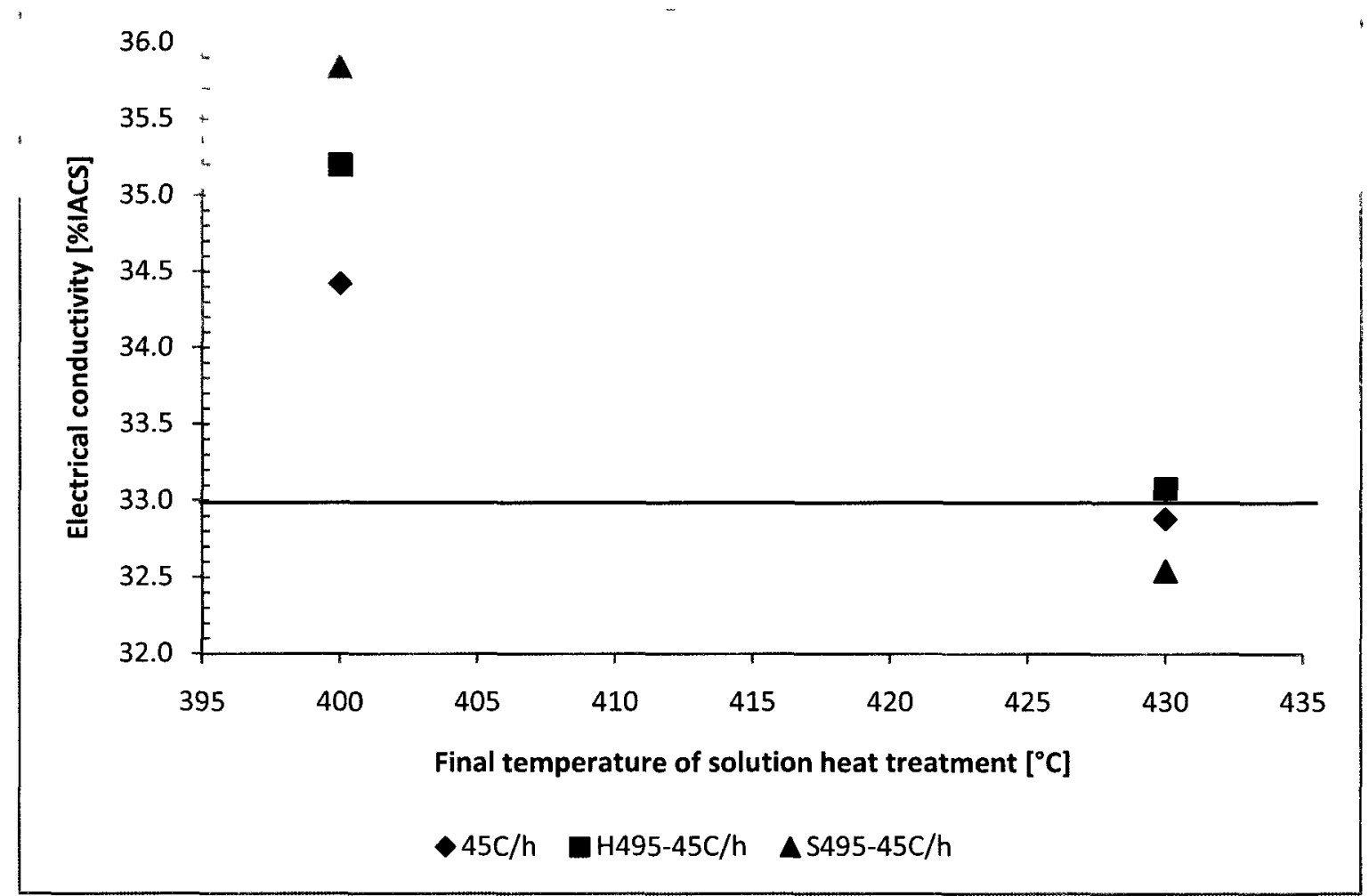

Figure 71: Electrical conductivity as a function of final temperature of solution heat treatment for tempers cooled at $45^{\circ} \mathrm{C} / \mathrm{h}$ 
The first observation that can be made from Figure 69 and Figure 70 is that the mechanical properties are improved by cooling to $430^{\circ} \mathrm{C}$ compared to $400^{\circ} \mathrm{C}$. Cooling to $430^{\circ} \mathrm{C}$ prior to quenching does not allow for precipitation of the $\eta$ phase during the HTPP treatment since the entire solution heat treatment is either above the solvus temperature or the undercooling is too small to provide the required driving force for precipitation, given that the solvus is thought to be between 420 and $445^{\circ} \mathrm{C}$. During the subsequent ageing treatment, the conditions cooled to $430^{\circ} \mathrm{C}$ will follow the typical precipitation sequence outlined in section 2.2 .1 , so primarily strengthening GP zones and n' precipitates will be developed in these tempers; however, the tempers cooled to $400^{\circ} \mathrm{C}$ will have already nucleated some $\eta$ phase directly during the HTPP treatment, so they will develop fewer GP zones and $\eta^{\prime}$, due to the depletion of solute in the matrix, and the existing $\eta$ precipitates will be coarsened during ageing resulting in reduced strength.

Figure 71 illustrates the increase in EC that results from a lower final temperature of the solutionizing treatment. The lower EC of the tempers cooled to $430^{\circ} \mathrm{C}$ is due to two factors. First, solute depletion from the matrix caused by the precipitation of $\eta$ during cooling will occur in the tempers cooled to $400^{\circ} \mathrm{C}$, while the tempers cooled to $430^{\circ} \mathrm{C}$ will have retained a higher matrix solute content. Second, the precipitates nucleated during ageing in the tempers cooled to $430^{\circ} \mathrm{C}$ will be GP zones or $\eta^{\prime}$ which have a coherent or semicoherent interface with the matrix, respectively. Both of these factors serve to depress the EC of the alloy according to [23].

\subsubsection{Effect of Increased Solution Heat Treatment Temperature}

Figure 72 and Figure 73 show a comparison of the yield strength and hardness, respectively, for the T651, T6*, S495, H480, and H495 tempers. 


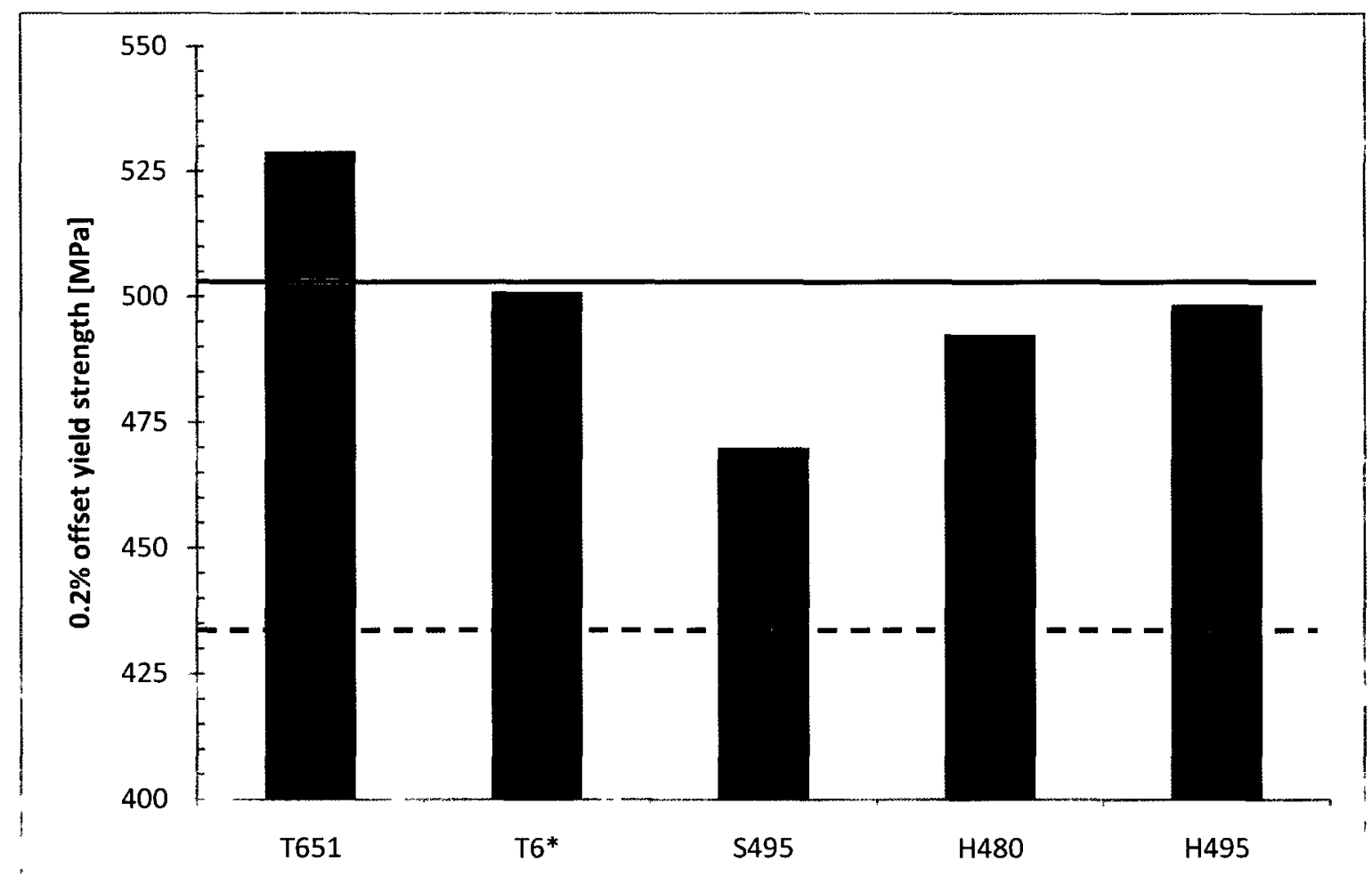

Figure 72: Comparison of yield strengths of $\mathrm{T} 651, \mathrm{~T} 6^{*}, \mathrm{~S} 495, \mathrm{H} 480$, and $\mathrm{H} 495$ tempers

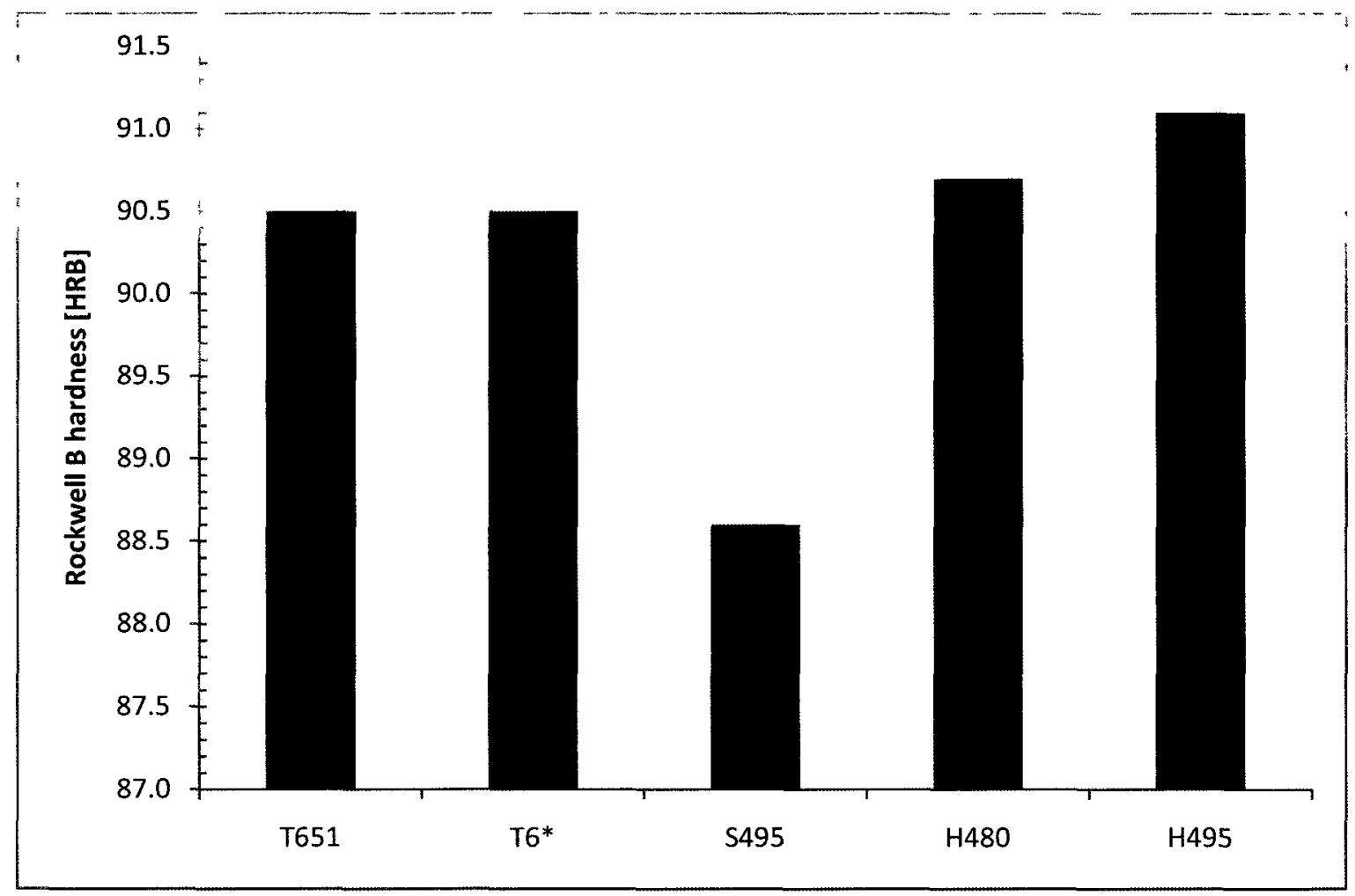

Figure 73: Comparison of hardness of T651, T6*, S495, H480, and H495 tempers 
From Figure 72, it is apparent that the yield strength of all three experimental tempers is below that of the T6 from the reference and the T6* and T651 tested, but this disagrees with what is published in the literature. Data for Al alloys 2024 and 6061 solution heat treated at various temperatures show an increase in both the yield strength and UTS after ageing with increasing solutionizing temperature [45]. Based on these trends in the other two series of precipitation hardenable Al alloys, the $2 X X X$ and $6 X X X$ series, it is logical to assume that the 7XXX series alloys should exhibit a similar tendency. Solutionizing at a higher temperature should result in higher strength, given the same ageing treatment, due to the higher rate of GP zone formation at vacancies as discussed in section 2.2.1. The solution heat treatment temperature of the T6 temper is $465^{\circ} \mathrm{C}$ while the maximum temperature of the solution heat treatments for the $S$ and $\mathrm{H}$ series tempers was in the range from 480 to $495^{\circ} \mathrm{C}$; however, the yield strength of the $\mathrm{S}$ and $\mathrm{H}$ series were below the T6. Within the $H$ series tempers, the proposed trend does exist as the H495 condition has slightly higher yield strength than the H480 temper, but the S495 temper exhibits much lower strength than either of the $\mathrm{H}$ series tempers.

One possible explanation for these results is that some incipient melting may have occurred in the $\mathrm{S}$ and $\mathrm{H}$ series specimens. As discussed in section 2.1.2, the solidus temperature for 7075 may be as low as $477^{\circ} \mathrm{C}$ for material that is not well homogenized. While all of the material used in this study had been previously solution heat treated, and presumably homogenized as well, there still exists the possibility that some small amount of melting may have occurred in these conditions due to the application of a maximum solution heat treatment temperature of $495^{\circ} \mathrm{C}$. In the data presented in [45], none of the solution heat treatment temperatures exceeded the minimum solidus temperatures for 2024 or 6061 , so there is no chance that melting could have occurred in these specimens.

The theory that incipient melting may have occurred may also explain the discrepancy between the yield strength and hardness results for the $H$ series and T6 tempers. Figure 73 shows that the $\mathrm{H}$ series tempers exhibited hardness above that measured for the T6* and T651 tempers while the yield strengths of the T6-type tempers were higher than those of the $\mathrm{H}$ series. This suggests that the higher solution heat treatment temperatures may have indeed resulted in increased precipitation of the strengthening phases in the matrix during ageing, but any incipient melting that may have occurred may have detrimentally affected the strength of certain regions in the material. Since hardness indentation results in very localized deformation any reduction in strength due to incipient melting may have had a significantly reduced effect on the hardness results compared to the tensile results.

The effects of any incipient melting may have been alleviated somewhat in the $\mathrm{H}$ series tempers compared to the $\$ 495$ temper due to the period of lower temperature solution heat treatment and the slow rate of heating to the maximum temperature applied to the $\mathrm{H}$ series. This first stage of the $\mathrm{H}$ series solution heat treatments may have imparted some homogenizing effect that the $\mathbf{S} 495$ temper did not experience, so the likelihood of more extensive incipient melting occurring was higher in the $\$ 495$ temper. This may have ultimately resulted in the degraded yield strength and hardness of this temper compared to the $\mathrm{H}$ series, T6*, and T651 tempers. 


\subsubsection{Change in Hardness and Electrical Conductivity with Ageing}

The hardness and EC of all experimental tempers increased from before to after the application of the ageing treatment. Figure 74 and Figure 75 illustrate this change for the tensile and DB specimen blanks of the experimental tempers.

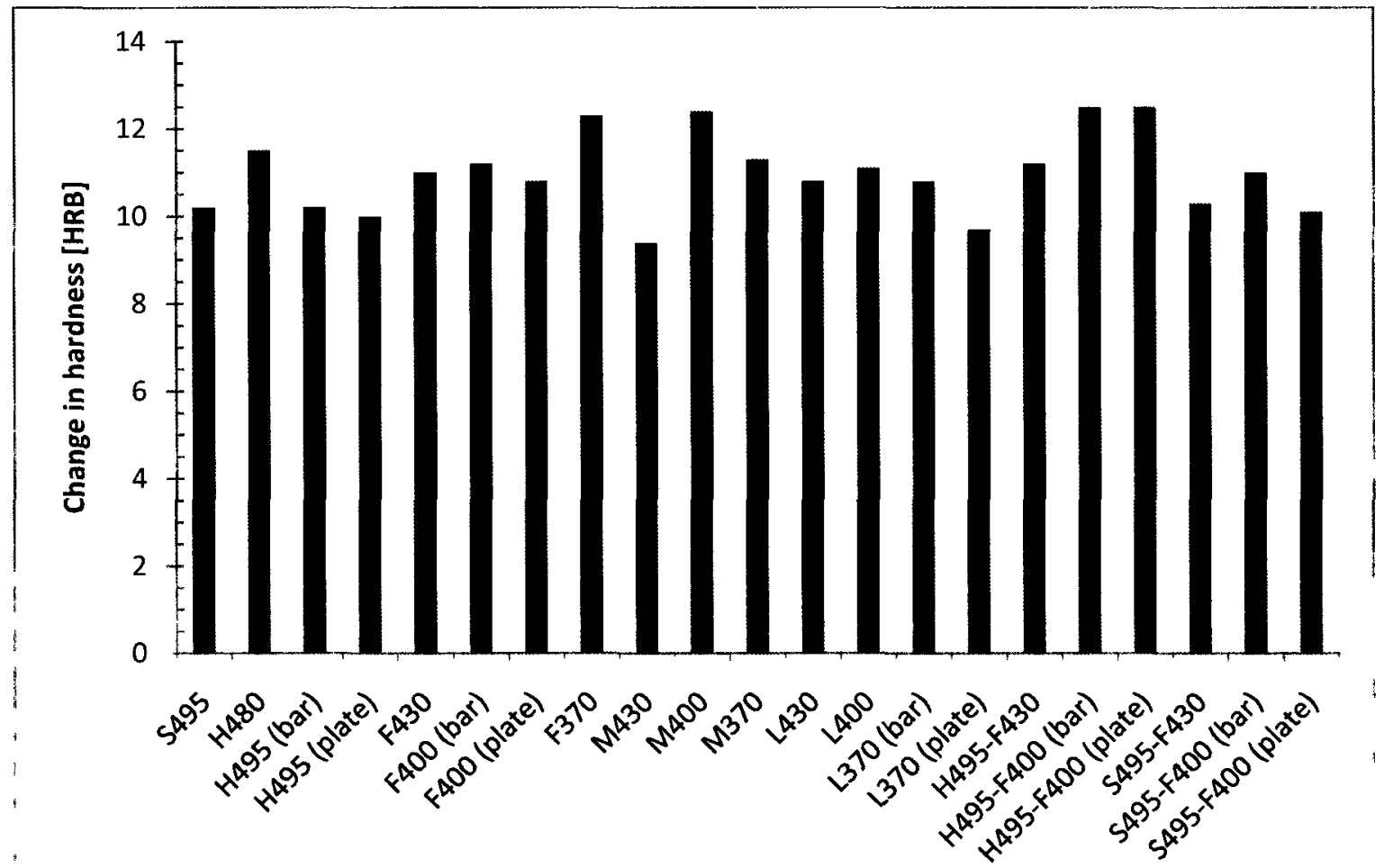

Figure 74: Change in hardness from pre- to post-ageing for tensile and DB specimen blanks of all experimental tempers 


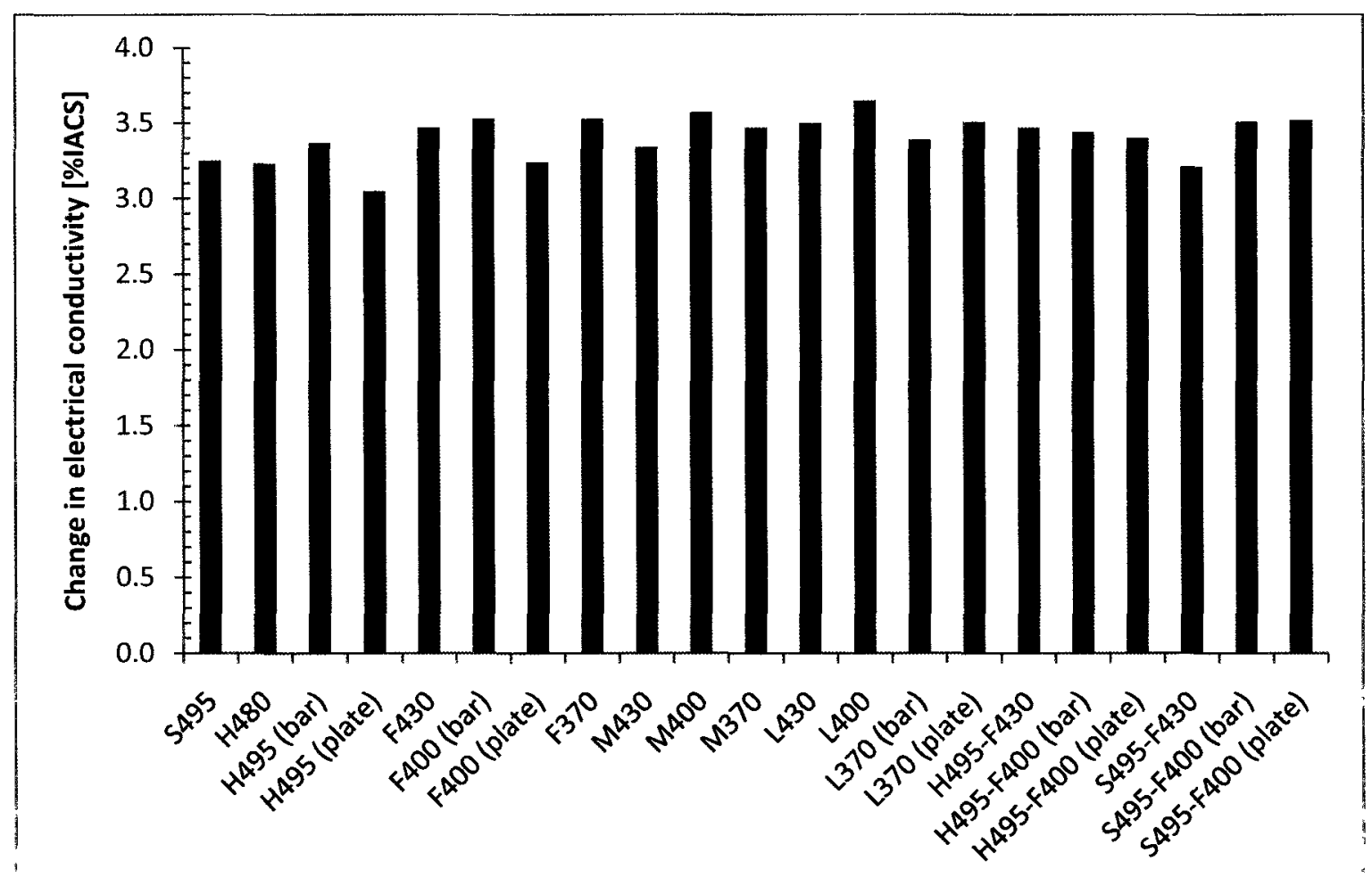

Figure 75: Change in hardness from pre- to post-ageing for tensile and DB specimen blanks of all experimental tempers

From Figure $\mathbf{7 4}$ it is clear that there is some variation in the hardness increase caused by ageing between the various tempers; however, for the majority of tempers the difference between the increase in hardness for that temper and the average increase in hardness was statistically insignificant based on a $95 \%$ confidence interval on the average. The mean change in hardness, and the $95 \%$ confidence interval on the mean, were calculated independently for the tensile specimen blanks and DB specimen blanks since they were not produced from the same parent material. These average values were 11.1 and $10.6 \mathrm{HRB}$ for the tensile and DB specimen blanks, respectively. Although some tempers did show an increase in hardness that differed from the average increase by a statistically significant amount, the change for at least one temper from each series, $H, F, M, L, H-F$, and $S-F$, was not statistically significant, so no trends can be inferred from these data.

Figure 75 shows that the increase in EC from pre- to post-ageing showed very little variation between tempers. The average change in EC and the $95 \%$ confidence interval on this average were again calculated independently for the specimens produced from bar and plate, and these average values were 3.42 and $3.34 \% \mathrm{IACS}$, respectively. None of the experimental tempers exhibited an increase in EC that differed from the mean increase by a statistically significant amount. 


\subsection{Correlation of Hardness and Tensile Test Data}

Figure 76 and Figure 77 show the yield strength and UTS, respectively, as a function of hardness for all tempers. From these figures it is apparent that there is a strong positive correlation between both sets of data.

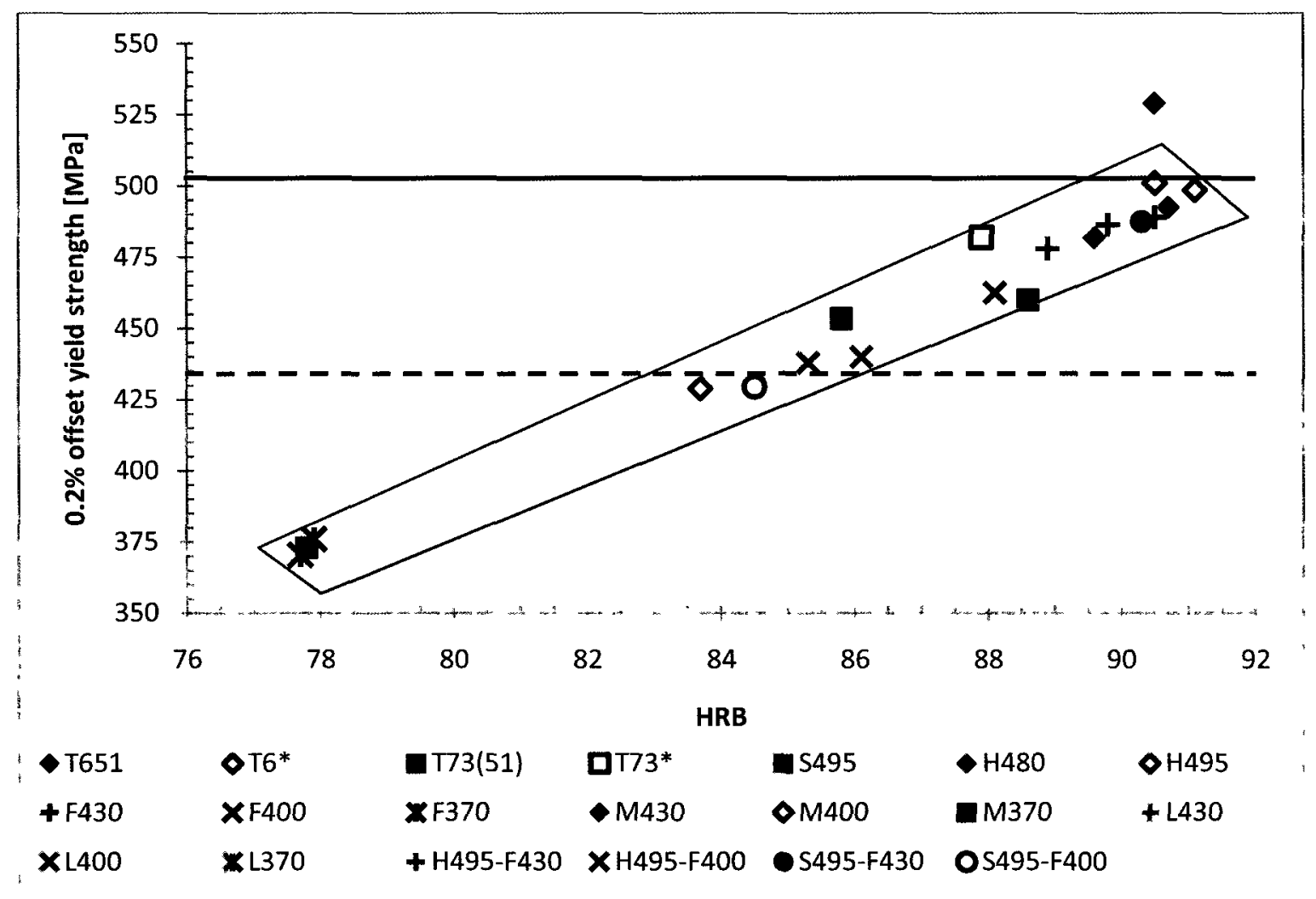

Figure 76: Yield strength as a function of Rockwell B hardness for all tempers 


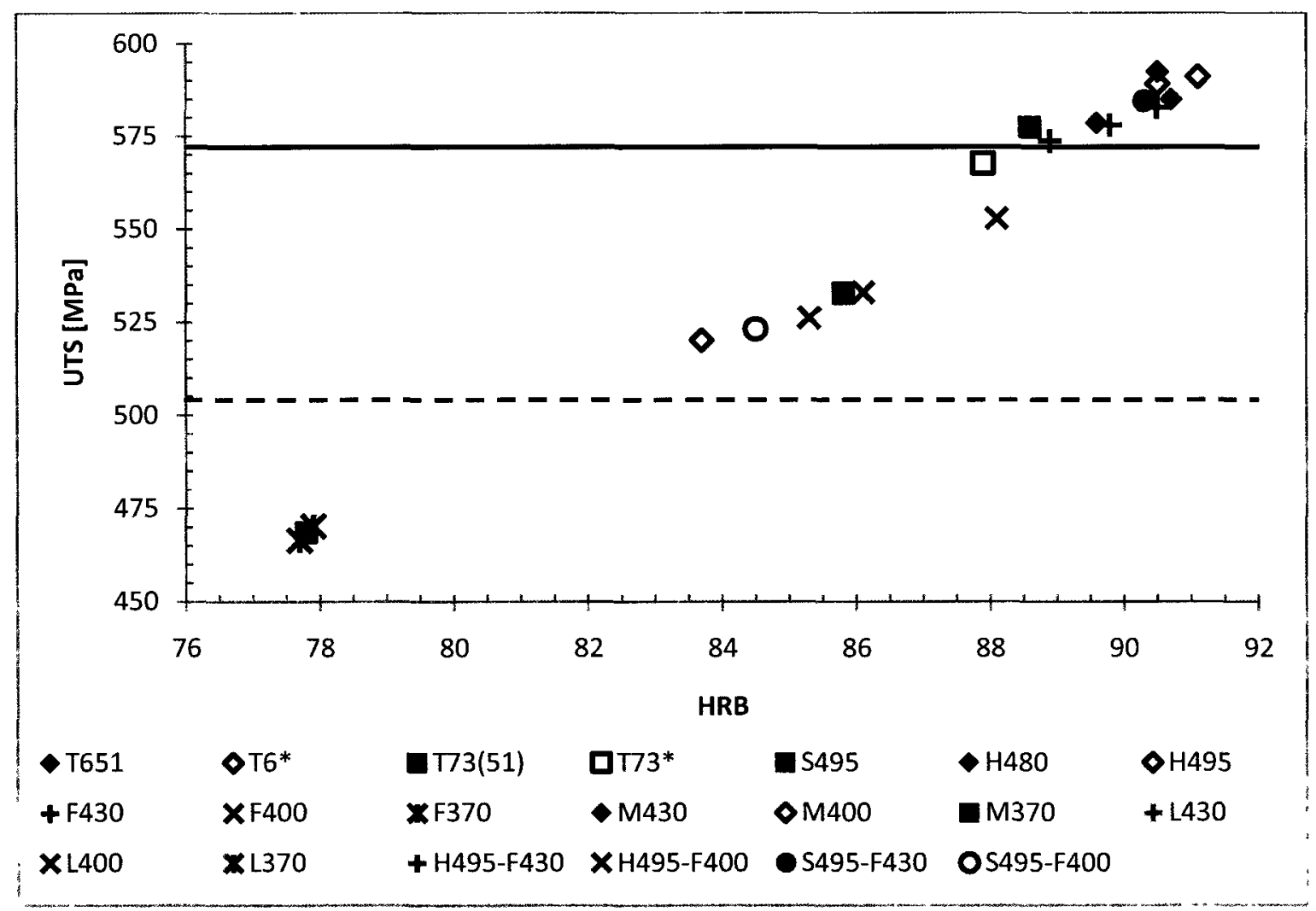

Figure 77: Tensile strength as a function of Rockwell B hardness for all tempers

In Figure 76 the data for all but one temper, T651, appear to show a linear correlation within a small range of scatter; however, the T651 does not seem to fall on the same line. Conversely, in Figure 77 the T651 does not appear to fall as an outlier, but rather it is within the same range of scatter as the data for all other tempers.

This strong correlation between the strength and hardness data suggests that tensile testing may not be necessary in an experimental program of this type. If hardness testing on smail specimens of fully heat treated material can reveal the same trends between tempers as tensile testing, then the much greater amount of time and material required for tensile testing can be spared. In the case of this research, it is fortunate that tensile tests were conducted as these tests revealed a difference between the yield behaviour of the $T 6^{*}$ and $T 651$ conditions, and this will be discussed in detail in the following section.

\subsection{Yield Behaviour of T6* Compared to T651}

In the literature, the mechanical properties of the T6 and T651 tempers are frequently given as having the same values; however, in this study this was not the case. From the data presented in Table 10 and Figure 42, it can be seen that the UTS of the T6* condition is virtually the same as that for the T651, a difference of just $3.4 \mathrm{MPa}$, but there is a significant difference in the $0.2 \%$ offset yield strength of the two tempers as they differ by almost $30 \mathrm{MPa}$. The onset of yielding, or the proportional limit, where the stress-strain relationship first deviates from being linear 
also differs by about $60 \mathrm{MPa}$ : yielding first occurs at approximately $440 \mathrm{MPa}$ in the T6* temper and at about $500 \mathrm{MPa}$ in the T651.

To understand this difference in yield behaviour a comparison must be made between the stress-strain curves for the T6* and T651 conditions. Figure 78 shows the tensile stress-strain curves for the two specimens of the T6* temper and the two specimens of the T651 temper on the same plot.

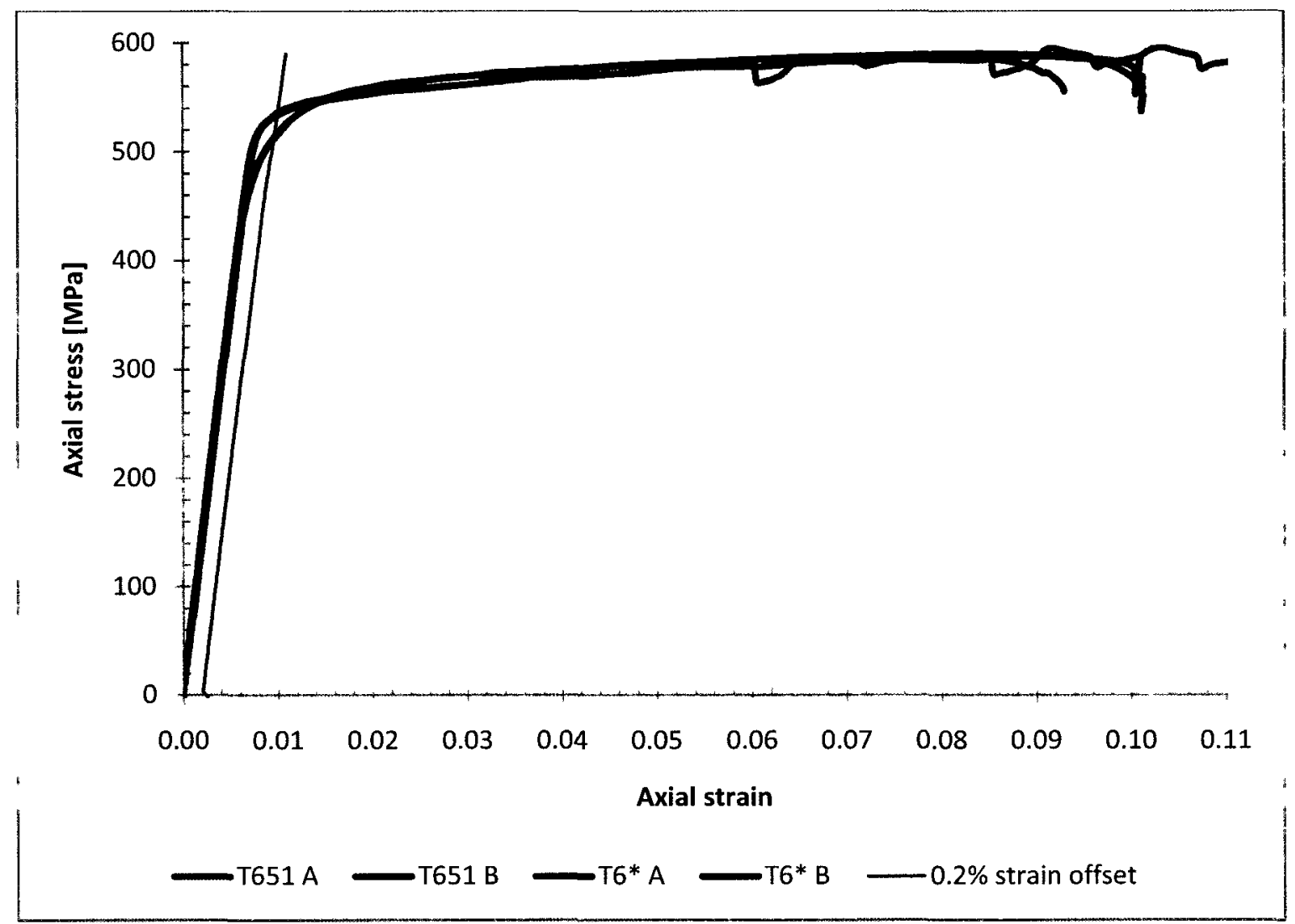

Figure 78: Tensile stress-strain curves for T6* and T651 specimens

In the T651 condition the yield point is fairly sharp and the transition into very gradual work hardening occurs over a very small range of strain. Conversely, in the T6* condition yielding is much more gradual and first occurs at a much lower stress. Figure 79 shows the portion of the stress-strain curves near the yield point for the two T6* specimens and the two T651 specimens. 


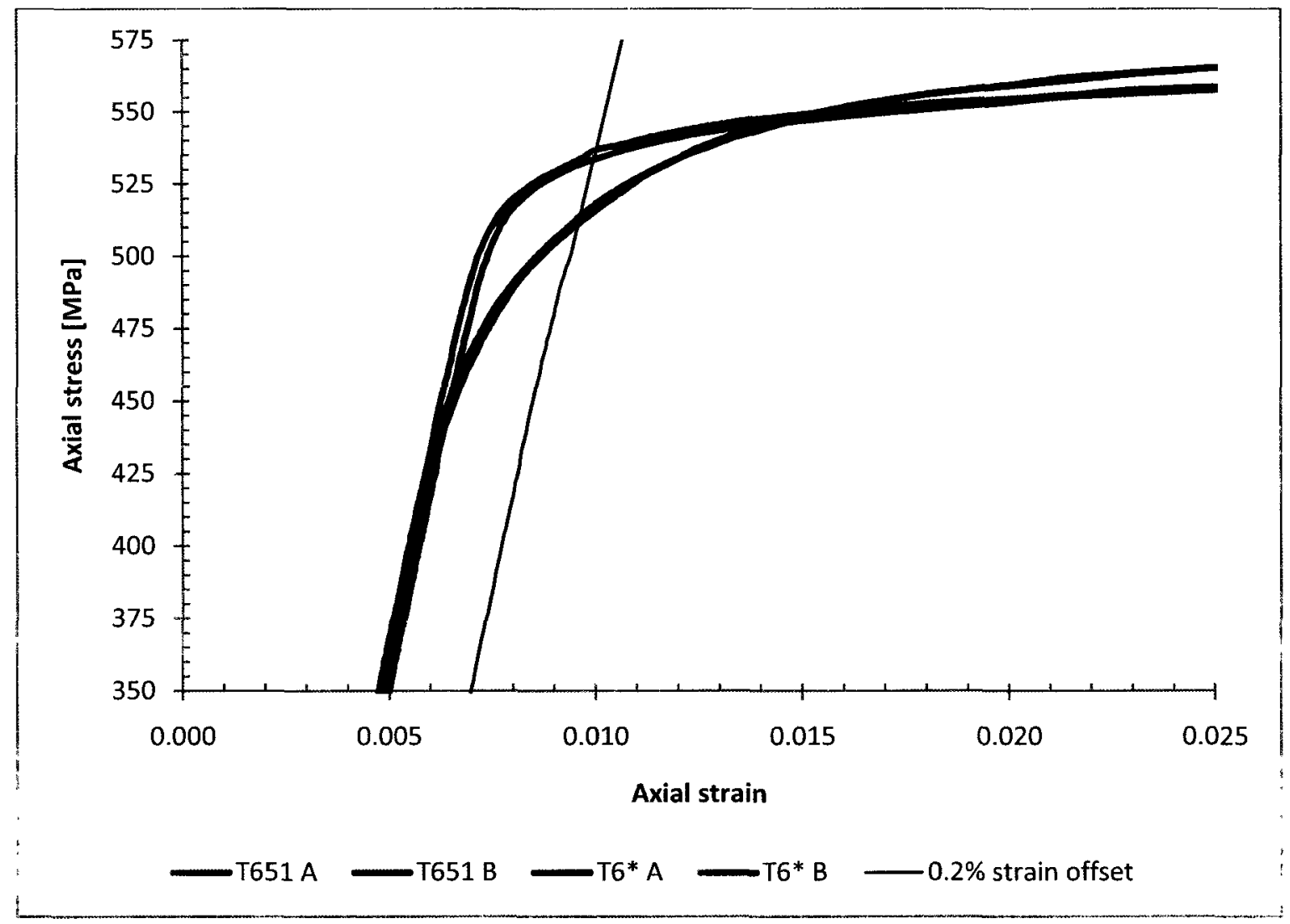

Figure 79: Portion of the tensile stress-strain curves near the yield point for T6* and T651 specimens

The yield behaviour of the $T 73^{*}$ and T73(51) tempers showed a similar trend with yielding occurring more gradually in the T73* compared to the T73(51).

These results can be explained on the basis of dislocation density. The difference between the T6 and T651 tempers is the application of a small tensile strain to the latter condition prior to ageing, somewhere in the range from 1.5 to $3 \%$ strain. This small amount of stretching is applied to straighten products which may have been warped by thermal stresses during quenching. Even these small amounts of deformation can have a significant effect on the dislocation density of Al, as shown in Figure 80. 


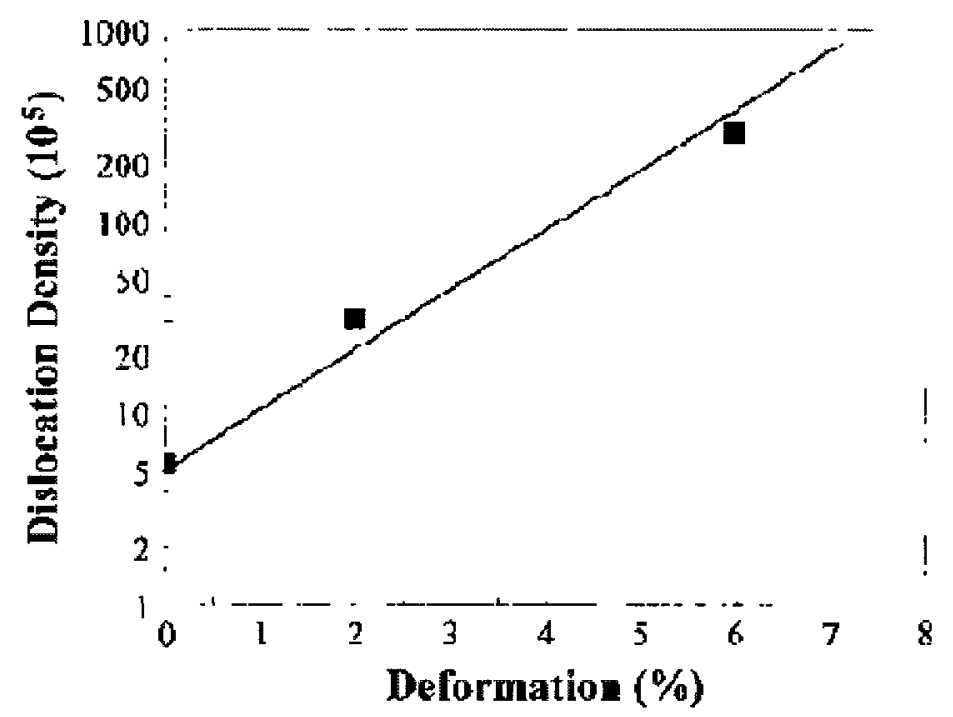

Figure 80: Variation in dislocation density with increasing deformation in an Al-Li-Cu alloy [4]

As illustrated in Figure 80 , the application of just $2 \%$ strain results in an almost ten times increase in the dislocation density, and while the data presented in this figure are for an Al-Li-Cu alloy the behaviour is likely similar in other Al alloys. For most metals the dislocation density can increase by as much as four orders of magnitude from completely annealed to heavily cold worked material $[46,47]$.

In the $6^{*}$ condition, the dislocation density is initially relatively low as only dislocations generated during quenching from the solution heat treatment temperature will be present, and as a result most slip planes will have very few dislocations present. Yielding will begin to occur in the T6* condition at a much lower stress because the few dislocations that are present are relatively mobile; however, as deformation continues many more dislocations will be generated through mechanisms such as Frank-Read sources, which are described in detail in references such as $[46,47,48]$. As the dislocation density increases, dislocations will tend to interact with each other more frequently resulting in dislocation tangles and pile-ups at grain boundaries and other obstacles, such as precipitates, which make subsequent deformation more difficult. This gradual increase in dislocation density and dislocation interactions results in the behaviour shown for the T6* in Figure 78 and Figure 79 where yielding occurs gradually over a range of about $0.015(1.5 \%)$ strain.

Conversely, in the T651 temper the initial dislocation density will be much higher due to the stretching applied prior to ageing, so most slip planes will already have a relatively high population of dislocations. Dislocation tangles and pile-ups may already be present, so a much higher stress is required to initiate yielding. Yielding also occurs much more abruptly in the T651 condition with the onset of yielding and the completion of yielding occurring within a range of approximately $0.006(0.6 \%)$ strain.

Aside from strengthening effects, dislocation density has been proposed to affect the SCC behaviour of 7XXX series Al alloys, as outlined in section 3.3.4. While a comparison of the SCC 
resistance of the $T 6^{*}$ and $T 651$ conditions was not undertaken in this research, the results of Figure 78 indicate that a careful comparison of the SCC behaviour of these two conditions may be warranted.

\subsection{Effects of Variation in Solution Heat Treatment on SCC Behaviour}

\subsubsection{Crack Growth Behaviour}

To compare the stress corrosion crack growth behaviour of the various tempers, a number of $V$ $\mathrm{K}$ plots, crack velocity as a function of stress intensity, were generated. Figure 81 shows the $\mathrm{V}-\mathrm{K}$ plot for the T651 and T73(51) conditions.

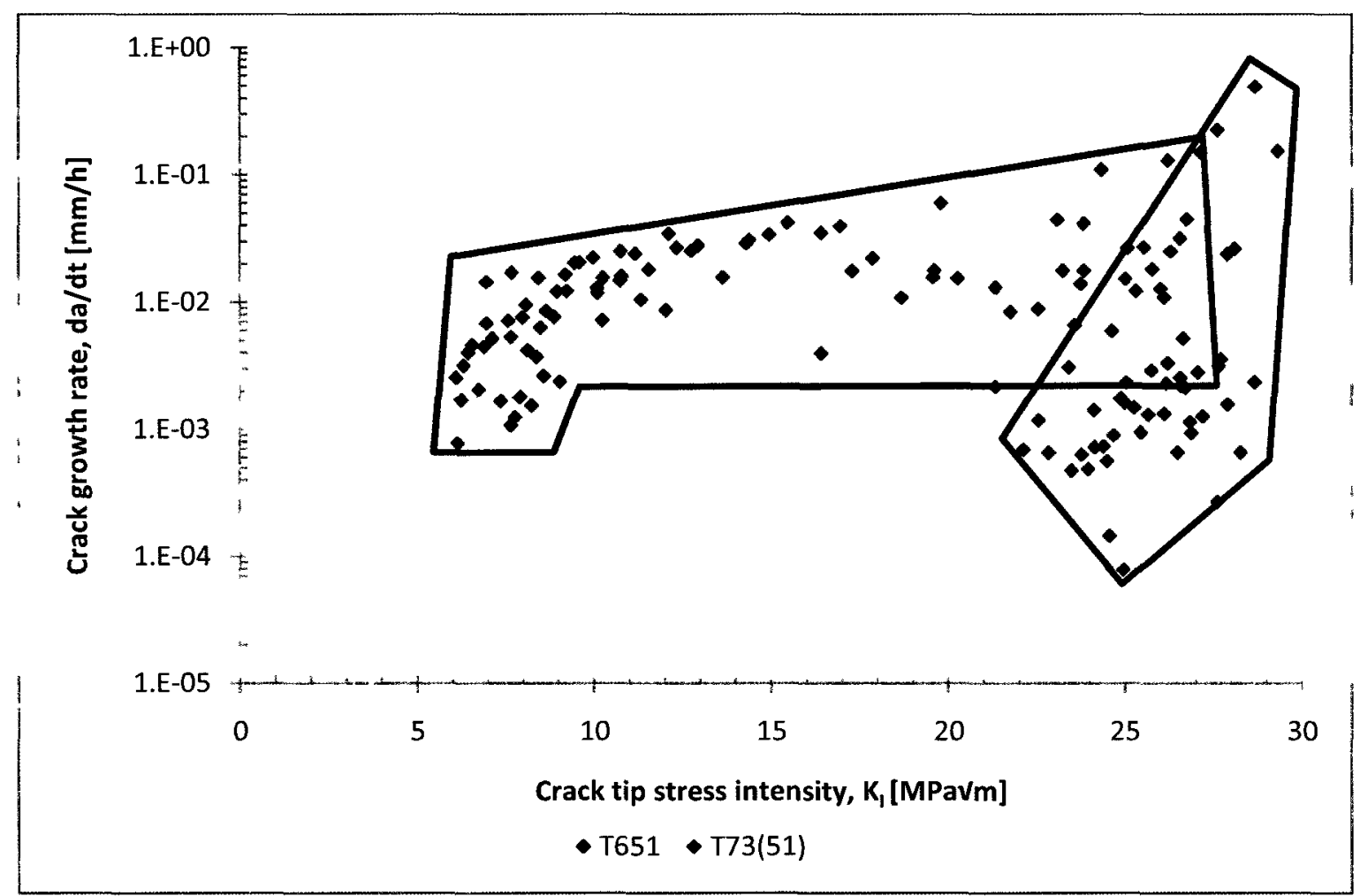

Figure 81: Crack growth rate as a function of stress intensity for the T651 and T73(51) DB specimens

A few observations can be made from Figure 81: first, the crack growth rates of the T73(51) specimens vary by several orders of magnitude over a very small range of stress intensities. This suggests that this range of stress intensities and crack velocities corresponds to region I crack growth. For the T651 specimens, there appear to be both regions I and II present in Figure 81, albeit with some considerable scatter present in region II. Second, the stress intensities that give similar crack growth rates are much lower in the T651 specimens compared to the T73(51) specimens. Finally, the apparent threshold stress intensity for SCC, $\mathrm{K}_{\mathrm{Isc}}$, is much lower in the T651 condition. 
These results are in good agreement with the literature and the microstructural results presented in section 6.4. In the T73(51) microstructures, Figure 53 through Figure 56, coarse, discontinuously spaced precipitates are present along the grain boundaries, but in the T651 microstructures, Figure 49 through Figure 52, these grain boundary precipitates are either absent or too small to be visible at the given magnifications. In much of the literature presented in chapter four coarse grain boundary precipitates are discussed as the microstructural feature that has the greatest effect on SCC $[4,33,35,36,38,41,42]$. As such, the results for the T651 and $T 73(51)$ tempers will be used as a basis for comparison with the experimental conditions in terms of microstructure and SCC behaviour.

Figure 82 presents a V-K plot for the T651 and H495 tempers.

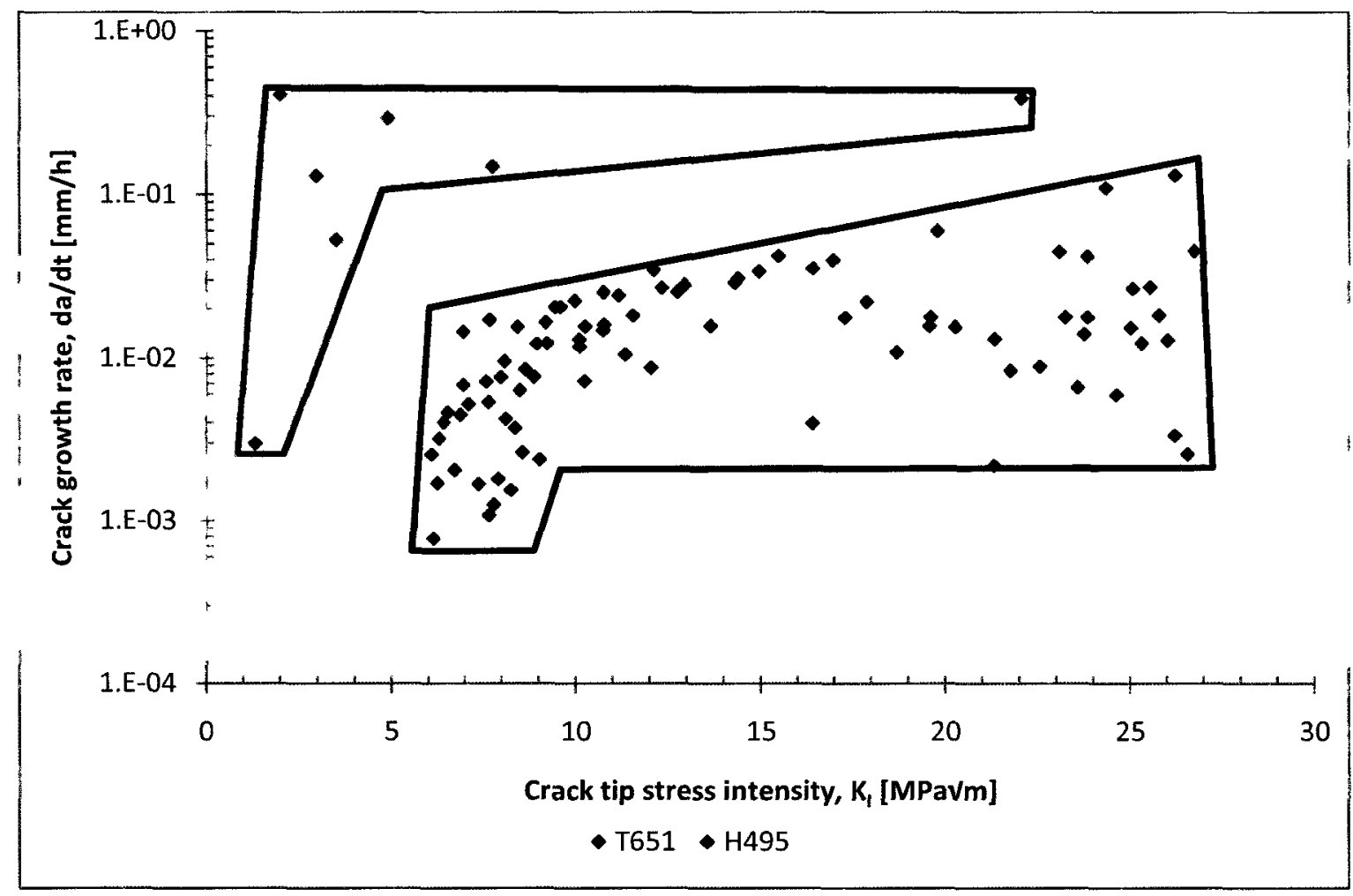

Figure 82: Crack growth rate as a function of stress intensity for the T651 and H495 DB specimens

Figure 82 shows that the SCC resistance of the H495 temper is inferior to that of the T651 condition. The crack velocity at similar stress intensities is higher by an order or magnitude, or more, in the $\mathrm{H} 495$ condition, and the threshold stress intensity for SCC is less than half that of the T651. If the H495 microstructure, Figure 57 and Figure 58, is compared to the T651 and T73(51) microstructures, it is apparent that the $\mathrm{H} 495$ more closely resembles that of the T651: no coarse precipitates are observed on the grain boundaries. The H495-F400 and \$495-F400 microstructures, Figure 59 and Figure 60 and Figure 61 and Figure 62, respectively, show this same similarity to the T651 microstructure. The V-K plot for the T651, F400, H495-F400, and S495-F400 tempers is shown in Figure 83. 


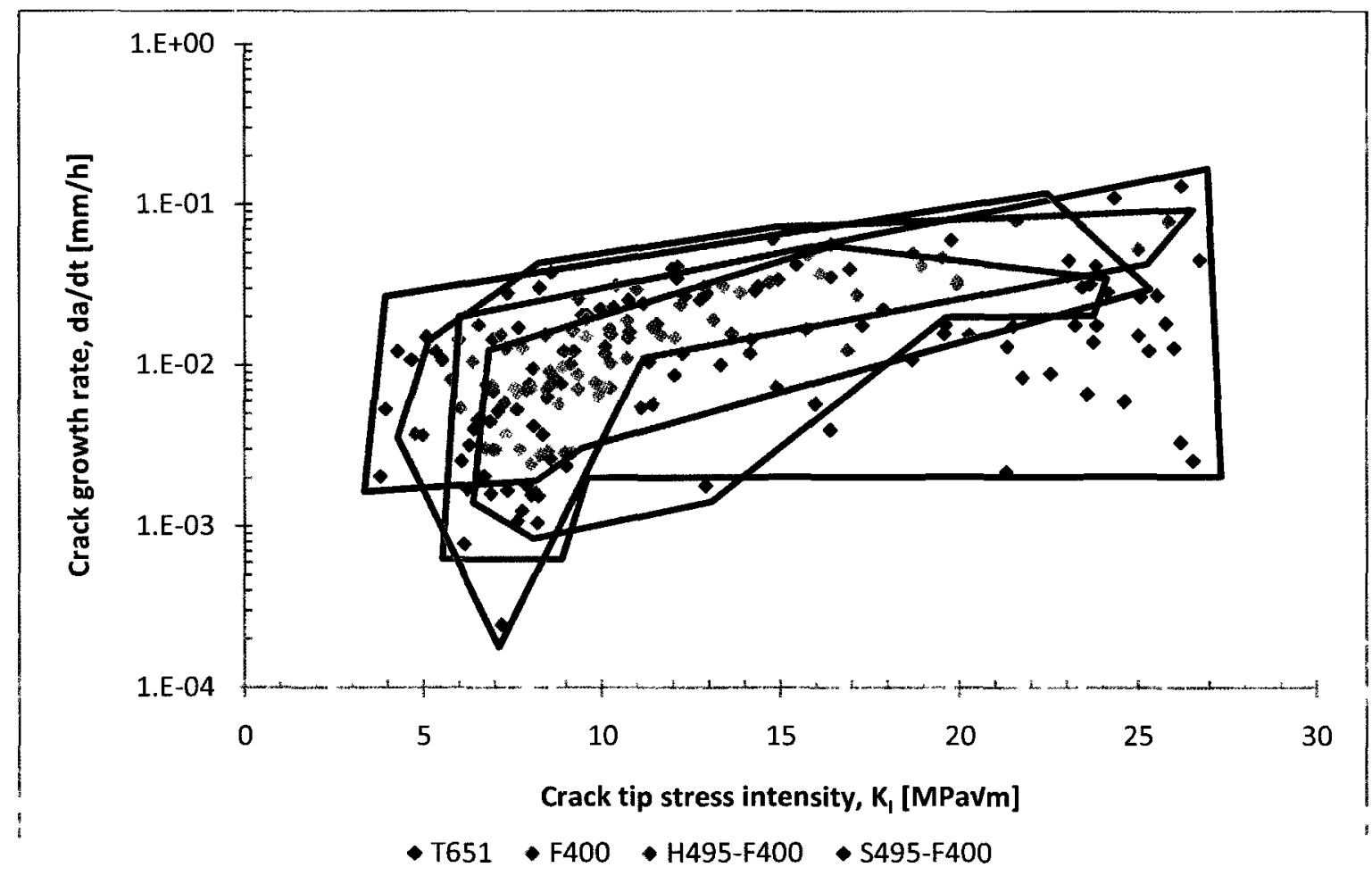

Figure 83: Crack growth rate as a function of stress intensity for the T651, F400, H495-F400, and S495-F400 DB specimens

The crack growth rates are very similar for all four conditions in region II, and only one temper, H495-F400, showed region I shifted to lower stress intensities. This same temper also showed a slight decrease in the threshold stress intensity for SCC.

These results seem to disagree with those presented in [41]. These authors found that adding slow heating or slow heating and slow cooling to the standard isothermal solution heat treatment improved the SCC resistance in terms of shifting region II to lower crack velocities and shifting region I to higher stress intensities. This study also found that some coarse grain boundary particles were present on the grain boundaries after cooling to $400^{\circ} \mathrm{C}$ prior to quenching. It is possible that the grain boundary precipitates were simply not visible at the magnifications used in the present research as the images shown in [41] are at a higher magnification.

There are two possible reasons for the discrepancy between the results of the present study and those presented in [41]: first, the alloy studied in [41] was not 7075. While it was an Al-Zn-Mg$\mathrm{Cu}$ alloy, it had a much lower $\mathrm{Cu}$ content and contained $\mathrm{Zr}$ instead of $\mathrm{Cr}$ as a dispersoid forming element. $\mathrm{Zr}$ forms coherent dispersoids which are much less active as precipitation sites during cooling and quenching than the incoherent dispersoids formed by $\mathrm{Cr}$. Second, the temperatures employed in this study were slightly different. While the final temperatures of the HTPP treatments were the same, the initial solution heat treatment temperature and the maximum temperature during the solutionizing treatment were higher for the current research. 
A likely explanation is that some small amount of incipient melting may have occurred during solution heat treatment of the H495, H495-F400, and S495-F400 tempers as discussed previously in section 7.1.3.

Incipient melting may have occurred in all of the tempers heated to $495^{\circ} \mathrm{C}$ during solution heat treatment, but only the $\mathrm{H} 495$ temper displayed severely degraded SCC resistance. There are two possible explanations for this difference: first, in the tempers subsequently cooled prior to quenching, H495-F400 and S495-F400, any material that may have melted would have resolidified during the latter portion of the heat treatment that was well below even the lowest possible solidus temperature. Conversely, any incipient melting that may have occurred in the H495 temper would have been quenched in, and this may have resulted in the very poor SCC performance of this temper. Second, incipient melting may not have occurred at all, and quenched in dislocations may be responsible for the poor SCC resistance as proposed in [21]. Just as with vacancy concentration, quenching from a higher solution heat treatment temperature will lead to an increase in quenched in dislocation density; hence, the $\mathrm{H} 495$ temper should have an elevated dislocation density and reduced SCC resistance compared to the $\mathrm{H} 495$ F400 and S495-F400 tempers.

Only one of the experimental tempers showed an improvement in SCC resistance compared to the T651 condition, and that was the L370 temper. The V-K plot for the L370 and T651 conditions is given in Figure 84.

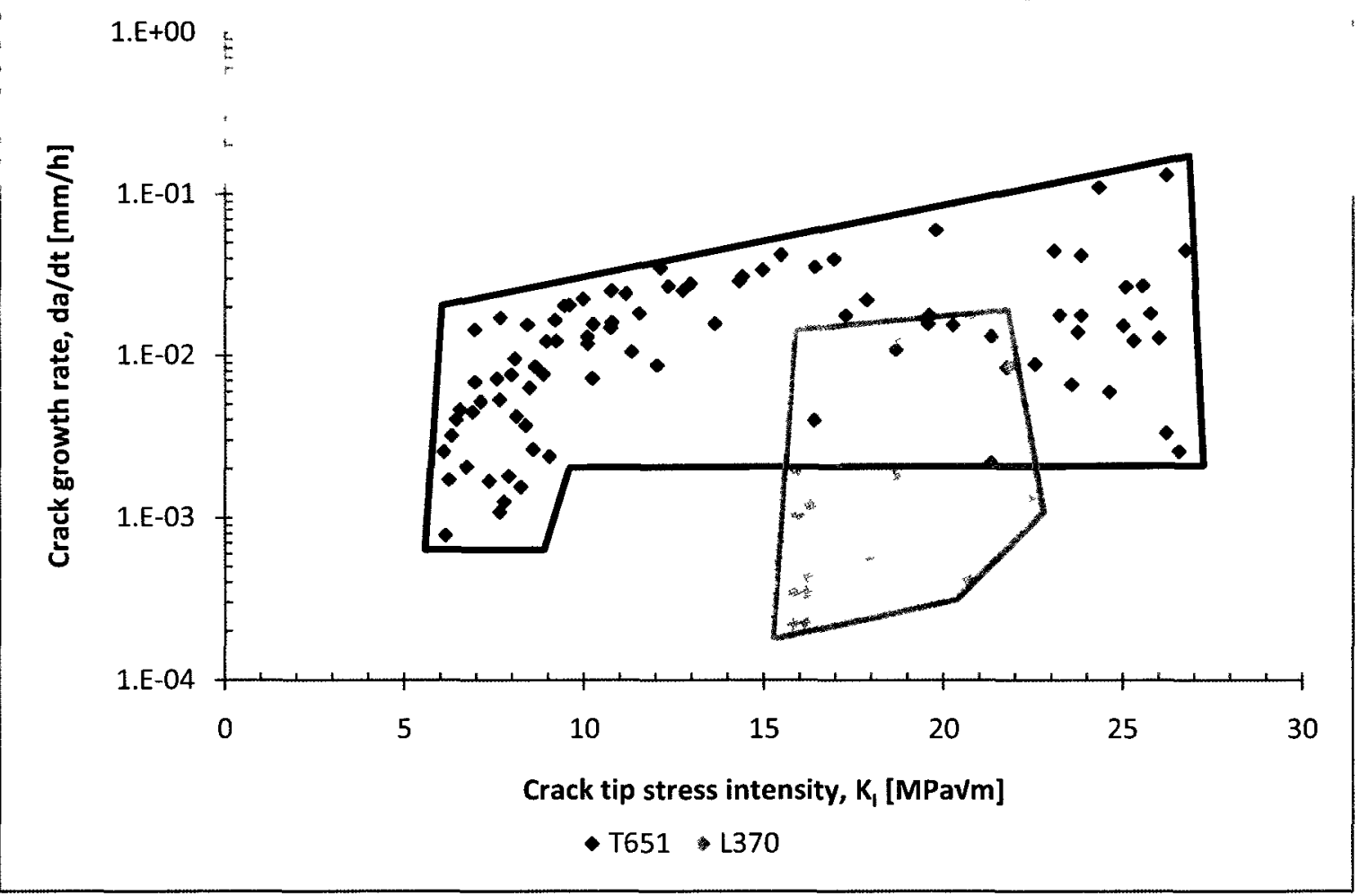

Figure 84: Crack growth rate as a function of stress intensity for the T651 and L370 DB specimens 


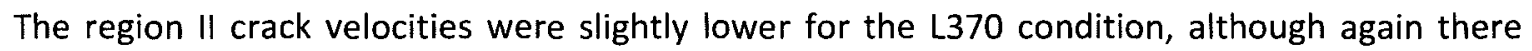
was significant scatter in the data for both tempers, and region I is shifted to much higher stress intensities compared to the T651. The value of $\mathrm{K}_{\mathrm{Iscc}}$ is also improved by approximately $10 \mathrm{MPaVm}$. While this temper shows superior SCC resistance compared to T651, comparison to the $T 73(51)$ condition shows that the latter has better SCC resistance. This is illustrated in Figure 85.

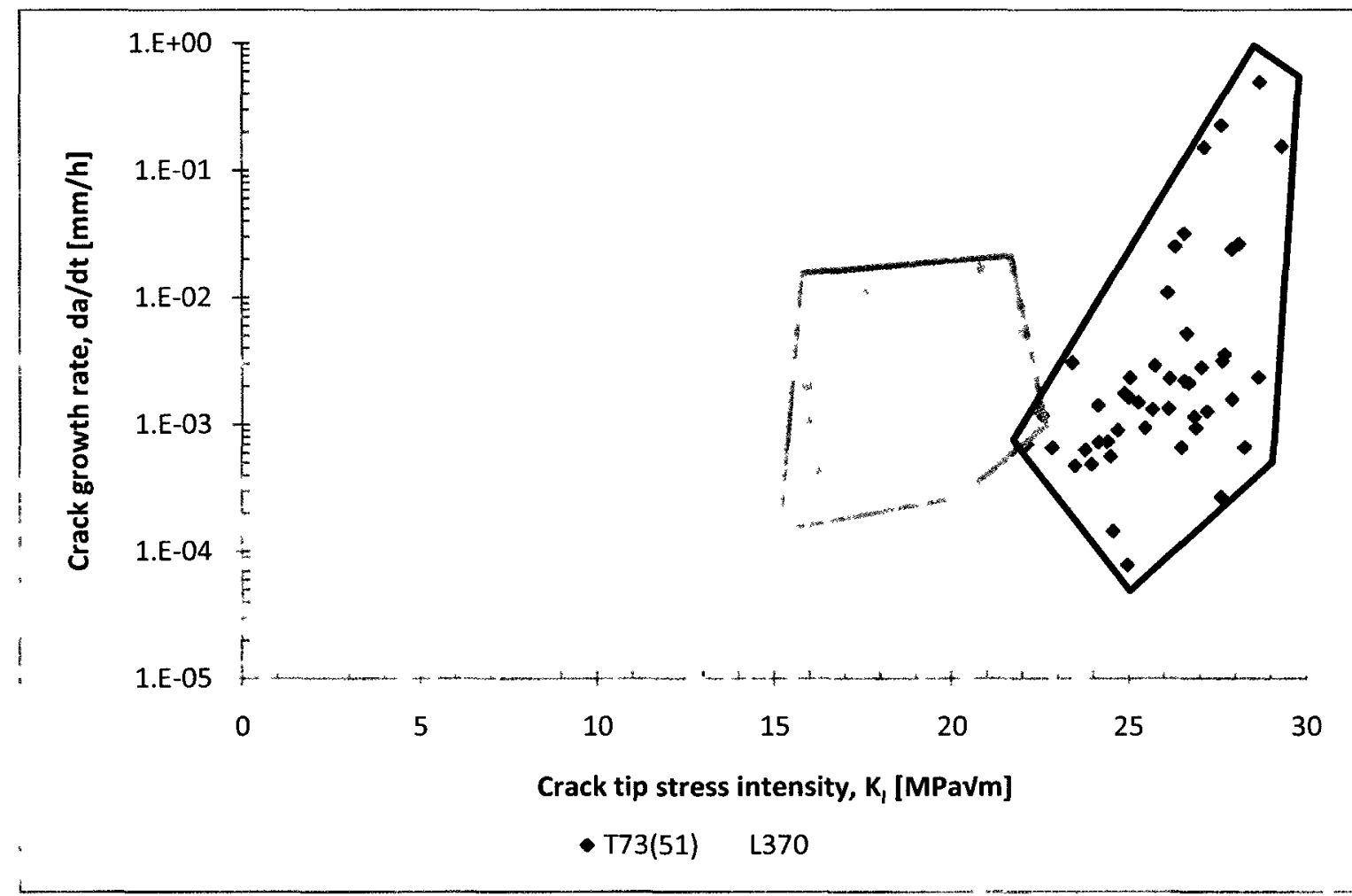

Figure 85: Crack growth rate as a function of stress intensity for the T73(51) and L370 DB specimens

The region II stress intensities for the $\mathrm{L} 370$ condition are approximately $10 \mathrm{MPaVm}$ lower than those for the $T 73(51)$, and the threshold stress intensity for SCC is similarly shifted to a lower value.

Examination of the L370 microstructure could give some indication as to the reasons for the intermediate SCC resistance of this temper compared to the T651 and T73(51); however, this is not possible as no high magnification images of the L370 microstructure could be captured. Based on the literature $[41,42]$, it is expected that the grain boundaries in the L370 microstructure would be more similar to those in the T73(51) microstructure than any of the other experimental tempers. Due to the slow cooling rate and relatively low final temperature of the HTPP treatment applied to the $\mathbf{3 7 0}$ condition, it is expected that this temper would show some coarse grain boundary precipitation. 
In all of the figures presented in this section there is some significant scatter in the crack growth rate results. This is due to the difficulty experienced in accurately measuring the crack lengths on the specimen side surfaces. During testing, dried salt and corrosion products built up on the surfaces of the DB specimens. These obstructions were removed as much as possible prior to crack length measurement, but due to the often very small changes in crack length accurate measurement was nonetheless quite difficult.

\subsubsection{Correlation between SCC Behaviour and Electrical Conductivity}

To examine the relationship between the EC and SCC behaviour of the various tempers studied in this research the $K_{\mathrm{Iscc}}$ was plotted as a function of EC, and this is shown in Figure 86.

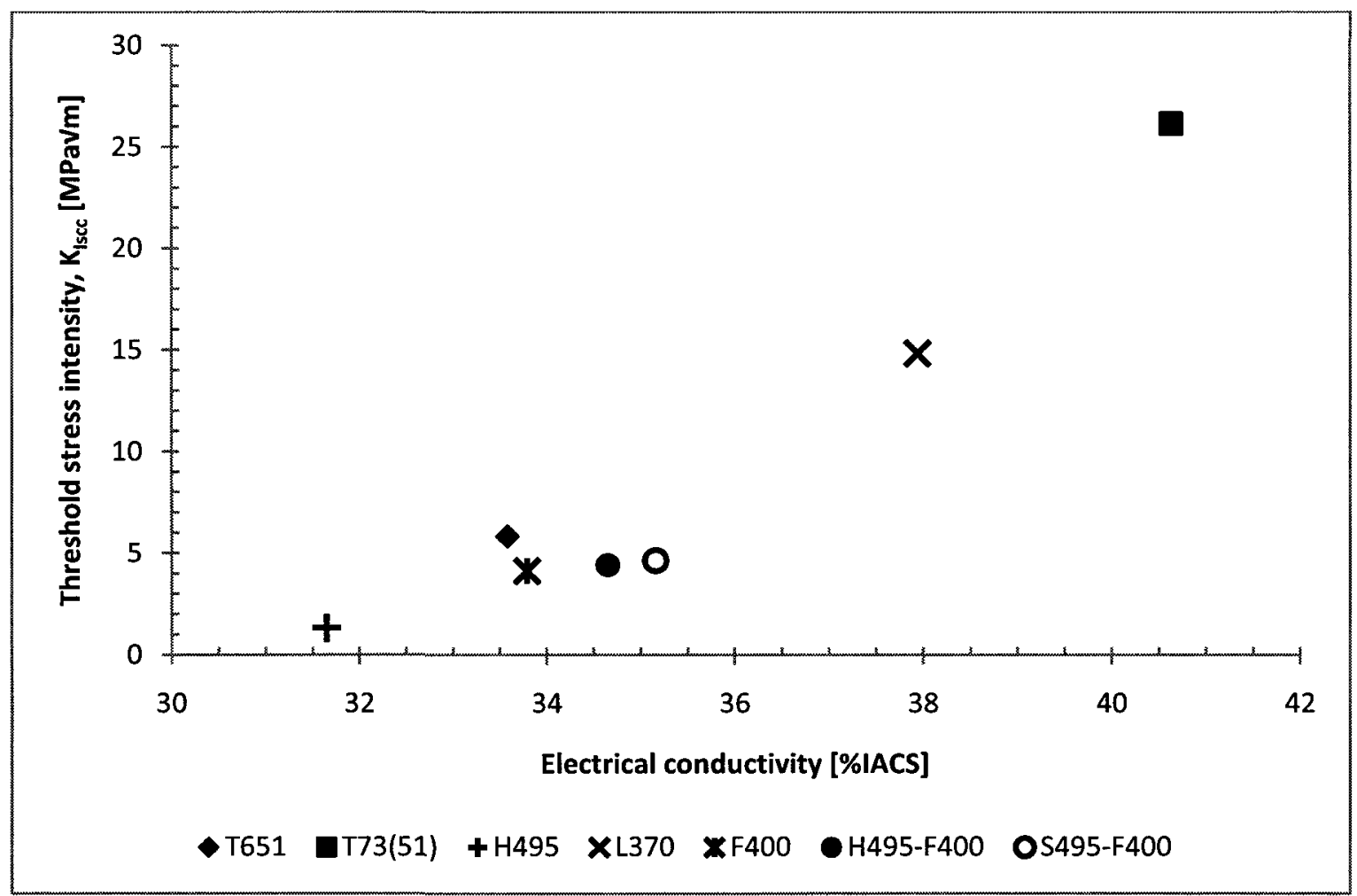

Figure 86: Threshold stress intensity for SCC as a function of electrical conductivity

The first observation that can be made from Figure 86 is that the $\mathrm{H} 495$ condition has lower EC than all other tempers and exhibits the lowest SCC resistance, and that the L370 temper has both EC and SCC resistance between that of the T651 and T73(51). These results support the correlation between EC and SCC susceptibility discussed in section 3.4; however, the results of the three tempers cooled to $400^{\circ} \mathrm{C}$ prior to quenching do not appear to follow this trend.

A likely explanation for this discrepancy is that EC responds to microstructural changes in the matrix, but it cannot detect changes to microstructural features such as grain size and grain boundary structures [23]. While it was not directly observed from the microstructures the F400, $\mathrm{H} 495-\mathrm{F} 400$, and S495-F400 tempers most likely experienced some precipitation during the HTPP portion of the solution heat treatment, and this resulted in a slight reduction in matrix solute 
content prior to ageing; hence the EC of these tempers is higher than that of the T651. Precipitation of coarse grain boundary precipitates similar to those observed in the T73(51) temper did not appear to occur, and as a result the SCC resistance of these three tempers is similar to that of the T651 temper. This suggests that EC cannot necessarily be used as a means of comparing the SCC resistance of $\mathrm{Al}-\mathrm{Zn}-\mathrm{Mg}-\mathrm{Cu}$ alloys when the solution heat treatment is not consistent between the conditions in question. 


\section{Summary, Conclusions, and Recommendations for Future Work}

\subsection{Summary and Conclusions}

An experimental program was executed to evaluate the effects of modified solution heat treatment on the microstructure, mechanical properties, electrical conductivity, and SCC resistance of Al alloy 7075. Various solution heat treatments were applied to the as-received material, and the same ageing treatment was subsequently applied to all conditions. All standard and experimental tempers were subjected to Rockwell B hardness testing, EC measurements by eddy current probe, and uniaxial tensile tests, and constant displacement double beam specimen SCC testing and microstructural analysis by SEM were conducted on selected conditions. The following conclusions can be made based on the results of this experimental program:

- All of the experimental solution heat treatments resulted in degraded mechanical properties compared to the T6/T651 temper, and in some cases properties were below T73/T7351 levels.

- Given the same subsequent ageing treatment, solution heat treatments with a maximum temperature in the range from 480 to $495^{\circ} \mathrm{C}$ result in reduced strength compared to the standard solution heat treatment temperature of $465^{\circ} \mathrm{C}$.

- Both yield strength and UTS were found to have a strong positive correlation with hardness, so tensile testing may not be necessary in an experimental program of this type where only the trends in properties between tempers are desired. UTS is more closely related to hardness than is yield strength.

- The cooling rate applied during the HTPP portion of the solution heat treatment has an insignificant effect on the hardness, yield strength, or EC in the range from $15^{\circ} \mathrm{C} / \mathrm{h}$ to $45^{\circ} \mathrm{C} / \mathrm{h}$.

- The final temperature prior to quenching during the HTPP treatment has a substantial effect on the hardness, yield strength, and EC in the range from $370^{\circ} \mathrm{C}$ to $430^{\circ} \mathrm{C}$. In this temperature range hardness and yield strength increase with increasing final temperature, and EC decreases with increasing final temperature.

- All of the experimental tempers exhibited inferior SCC resistance compared to the T73(51) condition in terms of crack growth rate as a function of stress intensity and threshold stress intensity for SCC. Most of the experimental tempers displayed SCC behaviour similar to, or worse than, the T651 temper, and one condition, L370, had SCC resistance between that of the $T 651$ and T73(51) tempers. 
- Coarse grain boundary precipitates, similar to those found in the $T 73(51)$ microstructure, were not observed in the T651 or any of the experimental tempers, and this is likely the reason for the inferior SCC resistance of these conditions compared to the T73(51) temper. It is expected that these precipitates would be present in the L370 temper due to the improvement in SCC resistance of this temper compared to T651 and all other experimental tempers; however, microstructural observations to support this result could not be obtained.

- Electrical conductivity is not necessarily a good indicator of SCC resistance in Al-Zn-Mg$\mathrm{Cu}$ alloys. The grain boundary structure, specifically the precipitates, is thought to be one of the main microstructural features controlling SCC in these alloys, and EC responds to microstructural changes occurring in the matrix, not those at the grain boundaries.

\subsection{Recommendations for Future Work}

Based on the results of this research and some of the difficulties encountered in the experimental program, specifically the microstructural observation, the following future research is recommended:

- Transmission electron microscopy (TEM) should be used instead of SEM to examine the grain boundary areas in the experimental tempers since TEM can provide much higher magnification images. A TEM study of all of the experimental tempers subjected to SCC testing may be able to provide more concrete microstructural evidence to support the results of the SCC tests, and ideally some quantitative assessment of the size and spacing of grain boundary precipitates could be made.

- SCC testing of the T6 and T651 tempers should be undertaken to determine if there is a difference in the SCC behaviour of these conditions. The yield behaviour of these two tempers was found to be quite different, and this is likely due to the difference in dislocation density between the two. One theory proposed that dislocations at and near the grain boundaries have a significant effect on the SCC resistance of 7XXX series Al alloys [21], so it is possible that the SCC susceptibility of the T6 and T651 conditions may be different for this same reason.

- A similar study to the one described in this thesis should be conducted on Al alloy 7050 to determine the effects of modified solution heat treatment on this alloy. The composition of 7050 is given in Table 12.

Table 12: Compositional limits of 7050 [10]

\begin{tabular}{|c|c|c|c|c|c|c|c|c|c|}
\hline \multicolumn{10}{|c|}{ Concentration [wt\%] } \\
\hline $\mathrm{Cr}$ & $\mathrm{Cu}$ & $\mathrm{Fe}$ & $\mathrm{Mg}$ & $\mathrm{Mn}$ & $\mathrm{Si}$ & $\mathrm{Ti}$ & $\mathrm{Zn}$ & $\begin{array}{c}\text { Other } \\
\text { (each/total) }\end{array}$ & $\mathrm{Al}$ \\
\hline$<0.04$ & $2.0-2.6$ & $<0.15$ & $1.9-2.6$ & $<0.10$ & $<0.12$ & $<0.06$ & $5.7-6.7$ & $0.05 / 0.15$ & Balance \\
\hline
\end{tabular}


The primary compositional differences between 7050 and 7075 are the substitution of $\mathrm{Zr}$ for $\mathrm{Cr}$ as a dispersoid forming element and lower Fe and Si content, so 7050 exhibits reduced quench sensitivity compared to 7075 as illustrated in Figure 12 . Some of the modified solutionizing treatments applied to 7075 in this research may have very different effects on the microstructure and properties of 7050 due to these compositional differences. 


\section{References}

1. Brown, B.F., 1972, "Fundamentals," Stress-Corrosion Cracking in High Strength Steels and in Titanium and Aluminum Alloys, Brown, B.F. (ed.), Naval Research Laboratory, Washington, D.C., pp.iii, 2-3, 6-7, 13-16.

2. Callister, W.D., 2007, Materials Science and Engineering: An Introduction, Wiley, New York, pp.190-191, 402-403, 646-647.

3. Burleigh, T.D., 1991, "The Postulated Mechanisms for Stress Corrosion Cracking of Aluminum Alloys," Corrosion, 47 (2), pp.89-98.

4. Tiryakioğlu, M. and Staley, J.T., 2003, "Physical Metallurgy and the Effect of Alloying Additions in Aluminum Alloys," Handbook of Aluminum, Vol. 1: Physical Metallurgy and Processes, Totten, G.E. and MacKenzie, D.S. (eds.), Marcel Dekker, New York, pp.81-82, 9394, 97, 106, 121-130, 185-194.

5. Cayless, R.B.C., 1990, "Alloy and Temper Designation Systems for Aluminum and Aluminum Alloys: Wrought Aluminum and Aluminum Alloys," ASM Handbook, Vol. 2: Properties and Selection, Nonferrous Alloys and Special Purpose Materials, ASM International, Materials Park, $\mathrm{OH}$.

6. Cayless, R.B.C., 1990, "Alloy and Temper Designation Systems for Aluminum and Aluminum Alloys: Temper Designation System for Aluminum and Aluminum Alloys," ASM Handbook, Vol. 2: Properties and Selection, Nonferrous Alloys and Special Purpose Materials, ASM International, Materials Park, $\mathrm{OH}$.

7. Davis, J.R., 1993, Aluminum and Aluminum Alloys, ASM International, Materials Park, $\mathrm{OH}$, pp.40-46, 59-62, 591.

8. Alcoa, "Alloy 7075 Plate and Sheet," Alcoa Mill Products, Bettendorf, IA.

9. Alcoa, 2004, "Understanding Cold Finished Aluminum Alloys: Alloy 7075," Alcoa Global Cold Finished Products, Massena, NY.

10. The Aluminum Association, 2009, "International Alloy Designations and Chemical Composition Limits for Wrought Aluminum and Wrought Aluminum Alloys," The Aluminum Association, Arlington, VA.

11. ASM International, 1990, "Properties of Wrought Aluminum and Aluminum Alloys, 7075, Alclad 7075," ASM Handbook, Vol 2: Properties and Selection, Nonferrous Alloys and Special Purpose Materials, ASM International, Materials Park, $\mathrm{OH}$. 
12. Porter, D.A. and Easterling, K.E., 1992, Phase Transformations in Metals and Alloys, Taylor and Francis Group, Boca Raton, FL, pp.291-308.

13. Howard, R., Bogh, N., and MacKenzie, D.S., "Heat Treating Processes and Equipment," Handbook of Aluminum, Vol. 1: Physical Metallurgy and Processes, Totten, G.E. and Mackenzie, D.S. (eds.), Marcel Dekker, New York, pp.888-914, 916, 925, 928.

14. Petrov, D., Watson, A., Grobner, J., Rogl, P., Tedenac, J-C., Bulanova, M., and Turkevich, V., 2007, "Aluminum-Magnesium-Zinc," in Light Metal Ternary Systems: Phase Diagrams, Crystallographic and Thermodynamic Data, Vol. 11 A3 Light Metals Systems part 3, Springer, Berlin.

15. Belov, N.A., Eskin, D.G., and Aksenov, A.A., 2005, Multicomponent Phase Diagrams: Applications for Commercial Aluminum Alloys, Elsevier, Oxford, p.208.

16. Hyatt, M.V. and Speidel, M.O., 1972, "High Strength Aluminum Alloys," Stress-Corrosion Cracking in High Strength Steels and in Titanium and Aluminum Alloys, Brown, B.F. (ed.), Naval Research Laboratory, Washington, D.C., pp.149, 157, 162, 176-180, 196-201, 216-218.

17. Revie, R.W. and Uhlig, H.H., 2008, Corrosion and Corrosion Control, Wiley, Hoboken, NJ, pp.150-151, 156-160, 165-167, 170.

18. Jones, R.H., 2003, "Stress-Corrosion Cracking," ASM Handbook, Vol. 13A: Corrosion: Fundamentals, Testing, and Protection, ASM International, Materials Park, $\mathrm{OH}$.

19. Kaufman, J.G., 2005, "Corrosion of Aluminum and Aluminum Alloys, Stress-Corrosion Cracking," ASM Handbook, Vol. 13B: Corrosion: Materials, ASM International, Materials Park, $\mathrm{OH}$.

20. Holroyd, N.J.H. and Scamans, G.M., 1985, "The Role of Magnesium During EnvironmentSensitive Fracture of Aluminum Alloys," Scripta Metallurgica, 19, pp.915-916.

21. Talianker, M. and Cina, B., 1989, "Retrogression and Reaging and the Role of Dislocations in the Stress Corrosion of 7000-Type Aluminum Alloys," Metallurgical Transactions A, 20A (10), pp. 2087-2092.

22. Albrecht, J., Thompson, A.W., and Berstein, I.M., 1982, "Evidence for Dislocation Transport of Hydrogen in Aluminum," Metallurgical Transactions A, 13A (5), pp.811-820.

23. Tsai, T.C. and Chuang, T.H., 1996, "Technical Note: Relationship Between Electrical Conductivity and Stress Corrosion Cracking Susceptibility of Al 7075 and Al 7475 Alloys," Corrosion, 52 (6), pp.415-416.

24. US Department of Defense, 2002, "Test Method Standard for Electrical Conductivity Test for Verification of Heat Treatment of Aluminum Alloys, Eddy Current Method," MIL-STD-1537C. 
25. Islam, M.U. and Wallace, W., 1983, "Retrogression and reaging response of 7475 aluminum alloy," Metals Technology, 10, pp.386-392.

26. Smith, H.R. and Piper, D.E., 1972, "Stress Corrosion Testing with Precracked Specimens," Stress-Corrosion Cracking in High Strength Steels and in Titanium and Aluminum Alloys, Brown, B.F. (ed.), Naval Research Laboratory, Washington, D.C., pp.28-31.

27. ASTM International, 2005, "Standard Practice for Preparation and Use of Direct Tension Stress-Corrosion Test Specimens," ASTM Standard G49-85.

28. ASTM International, 2009, "Standard Test Methods for Tension Testing of Metallic Materials," ASTM Standard E8/E8M-09.

29. Perez, N., 2004, Electrochemistry and Corrosion Science, Kluwer Academic Publishers, Norwell, MA, pp.21.

30. ASTM International, 2007, "Standard Practice for Making and Using C-Ring Stress Corrosion Test Specimens," ASTM Standard G38-01.

31. ASTM International, 2006, "Standard Practice for Making and Using Precracked Double Beam Stress Corrosion Specimens," ASTM Standard G 168-00.

32. ASTM International, 2009, "Standard Test Method for Linear-Elastic Plane-Strain Fracture Toughness $K_{\mathrm{lc}}$ of Metallic Materials," ASTM Standard E399-09.

33. Staley, J.T., 1976, "Aluminum Alloy and Process Developments for Aerospace," Metals Engineering Quarterly, 16 (2), pp.52-57.

34. Dorward, R.C., 1999, "Precipitate coarsening during overaging of Al-Zn-Mg-Cu alloy," Materials Science and Technology, 15, pp. 1133-1138.

35. Holroyd, N.J.H., 1988, "Environment-induced Cracking of High-strength Aluminum Alloys," Proceedings of the First International Conference on Environment-Induced Cracking of Metals, Gangloff, R.P. and Ives, M.B. (eds.), National Association of Corrosion Engineers, Houston, TX, pp.311-345.

36. Rajan, K., Wallace, W., and Beddoes, J.C., 1982, "Microstructural study of a high-strength stress-corrosion resistant 7075 aluminum alloy," Journal of Materials Science, 17 (10), pp.2817-2824.

37. Cina, B.M., 1974, US Patent 3,856,584.

38. Lukasak, D.A. and Hart, R.M., 1991, “Aluminum Alloy Development," Aerospace Engineering, 11 (9), pp.21-24. 
39. Ferrer, C.P., Koul, M.G., Connolly, B.J., and Moran, A.L., 2003, "Improvements in Strength and Stress Corrosion Cracking Properties in Aluminum Alloy 7075 via Low-Temperature Retrogression and Re-Aging Heat Treatments," Corrosion, 59 (6), pp.520-528.

40. Wallace, W., Beddoes, J.C., and de Malherbe, M.C., "A New Approach to the Problem of Stress Corrosion Cracking in 7075-T6 Aluminum," Canadian Aeronautics and Space Journal, 27, pp.222-232.

41. Song, M. and Chen, K., 2008, "Effects of the enhanced hat treatment on the mechanical properties and stress corrosion behavior of an Al-Zn-Mg alloy," Journal of Materials Science, 43 (15) pp.5256-5273.

42. Huang, L.P., Chen, K.H., Li, S., and Song, M., 2007, "Influence of high-temperature preprecipitation on local corrosion behaviours of Al-Zn-Mg alloy," Scripta Materialia, 56, pp.305-308.

43. Vander Voort, G.F. and Van Geertruyden, W., 2007, "Specimen Preparation for Electron Backscattered Diffraction," Buehler, Lake Bluff, IL, p.5.

44. Vander Voort, G.F., 1984, Metallography, Principles and Practice, McGraw-Hill, New York, p.610.

45. Katgerman, L. and Eskin, D., 2003, "Hardening, Annealing, and Aging," Handbook of Aluminum, Vol. 1: Physical Metallurgy and Processes, Totten, G.E. and MacKenzie, D.S. (eds.), Marcel Dekker, New York, p.267.

46. Dieter, G.E., 1986, Mechanical Metallurgy, McGraw-Hill, New York, pp.176-179.

47. Le May, I., 1981, Principles of Mechanical Metallurgy, Elsevier, New York, pp.113-115.

48. Honeycombe, R.W.K., 1984, The Plastic Deformation of Metals, Edward Arnold, London, pp.42-45. 
Appendix A: Tensile and DB Specimen Geometries

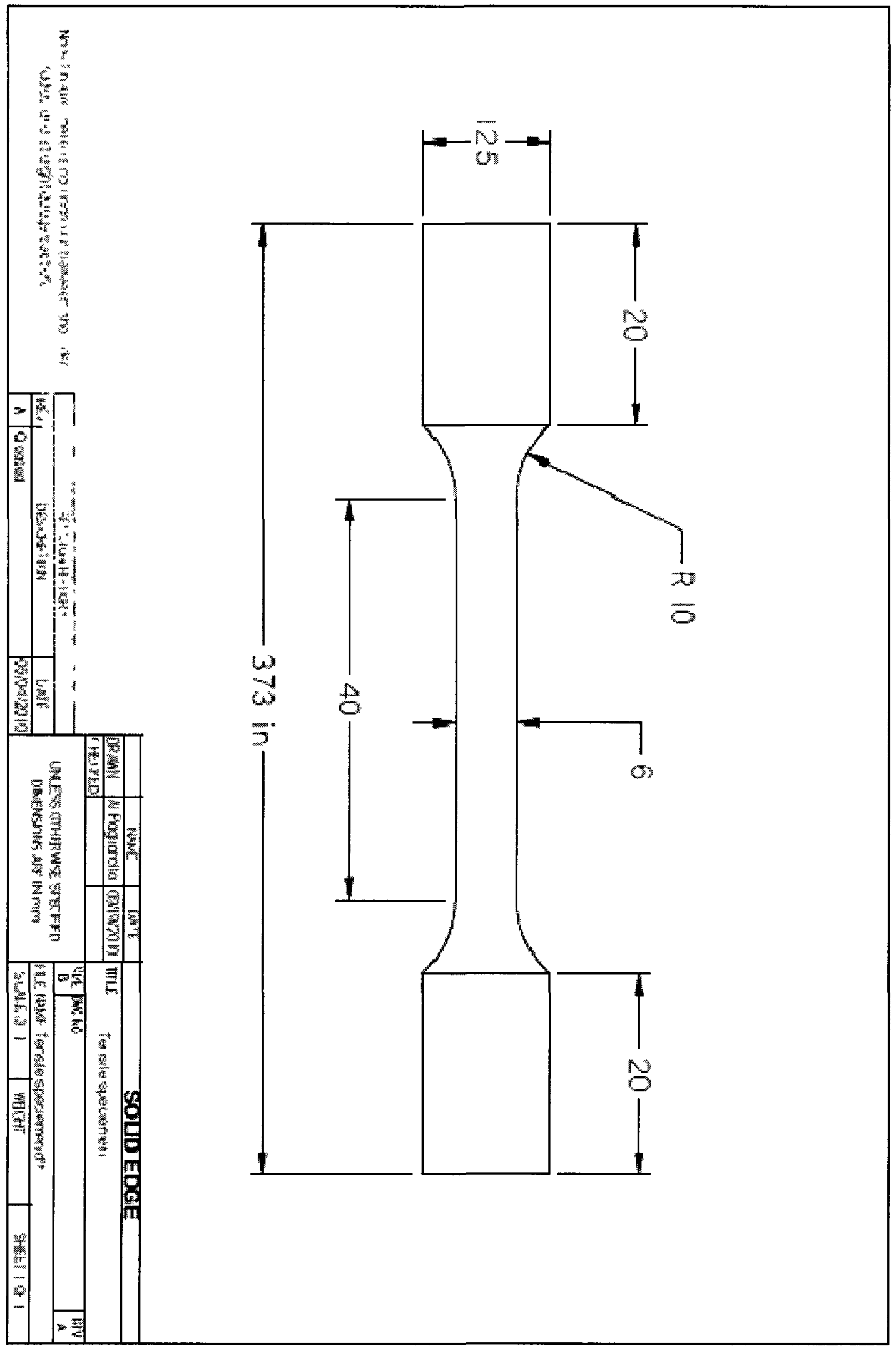




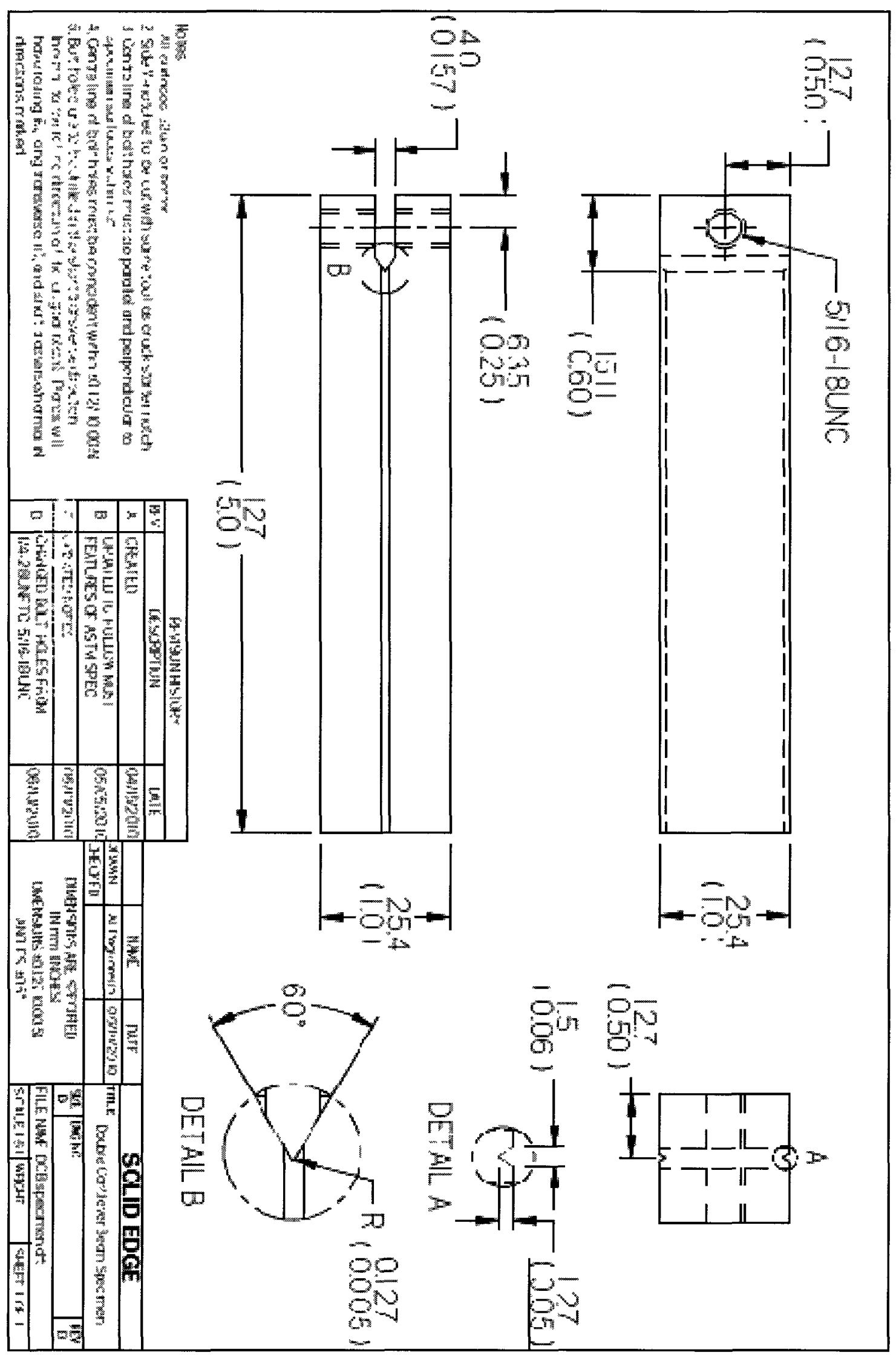


Appendix B: DB Specimen Test Environmental Measurements

Table B 1: Temperature and humidity measurements during DB specimen tests

\begin{tabular}{|c|c|c|c|c|}
\hline Date & Time & Elapsed time [h] & Temperature $\left[{ }^{\circ} \mathrm{C}\right]$ & \%RH \\
\hline 07-Jul-2010 & 1:00 PM & 0.00 & 31 & 59 \\
\hline 08-Jul-2010 & $8: 45 \mathrm{AM}$ & 19.75 & 31 & 47 \\
\hline 08-Jul-2010 & 9:47 PM & 32.78 & 32 & 52 \\
\hline 09-Jul-2010 & $8: 34 \mathrm{AM}$ & 43.57 & 29 & 59 \\
\hline 09-Jul-2010 & 10:43 PM & 57.75 & 28 & 60 \\
\hline 10-Jul-2010 & $12: 23 \mathrm{PM}$ & 71.42 & 26 & 60 \\
\hline 10-Jul-2010 & 10:34 PM & 81.23 & 27 & 52 \\
\hline 11-Jul-2010 & 2:09 PM & 96.82 & 27 & 44 \\
\hline 11-Jul-2010 & 10:32 PM & 105.20 & 28 & 49 \\
\hline 12-Jul-2010 & 9:30 AM & 116.17 & 25 & 54 \\
\hline 12-Jul-2010 & 11:32 PM & 130.20 & 25 & 59 \\
\hline 13-Jul-2010 & 10:02 AM & 140.70 & 24 & 62 \\
\hline 13-Jul-2010 & $11: 22 \mathrm{PM}$ & 174.30 & 25 & 67 \\
\hline 14-Jul-2010 & 9:38 AM & 184.57 & 25 & 65 \\
\hline 15-Jul-2010 & $12: 40 \mathrm{AM}$ & 199.60 & 27 & 57 \\
\hline 15-Jul-2010 & $9: 35 \mathrm{AM}$ & 208.52 & 26 & 59 \\
\hline 15-Jul-2010 & $10: 28 \mathrm{PM}$ & 221.40 & 28 & 50 \\
\hline 16-Jul-2010 & 9:47 AM & 232.72 & 26 & 66 \\
\hline 16-Jul-2010 & 10:40 PM & 245.60 & 24 & 55 \\
\hline 17-Jul-2010 & 10:11 AM & 257.12 & 23 & 59 \\
\hline 17-Jul-2010 & $10: 58 \mathrm{PM}$ & 269.90 & 28 & 45 \\
\hline 18-Jul-2010 & 11:05 PM & 294.02 & 26 & 46 \\
\hline 19-Jul-2010 & 9:20 AM & 304.27 & 25 & 57 \\
\hline 20-Jul-2010 & 9:35 AM & 328.52 & 24 & 53 \\
\hline 20-Jul-2010 & 11:12 PM & 342.13 & 26 & 44 \\
\hline 21-Jul-2010 & $9: 30 \mathrm{AM}$ & 352.43 & 25 & 58 \\
\hline 21-Jul-2010 & 11:40 PM & 366.60 & 24 & 60 \\
\hline 22-Jul-2010 & 10:11 AM & 377.12 & 24 & 57 \\
\hline 22-Jul-2010 & 11:01 PM & 389.95 & 25 & 48 \\
\hline 23-Jul-2010 & 9:37 AM & 400.55 & 23 & 59 \\
\hline 23-Jul-2010 & 9:45 PM & 412.68 & 24 & 58 \\
\hline 24-Jul-2010 & 6:33 AM & 421.48 & 22 & 73 \\
\hline 24-Jul-2010 & 11:03 PM & 437.98 & 26 & 60 \\
\hline 25-Jul-2010 & 9:30 AM & 444.88 & 23 & 52 \\
\hline 25-Jul-2010 & $11: 17 \mathrm{PM}$ & 458.67 & 23 & 45 \\
\hline 26-Jul-2010 & 9:02 AM & 453.07 & 22 & 55 \\
\hline 26-Jul-2010 & 11:33 PM & 467.58 & 25 & 42 \\
\hline 27-Jul-2010 & 9:30 AM & 477.53 & 24 & 53 \\
\hline 27-Jul-2010 & 10:31 PM & 490.55 & 27 & 55 \\
\hline 28-Jul-2010 & 9:03 AM & 501.02 & 24 & 59 \\
\hline
\end{tabular}




\begin{tabular}{|c|c|c|c|c|}
\hline 28-Jul-2010 & 11:20 PM & 515.30 & 25 & 56 \\
\hline 29-Jul-2010 & 9:19 AM & 525.28 & 22 & 46 \\
\hline 29-Jul-2010 & $11: 21 \mathrm{PM}$ & 539.32 & 23 & 42 \\
\hline 30-Jul-2010 & 12:08 PM & 552.10 & 21 & 36 \\
\hline 30-Jul-2010 & 10:02 PM & 562.00 & 21 & 37 \\
\hline 31-Jul-2010 & $11: 33 \mathrm{AM}$ & 575.52 & 20 & 48 \\
\hline 31-Jul-2010 & 11:18 PM & 587.27 & 21 & 52 \\
\hline 01-Aug-2010 & 11:08 PM & 611.10 & 23 & 59 \\
\hline 02-Aug-2010 & 12:14 PM & 624.20 & 24 & 65 \\
\hline 02-Aug-2010 & 11:30 PM & 635.47 & 25 & 67 \\
\hline 03-Aug-2010 & $8: 56$ AM & 644.90 & 24 & 73 \\
\hline 03-Aug-2010 & 10:32 PM & 658.50 & 25 & 73 \\
\hline 04-Aug-2010 & $9: 17 \mathrm{AM}$ & 669.25 & 25 & 71 \\
\hline 04-Aug-2010 & 10:18 PM & 682.27 & 27 & 74 \\
\hline 05-Aug-2010 & $10: 52 \mathrm{AM}$ & 694.83 & 26 & 66 \\
\hline 05-Aug-2010 & 11:30 PM & 707.47 & 26 & 55 \\
\hline 06-Aug-2010 & $8: 14$ AM & 716.20 & 22 & 45 \\
\hline 07-Aug-2010 & $12: 09 \mathrm{AM}$ & 732.12 & 21 & 50 \\
\hline 07-Aug-2010 & $10: 51 \mathrm{AM}$ & 742.82 & 20 & 45 \\
\hline 07-Aug-2010 & 10:20 PM & 754.30 & 21 & 46 \\
\hline 08-Aug-2010 & 11:09 PM & 779.12 & 23 & 65 \\
\hline 09-Aug-2010 & $10: 48 \mathrm{AM}$ & 790.77 & 24 & 62 \\
\hline 09-Aug-2010 & 11:43 PM & 803.68 & 25 & 64 \\
\hline 10-Aug-2010 & 9:06 AM & 813.07 & 24 & 67 \\
\hline 10-Aug-2010 & 11:00 PM & 826.97 & 26 & 64 \\
\hline 11-Aug-2010 & $10: 00 \mathrm{AM}$ & 837.97 & 26 & 64 \\
\hline 11-Aug-2010 & $11: 29$ PM & 851.45 & 27 & 59 \\
\hline 12-Aug-2010 & $10: 54 \mathrm{AM}$ & 862.87 & 23 & 53 \\
\hline 12-Aug-2010 & 11:03 PM & 875.02 & 23 & 47 \\
\hline 13-Aug-2010 & $9: 11$ AM & 885.15 & 21 & 53 \\
\hline 13-Aug-2010 & 10:28 PM & 898.43 & 24 & 64 \\
\hline 14-Aug-2010 & 4:56 PM & 916.90 & 26 & 53 \\
\hline 14-Aug-2010 & 11:38 PM & 923.60 & 25 & 66 \\
\hline 15-Aug-2010 & 11:32 AM & 935.50 & 22 & 77 \\
\hline 15-Aug-2010 & $11: 25$ PM & 947.38 & 23 & 71 \\
\hline 16-Aug-2010 & $11: 17 \mathrm{AM}$ & 959.25 & 25 & 70 \\
\hline 17-Aug-2010 & $12: 08 \mathrm{AM}$ & 972.10 & 23 & 59 \\
\hline 17-Aug-2010 & $9: 28$ AM & 981.43 & 22 & 59 \\
\hline 17-Aug-2010 & 10:30 PM & 994.47 & 23 & 48 \\
\hline 18-Aug-2010 & $8: 54 \mathrm{AM}$ & 1004.87 & 21 & 58 \\
\hline 18-Aug-2010 & 10:49 PM & 1018.78 & 22 & 49 \\
\hline 19-Aug-2010 & $9: 44$ AM & 1029.70 & 22 & 58 \\
\hline 19-Aug-2010 & 11:01 PM & 1042.98 & 22 & 61 \\
\hline
\end{tabular}




\begin{tabular}{|c|c|c|c|c|}
\hline 20 -Aug-2010 & $11: 20 \mathrm{AM}$ & 1055.30 & 21 & 50 \\
\hline 20-Aug-2010 & $11: 45$ PM & 1067.72 & 21 & 57 \\
\hline 21-Aug-2010 & 9:01 AM & 1076.98 & 20 & 60 \\
\hline 22-Aug-2010 & $9: 43 \mathrm{AM}$ & 1101.68 & 19 & 68 \\
\hline 22-Aug-2010 & $11: 27$ PM & 1115.42 & 20 & 71 \\
\hline 23-Aug-2010 & $9: 35 \mathrm{AM}$ & 1125.55 & 20 & 70 \\
\hline 23-Aug-2010 & 9:36 PM & 1137.57 & 23 & 61 \\
\hline 24-Aug-2010 & 11:03 PM & 1163.02 & 22 & 60 \\
\hline 25-Aug-2010 & $9: 24 \mathrm{AM}$ & 1173.37 & 21 & 61 \\
\hline 25-Aug-2010 & 11:04 PM & 1187.03 & 22 & 71 \\
\hline 26-Aug-2010 & $8: 43 \mathrm{AM}$ & 1196.68 & 21 & 64 \\
\hline 26-Aug-2010 & 10:15 PM & 1210.22 & 21 & 58 \\
\hline 27-Aug-2010 & $9: 23 \mathrm{AM}$ & 1221.35 & 20 & 55 \\
\hline 27-Aug-2010 & 9:58 PM & 1233.93 & 21 & 55 \\
\hline 28-Aug-2010 & 12:58 PM & 1248.93 & 21 & 62 \\
\hline 28-Aug-2010 & 10:01 PM & 1257.98 & 24 & 60 \\
\hline 29-Aug-2010 & $7: 55 \mathrm{AM}$ & 1267.88 & 23 & 64 \\
\hline 29-Aug-2010 & $10: 26 \mathrm{PM}$ & 1282.40 & 26 & 56 \\
\hline 30-Aug-2010 & $7: 20 \mathrm{AM}$ & 1291.30 & 24 & 53 \\
\hline 30-Aug-2010 & 10:02 PM & 1306.00 & 28 & 57 \\
\hline 31-Aug-2010 & $8: 58 \mathrm{AM}$ & 1316.93 & 26 & 54 \\
\hline 31-Aug-2010 & $11: 40$ PM & 1331.63 & 28 & 61 \\
\hline 01-Sep-2010 & $10: 41$ AM & 1341.68 & 27 & 65 \\
\hline 02-Sep-2010 & $8: 26$ AM & 1363.43 & 26 & 62 \\
\hline 02-Sep-2010 & $11: 26 \mathrm{PM}$ & 1378.43 & 27 & 69 \\
\hline 03-Sep-2010 & $8: 53 \mathrm{AM}$ & 1388.33 & 24 & 68 \\
\hline 03-Sep-2010 & $10: 26 \mathrm{PM}$ & 1401.43 & 25 & 64 \\
\hline 04-Sep-2010 & $9: 21 \mathrm{AM}$ & 1412.80 & 20 & 61 \\
\hline 04-Sep-2010 & 11:04 PM & 1426.07 & 20 & 58 \\
\hline 05-Sep-2010 & $7: 23 \mathrm{AM}$ & 1434.83 & 19 & 55 \\
\hline 05-Sep-2010 & $11: 13$ PM & 1450.22 & 19 & 60 \\
\hline 06-Sep-2010 & $7: 29 \mathrm{AM}$ & 1458.93 & 18 & 59 \\
\hline 06-Sep-2010 & $11: 10$ PM & 1474.17 & 19 & 69 \\
\hline 07-Sep-2010 & $8: 05 \mathrm{AM}$ & 1483.53 & 19 & 69 \\
\hline 07-Sep-2010 & $10: 21 \mathrm{PM}$ & 1497.35 & 22 & 71 \\
\hline 08-Sep-2010 & $8: 38 \mathrm{AM}$ & 1508.08 & 21 & 65 \\
\hline 08-Sep-2010 & $11: 16$ PM & 1522.27 & 21 & 60 \\
\hline 09-Sep-2010 & 8:05 AM & 1531.53 & 20 & 61 \\
\hline 09-Sep-2010 & 11:41 PM & 1546.68 & 19 & 63 \\
\hline 10-Sep-2010 & $9: 20 \mathrm{AM}$ & 1556.78 & 18 & 66 \\
\hline 10-Sep-2010 & 10:41 PM & 1569.68 & 20 & 60 \\
\hline 11-Sep-2010 & $8: 08 \mathrm{AM}$ & 1579.58 & 19 & 63 \\
\hline 11-Sep-2010 & $10: 43 \mathrm{PM}$ & 1593.72 & 21 & 69 \\
\hline
\end{tabular}




\begin{tabular}{|c|c|c|c|c|}
\hline 12-Sep-2010 & $7: 25$ AM & 1602.87 & 20 & 60 \\
\hline 12-Sep-2010 & 10:31 PM & 1617.52 & 19 & 65 \\
\hline 13-Sep-2010 & $7: 18$ AM & 1626.75 & 19 & 65 \\
\hline 13-Sep-2010 & 11:10 PM & 1642.17 & 20 & 68 \\
\hline 14-Sep-2010 & $9: 13$ AM & 1652.67 & 19 & 70 \\
\hline 14-Sep-2010 & 11:11 PM & 1666.18 & 19 & 59 \\
\hline 15-Sep-2010 & $8: 15$ AM & 1675.70 & 17 & 63 \\
\hline 15-Sep-2010 & 10:59 PM & 1689.98 & 18 & 59 \\
\hline 16-Sep-2010 & $8: 26$ AM & 1699.88 & 16 & 63 \\
\hline 16-Sep-2010 & 11:28 PM & 1714.47 & 16 & 70 \\
\hline 17-Sep-2010 & 9:32 AM & 1724.98 & 15 & 73 \\
\hline 17-Sep-2010 & 10:15 PM & 1737.25 & 17 & 73 \\
\hline 18-Sep-2010 & $7: 51 \mathrm{AM}$ & 1747.30 & 16 & 68 \\
\hline 18-Sep-2010 & $10: 22 \mathrm{PM}$ & 1761.37 & 17 & 67 \\
\hline 19-Sep-2010 & 7:32 AM & 1770.98 & 17 & 71 \\
\hline 19-Sep-2010 & 11:34 PM & 1786.57 & 18 & 66 \\
\hline 20-Sep-2010 & $10: 32 \mathrm{AM}$ & 1797.98 & 20 & 62 \\
\hline 20-Sep-2010 & 11:12 PM & 1810.20 & 21 & 50 \\
\hline 21-Sep-2010 & $8: 55$ AM & 1820.37 & 20 & 56 \\
\hline 21-Sep-2010 & 11:03 PM & 1834.05 & 19 & 60 \\
\hline 22-Sep-2010 & $7: 52$ AM & 1843.32 & 19 & 65 \\
\hline 22-Sep-2010 & 10:30 PM & 1857.50 & 21 & 63 \\
\hline 23-Sep-2010 & 9:07 AM & 1868.57 & 21 & 56 \\
\hline 24-Sep-2010 & $8: 53$ AM & 1892.33 & 19 & 59 \\
\hline 24-Sep-2010 & 11:40 PM & 1906.67 & 21 & 72 \\
\hline $25-$ Sep-2010 & $9: 42 \mathrm{AM}$ & 1917.15 & 18 & 59 \\
\hline 25-Sep-2010 & 11:31 PM & 1930.52 & 20 & 65 \\
\hline 26-Sep-2010 & 9:02 AM & 1940.48 & 19 & 61 \\
\hline 26-Sep-2010 & 10:37 PM & 1953.62 & 19 & 69 \\
\hline 27-Sep-2010 & 8:29 AM & 1963.93 & 19 & 66 \\
\hline 27-Sep-2010 & $10: 48$ PM & 1977.80 & 19 & 67 \\
\hline 28-Sep-2010 & 10:20 AM & 1989.78 & 19 & 69 \\
\hline 28-Sep-2010 & 10:34 PM & 2001.57 & 21 & 73 \\
\hline 29-Sep-2010 & $8: 45$ AM & 2012.20 & 20 & 68 \\
\hline 29-Sep-2010 & $11: 32$ PM & 2026.53 & 20 & 67 \\
\hline 30-Sep-2010 & $7: 25$ AM & 2034.87 & 19 & 67 \\
\hline 30-Sep-2010 & 10:28 PM & 2049.47 & 19 & 70 \\
\hline $01-$ Oct-2010 & $7: 45$ AM & 2059.20 & 19 & 71 \\
\hline 01-Oct-2010 & 10:25 PM & 2073.42 & 20 & 62 \\
\hline $02-$ Oct- 2010 & $10: 28 \mathrm{AM}$ & 2085.47 & 21 & 58 \\
\hline 02-Oct-2010 & $10: 56 \mathrm{PM}$ & 2097.93 & 20 & 61 \\
\hline $03-$ Oct- 2010 & $8: 16$ AM & 2107.27 & 20 & 57 \\
\hline 03-Oct- 2010 & 11:31 PM & 2122.52 & 19 & 55 \\
\hline
\end{tabular}




\begin{tabular}{|c|c|c|c|c|}
\hline $04-O c t-2010$ & $8: 19$ AM & 2131.32 & 19 & 52 \\
\hline $04-O c t-2010$ & 11:08 PM & 2146.13 & 20 & 57 \\
\hline $05-O c t-2010$ & $9: 44 \mathrm{AM}$ & 2156.73 & 20 & 57 \\
\hline $05-$ Oct-2010 & $11: 32 \mathrm{PM}$ & 2170.53 & 20 & 54 \\
\hline $06-$ Oct- 2010 & $8: 18$ AM & 2179.30 & 19 & 54 \\
\hline $06-O c t-2010$ & $11: 32$ PM & 2194.53 & 19 & 61 \\
\hline $07-$ Oct- 2010 & $8: 57$ AM & 2203.95 & 19 & 59 \\
\hline $07-$ Oct-2010 & 11:07 PM & 2218.12 & 19 & 55 \\
\hline $08-$ Oct- 2010 & $7: 46$ AM & 2226.77 & 19 & 60 \\
\hline $08-O c t-2010$ & $11: 28 \mathrm{PM}$ & 2242.47 & 18 & 59 \\
\hline 09-Oct-2010 & 9:38 AM & 2252.63 & 19 & 54 \\
\hline $10-$ Oct- 2010 & $12: 59 \mathrm{AM}$ & 2267.98 & 19 & 56 \\
\hline $10-$ Oct-2010 & $10: 42 \mathrm{PM}$ & 2289.70 & 19 & 66 \\
\hline $11-$ Oct- 2010 & $8: 23$ AM & 2299.38 & 18 & 64 \\
\hline 11 -Oct-2010 & $10: 38 \mathrm{PM}$ & 2313.63 & 19 & 57 \\
\hline 12 -Oct-2010 & $9: 28 \mathrm{AM}$ & 2324.47 & 20 & 54 \\
\hline 12 -Oct-2010 & $11: 17$ PM & 2338.28 & 21 & 54 \\
\hline $13-$ Oct- 2010 & $8: 36$ AM & 2347.60 & 18 & 52 \\
\hline 13 -Oct- 2010 & $10: 55$ PM & 2361.92 & 19 & 55 \\
\hline $14-$ Oct- 2010 & 8:43 AM & 2371.72 & 19 & 55 \\
\hline $14-$ Oct- 2010 & 11:32 PM & 2386.53 & 20 & 61 \\
\hline 15 -Oct- 2010 & $8: 38 \mathrm{AM}$ & 2395.63 & 19 & 59 \\
\hline 15 -Oct- 2010 & 10:47 PM & 2409.78 & 19 & 60 \\
\hline $16-$ Oct- 2010 & $8: 22 \mathrm{AM}$ & 2419.37 & 19 & 57 \\
\hline $16-$ Oct- 2010 & 11:34 PM & 2434.57 & 18 & 61 \\
\hline $17-$ Oct- 2010 & $7: 34 \mathrm{AM}$ & 2442.57 & 18 & 56 \\
\hline 17-Oct-2010 & 10:51 PM & 2458.28 & 19 & 63 \\
\hline 18 -Oct- 2010 & 9:27 AM & 2468.45 & 19 & 59 \\
\hline 18 -Oct-2010 & $11: 04$ PM & 2482.50 & 19 & 56 \\
\hline $19-$ Oct- 2010 & $8: 39$ AM & 2491.65 & 18 & 51 \\
\hline 19-Oct-2010 & $11: 39$ PM & 2507.08 & 18 & 47 \\
\hline 20-Oct-2010 & $8: 43 \mathrm{AM}$ & 2515.72 & 18 & 49 \\
\hline 20 -Oct- 2010 & $10: 35$ PM & 2530.02 & 19 & 50 \\
\hline 21-Oct-2010 & $8: 20 \mathrm{AM}$ & 2539.33 & 19 & 55 \\
\hline 21-Oct-2010 & $10: 43$ PM & 2554.15 & 19 & 48 \\
\hline 22-Oct-2010 & $7: 42$ AM & 2562.70 & 19 & 54 \\
\hline $22-$ Oct-2010 & 10:50 PM & 2578.27 & 20 & 46 \\
\hline 23-Oct-2010 & $8: 31$ AM & 2587.52 & 20 & 43 \\
\hline 23-Oct-2010 & 11:05 PM & 2602.52 & 20 & 47 \\
\hline 24-Oct-2010 & $10: 12 \mathrm{AM}$ & 2613.20 & 21 & 38 \\
\hline 24-Oct-2010 & $10: 47$ PM & 2626.22 & 20 & 42 \\
\hline 25 -Oct- 2010 & $8: 48$ AM & 2635.63 & 20 & 39 \\
\hline $25-$ Oct- 2010 & $11: 00$ PM & 2650.43 & 19 & 49 \\
\hline
\end{tabular}




\begin{tabular}{|c|c|c|c|c|}
\hline 26-Oct-2010 & $8: 30$ AM & 2659.33 & 19 & 47 \\
\hline 26-Oct-2010 & 10:32 PM & 2673.97 & 19 & 53 \\
\hline 27-Oct-2010 & $7: 29 \mathrm{AM}$ & 2682.32 & 19 & 56 \\
\hline 27-Oct-2010 & 11:06 PM & 2698.53 & 20 & 54 \\
\hline $28-$ Oct-2010 & 9:07 AM & 2707.95 & 19 & 54 \\
\hline 28-Oct-2010 & 11:07 PM & 2722.55 & 18 & 53 \\
\hline 29-Oct-2010 & 7:39 AM & 2730.48 & 19 & 50 \\
\hline $29-$ Oct-2010 & 11:52 PM & 2747.30 & 19 & 44 \\
\hline $30-$ Oct-2010 & $8: 31$ AM & 2755.35 & 18 & 44 \\
\hline $30-$ Oct-2010 & 10:43 PM & 2770.15 & 18 & 43 \\
\hline 31-Oct-2010 & 11:03 AM & 2782.48 & 18 & 43 \\
\hline $31-$ Oct-2010 & 10:44 PM & 2794.17 & 19 & 44 \\
\hline 01-Nov-2010 & $8: 51$ AM & 2803.68 & 18 & 40 \\
\hline 01-Nov-2010 & 10:52 PM & 2818.30 & 21 & 40 \\
\hline 02-Nov-2010 & $8: 28$ AM & 2827.30 & 21 & 37 \\
\hline 02-Nov-2010 & 10:58 PM & 2842.40 & 20 & 39 \\
\hline 03-Nov-2010 & $8: 16$ AM & 2851.10 & 20 & 37 \\
\hline 03-Nov-2010 & 10:13 PM & 2865.65 & 19 & 39 \\
\hline 04-Nov-2010 & $8: 16$ AM & 2875.10 & 19 & 39 \\
\hline 04-Nov-2010 & 10:57 PM & 2890.28 & 19 & 44 \\
\hline 05-Nov-2010 & $8: 42$ AM & 2899.53 & 19 & 40 \\
\hline $05-N o v-2010$ & 10:53 PM & 2914.21 & 19 & 40 \\
\hline 06-Nov-2010 & $7: 48 \mathrm{AM}$ & 2922.63 & 19 & 40 \\
\hline 06-Nov-2010 & 10:01 PM & 2937.35 & 19 & 34 \\
\hline 07-Nov-2010 & 9:50 AM & 2948.67 & 20 & 35 \\
\hline 07-Nov-2010 & 10:51 PM & 2962.18 & 19 & 43 \\
\hline 08-Nov-2010 & 8:04 AM & 2970.90 & 18 & 41 \\
\hline 08-Nov-2010 & 10:16 PM & 2985.60 & 20 & 40 \\
\hline 09-Nov-2010 & $8: 11$ AM & 2995.02 & 20 & 39 \\
\hline 09-Nov-2010 & 11:13 PM & 3010.55 & 20 & 40 \\
\hline 10-Nov-2010 & 8:38 AM & 3019.47 & 20 & 37 \\
\hline 10-Nov-2010 & 11:19 PM & 3034.65 & 20 & 37 \\
\hline 11-Nov-2010 & 8:06 AM & 3042.93 & 19 & 38 \\
\hline 11-Nov-2010 & 10:50 PM & 3058.16 & 20 & 39 \\
\hline 12-Nov-2010 & $8: 46$ AM & 3067.60 & 20 & 35 \\
\hline 13-Nov-2010 & $12: 56 \mathrm{AM}$ & 3083.77 & 20 & 35 \\
\hline 13-Nov-2010 & $10: 43$ AM & 3093.55 & 20 & 35 \\
\hline 13-Nov-2010 & 11:17 PM & 3106.12 & 20 & 41 \\
\hline 14-Nov-2010 & $10: 42 \mathrm{AM}$ & 3117.53 & 19 & 38 \\
\hline 14-Nov-2010 & 10:30 PM & 3129.33 & 22 & 39 \\
\hline 15-Nov-2010 & 8:04 AM & 3138.90 & 19 & 40 \\
\hline $15-N o v-2010$ & 10:29 PM & 3153.32 & 20 & 41 \\
\hline $16-N o v-2010$ & 8:06 AM & 3162.93 & 20 & 39 \\
\hline
\end{tabular}




\begin{tabular}{|c|c|c|c|c|}
\hline 16-Nov-2010 & $11: 30$ PM & 3178.33 & 19 & 44 \\
\hline $17-N o v-2010$ & $7: 08$ AM & 3185.97 & 19 & 45 \\
\hline $17-N o v-2010$ & $11: 09$ PM & 3201.98 & 18 & 47 \\
\hline $18-N o v-2010$ & $8: 18$ AM & 3211.13 & 18 & 44 \\
\hline $18-N o v-2010$ & $10: 17$ PM & 3225.12 & 19 & 44 \\
\hline $19-N o v-2010$ & $8: 49$ AM & 3235.65 & 20 & 37 \\
\hline $19-N o v-2010$ & $11: 19$ PM & 3250.15 & 20 & 43 \\
\hline 20-Nov-2010 & $10: 08$ AM & 3260.97 & 20 & 36 \\
\hline 20-Nov-2010 & $11: 19$ PM & 3274.15 & 19 & 35 \\
\hline $21-N o v-2010$ & $8: 51$ AM & 3283.25 & 20 & 32 \\
\hline $21-N o v-2010$ & $10: 34$ PM & 3297.40 & 19 & 31 \\
\hline $22-N o v-2010$ & $8: 38$ AM & 3307.03 & 19 & 31 \\
\hline 22-Nov-2010 & $11: 03$ PM & 3321.88 & 19 & 36 \\
\hline 23-Nov-2010 & $9: 27$ AM & 3331.85 & 19 & 36 \\
\hline 23-Nov-2010 & $10: 58$ PM & 3345.80 & 21 & 41 \\
\hline 24-Nov-2010 & $8: 25$ AM & 3354.82 & 21 & 35 \\
\hline
\end{tabular}




\section{Appendix C: Complete Results of Uniaxial Tensile Tests}

Table C 1: Complete tensile test results

\begin{tabular}{|c|c|c|c|c|}
\hline Specimen & E [GPa] & $\sigma_{\mathrm{y}}[\mathrm{MPa}]$ & UTS [MPa] & Ductility [\%EL] \\
\hline T651 A & 70.55 & 530 & 597.17 & 12.6 \\
\hline T651 B & 68.75 & 528 & 587.56 & 10.2 \\
\hline$T 6 * A$ & 71.02 & 500 & 587.97 & 9.3 \\
\hline T6* B & 70.50 & 502 & 590.09 & 10.1 \\
\hline T73(51) A & 70.43 & 450 & 531.49 & 15.9 \\
\hline $\mathrm{T73}(51) \mathrm{B}$ & 70.71 & 457 & 533.93 & 8.4 \\
\hline T73*A & 70.03 & 485 & 568.09 & 6.4 \\
\hline T73*B & 70.60 & 479 & 567.24 & 13.5 \\
\hline S495 A & 19.91 & 450 & 581.97 & 8.4 \\
\hline S495 B & 69.92 & 470 & 572.75 & 13.9 \\
\hline $\mathrm{H} 480 \mathrm{~A}$ & 70.33 & 495 & 584.20 & 10.5 \\
\hline $\mathrm{H} 480 \mathrm{~B}$ & 70.07 & 490 & 585.60 & 12.7 \\
\hline $\mathrm{H} 495 \mathrm{~A}$ & 69.25 & 497 & 593.10 & 9.7 \\
\hline H495 B & 70.09 & 500 & 588.97 & 18.0 \\
\hline F430 A & 70.70 & 488 & 581.78 & 15.0 \\
\hline F430 B & 69.78 & 490 & 583.63 & 14.3 \\
\hline $\mathrm{F} 400 \mathrm{~A}$ & 69.54 & 462 & 553.01 & 15.2 \\
\hline $\mathrm{F} 400 \mathrm{~B}$ & 70.01 & 463 & 552.56 & 13.8 \\
\hline $\mathrm{F} 370 \mathrm{~A}$ & 70.28 & 375 & 468.87 & 13.4 \\
\hline F370 B & 69.23 & 377 & 471.45 & 14.8 \\
\hline $\mathrm{M} 430 \mathrm{~A}$ & 70.53 & 482 & 576.96 & 17.6 \\
\hline $\mathrm{M} 430 \mathrm{~B}$ & 69.54 & 482 & 580.09 & 15.7 \\
\hline $\mathrm{M} 400 \mathrm{~A}$ & 70.40 & 432 & 522.86 & 17.1 \\
\hline $\mathrm{M} 400 \mathrm{~B}$ & 70.51 & 426 & 517.36 & 15.8 \\
\hline M370 A & 69.25 & 374 & 468.25 & 11.6 \\
\hline M370 B & 70.70 & 372 & 468.86 & 14.9 \\
\hline L430 A & 70.35 & 476 & 575.51 & 16.5 \\
\hline L430 B & 71.27 & 480 & 571.83 & 16.1 \\
\hline L400 A & 71.54 & 438 & 527.31 & 16.5 \\
\hline L400 B & 70.93 & 438 & 524.85 & 12.6 \\
\hline L370 A & 70.02 & 374 & 466.15 & 12.1 \\
\hline L370 B & 69.94 & 367 & 466.57 & 14.0 \\
\hline $\mathrm{H} 495-\mathrm{F} 430 \mathrm{~A}$ & 69.87 & 486 & 578.66 & 16.5 \\
\hline $\mathrm{H} 495-\mathrm{F} 430 \mathrm{~B}$ & 69.92 & 487 & 577.21 & 14.6 \\
\hline H495-F400 A & 70.26 & 442 & 534.34 & 13.5 \\
\hline H495-F400 B & 69.37 & 438 & 531.47 & 13.6 \\
\hline S495-F430 A & 71.44 & 488 & 583.54 & 12.7 \\
\hline S495-F430 B & 71.22 & 487 & 585.39 & 16.6 \\
\hline S495-F400 A & 70.34 & 425 & 522.43 & 14.3 \\
\hline S495-F400 B & 70.37 & 434 & 523.67 & 14.0 \\
\hline
\end{tabular}




\section{Appendix D: Interim DB Specimen Measurements}

Table D 2: Specimen T651 C

\begin{tabular}{|c|c|c|c|c|c|c|}
\hline \multirow{2}{*}{$\frac{\text { elapsed time }[\mathrm{h}]}{0}$} & \multicolumn{3}{|c|}{$\begin{array}{c}\text { crack length [mm] } \\
\text { (one side/other side/avg) }\end{array}$} & \multirow[t]{2}{*}{$\mathrm{da} / \mathrm{dt}[\mathrm{mm} / \mathrm{h}]$} & \multirow{2}{*}{$\frac{\text { K_I [MPaVm] }}{26.40}$} & \multirow[t]{2}{*}{ avg K_I } \\
\hline & 14.50 & 15.20 & 14.85 & & & \\
\hline 60.28 & 14.90 & 15.20 & 15.05 & 0.0033 & 26.01 & 26.21 \\
\hline 143.97 & 18.47 & 19.08 & 18.77 & 0.0445 & 20.14 & 23.08 \\
\hline 203.28 & 18.82 & 20.59 & 19.70 & 0.0157 & 19.00 & 19.57 \\
\hline 298.92 & 20.53 & 23.11 & 21.82 & 0.0221 & 16.75 & 17.87 \\
\hline 371.37 & 24.47 & 25.25 & 24.86 & 0.0420 & 14.17 & 15.46 \\
\hline 467.40 & 26.75 & 25.97 & 26.36 & 0.0156 & 13.11 & 13.64 \\
\hline 563.43 & 29.20 & 28.67 & 28.93 & 0.0268 & 11.56 & 12.34 \\
\hline 645.97 & 29.98 & 29.62 & 29.80 & 0.0105 & 11.10 & 11.33 \\
\hline 730.07 & 30.40 & 31.88 & 31.14 & 0.0159 & 10.44 & 10.77 \\
\hline 851.03 & 33.36 & 32.05 & 32.70 & 0.0129 & 9.74 & 10.09 \\
\hline 1023.67 & 35.22 & 35.87 & 35.54 & 0.0165 & 8.64 & 9.19 \\
\hline 1199.00 & 35.26 & 36.75 & 36.00 & 0.0026 & 8.48 & 8.56 \\
\hline 1389.57 & 36.06 & 37.36 & 36.71 & 0.0037 & 8.24 & 8.36 \\
\hline 1594.88 & 37.56 & 37.58 & 37.57 & 0.0042 & 7.97 & 8.11 \\
\hline 1839.72 & 37.83 & 38.19 & 38.01 & 0.0018 & 7.83 & 7.90 \\
\hline 2180.27 & 38.40 & 38.47 & 38.43 & 0.0012 & 7.70 & 7.77 \\
\hline 2560.65 & 38.75 & 38.94 & 38.84 & 0.0011 & 7.58 & 7.64 \\
\hline
\end{tabular}

Table D 3: Specimen T651 D

\begin{tabular}{|c|c|c|c|c|c|c|}
\hline elapsed time [h] & $\begin{array}{r}\mathrm{cra} \\
\text { (one } \mathrm{s}\end{array}$ & $\begin{array}{l}\text { length } \\
\text { /other }\end{array}$ & $\begin{array}{l}\mathrm{fm]} \\
\text { de/avg) }\end{array}$ & $\mathrm{da} / \mathrm{dt}[\mathrm{mm} / \mathrm{h}]$ & K_I [MPaVm] & avg K_I \\
\hline 0 & 12.79 & 13.45 & 13.12 & & 26.06 & \\
\hline 60.40 & 14.13 & 13.59 & 13.86 & 0.0123 & 24.55 & 25.31 \\
\hline 144.07 & 15.71 & 14.98 & 15.34 & 0.0177 & 21.93 & 23.24 \\
\hline 203.43 & 17.21 & 15.03 & 16.12 & 0.0131 & 20.74 & 21.33 \\
\hline 299.00 & 20.31 & 15.32 & 17.81 & 0.0177 & 18.47 & 19.60 \\
\hline 371.45 & 23.40 & 17.96 & 20.68 & 0.0395 & 15.43 & 16.95 \\
\hline 467.50 & 24.21 & 22.70 & 23.45 & 0.0289 & 13.17 & 14.30 \\
\hline 563.52 & 27.33 & 26.23 & 26.78 & 0.0346 & 11.06 & 12.11 \\
\hline 646.03 & 28.41 & 27.58 & 27.99 & 0.0147 & 10.42 & 10.74 \\
\hline 730.15 & 29.19 & 30.55 & 29.87 & 0.0223 & 9.53 & 9.98 \\
\hline 851.10 & 32.15 & 30.55 & 31.35 & 0.0122 & 8.91 & 9.22 \\
\hline 1023.73 & 33.28 & 32.36 & 32.82 & 0.0085 & 8.35 & 8.63 \\
\hline 1199.07 & 34.81 & 34.17 & 34.49 & 0.0095 & 7.78 & 8.06 \\
\hline 1389.72 & 36.18 & 35.53 & 35.85 & 0.0072 & 7.35 & 7.57 \\
\hline 1594.97 & 39.74 & 37.88 & 38.81 & 0.0144 & 6.54 & 6.95 \\
\hline 1839.88 & 39.90 & 39.68 & 39.79 & 0.0040 & 6.30 & 6.42 \\
\hline
\end{tabular}




\begin{tabular}{|l|l|l|l|l|l|l|}
\hline 2180.35 & 40.02 & 40.72 & 40.37 & 0.0017 & 6.17 & 6.24 \\
\hline 2560.73 & 40.35 & 40.98 & 40.66 & 0.0008 & 6.10 & 6.14 \\
\hline
\end{tabular}

Table D 4: Specimen T651 E

\begin{tabular}{|c|c|c|c|c|c|c|}
\hline \multirow{2}{*}{$\begin{array}{c}\text { elapsed time }[\mathrm{h}] \\
0.00\end{array}$} & \multicolumn{3}{|c|}{$\begin{array}{c}\text { crack length [mm] } \\
\text { (one side/other side/avg) }\end{array}$} & \multirow[t]{2}{*}{$\mathrm{da} / \mathrm{dt}[\mathrm{mm} / \mathrm{h}]$} & \multirow{2}{*}{$\frac{\text { K_I [MPaVm] }}{26.99}$} & \multirow[t]{2}{*}{ avg K_! } \\
\hline & 14.32 & 14.52 & 14.42 & & & \\
\hline 5.45 & 14.77 & 14.56 & 14.66 & 0.0450 & 26.49 & 26.74 \\
\hline 19.75 & 14.76 & 14.45 & 14.60 & -0.0042 & 26.61 & 26.55 \\
\hline 22.82 & 15.05 & 14.96 & 15.00 & 0.1304 & 25.82 & 26.21 \\
\hline 25.02 & 15.09 & 15.00 & 15.04 & 0.0182 & 25.74 & 25.78 \\
\hline 32.78 & 15.28 & 15.23 & 15.25 & 0.0270 & 25.35 & 25.54 \\
\hline 43.72 & 15.40 & 15.69 & 15.54 & 0.0265 & 24.81 & 25.08 \\
\hline 48.73 & 15.53 & 16.66 & 16.09 & 0.1096 & 23.85 & 24.33 \\
\hline 57.72 & 15.59 & 16.85 & 16.22 & 0.0139 & 23.64 & 23.75 \\
\hline 71.38 & 15.64 & 16.98 & 16.31 & 0.0066 & 23.49 & 23.57 \\
\hline 81.57 & 15.00 & 15.51 & 15.25 & -0.1036 & 25.35 & 24.42 \\
\hline 105.53 & 14.78 & 16.46 & 15.62 & 0.0152 & 24.68 & 25.01 \\
\hline 116.50 & 14.97 & 16.40 & 15.68 & 0.0059 & 24.56 & 24.62 \\
\hline 164.63 & 15.42 & 17.65 & 16.53 & 0.0176 & 23.13 & 23.85 \\
\hline 249.97 & 16.20 & 18.38 & 17.29 & 0.0088 & 21.96 & 22.55 \\
\hline 308.58 & 20.53 & 21.05 & 20.79 & 0.0597 & 17.60 & 19.78 \\
\hline 380.62 & 24.07 & 22.58 & 23.32 & 0.0352 & 15.23 & 16.41 \\
\hline 452.03 & 25.45 & 25.59 & 25.52 & 0.0307 & 13.54 & 14.38 \\
\hline 549.63 & 27.54 & 28.44 & 27.99 & 0.0253 & 11.97 & 12.75 \\
\hline 634.40 & 29.29 & 29.76 & 29.52 & 0.0181 & 11.12 & 11.54 \\
\hline 693.75 & 32.33 & 29.70 & 31.01 & 0.0251 & 10.39 & 10.75 \\
\hline 789.58 & 32.06 & 31.35 & 31.70 & 0.0072 & 10.07 & 10.23 \\
\hline 861.75 & 29.95 & 32.23 & 31.09 & -0.0085 & 10.35 & 10.21 \\
\hline 958.07 & 31.88 & 32.56 & 32.22 & 0.0117 & 9.84 & 10.10 \\
\hline 1053.93 & 35.85 & 32.48 & 34.16 & 0.0203 & 9.05 & 9.45 \\
\hline 1136.33 & 35.89 & 32.83 & 34.36 & 0.0024 & 8.98 & 9.02 \\
\hline 1220.27 & 37.27 & 32.73 & 35.00 & 0.0076 & 8.74 & 8.86 \\
\hline 1341.45 & 38.74 & 35.00 & 36.87 & 0.0154 & 8.10 & 8.42 \\
\hline 1514.22 & 40.73 & 38.91 & 39.82 & 0.0171 & 7.23 & 7.67 \\
\hline 1689.72 & 40.86 & 40.60 & 40.73 & 0.0052 & 6.99 & 7.11 \\
\hline 1880.07 & 42.01 & 41.15 & 41.58 & 0.0045 & 6.77 & 6.88 \\
\hline 2097.30 & 42.58 & 41.47 & 42.02 & 0.0020 & 6.67 & 6.72 \\
\hline 2335.18 & 44.16 & 42.08 & 43.12 & 0.0046 & 6.41 & 6.54 \\
\hline 2669.97 & 44.33 & 44.04 & 44.18 & 0.0032 & 6.17 & 6.29 \\
\hline 3050.33 & 46.67 & 43.63 & 45.15 & 0.0025 & 5.97 & 6.07 \\
\hline
\end{tabular}


Table D 5: Specimen T651 F

\begin{tabular}{|c|c|c|c|c|c|c|}
\hline \multirow{2}{*}{ elapsed time [h] } & \multicolumn{3}{|c|}{ crack length [mm] } & da/dt [mm/h] & K_I [MPaVm] & avg K_I \\
\hline & (one side/other side/avg) & & & \\
\hline 0.00 & 12.50 & 15.85 & 14.17 & & 26.62 & \\
\hline 23.52 & 12.57 & 15.90 & 14.23 & 0.0026 & 26.49 & 26.55 \\
\hline 61.07 & 13.08 & 16.35 & 14.71 & 0.0128 & 25.54 & 26.01 \\
\hline 108.98 & 15.92 & 17.49 & 16.70 & 0.0415 & 22.12 & 23.83 \\
\hline 167.47 & 16.59 & 17.80 & 17.19 & 0.0084 & 21.39 & 21.76 \\
\hline 215.82 & 16.82 & 17.78 & 17.30 & 0.0022 & 21.24 & 21.32 \\
\hline 311.00 & 18.06 & 19.47 & 18.76 & 0.0154 & 19.30 & 20.27 \\
\hline 408.52 & 18.44 & 21.20 & 19.82 & 0.0108 & 18.06 & 18.68 \\
\hline 493.25 & 19.63 & 23.00 & 21.31 & 0.0176 & 16.51 & 17.29 \\
\hline 552.63 & 19.65 & 23.45 & 21.55 & 0.0040 & 16.29 & 16.40 \\
\hline 648.42 & 23.88 & 25.71 & 24.79 & 0.0339 & 13.61 & 14.95 \\
\hline 720.63 & 26.63 & 26.98 & 26.80 & 0.0278 & 12.28 & 12.94 \\
\hline 816.92 & 27.51 & 27.77 & 27.64 & 0.0087 & 11.78 & 12.03 \\
\hline 912.83 & 30.46 & 29.45 & 29.95 & 0.0241 & 10.55 & 11.16 \\
\hline 995.22 & 31.99 & 30.48 & 31.23 & 0.0155 & 9.95 & 10.25 \\
\hline 1079.13 & 32.11 & 33.80 & 32.95 & 0.0205 & 9.23 & 9.59 \\
\hline 1200.32 & 33.79 & 35.07 & 34.43 & 0.0122 & 8.66 & 8.94 \\
\hline 1373.10 & 35.04 & 36.00 & 35.52 & 0.0063 & 8.28 & 8.47 \\
\hline 1548.60 & 35.50 & 36.08 & 35.79 & 0.0015 & 8.19 & 8.24 \\
\hline 1738.93 & 37.72 & 36.75 & 37.23 & 0.0076 & 7.73 & 7.96 \\
\hline 1944.20 & 37.00 & 36.75 & 36.87 & -0.0018 & 7.84 & 7.79 \\
\hline 2194.08 & 39.25 & 37.16 & 38.20 & 0.0053 & 7.44 & 7.64 \\
\hline 2528.83 & 39.51 & 38.02 & 38.76 & 0.0017 & 7.28 & 7.36 \\
\hline 2909.30 & 41.86 & 40.87 & 41.36 & 0.0068 & 6.61 & 6.94 \\
\hline & & & & & & \\
\hline
\end{tabular}

Table D 6: Specimen T73(51) C

\begin{tabular}{|c|c|c|c|c|c|c|}
\hline \multirow{2}{*}{$\begin{array}{c}\text { elapsed time }[\mathrm{h}] \\
0\end{array}$} & \multicolumn{3}{|c|}{$\begin{array}{c}\text { crack length [mm] } \\
\text { (one side/other side/avg) }\end{array}$} & \multirow[t]{2}{*}{$\mathrm{da} / \mathrm{dt}[\mathrm{mm} / \mathrm{h}]$} & \multirow{2}{*}{$\frac{\text { K_I }[\mathrm{MPaVm}]}{29.00}$} & \multirow[t]{2}{*}{ avg K_I } \\
\hline & 13.22 & 12.99 & 13.10 & & & \\
\hline 144.10 & 13.25 & 12.88 & 13.06 & -0.0003 & 29.09 & 29.04 \\
\hline 299.90 & 13.70 & 13.16 & 13.43 & 0.0023 & 28.24 & 28.66 \\
\hline 467.53 & 14.14 & 13.78 & 13.96 & 0.0032 & 27.07 & 27.65 \\
\hline 646.08 & 14.52 & 13.81 & 14.16 & 0.0011 & 26.64 & 26.85 \\
\hline 851.18 & 14.70 & 13.90 & 14.30 & 0.0007 & 26.36 & 26.50 \\
\hline 1023.80 & 15.01 & 14.05 & 14.53 & 0.0013 & 25.90 & 26.13 \\
\hline 1199.13 & 15.37 & 14.15 & 14.76 & 0.0013 & 25.45 & 25.67 \\
\hline 1389.80 & 15.37 & 15.04 & 15.20 & 0.0023 & 24.62 & 25.03 \\
\hline 1839.93 & 15.39 & 15.15 & 15.27 & 0.0001 & 24.50 & 24.56 \\
\hline
\end{tabular}


Table D 7: Specimen T73(51) D

\begin{tabular}{|c|c|c|c|c|c|c|}
\hline \multirow{2}{*}{$\begin{array}{c}\text { elapsed time }[\mathrm{h}] \\
0 \\
\end{array}$} & \multicolumn{3}{|c|}{$\begin{array}{c}\text { crack length [mm] } \\
\text { (one side/other side/avg) }\end{array}$} & \multirow[t]{2}{*}{$\mathrm{da} / \mathrm{dt}[\mathrm{mm} / \mathrm{h}]$} & \multirow{2}{*}{$\frac{\mathrm{K}_{-} \mathrm{I}[\mathrm{MPaVm}]}{28.38}$} & \multirow[t]{2}{*}{ avg K_I } \\
\hline & 13.80 & 15.36 & 14.58 & & & \\
\hline 144.18 & 13.85 & 15.50 & 14.67 & 0.0007 & 28.18 & 28.28 \\
\hline 299.98 & 14.23 & 15.61 & 14.92 & 0.0016 & 27.66 & 27.92 \\
\hline 467.62 & 14.42 & 15.51 & 14.96 & 0.0003 & 27.57 & 27.61 \\
\hline 646.20 & 14.68 & 14.40 & 14.54 & -0.0024 & 28.47 & 28.02 \\
\hline 851.28 & 15.15 & 15.39 & 15.27 & 0.0036 & 26.95 & 27.71 \\
\hline 1023.85 & 15.60 & 15.70 & 15.65 & 0.0022 & 26.21 & 26.58 \\
\hline 1199.23 & 15.66 & 16.66 & 16.16 & 0.0029 & 25.28 & 25.75 \\
\hline 1389.85 & 15.66 & 17.28 & 16.47 & 0.0016 & 24.73 & 25.00 \\
\hline 1840.07 & 15.72 & 16.70 & 16.21 & $7.8 \mathrm{E}-05$ & 25.19 & 24.96 \\
\hline
\end{tabular}

Table D 8: Specimen T73(51) E

\begin{tabular}{|c|c|c|c|c|c|c|}
\hline \multirow{2}{*}{$\frac{\text { elapsed time }[\mathrm{h}]}{0.00}$} & \multicolumn{3}{|c|}{$\begin{array}{c}\text { crack length [mm] } \\
\text { (one side/other side/avg) }\end{array}$} & \multirow[t]{2}{*}{$\mathrm{da} / \mathrm{dt}[\mathrm{mm} / \mathrm{h}]$} & \multirow{2}{*}{$\frac{\left.\mathrm{K}_{-}\right][\mathrm{MPaVm}]}{28.27}$} & \multirow[t]{2}{*}{ avg K_l } \\
\hline & 12.83 & 13.17 & 13.00 & & & \\
\hline 5.53 & 12.79 & 13.50 & 13.14 & 0.0262 & 27.94 & 28.11 \\
\hline 19.77 & 12.86 & 13.38 & 13.12 & -0.0018 & 28.00 & 27.97 \\
\hline 22.90 & 12.80 & 13.59 & 13.19 & 0.0239 & 27.82 & 27.91 \\
\hline 27.05 & 13.78 & 13.86 & 13.82 & 0.1506 & 26.46 & 27.14 \\
\hline 32.82 & 13.87 & 14.06 & 13.96 & 0.0251 & 26.15 & 26.30 \\
\hline 43.67 & 13.98 & 13.36 & 13.67 & -0.0272 & 26.77 & 26.46 \\
\hline 48.77 & 13.76 & 13.49 & 13.62 & -0.0088 & 26.87 & 26.82 \\
\hline 57.73 & 13.98 & 13.84 & 13.91 & 0.0318 & 26.27 & 26.57 \\
\hline 71.47 & 14.20 & 13.92 & 14.06 & 0.0109 & 25.96 & 26.11 \\
\hline 105.62 & 11.58 & 11.98 & 11.78 & 0.4919 & 31.42 & 28.69 \\
\hline 116.55 & 13.50 & 13.42 & 13.46 & 0.1537 & 27.23 & 29.33 \\
\hline 164.78 & 13.42 & 13.10 & 13.26 & -0.0041 & 27.68 & 27.45 \\
\hline 308.97 & 13.44 & 13.17 & 13.30 & 0.2256 & 27.57 & 27.62 \\
\hline 476.47 & 14.40 & 13.95 & 14.17 & 0.0052 & 25.73 & 26.65 \\
\hline 789.63 & 14.69 & 14.59 & 14.64 & 0.0015 & 24.83 & 25.28 \\
\hline 958.13 & 14.56 & 14.71 & 14.63 & $-2.9 \mathrm{E}-05$ & 24.84 & 24.83 \\
\hline 1136.43 & 14.75 & 14.84 & 14.79 & 0.0009 & 24.54 & 24.69 \\
\hline 1341.53 & 14.80 & 15.09 & 14.94 & 0.0007 & 24.26 & 24.40 \\
\hline 1514.33 & 14.97 & 15.17 & 15.07 & 0.0007 & 24.04 & 24.15 \\
\hline 1689.82 & 15.05 & 15.26 & 15.15 & 0.0005 & 23.89 & 23.96 \\
\hline 1880.17 & 15.15 & 15.40 & 15.27 & 0.0006 & 23.68 & 23.78 \\
\hline 2335.32 & 15.13 & 15.85 & 15.49 & 0.0005 & 23.31 & 23.49 \\
\hline
\end{tabular}


Table D 9: Specimen T73(51) F

\begin{tabular}{|c|c|c|c|c|c|c|}
\hline \multirow{2}{*}{$\begin{array}{c}\text { elapsed time [h] } \\
0.00\end{array}$} & \multicolumn{3}{|c|}{$\begin{array}{c}\text { crack length [mm] } \\
\text { (one side/other side/avg) }\end{array}$} & \multirow[t]{2}{*}{$\mathrm{da} / \mathrm{dt}[\mathrm{mm} / \mathrm{h}]$} & \multirow{2}{*}{$\frac{\text { K_I [MPaVm] }}{27.24}$} & \multirow[t]{2}{*}{ avg K_I } \\
\hline & 13.66 & 12.39 & 13.02 & & & \\
\hline 23.68 & 13.70 & 12.41 & 13.05 & 0.0013 & 27.18 & 27.21 \\
\hline 61.12 & 13.77 & 12.55 & 13.16 & 0.0028 & 26.94 & 27.06 \\
\hline 109.07 & 13.81 & 12.60 & 13.20 & 0.0009 & 26.84 & 26.89 \\
\hline 167.88 & 13.85 & 12.81 & 13.33 & 0.0021 & 26.57 & 26.71 \\
\hline 335.38 & 13.68 & 13.75 & 13.71 & 0.0023 & 25.76 & 26.16 \\
\hline 648.48 & 13.74 & 14.28 & 14.01 & 0.0009 & 25.16 & 25.46 \\
\hline 816.98 & 13.82 & 14.79 & 14.30 & 0.0018 & 24.59 & 24.88 \\
\hline 995.30 & 13.93 & 14.88 & 14.40 & 0.0006 & 24.40 & 24.50 \\
\hline 1200.38 & 14.14 & 15.25 & 14.69 & 0.0014 & 23.87 & 24.14 \\
\hline 1373.18 & 14.98 & 15.47 & 15.22 & 0.0031 & 22.94 & 23.41 \\
\hline 1548.67 & 15.17 & 15.51 & 15.34 & 0.0007 & 22.75 & 22.85 \\
\hline 1739.02 & 15.42 & 15.71 & 15.56 & 0.0012 & 22.38 & 22.57 \\
\hline 2194.20 & 15.69 & 16.07 & 15.88 & 0.0007 & 21.88 & 22.13 \\
\hline
\end{tabular}

Table D 10: Specimen H495 C

\begin{tabular}{|c|c|c|c|c|c|c|}
\hline elapsed time $[\mathrm{h}]$ & \multicolumn{3}{|c|}{ crack length $[\mathrm{mm}]$} & $\mathrm{da} / \mathrm{dt}[\mathrm{mm} / \mathrm{h}]$ & K_I [MPaVm] & avg K_I \\
\hline 0 & 16.36 & 16.55 & 16.45 & & 31.26 & \\
\hline 60.42 & 21.68 & 21.07 & 21.37 & 0.0814 & 22.86 & 27.06 \\
\hline 144.28 & 27.38 & 29.35 & 28.36 & 0.0833 & 15.79 & 19.32 \\
\hline 203.48 & 30.67 & 29.88 & 30.27 & 0.0323 & 14.44 & 15.12 \\
\hline 299.12 & 32.37 & 31.74 & 32.05 & 0.0186 & 13.33 & 13.88 \\
\hline 371.50 & 32.89 & 32.28 & 32.58 & 0.0073 & 13.02 & 13.17 \\
\hline 467.68 & 32.89 & 33.47 & 33.18 & 0.0062 & 12.69 & 12.85 \\
\hline 563.60 & 33.06 & 33.47 & 33.26 & 0.0009 & 12.64 & 12.67 \\
\hline 646.28 & 33.34 & 33.65 & 33.49 & 0.0028 & 12.52 & 12.58 \\
\hline 730.22 & 34.44 & 35.43 & 34.93 & 0.0172 & 11.78 & 12.15 \\
\hline 851.32 & 34.61 & 36.08 & 35.34 & 0.0034 & 11.59 & 11.68 \\
\hline 1023.93 & 34.61 & 36.08 & 35.34 & 0 & 11.59 & 11.59 \\
\hline 1199.33 & 36.38 & 36.35 & 36.36 & 0.0058 & 11.11 & 11.35 \\
\hline 1389.92 & 34.31 & 36.31 & 35.31 & -0.0055 & 11.60 & 11.36 \\
\hline 1595.15 & 36.68 & 36.14 & 36.41 & 0.0054 & 11.09 & 11.35 \\
\hline 1840.15 & 36.62 & 36.71 & 36.66 & 0.0010 & 10.98 & 11.04 \\
\hline & & & & & &
\end{tabular}

Table D 11: Specimen H495 D

\begin{tabular}{|c|c|c|c|c|c|c|}
\hline elapsed time $[\mathrm{h}]$ & \multicolumn{3}{|c|}{ crack length [mm] } & da/dt $[\mathrm{mm} / \mathrm{h}]$ & K_I [MPaVm] & avg K_I \\
\hline 60.73 & 36.75 & 36.27 & 36.51 & 0.3864 & 9.46 & 22.05 \\
\hline
\end{tabular}




\begin{tabular}{|l|c|c|c|c|c|c|}
\hline 144.32 & 48.03 & 49.78 & 48.90 & 0.1483 & 6.07 & 7.76 \\
\hline 203.63 & 65.6 & 66.74 & 66.17 & 0.2911 & 3.72 & 4.90 \\
\hline 299.25 & 74.11 & 68.33 & 71.22 & 0.0528 & 3.29 & 3.51 \\
\hline 371.57 & 83.09 & 78.12 & 80.60 & 0.1298 & 2.67 & 2.98 \\
\hline 467.75 & 119.62 & 119.58 & 119.60 & 0.4054 & 1.33 & 2.00 \\
\hline 563.68 & 119.75 & 120.02 & 119.88 & 0.0030 & 1.33 & 1.33 \\
\hline
\end{tabular}

Table D 12: Specimen F400 C

\begin{tabular}{|c|c|c|c|c|c|c|}
\hline \multirow{2}{*}{\begin{tabular}{|c|} 
elapsed time $[\mathrm{h}]$ \\
0
\end{tabular}} & \multicolumn{3}{|c|}{$\begin{array}{c}\text { crack length [mm] } \\
\text { (one side/other side/avg) }\end{array}$} & \multirow[t]{2}{*}{$\mathrm{da} / \mathrm{dt}[\mathrm{mm} / \mathrm{h}]$} & \multirow{2}{*}{$\frac{\mathrm{K} \_\mathrm{I}[\mathrm{MPaVm}]}{30.54}$} & \multirow[t]{2}{*}{ avg K_I } \\
\hline & 11.88 & 12.58 & 12.23 & & & \\
\hline 60.80 & 16.26 & 17.80 & 17.03 & 0.0789 & 21.15 & 25.85 \\
\hline 144.43 & 21.82 & 20.55 & 21.18 & 0.0497 & 16.27 & 18.71 \\
\hline 203.67 & 26.12 & 23.43 & 24.77 & 0.0606 & 13.32 & 14.80 \\
\hline 299.30 & 29.57 & 27.78 & 28.67 & 0.0408 & 10.96 & 12.14 \\
\hline 371.67 & 33.35 & 28.52 & 30.93 & 0.0312 & 9.86 & 10.41 \\
\hline 467.85 & 35.26 & 29.50 & 32.38 & 0.0150 & 9.25 & 9.56 \\
\hline 563.73 & 36.91 & 35.03 & 35.97 & 0.0374 & 7.95 & 8.60 \\
\hline 646.33 & 37.39 & 36.67 & 37.03 & 0.0128 & 7.62 & 7.79 \\
\hline 730.27 & 37.49 & 37.77 & 37.63 & 0.0071 & 7.44 & 7.53 \\
\hline 851.37 & 40.09 & 38.91 & 39.50 & 0.0154 & 6.92 & 7.18 \\
\hline 1024.03 & 42.68 & 38.91 & 40.79 & 0.0075 & 6.60 & 6.76 \\
\hline 1199.38 & 43.88 & 41.41 & 42.64 & 0.0106 & 6.17 & 6.38 \\
\hline 1390.00 & 44.42 & 42.94 & 43.68 & 0.0054 & 5.95 & 6.06 \\
\hline 1595.27 & 47.01 & 43.67 & 45.34 & 0.0081 & 5.62 & 5.78 \\
\hline 1840.23 & 49.97 & 46.64 & 48.30 & 0.0121 & 5.09 & 5.35 \\
\hline 2194.78 & 51.12 & 48.09 & 49.60 & 0.0037 & 4.88 & 4.98 \\
\hline 2573.07 & 52.83 & 49.20 & 51.01 & 0.0037 & 4.67 & 4.78 \\
\hline
\end{tabular}

Table D 13: Specimen F400 D

\begin{tabular}{|c|c|c|c|c|c|c|}
\hline elapsed time [h] & \multicolumn{3}{|c|}{ crack length [mm] } & da/dt $[\mathrm{mm} / \mathrm{h}]$ & K_I [MPavm] & avg K_I \\
\hline 0 & 12.70 & 13.50 & 13.10 & & 28.04 & \\
\hline 61.08 & 17.66 & 14.96 & 16.31 & 0.0526 & 21.98 & 25.01 \\
\hline 144.47 & 20.37 & 20.00 & 20.18 & 0.0465 & 17.08 & 19.53 \\
\hline 203.77 & 23.40 & 22.70 & 23.05 & 0.0483 & 14.46 & 15.77 \\
\hline 299.38 & 26.11 & 25.84 & 25.97 & 0.0306 & 12.38 & 13.42 \\
\hline 371.73 & 27.13 & 26.96 & 27.04 & 0.0148 & 11.73 & 12.05 \\
\hline 467.93 & 29.65 & 30.12 & 29.88 & 0.0295 & 10.23 & 10.98 \\
\hline 563.83 & 31.06 & 30.12 & 30.59 & 0.0074 & 9.90 & 10.07 \\
\hline 646.40 & 32.07 & 32.28 & 32.17 & 0.0192 & 9.23 & 9.57 \\
\hline 730.33 & 32.32 & 32.51 & 32.41 & 0.0029 & 9.13 & 9.18 \\
\hline
\end{tabular}




\begin{tabular}{|c|c|c|c|c|c|c|}
\hline 851.47 & 34.08 & 33.11 & 33.59 & 0.0097 & 8.68 & 8.90 \\
\hline 1024.28 & 33.80 & 35.84 & 34.82 & 0.0071 & 8.24 & 8.46 \\
\hline 1199.45 & 35.97 & 36.17 & 36.07 & 0.0071 & 7.83 & 8.03 \\
\hline 1390.05 & 37.19 & 37.53 & 37.36 & 0.0068 & 7.44 & 7.63 \\
\hline 1595.33 & 37.19 & 39.05 & 38.12 & 0.004 & 7.22 & 7.33 \\
\hline 1840.30 & 37.60 & 38.76 & 38.18 & 0.0002 & 7.20 & 7.21 \\
\hline 2194.85 & 39.69 & 38.77 & 39.23 & 0.0030 & 6.92 & 7.06 \\
\hline 2573.13 & 40.65 & 40.11 & 40.38 & 0.0030 & 6.62 & 6.77 \\
\hline
\end{tabular}

Table D 14: Specimen L370 C

\begin{tabular}{|c|c|c|c|c|c|c|}
\hline \multirow{2}{*}{ elapsed time [h] } & \multicolumn{3}{|c|}{ crack length [mm] } & da/dt [mm/h] & K_I [MPavm] & avg K_I \\
\hline 0 & 14.69 & 15.54 & 15.11 & & 22.31 & \\
\hline 61.32 & 15.10 & 16.18 & 15.64 & 0.0086 & 21.46 & 21.88 \\
\hline 144.55 & 15.75 & 16.60 & 16.17 & 0.0064 & 20.66 & 21.06 \\
\hline 203.82 & 15.42 & 16.98 & 16.20 & 0.0004 & 20.62 & 20.64 \\
\hline 299.45 & 17.15 & 17.16 & 17.15 & 0.0010 & 19.30 & 19.96 \\
\hline 371.83 & 17.35 & 16.78 & 17.06 & -0.0012 & 19.42 & 19.36 \\
\hline 468.00 & 17.97 & 18.62 & 18.29 & 0.0128 & 17.90 & 18.66 \\
\hline 563.92 & 18.14 & 18.56 & 18.35 & 0.0006 & 17.84 & 17.87 \\
\hline 646.47 & 18.80 & 18.46 & 18.63 & 0.0034 & 17.52 & 17.68 \\
\hline 730.38 & 19.90 & 19.55 & 19.72 & 0.0130 & 16.35 & 16.93 \\
\hline 850.55 & 19.94 & 19.79 & 19.86 & 0.0012 & 16.21 & 16.28 \\
\hline 1024.35 & 20.05 & 19.83 & 19.94 & 0.0004 & 16.14 & 16.17 \\
\hline 1199.53 & 20.11 & 19.85 & 19.98 & 0.0002 & 16.10 & 16.12 \\
\hline 1390.12 & 20.18 & 20.53 & 20.35 & 0.0020 & 15.74 & 15.92 \\
\hline 1840.37 & 19.94 & 20.46 & 20.20 & 0.0003 & 15.88 & 15.81 \\
\hline & & & & & \\
\hline
\end{tabular}

Table D 15: Specimen L370 D

\begin{tabular}{|c|c|c|c|c|c|c|}
\hline \multirow{2}{*}{$\frac{\text { elapsed time }[\mathrm{h}]}{0}$} & \multicolumn{3}{|c|}{$\begin{array}{c}\text { crack length [mm] } \\
\text { (one side/other side/avg) }\end{array}$} & \multirow[t]{2}{*}{$\mathrm{da} / \mathrm{dt}[\mathrm{mm} / \mathrm{h}]$} & \multirow{2}{*}{$\frac{\text { K_I [MPaVm] }}{22.48}$} & \multirow[t]{2}{*}{ avg K_I } \\
\hline & 12.86 & 13.78 & 13.32 & & & \\
\hline 61.37 & 12.96 & 13.84 & 13.40 & 0.0013 & 22.33 & 22.40 \\
\hline 144.6 & 13.09 & 14.57 & 13.83 & 0.0052 & 21.57 & 21.95 \\
\hline 203.90 & 14.52 & 15.12 & 14.82 & 0.0167 & 19.99 & 20.78 \\
\hline 299.52 & 15.61 & 15.27 & 15.44 & 0.0065 & 19.09 & 19.54 \\
\hline 371.87 & 15.30 & 15.49 & 15.39 & -0.0006 & 19.15 & 19.12 \\
\hline 468.08 & 15.89 & 15.49 & 15.69 & 0.0031 & 18.75 & 18.95 \\
\hline 564.10 & 15.95 & 15.78 & 15.86 & 0.0018 & 18.51 & 18.63 \\
\hline 646.53 & 15.98 & 16.31 & 16.14 & 0.0034 & 18.15 & 18.33 \\
\hline 731.45 & 16.84 & 17.32 & 17.08 & 0.0110 & 17.01 & 17.58 \\
\hline 851.63 & 17.84 & 17.75 & 17.79 & 0.0059 & 16.21 & 16.61 \\
\hline
\end{tabular}




\begin{tabular}{|l|c|c|c|c|c|c|}
\hline 1024.42 & 17.91 & 17.8 & 17.85 & 0.0003 & 16.15 & 16.18 \\
\hline 1199.58 & 18.02 & 17.91 & 17.96 & 0.0006 & 16.03 & 16.09 \\
\hline 1390.18 & 18.11 & 18.21 & 18.16 & 0.0010 & 15.83 & 15.93 \\
\hline 1845.25 & 18.29 & 18.23 & 18.26 & 0.0002 & 15.72 & 15.78 \\
\hline
\end{tabular}

Table D 16: Specimen H495-F400 C

\begin{tabular}{|c|c|c|c|c|c|c|}
\hline \multirow{2}{*}{$\begin{array}{c}\text { elapsed time }[\mathrm{h}] \\
0\end{array}$} & \multicolumn{3}{|c|}{$\begin{array}{c}\text { crack length [mm] } \\
\text { (one side/other side/avg) }\end{array}$} & \multirow[t]{2}{*}{$\mathrm{da} / \mathrm{dt}[\mathrm{mm} / \mathrm{h}]$} & \multirow{2}{*}{$\frac{\mathrm{K} \_\mathrm{I}[\mathrm{MPaVm}]}{25.71}$} & \multirow[t]{2}{*}{ avg K_I } \\
\hline & 13.44 & 15.22 & 14.33 & & & \\
\hline 61.43 & 14.75 & 17.43 & 16.09 & 0.0286 & 22.58 & 24.15 \\
\hline 144.68 & 17.12 & 17.98 & 17.55 & 0.0175 & 20.42 & 21.50 \\
\hline 203.95 & 18.84 & 21.16 & 20.00 & 0.0413 & 17.47 & 18.94 \\
\hline 299.58 & 19.65 & 22.72 & 21.18 & 0.0124 & 16.27 & 16.87 \\
\hline 371.93 & 20.00 & 24.78 & 22.39 & 0.0167 & 15.18 & 15.72 \\
\hline 468.12 & 20.13 & 26.05 & 23.09 & 0.0073 & 14.60 & 14.89 \\
\hline 564.17 & 22.28 & 26.17 & 24.22 & 0.0118 & 13.72 & 14.16 \\
\hline 646.58 & 25.20 & 28.31 & 26.75 & 0.0307 & 12.03 & 12.88 \\
\hline 730.52 & 26.59 & 29.50 & 28.04 & 0.0154 & 11.29 & 11.66 \\
\hline 851.70 & 29.59 & 31.07 & 30.33 & 0.0189 & 10.14 & 10.72 \\
\hline 1024.48 & 29.95 & 32.94 & 31.44 & 0.0065 & 9.64 & 9.89 \\
\hline 1199.67 & 31.40 & 34.55 & 32.97 & 0.0087 & 9.01 & 9.33 \\
\hline 1390.27 & 33.53 & 34.6 & 34.06 & 0.0057 & 8.60 & 8.81 \\
\hline 1595.53 & 34.55 & 34.77 & 34.66 & 0.0029 & 8.39 & 8.50 \\
\hline 1845.37 & 35.11 & 35.59 & 35.35 & 0.0028 & 8.15 & 8.27 \\
\hline 2194.92 & 35.27 & 37.13 & 36.20 & 0.0024 & 7.88 & 8.02 \\
\hline 2573.20 & 35.43 & 39.23 & 37.33 & 0.0030 & 7.53 & 7.70 \\
\hline
\end{tabular}

Table D 17: Specimen H495-F400 C

\begin{tabular}{|c|c|c|c|c|c|c|}
\hline \multirow{2}{*}{$\begin{array}{c}\text { elapsed time }[\mathrm{h}] \\
0\end{array}$} & \multicolumn{3}{|c|}{$\begin{array}{c}\text { crack length [mm] } \\
\text { (one side/other side/avg) }\end{array}$} & \multirow[t]{2}{*}{$\mathrm{da} / \mathrm{dt}[\mathrm{mm} / \mathrm{h}]$} & \multirow{2}{*}{$\frac{K_{-} I[\mathrm{MPaVm}]}{25.49}$} & \multirow[t]{2}{*}{ avg K_I } \\
\hline & 12.45 & 12.80 & 12.62 & & & \\
\hline 61.47 & 17.35 & 17.68 & 17.51 & 0.0796 & 17.68 & 21.59 \\
\hline 144.72 & 19.48 & 21.70 & 20.59 & 0.0369 & 14.56 & 16.12 \\
\hline 204.02 & 20.86 & 23.67 & 22.26 & 0.0282 & 13.20 & 13.88 \\
\hline 299.65 & 25.48 & 26.67 & 26.07 & 0.0398 & 10.76 & 11.98 \\
\hline 372.02 & 26.77 & 28.69 & 27.73 & 0.0229 & 9.90 & 10.33 \\
\hline 468.38 & 29.79 & 30.66 & 30.22 & 0.0259 & 8.80 & 9.35 \\
\hline 564.22 & 33.52 & 32.74 & 33.13 & 0.0303 & 7.73 & 8.27 \\
\hline 646.65 & 34.78 & 36.12 & 35.45 & 0.0281 & 7.01 & 7.37 \\
\hline 730.57 & 36.07 & 36.07 & 36.07 & 0.0074 & 6.84 & 6.93 \\
\hline 851.75 & 37.25 & 39.20 & 38.22 & 0.0178 & 6.28 & 6.56 \\
\hline 1024.57 & 41.05 & 40.35 & 40.70 & 0.0143 & 5.72 & 6.00 \\
\hline
\end{tabular}




\begin{tabular}{|l|l|l|l|l|l|l|}
\hline 1199.72 & 42.33 & 42.83 & 42.58 & 0.0107 & 5.34 & 5.53 \\
\hline 1390.35 & 45.00 & 45.87 & 45.43 & 0.0150 & 4.83 & 5.09 \\
\hline 1595.58 & 48.13 & 47.17 & 47.65 & 0.0108 & 4.49 & 4.66 \\
\hline 1845.45 & 51.23 & 50.16 & 50.69 & 0.0122 & 4.07 & 4.28 \\
\hline 2194.98 & 52.45 & 52.66 & 52.55 & 0.0053 & 3.85 & 3.96 \\
\hline 2573.28 & 53.99 & 52.66 & 53.32 & 0.0020 & 3.76 & 3.80 \\
\hline
\end{tabular}

Table D 18: Specimen S495-F400 C

\begin{tabular}{|c|c|c|c|c|c|c|}
\hline elapsed time [h] & $\begin{array}{r}\text { cra } \\
\text { (one si }\end{array}$ & $\begin{array}{l}\mathrm{k} \text { length } \\
\mathrm{e} / \text { other }\end{array}$ & $\begin{array}{l}\mathrm{nm}] \\
\text { de/avg) }\end{array}$ & $\mathrm{da} / \mathrm{dt}[\mathrm{mm} / \mathrm{h}]$ & K_I [MPaVm] & avg K_I \\
\hline 0 & 13.51 & 13.64 & 13.57 & & 25.12 & \\
\hline 61.52 & 16.51 & 14.40 & 15.45 & 0.0306 & 21.75 & 23.44 \\
\hline 144.78 & 19.00 & 17.23 & 18.11 & 0.0319 & 18.11 & 19.93 \\
\hline 204.08 & 23.08 & 19.82 & 21.45 & 0.0562 & 14.75 & 16.43 \\
\hline 299.73 & 24.38 & 21.28 & 22.83 & 0.0144 & 13.63 & 14.19 \\
\hline 372.08 & 25.11 & 23.31 & 24.21 & 0.0191 & 12.64 & 13.13 \\
\hline 468.43 & 26.16 & 24.54 & 25.35 & 0.0118 & 11.90 & 12.27 \\
\hline 564.28 & 26.88 & 27.12 & 27.00 & 0.0172 & 10.94 & 11.42 \\
\hline 646.70 & 28.10 & 27.71 & 27.90 & 0.0110 & 10.46 & 10.70 \\
\hline 730.63 & 29.54 & 27.99 & 28.76 & 0.0102 & 10.04 & 10.25 \\
\hline 851.80 & 30.62 & 28.79 & 29.70 & 0.0078 & 9.61 & 9.82 \\
\hline 1024.60 & 31.18 & 30.68 & 30.93 & 0.0071 & 9.08 & 9.34 \\
\hline 1199.77 & 31.38 & 31.48 & 31.43 & 0.0029 & 8.88 & 8.98 \\
\hline 1390.43 & 31.45 & 34.89 & 33.17 & 0.0091 & 8.23 & 8.55 \\
\hline 1595.63 & 31.54 & 35.46 & 33.50 & 0.0016 & 8.11 & 8.17 \\
\hline 1845.52 & 31.66 & 36.12 & 33.89 & 0.0016 & 7.98 & 8.04 \\
\hline 2195.03 & 38.46 & 38.19 & 38.32 & 0.0127 & 6.67 & 7.32 \\
\hline 2573.33 & 32.32 & 39.8 & 36.06 & 0.0030 & 7.29 & 6.98 \\
\hline
\end{tabular}

Table D 19: Specimen S495-F400 D

\begin{tabular}{|c|c|c|c|c|c|c|}
\hline elapsed time [h] & \multicolumn{6}{|c|}{ crack length [mm] } \\
(one side/other side/avg) & da/dt [mm/h] & K_I [MPavm] & avg K_I \\
\hline 0 & 13.39 & 13.11 & 13.25 & & 25.47 & \\
\hline 61.57 & 14.48 & 15.95 & 15.21 & 0.0319 & 21.87 & 23.67 \\
\hline 144.82 & 17.94 & 18.04 & 17.99 & 0.0333 & 18.03 & 19.95 \\
\hline 204.15 & 18.59 & 20.64 & 19.61 & 0.0274 & 16.26 & 17.15 \\
\hline 299.82 & 19.30 & 21.03 & 20.16 & 0.0057 & 15.72 & 15.99 \\
\hline 372.15 & 22.23 & 22.83 & 22.53 & 0.0327 & 13.69 & 14.71 \\
\hline 468.48 & 23.75 & 23.23 & 23.49 & 0.0100 & 12.98 & 13.33 \\
\hline 564.35 & 23.77 & 23.55 & 23.66 & 0.0018 & 12.86 & 12.92 \\
\hline 646.77 & 25.61 & 25.63 & 25.62 & 0.0238 & 11.59 & 12.22 \\
\hline 730.68 & 26.57 & 25.63 & 26.10 & 0.0057 & 11.31 & 11.45 \\
\hline
\end{tabular}




\begin{tabular}{|c|c|c|c|c|c|c|}
\hline 851.87 & 27.30 & 26.22 & 26.76 & 0.0054 & 10.94 & 11.12 \\
\hline 1024.65 & 30.73 & 28.56 & 29.64 & 0.0167 & 9.51 & 10.23 \\
\hline 1199.85 & 31.55 & 31.29 & 31.42 & 0.0101 & 8.77 & 9.14 \\
\hline 1390.48 & 33.16 & 32.48 & 32.82 & 0.0073 & 8.25 & 8.51 \\
\hline 1595.72 & 33.94 & 32.13 & 33.03 & 0.0010 & 8.17 & 8.21 \\
\hline 1845.60 & 34.26 & 35.28 & 34.77 & 0.0069 & 7.59 & 7.88 \\
\hline 2195.10 & 37.63 & 35.99 & 36.81 & 0.0058 & 6.99 & 7.29 \\
\hline 2573.40 & 38.61 & 36.21 & 37.41 & 0.0016 & 6.82 & 6.91 \\
\hline
\end{tabular}

